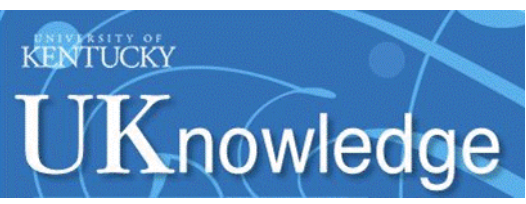

University of Kentucky

UKnowledge

$10-2014$

\title{
Systematic Review of Potential Health Risks Posed by Pharmaceutical, Occupational and Consumer Exposures to Metallic and Nanoscale Aluminum, Aluminum Oxides, Aluminum Hydroxide and Its Soluble Salts
}

Calvin C. Willhite

Risk Sciences International, Canada

Nataliya A. Karyakina

Risk Sciences International, Canada

Robert A. Yokel

University of Kentucky, ryokel@email.uky.edu

Nagarajkumar Yenugadhati

McLaughlin Centre for Population Health Risk Assessment, Canada

See next page for additional authors

Right click to open a feedback form in a new tab to let us know how this document benefits you. Follow this and additional works at: https://uknowledge.uky.edu/ps_facpub

Part of the Community Health and Preventive Medicine Commons, Epidemiology Commons, Neurology Commons, Occupational Health and Industrial Hygiene Commons, and the Pharmacy and Pharmaceutical Sciences Commons 


\section{Systematic Review of Potential Health Risks Posed by Pharmaceutical, Occupational and Consumer Exposures to Metallic and Nanoscale Aluminum, Aluminum Oxides, Aluminum Hydroxide and Its Soluble Salts}

Digital Object Identifier (DOI)

https://doi.org/10.3109/10408444.2014.934439

Notes/Citation Information

Published in Critical Reviews in Toxicology, v. 44, suppl 4, p. 1-80.

(c) 2014 Informa Healthcare USA, Inc.

The copyright holder has granted the permission for posting the article here.

This is an Accepted Manuscript of an article published by Taylor \& Francis in Critical Reviews in Toxicology in October 2014, available online: http://www.tandfonline.com/10.3109/

10408444.2014.934439.

Authors

Calvin C. Willhite, Nataliya A. Karyakina, Robert A. Yokel, Nagarajkumar Yenugadhati, Thomas M. Wisniewski, Ian M. F. Arnold, Franco Momoli, and Daniel Krewski 


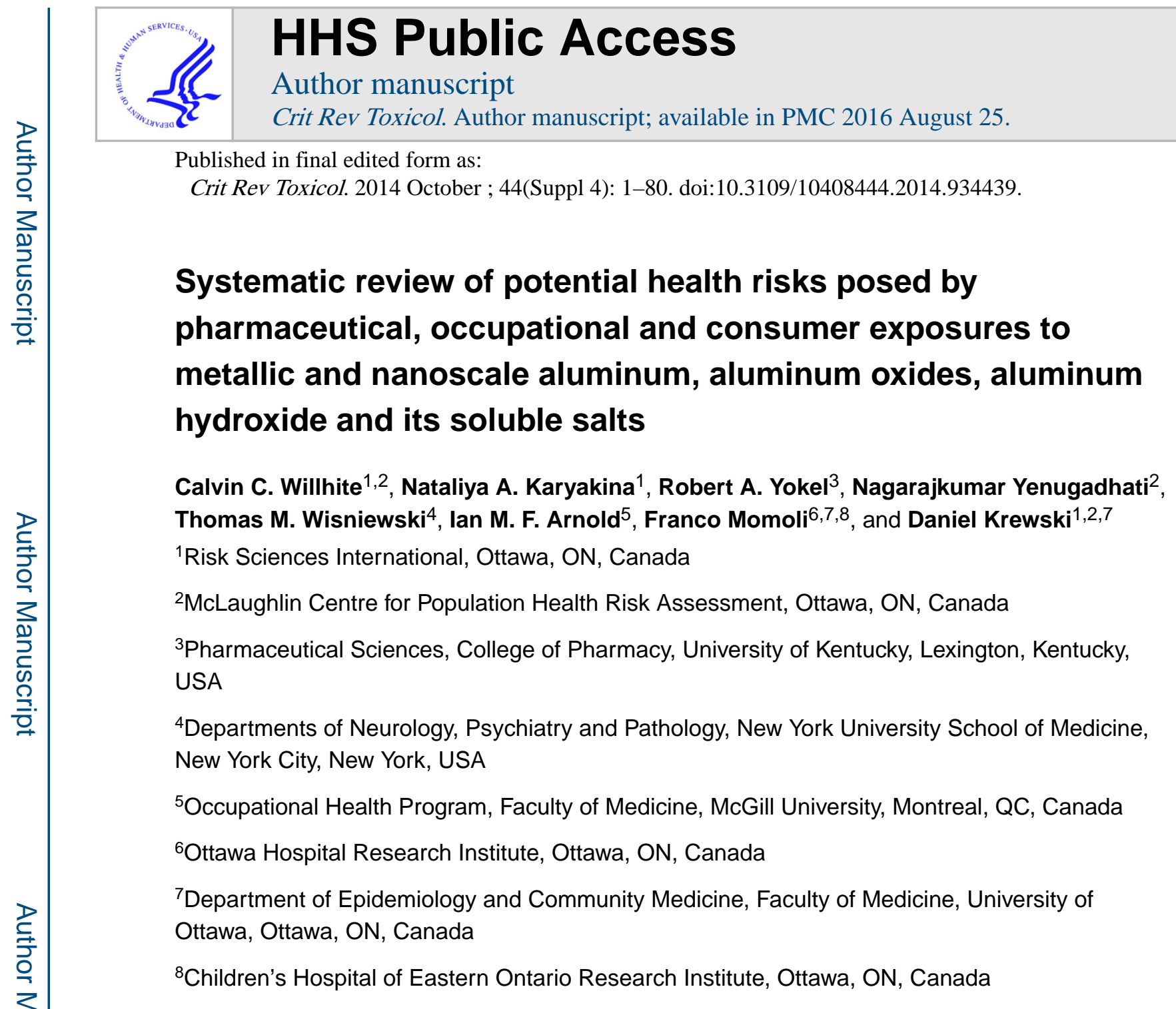

\title{
Abstract
}

\begin{abstract}
Aluminum (Al) is a ubiquitous substance encountered both naturally (as the third most abundant element) and intentionally (used in water, foods, pharmaceuticals, and vaccines); it is also present in ambient and occupational airborne particulates. Existing data underscore the importance of $\mathrm{Al}$ physical and chemical forms in relation to its uptake, accumulation, and systemic bioavailability.
\end{abstract}

\footnotetext{
Address for correspondence: Calvin C. Willhite, Risk Sciences International, 55 Metcalfe Street, Suite 700, Ottawa, ON, Canada. calvinwillhite@hotmail.com.

Declaration of interest

Partial funding for this work was provided by a contract to review the recent scientific literature on health effects of aluminum between the International Aluminium Institute (IAI, www.world-aluminium.org), the Aluminium Reach Consortium (ARC, www.aluminium-reach-consortium.eu), and Risk Sciences International (RSI, www.risksciences.com), a Canadian company established in 2006 in partnership with the University of Ottawa. Additional financial support was provided by the Natural Sciences and Engineering Research Council of Canada (NSERC) to D. Krewski, who holds the NSERC Chair in Risk Science at the University of Ottawa. C.C. Willhite, N.A. Karyakina, F. Momoli, and N. Yenugadhati were compensated by RSI for their contributions to the review. I. Arnold, T. Wisniewski and R. Yokel received no compensation from RSI for their contributions to this work. The authors, whose affiliations are shown on the title page, had sole responsibility for preparation of this paper, including determining the strategy for reviewing the scientific literature summarized in this article, synthesizing the findings, and drawing conclusions. Scientists associated with IAI/ARC were given the opportunity to review and offer technical comments on the paper, prior to submission to Critical Reviews in Toxicology. I. Arnold serves as a consultant to the International Aluminium Institute. None of the authors have appeared before regulatory agencies on behalf of the sponsors, or appeared as experts in legal proceedings concerning matters reviewed in this paper. The scientific opinions and conclusions expressed in the paper are exclusively those of the authors, and are independent of the sources of financial support.
} 
The present review represents a systematic examination of the peer-reviewed literature on the adverse health effects of $\mathrm{Al}$ materials published since a previous critical evaluation compiled by Krewski et al. (2007).

Challenges encountered in carrying out the present review reflected the experimental use of different physical and chemical $\mathrm{Al}$ forms, different routes of administration, and different target organs in relation to the magnitude, frequency, and duration of exposure. Wide variations in diet can result in $\mathrm{Al}$ intakes that are often higher than the World Health Organization provisional tolerable weekly intake (PTWI), which is based on studies with Al citrate. Comparing daily dietary $\mathrm{Al}$ exposures on the basis of "total Al" assumes that gastrointestinal bioavailability for all dietary $\mathrm{Al}$ forms is equivalent to that for $\mathrm{Al}$ citrate, an approach that requires validation. Current occupational exposure limits (OELs) for identical $\mathrm{Al}$ substances vary as much as 15-fold.

The toxicity of different $\mathrm{Al}$ forms depends in large measure on their physical behavior and relative solubility in water. The toxicity of soluble $\mathrm{Al}$ forms depends upon the delivered dose of $\mathrm{Al}^{+3}$ to target tissues. Trivalent $\mathrm{Al}$ reacts with water to produce bidentate superoxide coordination spheres $\left[\mathrm{Al}\left(\mathrm{O}_{2}\right)\left(\mathrm{H}_{2} \mathrm{O}_{4}\right)^{+2}\right.$ and $\mathrm{Al}\left(\mathrm{H}_{2} \mathrm{O}\right)_{6}{ }^{+3}$ ] that after complexation with $\mathrm{O}_{2}{ }^{--}$, generate $\mathrm{Al}$ superoxides $\left.\left[\mathrm{Al}\left(\mathrm{O}_{2}{ }^{\circ}\right)\right]\left(\mathrm{H}_{2} \mathrm{O}_{5}\right)\right]^{+2}$. Semireduced $\mathrm{AlO}_{2}{ }^{\circ}$ radicals deplete mitochondrial $\mathrm{Fe}$ and promote generation of $\mathrm{H}_{2} \mathrm{O}_{2}, \mathrm{O}_{2}{ }^{-}$and $\mathrm{OH}^{\bullet}$. Thus, it is the $\mathrm{Al}^{+3}$-induced formation of oxygen radicals that accounts for the oxidative damage that leads to intrinsic apoptosis. In contrast, the toxicity of the insoluble $\mathrm{Al}$ oxides depends primarily on their behavior as particulates.

Aluminum has been held responsible for human morbidity and mortality, but there is no consistent and convincing evidence to associate the $\mathrm{Al}$ found in food and drinking water at the doses and chemical forms presently consumed by people living in North America and Western Europe with increased risk for Alzheimer's disease (AD). Neither is there clear evidence to show use of Alcontaining underarm antiperspirants or cosmetics increases the risk of $\mathrm{AD}$ or breast cancer. Metallic Al, its oxides, and common $\mathrm{Al}$ salts have not been shown to be either genotoxic or carcinogenic. Aluminum exposures during neonatal and pediatric parenteral nutrition (PN) can impair bone mineralization and delay neurological development. Adverse effects to vaccines with $\mathrm{Al}$ adjuvants have occurred; however, recent controlled trials found that the immunologic response to certain vaccines with $\mathrm{Al}$ adjuvants was no greater, and in some cases less than, that after identical vaccination without $\mathrm{Al}$ adjuvants.

The scientific literature on the adverse health effects of $\mathrm{Al}$ is extensive. Health risk assessments for Al must take into account individual co-factors (e.g., age, renal function, diet, gastric $\mathrm{pH}$ ).

Conclusions from the current review point to the need for refinement of the PTWI, reduction of Al contamination in PN solutions, justification for routine addition of $\mathrm{Al}$ to vaccines, and harmonization of OELs for $\mathrm{Al}$ substances.

\section{Keywords}

Alzheimer's disease; antiperspirants; aluminum nanoparticles; breast cancer; encephalopathy; microcytic anemia; minimal risk level; osteomalacia; parenteral nutrition; reactive oxygen; threshold limit value; tolerable weekly intake; vaccine adjuvants 


\section{Introduction}

The adverse neurologic, hematopoietic, skeletal, respiratory, immunologic, and other effects associated with excessive aluminum (Al) exposures are well known (reviewed in ATSDR 2008, Nordic Expert Group 2011, Willhite et al. 2012). Controversy over what constitutes "safe" Al exposure began at least 100 years ago (Gies 1911) and questions persist concerning the role of Al in AD (Campdelacreu 2012, Exley et al. 2012, Tomljenovic 2011, Solfrizzi et al. 2011, Walton 2012a) and other disease states (AFSSAPS 2011). Over the past two decades, a number of regulatory guidelines and limits on $\mathrm{Al}$ have been adopted and revised. To appreciate these changes in $\mathrm{Al}$ guidance and regulation, it is important to keep in mind that the physical and chemical nature of the particular $\mathrm{Al}$ form can be far more important to health outcomes than exposure to $\mathrm{Al}$ per se.

Krewski et al. (2007) summarized exposure and toxicity data for approximately 100 different $\mathrm{Al}$ forms and found that health risks to humans related to excessive $\mathrm{Al}$ exposure include:

- Osteomalacia and microcytic anemia after exposure from dialysate and/or gastric antacids or Al phosphate binders in people with compromised kidney function;

- $\quad$ Encephalopathy/dementia after exposure from dialysate and/or $\mathrm{Al}$ phosphate binders in patients with impaired renal function;

- $\quad$ Contact allergy and local irritation/adverse reations to vaccines with $\mathrm{Al}$ adjuvants;

- Pneumoconiosis after long-term inhalation of $\mathrm{Al}$ dusts or powders.

Krewski et al. (2007), like Sorenson et al. (1974), observed that most healthy adults tolerate comparatively large repeated daily oral Al exposures (up to 3500-7200 mg/day from antacids and buffered aspirin) without any adverse effect, but that other people (notably preterm infants, young children, and those with reduced kidney function) can be at serious risk for systemic $\mathrm{Al}$ intoxication even at much lower daily doses. Because $\mathrm{Al}$ gastrointestinal uptake varies from essentially non-detectable for hydrated Al silicates (Afriyie-Gyawu et al. 2005, Wiles et al. 2004), to $0.1-0.3 \%$ for sodium $\mathrm{Al}$ phosphates in foods, to $0.2 \%$ for $\mathrm{AlCl}_{3}$ to much higher values (> 2.0\%) after ingestion of organic Al (EFSA 2011, Krewski et al. 2007), exposures expressed as "total Al" are problematic for human health risk assessments.

The present review compiles recent environmental and occupational $\mathrm{Al}$ exposures, evaluates recent $\mathrm{Al}$ health effects data, and compares those outcomes with existing $\mathrm{Al}$ exposure standards and guidelines.

\section{Sources of information}

A systematic approach was undertaken to update the evidence for adverse health effects in humans of metallic $\mathrm{Al}, \mathrm{Al}$ oxides, and $\mathrm{Al}$ hydroxide considered by Krewski et al. (2007). The search strategy was designed to identify recently published studies that examined acute toxicity, irritation/corrosion, sensitization, mutagenicity/genotoxicity, carcinogenicity, 
repeated dose toxicity including neurotoxicity, reproduction and developmental toxicity associated with oral, inhalation, dermal, and intramuscular exposures to these $\mathrm{Al}$ substances. The Ovid MEDLINE, Ovid EMBASE and Toxline databases were searched to ensure that the database remained current during the conduct of the hazard assessments. The search strategy was first developed to cover the Ovid MEDLINE and the Ovid EMBASE and then adapted to cover the Toxline database. Search terms were grouped according to the Boolean operators OR and AND to develop the search profile. The titles and abstracts of all articles identified in the primary search were independently examined by two reviewers to determine the potential eligibility of each study for inclusion. No language exclusion criteria were applied at the screening stage in an effort to compensate for potential publication bias. Following the primary screening, the full articles were obtained and the inclusion/exclusion criteria applied. Only publications appearing in peer-reviewed sources (including book chapters and regulatory evaluations) were included; conference proceedings and abstracts were excluded. Where only abstracts of full studies could be located, or further details were required particularly relating to data reporting, the corresponding author was contacted to ascertain the particulars of the study. Where multiple publications on the same issue or data were identified, only the most relevant study was retained.

After all of the relevant studies were identified, the same two reviewers independently extracted data and entered the study results into a standard data abstraction form. The collected data related to referencing, Al compound(s) tested, subject selection/animal species/test system, study design, and results. The same two reviewers then independently assessed the methodological quality of all included studies. The quality of individual in vivo and in vitro studies was assessed using criteria developed by Klimisch et al. (1997) and Schneider et al. (2009). The overall methodological quality of individual epidemiological studies was assessed using a set of relevant check points used in the EU risk assessment of metals (EC 2005) and the Wells et al. (2003) and Bradford-Hill (1965) guidance. Differences in quality assessment of individual studies were resolved by consensus. No attempt was made to blind the reviewers to the authorship of the original publications. Consistency/ concordance or lack of concordance between results of comparable human studies, between results in studies of different genders, species and strains in comparable animal studies and between results of different in vitro assays designed to measure similar endpoints were taken into account.

Using our search algorithm, 3820 studies were identified since publication of the Krewski et al. (2007) monograph and of those 469 are included here. Publications dated prior to 2007 are cited where they contribute to understanding the more recent data. The more informative studies are discussed below whereas others deemed less so are summarized in tables.

\section{Environmental and occupational exposure}

Krewski et al. (2007) tabulated the major sources of Al exposure in humans. Daily exposures range from as little as less than $0.06 \mathrm{mg} /$ day as a result of inhaling $\mathrm{PM}_{10}$ particulates in ambient air with $0.6-7.0 \mu \mathrm{g} \mathrm{Al} / \mathrm{m}^{3}$ to as high as $3500-5200 \mathrm{mg} \mathrm{Al} /$ day as a result of consuming $\mathrm{Al}$ antacids. 
Yokel (2012) found that daily dietary $\mathrm{Al}$ contributed only a fraction (0.07-0.2\%) of that received from gastric antacids. Depending upon regional preferences, beverages can constitute a major source of ingested Al. Cao et al. (2010) measured $\mathrm{Al}$ in 17 fermented and 19 raw teas grown near Puerh City, China; the Al concentration in fermented tea (794 \pm 140 $\mathrm{mg} / \mathrm{kg}$ ) was somewhat higher than that in raw tea $(594 \pm 129 \mathrm{mg} / \mathrm{kg})$ and based on the tea consumption rates among 110 Puerh City and 109 Kumming City residents, mean daily Al doses from tea were 99 and $60 \mu \mathrm{g} / \mathrm{kg}$-day, respectively. Consumption of tea infusions can account for up to 50\% of one's daily Al exposure (Yokel 2013).

Aluminum concentrations in eight different infant formulas purchased in the United Kingdom ranged from 176 to $700 \mu \mathrm{g} / \mathrm{L}$ and the $\mathrm{Al}$ content in eight different reconstituted formulas ranged from 333 to $629 \mu \mathrm{g} / \mathrm{L}$. For a (50th percentile) five-month-old boy weighing $7.63 \mathrm{~kg}$ or a (50th percentile) 12 -and-a half- month-old $10.46 \mathrm{~kg}$ boy (CDC 2000), these concentrations correspond to daily Al consumption between $27-78$ and $19-57 \mu \mathrm{g} / \mathrm{kg}$-day, respectively (Burrell and Exley 2010). Those values are consistent with or generally less than those reported for Australian, Canadian, and French children (FSANZ 2011, Health Canada 2007, Rose et al. 2010).

Aluminum concentrations present in formula can vary by location, over time and with product type. Dabeka et al. (2011) calculated current mean total Al concentrations in Canadian ready-to-use milk- and soy-based formulas as 440 and $730 \mathrm{mg} / \mathrm{L}$, respectively. Compared to their previous study (Dabeka and McKenzie 1990) that found 130 and $1980 \mu \mathrm{g}$ $\mathrm{Al} / \mathrm{L}$ in similar products, mean $\mathrm{Al}$ levels in formula ranged from $72 \mu \mathrm{g} / \mathrm{L}$ in fat supplements to $510 \mu \mathrm{g} / \mathrm{L}$ in a whey-based formula. Lactose-free formula had a somewhat higher $\mathrm{Al}$ content than the standard milk-based formula, but the highest concentration $(3442 \mu \mathrm{g} / \mathrm{L})$ was found in a milk-based iron-fortified ready-to-use formula.

Dabeka et al. (2011) collected levels of Al in formula measured in Britain, the European continent, Nigeria, Spain, Saudi Arabia, and the United States. Aluminum concentrations as low as $6 \mu \mathrm{g} / \mathrm{L}$ to as high as $1152 \mu \mathrm{g} / \mathrm{L}$ (particularly for soy-based, lactose-free, and hypoallergenic formula) have been reported. However, the contemporary data all show $\mathrm{Al}$ levels far lower than the highest recorded $(5900 \mathrm{mg} / \mathrm{kg}$ ) for a dry formula purchased in the United Kingdom (Ministry of Agriculture, Fisheries and Food 1999). Assuming an infant consumed only commercial formula, Dabeka and McKenzie (1990) calculated that daily ingestion of a soy-based (high Al) formula by a 1- to 3 month-old baby corresponded to 363 $\mu \mathrm{g} / \mathrm{kg}$-day amounting to $\sim 700$ times the daily $\mathrm{Al}$ dose received by an infant consuming only cow's milk (0.5-2.0 $\mu \mathrm{g} / \mathrm{kg}$-day).

As with infant formula, the Al concentrations in milk vary by source, location, and local practice. Al-Ashmawy (2011) found differences in Al concentrations in raw cow's milk $(0.004 \pm 0.001 \mathrm{mg} / \mathrm{L})$, 'small market' milk $(0.081 \pm 0.010 \mathrm{mg} / \mathrm{L})$, powdered milk $(0.732$ $\pm 0.270 \mathrm{mg} / \mathrm{L})$ and processed cheese $(0.027-5.7 \mathrm{mg} / \mathrm{kg})$. The differences in $\mathrm{Al}$ concentrations between raw milk and "small market" milk were attributed to boiling raw milk in Al pans. Processed Egyptian cheese wrapped in Al foil had higher Al concentrations $(1.62 \pm 0.32 \mathrm{mg} / \mathrm{kg})$ than processed cheese packed in glass containers $(1.14 \pm 0.55 \mathrm{mg} / \mathrm{kg})$. 
Based on those results, Al-Ashmawy (2011) calculated maximum estimated daily intakes (MEDI) for consumption of $200 \mathrm{ml}$ Egyptian bulk farm milk or market milk per day or $45 \mathrm{~g}$ ( 1.5 ounces) processed cheese per day provided 0.029, 0.612, and $4.282 \mathrm{mg} \mathrm{Al} / \mathrm{kg}$-day, respectively. For a 60-kg Egyptian adult, the milk MEDI contributed $6 \mu \mathrm{g} / \mathrm{kg}$-day and consumption of processed Egyptian cheese (mean $\mathrm{Al}=1.1-1.6 \mathrm{mg} \mathrm{Al} / \mathrm{kg}$ ) contributed 2.2$4.28 \mathrm{mg} \mathrm{Al} / \mathrm{kg}$-day or $15-30 \mathrm{mg} \mathrm{Al} / \mathrm{kg}$-week, equivalent to 15 times the $2 \mathrm{mg} / \mathrm{kg}$-week PTWI (Benford et al. 2012). Assuming a 60-kg adult consumes $200 \mathrm{ml}$ of cow's milk per day, the daily Al dose varied from 0.23 to $13.1 \mu \mathrm{g} / \mathrm{kg}$-day (Arnich et al. 2012, FernandezLorenzo et al. 1999, Franzmann et al. 1976, Garcia et al. 1999, González-Weller et al. 2010: Hermansen et al. 2005). The $\mathrm{Al}$ concentrations in processed cheese reported by AlAshmawy (2011) are less than those reported in American cheese (411-695 mg/kg), in Swiss, cheddar, and bleu cheese (3.83-14.1 mg/kg) and in processed cheese $(297 \mathrm{mg} / \mathrm{kg}$ ) by Pennington (1987), Schenk et al. (1989) and Greger et al. (1985). The Al in processed cheese is related to the addition of anti-caking additives including sodium aluminosilicate (Saiyed and Yokel 2005, Schenk et al. 1989, Stahl et al. 2011).

A number of $\mathrm{Al}$ dietary exposure assessments considered fish and shellfish. As part of the 2006-2007 French national dietary survey, Arnich et al. (2012) found the highest Al concentrations in molluscs and crustaceans $(21.09 \mathrm{mg} / \mathrm{kg})$. Fish and its products had the highest Al levels of all French foods sampled, with mean levels in shrimp $(25.5 \mathrm{mg} / \mathrm{kg})$ and mussels $(42.9 \mathrm{mg} / \mathrm{kg})$ that were $7-10$ times those found in salmon $(4.57 \mathrm{mg} / \mathrm{kg})$ and other smoked or fried fish. Those results were generally consistent with those by Millour et al. (2011) who found $\mathrm{Al}$ at up to $116 \mathrm{mg} / \mathrm{kg}$ in shellfish. Employing microwave digestion and ICP-MS, Guerin et al. (2011) found a mean $1.35 \mathrm{mg} \mathrm{Al} / \mathrm{kg}$ in the edible portions of 159 species of saltwater organisms collected from four French coastal areas. The highest levels were present in sea urchin $(88.4 \mathrm{mg} / \mathrm{kg})$, gurnard $(9.68 \mathrm{mg} / \mathrm{kg})$, eel, anchovy and pollock $(2.53-3.59 \mathrm{mg} / \mathrm{kg})$. Those data were similar to the results for commercially important species from Agah et al. (2009), Erkan et al. (2009), Kelly et al. (2008), Leblanc et al. (2005), and Mahalakshmi et al. (2012). The levels reported by Agah et al. (2009), Kelly et al. (2008), and Leblanc et al. (2005) in fresh seafood do not account for the increased $\mathrm{Al}$ after baking or grilling in $\mathrm{Al}$ foil or other $\mathrm{Al}$ kitchenware (Ranau et al. 2001) or after addition of alum as a firming agent during canning (Wong et al. 2010).

Braganca et al. (2011) measured $\mathrm{Al}$ concentrations in commercial Brazilian grape, peach, mango, passion fruit, and guava juice. Depending upon the manufacturer, $\mathrm{Al}$ concentrations in grape juice ranged from less than 0.1 to $0.19 \mathrm{mg} / \mathrm{L}$, peach ranged from 0.15 to $0.31 \mathrm{mg} / \mathrm{L}$, mango varied from less than 0.1 to $0.25 \mathrm{mg} / \mathrm{L}$, passion fruit from less than 0.11 to $0.37 \mathrm{mg} / \mathrm{L}$ and $\mathrm{Al}$ concentrations in guava juice ranged from less than 0.19 to $0.3 \mathrm{mg} / \mathrm{L}$. Those levels were consistent with the mid-range Al concentrations $(0.05-1.1 \mathrm{mg} / \mathrm{L})$ in Spanish fruit juice (González-Weller et al. 2010) and taken together with the daily Al contributions from drinking water and soft drinks, the mean Spanish (non-alcoholic) beverage consumption amounted to $156 \mu \mathrm{g} \mathrm{Al} /$ person or $2.6 \mu \mathrm{g} / \mathrm{kg}$-day for a $60-\mathrm{kg}$ adult. Thus, the $\mathrm{Al}$ associated with consumption of fruit juice represented only a small fraction $(1.5 \%)$ of the total daily $\mathrm{Al}$ intake by Spanish adults (González-Weller et al. 2010). 
Tariba (2011) tabulated the (total) Al concentrations in wines from Argentina (0.017-0.018 $\mathrm{mg} / \mathrm{L})$, the Czech Republic $(0.132-1.67 \mathrm{mg} / \mathrm{L})$, Croatia $(0.244-0.81 \mathrm{mg} / \mathrm{L})$, Hungary $(0.01-$ $1.5 \mathrm{mg} / \mathrm{L})$ and Greece $(0.36-9.5 \mathrm{mg} / \mathrm{L})$. The major source of $\mathrm{Al}$ in wine is bentonite/ montmorillonite clay added during manufacture as a clarifying agent to reduce suspended proteins, polypeptides, and other particulates (McKinnon et al. 1992). Tariba (2011) pointed to the organic acids in wine as facilitating $\mathrm{Al}$ uptake from the gut, but neglected to note that the hydrated $\mathrm{Al}$ silicates (e.g., bentonite) in wine have no measurable oral bioavailability (Wiles et al. 2004).

Ohno et al. (2010) measured Al in Japanese rice, cereals and potatoes, sweets, oils and fats, legumes, fruit, green and yellow vegetables, seaweed, alcohol and other beverages, seafood, meat and poultry, dairy and seasonings. For most Japanese the highest Al daily exposure $(1.1 \mathrm{~g} /$ person) was associated with drinking $550 \mathrm{~g}$ of alcoholic beverages. The mean total daily dietary $\mathrm{Al}$ consumed by a 50-kg Japanese adult was $3.6 \pm 1.3 \mathrm{mg} /$ day $(25.2 \mathrm{mg} /$ week or $70 \mu \mathrm{g} / \mathrm{kg}$-day) or approximately $25 \%$ of the $285 \mu \mathrm{g} / \mathrm{kg}$-day PTWI (Benford et al. 2012). Ogimoto et al. (2012) conducted a similar survey and found that scones $(0.37 \mathrm{mg} / \mathrm{g})$, pound cake $(0.36 \mathrm{mg} / \mathrm{g})$, and salted jellyfish $(0.90 \mathrm{mg} / \mathrm{g})$ had the highest $\mathrm{Al}$ concentrations. Sato et al. (2014) found the highest $\mathrm{Al}$ concentrations in processed Japanese confections (21.73 $\mathrm{mg} / \mathrm{kg}$ ) and the lowest in rice $(0.32-0.43 \mathrm{mg} / \mathrm{kg})$.

The mean total daily Al dietary consumption (including alcoholic and non-alcoholic beverages, coffee, soups, and broth made with potable drinking water) by French adults and children (40 and $62.2 \mu \mathrm{g} / \mathrm{kg}$-day; $95 \% \mathrm{UCl}=69$ and $119 \mu \mathrm{g} / \mathrm{kg}$-day, respectively) (Arnich et al. 2012) was somewhat less than $\mathrm{Al}$ consumed by Japanese. Of the foods included in the 2011 French national dietary survey, pastries contained $\mathrm{Al}$ at up to $24 \mathrm{mg} / \mathrm{kg}$, biscuits contained $\mathrm{Al}$ at up to $10 \mathrm{mg} / \mathrm{kg}$ and dark chocolate contained $\mathrm{Al}$ at up to $54 \mathrm{mg} / \mathrm{kg}$ (Millour et al. 2011). At customary French consumption rates, coffee and vegetables (excluding potatoes) accounted for $24 \%$ of total daily dietary $\mathrm{Al}$ for an adult and pasta, pastries, cakes, and dairy products accounted for $19 \%$ of a child's daily Al consumption. For residents of the Canary Islands, the estimated total daily dietary Al intake was $10.2 \mathrm{mg} / \mathrm{day}(170 \mu \mathrm{g} / \mathrm{kg}$-day for a $60 \mathrm{~kg}$ adult) where the naturally occurring levels of $\mathrm{Al}$ in fruit were a major source (González-Weller et al. 2010).

Rose et al. (2010) found UK consumers received their highest Al dietary dose from cereals and that the highest $\mathrm{Al}$ levels provided adults and toddlers with 144 and $345 \mu \mathrm{g} / \mathrm{kg}$-day, respectively. Compared to the $2 \mathrm{mg} / \mathrm{kg}$-week PTWI (Benford et al. 2012) [equivalent to 120 $\mathrm{mg} /$ week for a $60-\mathrm{kg}$ woman or $285 \mu \mathrm{g} / \mathrm{kg}$-day], the average daily Al doses for UK residents aged 4-18 were less than the PTWI while those for residents 1.5-4.5 years consuming the highest Al levels were $20 \%$ greater than the PTWI.

Total dietary $\mathrm{Al}$ intakes vary with location

\begin{tabular}{lccl}
\hline Country & $\begin{array}{c}\text { Mean adult exposure }(\mu \mathrm{g} / \mathrm{kg}- \\
\text { day) }\end{array}$ & $\begin{array}{c}\text { Mean child exposure }(\mu \mathrm{g} / \mathrm{kg}- \\
\text { day) }\end{array}$ & References \\
\hline Australia & 36 & 44 & FSANZ (2011) \\
Japan & 70 & NR* & Ohno et al. (2010)
\end{tabular}

Crit Rev Toxicol. Author manuscript; available in PMC 2016 August 25. 


\begin{tabular}{lccl} 
& 43 & $64-123$ & Sato et al. (2014) \\
Hong Kong & 86 & NR & Wong et al. (2010) \\
Canada & 56 & 64 & Health Canada (2007) \\
Western Europe & $28.6-214$ & NR & EFSA (2008) \\
France & 40.3 & 62.2 & Arnich et al. (2012) \\
Italy & 60 & NR & Turconi et al. (2009) \\
United Kingdom & 71 & 187 & Rose et al. (2010) \\
Canary Islands & $124-204$ & NR & González-Weller et al. (2010) \\
\hline
\end{tabular}

$* N R$ not reported

Stahl et al. (2011) calculated Al consumption by German adults (70 kg) and children (30 $\mathrm{kg}$ ). Of all German foods considered, cocoa powders consistently had the highest mean $\mathrm{Al}$ $(165 \mathrm{mg} / \mathrm{kg})$ and chocolate had a mean $48 \mathrm{mg} \mathrm{Al} / \mathrm{kg}$. Based on average yearly cocoa consumption, the German child received $4 \%$ and the adult received $2 \%$ of the PTWI; chocolate provided up to $12 \%$ of the adult and $30 \%$ of the child's PTWI.

Yokel (2013) compiled typical median Al concentrations found in United States beer $(0.16$ $\mathrm{mg} / \mathrm{L})$, coffee $(0.24 \mathrm{mg} / \mathrm{L})$, fruit juice $(0.18-0.67 \mathrm{mg} / \mathrm{L})$, wine $(0.90 \mathrm{mg} / \mathrm{L})$, soft drinks $(0.25-0.41 \mathrm{mg} / \mathrm{L})$ and distilled spirits $(0.42 \mathrm{mg} / \mathrm{L})$. The highest $\mathrm{Al}$ concentrations were present in powdered non-dairy creamers $(38-170 \mathrm{mg} / \mathrm{kg})$, in paprika $(92 \mathrm{mg} / \mathrm{kg})$ and in single-serving packets of table salt $(180 \mathrm{mg} / \mathrm{kg})$. In general, current total Al dietary exposures in the United States are somewhat less than those measured during the 1990s when mean total daily adult dietary intake was 7-9 mg/day (ATSDR 2008, Pennington and Schoen 1995), an intake equivalent to $116-128 \mu \mathrm{g} \mathrm{Al} / \mathrm{kg}$-day for a 60-kg adult. Thus, dietary $\mathrm{Al}$ exposures for most Americans represent about 50\% of the PTWI. Assuming ingestion of five EU-approved Al food additives at their maximum permitted levels, the EFSA (2013) calculated Al doses for toddlers (11.3-156.2 mg/kg-week), children (26.9-286.8 mg/kgweek) and adults (2.3-100.4 mg/kg-week). All of the calculated values were greater than the PTWI.

\section{Consumer products}

Two studies found that certain metallic and ceramic products can leach considerable quantities of Al. Bolle et al. (2011) found 0.07-3.5 mg Al/L in aqueous citric acid ( $1 \mathrm{~g} / \mathrm{L}$ at pH 2.7 to simulate commercial lyophilized teas with lemon) extracts (30 min on a heated hotplate) from traditional Indian and Moroccan brass teapots. Demont and associates (2012) measured Al migration from glazed ceramic pots at up to $90 \mathrm{mg} / \mathrm{L}$ into $\mathrm{pH}$ 2.37-3.63 aqueous citric, acetic or maleic acids at $22^{\circ} \mathrm{C}$.

Aluminum migration from glass bottles into electrolyte and glucose solutions and into infant formula has been recognized for many years (Bohrer et al. 2001, 2003, Koo et al. 1988).

Fekete et al. (2012) investigated Al leaching from glass, ceramic, and stainless steel utensils as well as from $\mathrm{Al}$ plates and foil. Aluminum migration from these articles depends on temperature $\left(20-180^{\circ} \mathrm{C}\right)$, contact time (30-142 $\left.\mathrm{min}\right), \mathrm{pH}(2.2-7)$, and salt concentration (0$9.6 \mathrm{~g} / \mathrm{L}$ ) of the extractant (cream, tomato sauce, black tea, or salted lemon juice). Extreme temperature, low $\mathrm{pH}$ and prolonged contact times caused complete disintegration of $\mathrm{Al}$ foil 
and plates. When $\mathrm{pH} 4.5$ tomato sauce with $5 \mathrm{~g} / \mathrm{L}$ salt was used as the extractant, $\mathrm{Al}$ leaching from glass and stainless steel was less than the analytical limit of detection; daily $\mathrm{Al}$ doses depend not only on kitchenware and food type, but frequency of Al utensil use in food storage and preparation.

Verbeken et al. (2011) examined Al migration from the food-grade $\mathrm{Al}$ foil used in hospital cryo preservation of human skin. They found $1.4 \mathrm{mg} \mathrm{Al} / \mathrm{L}$ in pooled cryo preservation media (30\% v/v glycerol in physiological saline) for seven skin samples that had been frozen for 10 years.

Aluminum is present at $0.37 \%$ in tobacco and at $0.4 \%$ in marijuana (Exley et al. 2006). Intentional inhalation of glue (Akay et al. 2008), cocaine, and/or heroin ('Chasing the Dragon') can lead to $\mathrm{Al}$ exposure when $\mathrm{Al}$-bound drug vaporizes after heating on $\mathrm{Al}$ plates, cans, or foil (Boto de los Bueis et al. 2002, Pechansky et al. 2007), where Al can enter the brain via olfactory pathways (Perl and Good 1987, Divine et al. 1999, Exley et al. 1996, Yokel 2002). Aluminum concentrations in heroin (42-2280 ppm) increase as a result of its synthesis at elevated temperature in $\mathrm{Al}$ cookware (Bora et al. 2002). These exposures are such that elevated urinary $\mathrm{Al}$ can be measured after repeated heroin use either after it is inhaled off Al foil or after intravenous injection (Exley et al. 2007a). Intentional abuse of oral methadone delivered by intravenous injection has also been held responsible for $\mathrm{Al}$ intoxication (Friesen et al. 2006).

Da Silva et al. (2010) measured Al concentrations in 14 different calcium (Ca) dietary supplements and gastric antacid capsules or chewable tablets. These supplements were made of synthetic carbonate/phosphates, carbonate/citrate, carbonate malate/succinate/glutamate or crushed oyster shell, and the antacids were comprised of $\mathrm{Ca}$ carbonate compounded with $\mathrm{MgO}, \mathrm{Mg}$ stearate, aspartame, sucrose, powdered cellulose, and/or Na hexametaphosphate. Aluminum concentrations generally ranged from 0.24 to $0.65 \mathrm{mg} / \mathrm{g} \mathrm{Ca}$, but one antacid (sold under the tradename AntSyn2 with $\mathrm{H}_{2} \mathrm{MgO}_{2}, \mathrm{C}_{36} \mathrm{H}_{70} \mathrm{MgO}_{2}$, corn starch and dextrose) contained 1.22-1.25 mg Al/g Ca. All the chewable tablets had higher $\mathrm{Al}$ concentrations than any of the capsules; those chewable tablets provide 2-12 mg Al/day or 33-200 $\mu \mathrm{g} \mathrm{Al} / \mathrm{kg}$-day for a $60-\mathrm{kg}$ adult. Assuming consumption of a chewable daily Ca dietary supplement sufficient to provide $1500-3000 \mathrm{mg} \mathrm{Ca} /$ day represents $11-70 \%$ of the current $285 \mu \mathrm{g} / \mathrm{kg}$-day PTWI (Benford et al. 2012).

Prescription of Al-based phosphate binders has been discontinued in large part in North America and in the United Kingdom due to cases of Al-induced microcytic anemia, seizures, and osteomalacia (National Kidney Foundation 2003), but it remains common in Australia, New Zealand, Germany, Italy, and Spain (Mudge et al. 2011). Except in rare cases of equipment failure (CDC 2008) or inadvertent introduction of $\mathrm{Al}$ into dialysate (Berend et al. 2001), elevated serum Al and risk of dialysis encephalopathy have for all practical purposes been eliminated by controlling Al concentrations in dialysate to less than $10 \mu \mathrm{g} / \mathrm{L}$ (ANSI/ AAMI 2004, CAN/CSA-ISO 2011) and substituting Al phosphate binders with Ca acetate, $\mathrm{Ca}$ carbonate, sevelamer, or lanthanum. Abnormally high plasma and serum Al levels can result after daily consumption of the customary approximately $4 \mathrm{~g}$ of Al-based phosphate chelators even with regular clinical monitoring (Arenas et al. 2008, Cárdenas et al. 2010, 
Gault et al. 2006). Those observations contrast with Jimenez et al. (2011) and Mudge et al. (2011) who concluded Al-based phosphate chelators are not only economical and effective, but they have a high rate of patient compliance without undue health risk. In this regard, Mudge et al. (2011) presented Australian patient costs for $\mathrm{Al}(\mathrm{OH})_{3}$ (currently A72 $\varnothing /$ day) compared to $\mathrm{A} \$ 10.80 /$ day for sevelamer and $\mathrm{A} \$ 13.20 /$ day for lanthanum (equivalent to an annual $\mathrm{A} \$ 262$, $\mathrm{A} \$ 3942$, and $\mathrm{A} \$ 4818$, respectively).

Cárdenas and associates (2010) compared serum $\mathrm{Al}$ in 63 patients on renal dialysis (21-89 years of age) with that of 20 healthy referents (24-73 years of age). The dialysis water had less than $2 \mu \mathrm{g} \mathrm{Al} / \mathrm{L}$ and the mean serum $\mathrm{Al}$ in healthy people $(8.05 \pm 4.3 \mu \mathrm{g} / \mathrm{L})$ was less than the serum $\mathrm{Al}$ in those with kidney disease $(26.5 \pm 8.0 \mu \mathrm{g} / \mathrm{L})$. Given the very low $\mathrm{Al}$ concentration in dialysis water, Cárdenas et al. (2010) concluded that consumption of $\mathrm{Al}(\mathrm{OH})_{3}$ to mitigate hyperphosphatemia was the primary source of elevated serum $\mathrm{Al}$.

Kan et al. (2010) confirmed the on-going problem with elevated $\mathrm{Al}$ among HD patients. Pepper et al. (2011) evaluated serum Al using ICP-MS and measured Al body burdens using the 48-h low-dose $(500 \mathrm{mg}$ ) DFO challenge test in $39 \mathrm{HD}$ patients with a history of chronic (1-73 months) $\mathrm{Al}(\mathrm{OH})_{3}$ ingestion. Those patients were $56.5 \pm 2.4$ years of age, consumed on average a total of $1.2 \mathrm{~kg}(0.07-7.15 \mathrm{~kg})$ of $\mathrm{Al}(\mathrm{OH})_{3}$ over 23 months and the mean time since $\mathrm{Al}(\mathrm{OH})_{3}$ dosing ceased until evaluation was 12.9 months. Serum $\mathrm{Al}$ concentrations for 37 of the 39 subjects were less than $1.0 \mu \mathrm{mol} / \mathrm{L}(27 \mu \mathrm{g} / \mathrm{L}$ ) and the remaining two (who consumed 1.36-1.85 kg of $\left.\mathrm{Al}(\mathrm{OH})_{3}\right)$ had serum $\mathrm{Al}$ less than $3.0 \mu \mathrm{mol} / \mathrm{L}(80 \mu \mathrm{g} / \mathrm{L})$. Although serum $\mathrm{Al}$ increased significantly after DFO challenge, none of these patients experienced an increase higher than $3 \mu \mathrm{mol} / \mathrm{L}$. No confirmatory bone biopsy data were presented to support the contention that these doses of $\mathrm{Al}(\mathrm{OH})_{3}$ represent low risk. As there was no significant correlation $(p=0.10)$ between cumulative $\mathrm{Al}$ dose and post-DFO serum $\mathrm{Al}$ concentration, Pepper et al. (2011) suggested that $\mathrm{Al}$ exposure from phosphate binders "is likely to be dwarfed by other sources such as drinking water and foods." Pepper et al. (2011) offered no empirical comparisons to support that interpretation whereas Krewski et al. (2007) noted mean daily $\mathrm{Al}$ intake from food $(7.2-8.6 \mathrm{mg})$ and drinking water $(0.16 \mathrm{mg})$ were substantially less than the customary $4000 \mathrm{mg} \mathrm{Al} /$ day used by patients on kidney dialysis.

Evaluations of $\mathrm{Al}(\mathrm{OH})_{3}$ or other Al-based phosphate binders in routine management of patients with compromised kidney function are problematic (Jimenez et al. 2011). Hou et al. (2010) measured serum $\mathrm{Al}$ in 319 patients on chronic (41.5 \pm 34.9 months) HD (166 men and 153 women aged $21-89$ years) compared to 62 young ( $23.9 \pm 3.7$ years) healthy students and 81 patients $(57.9 \pm 15.2$ years) with renal failure who were not on dialysis. Those on HD had significantly higher serum $\mathrm{Al}(3-443 \mu \mathrm{g} / \mathrm{L})$ than renal patients not on dialysis $(2-237 \mu \mathrm{g} / \mathrm{L})$ or the healthy students $(1-14 \mu \mathrm{g} / \mathrm{L})$. There was no indication of gender-related differences at any age, but serum creatinine levels were inversely correlated ( $\mathrm{p}<0.0001)$ with serum Al. Older dialysis patients (67-89 years) had significantly higher serum $\mathrm{Al}$ than younger (21-43 years) dialysis patients. Out of the $319 \mathrm{HD}$ patients, 14 patients used oral $\mathrm{Al}(\mathrm{OH})_{3}$ to control serum phosphate and three had serum $\mathrm{Al}$ higher than $250 \mu \mathrm{g} / \mathrm{L}$. Ingested $\mathrm{Al}(\mathrm{OH})_{3}$ is not the only source of $\mathrm{Al}$ that Bohrer et al. (2009) found for patients with kidney disease, because injectable drugs (notably insulin, EPO, and Fe) were also significant Al sources. Jimenez et al. (2011) concluded that Al-based phosphate binders 
could be used but in light of the risks for adynamic bone disease other measures (reduced dietary phosphate and increased dialysis duration) should be exhausted prior to considering use of Al-based phosphate binders.

After reviewing the history of $\mathrm{Al}(\mathrm{OH})_{3}$ to control serum phosphate in patients with kidney disease, Mudge et al. (2011) calculated that at customary doses, $\mathrm{Al}(\mathrm{OH})_{3}$ reduced serum phosphate $0.3 \mathrm{mmol} / \mathrm{L}$ and that reduction is equivalent to a $10-15 \%$ reduction in cardiovascular mortality for these patients. Mudge et al. (2011) reported success with $\mathrm{Al}(\mathrm{OH})_{3}$ (as compared with Ca carbonate) and pointed out that there are no controlled prospective randomized clinical trials that have examined the safety and efficacy of different phosphate binders. Mudge et al. (2011) made no mention of restrictions to control dietary acids (e.g., ascorbate, citrate, and lactate) that enhance $\mathrm{Al}$ uptake from ingested $\mathrm{Al}(\mathrm{OH})_{3}$ (Coburn et al. 1991, Priest et al. 1996, Weberg and Berstad 1986). The experience described by Mudge et al. (2011) contrasts with the dose-dependent increase in serum $\mathrm{Al}$ and/or $\mathrm{Al}$ induced bone disease after oral $\mathrm{Al}(\mathrm{OH})_{3}$ among renal patients with no history of dialysis (Andreoli et al. 1984, Felsenfeld et al. 1982), who either all received identical Al exposures during dialysis (Cannata et al. 1983) or who were never exposed to excessive $\mathrm{Al}$ in dialysis fluid, but who used Al-based phosphate binders (Andress et al. 1986, Jenkins et al. 1989, Salusky et al. 1991).

\section{Drinking water}

Health Canada (2010) reported mean Al concentrations of 20-174 $\mu \mathrm{g} / \mathrm{L}$ in finished municipal tap water. Frankowski et al. (2011) measured $\mathrm{Al}$ in potable water using three analytical techniques (GFAAS, ICP-MS, and ICP-AES) and found the chemical forms depended upon water source $\mathrm{pH}$, temperature and the concentrations of organic carbon and the nature of the suspended particulates. At lower $\mathrm{Al}$ concentrations and at $\mathrm{pH}$ 5.5-6.5, the fluorides $\left(\mathrm{AlF}^{2+}, \mathrm{AlF}_{2}^{+}, \mathrm{AlF}_{3}{ }^{0}\right.$, and $\left.\mathrm{AlF}_{4}^{-}\right)$and sulfates $\left(\mathrm{AlSO}_{4}{ }^{+}\right.$, and $\left.\mathrm{Al}\left(\mathrm{SO}_{4}\right)^{2-}\right)$ predominated, but at higher $\mathrm{Al}$ concentrations and at neutral $\mathrm{pH}$, the hydroxides $\left(\mathrm{AlOH}^{2+}\right.$, $\mathrm{Al}(\mathrm{OH})_{2}{ }^{+}$, and $\left.\mathrm{Al}(\mathrm{OH})_{4}{ }^{-}\right)$and $\mathrm{Al}$ organics (e.g., fulvic and humic acids) were the major species.

Al-Ashmawy (2011) considered drinking water contributed approximately $1.2 \%$ of a typical Egyptian's daily Al intake, a conclusion that was consistent with Ohno et al. (2010) who found that adults living in six Japanese cities who consumed 2 liters of water each day received $80 \pm 7 \mu \mathrm{g} \mathrm{Al} /$ day or $2.2 \%$ of their total mean daily $\mathrm{Al}$ dietary intake $(3600 \pm 1370$ $\mu \mathrm{g} /$ day). Assuming a 50-kg Japanese adult consumes 2 liters of drinking water per day, water accounts for $1.6 \mu \mathrm{g} \mathrm{Al} / \mathrm{kg}$-day or $0.6 \%$ of the $285 \mu \mathrm{g} \mathrm{Al} / \mathrm{kg}$-day PTWI (Benford et al. 2012). Those concentrations are consistent with historical data from the United States where a median Al concentration in finished municipal drinking water $(0.112 \mathrm{mg} / \mathrm{L})$ corresponded to a daily ingested dose (assuming consumption of 1.4 1/day) of $160 \mu \mathrm{g} \mathrm{Al} / \mathrm{kg}$ or about $1 \%$ of the amount contributed by food for a 70-kg adult (ATSDR 2008, Krewski et al. 2007). Those estimates are lower than the $4 \%$ value put forward by WHO (2010) after assuming drinking water contained $0.1 \mathrm{mg} \mathrm{Al} / \mathrm{L}$. 


\section{Workplace air}

The air inside $\mathrm{Al}$ smelters, foundries, and remelting plants can contain appreciable concentrations of $\mathrm{Al}$ oxides and $\mathrm{Na}_{3} \mathrm{AlF}_{6}$ (Nordic Expert Group 2011, Westberg et al. 2001).

Weinbruch et al. (2010) used SEM and energy-dispersive X-ray microanalysis (EDX) to define the size, morphology, and composition of 543 Søderberg and 176 Prebake potroom aerosol particles (> $500 \mathrm{~nm}$ ); particles smaller than $500 \mathrm{~nm}$ were composed primarily of sodium Al fluorides. The highest mean inhalable particle mass concentration $\left(6800 \mu \mathrm{g} / \mathrm{m}^{3}\right)$ was found in Prebake potrooms. Total and respirable Al dust concentrations in workers' breathing zones during routine operations were $0.08-2.1 \mathrm{mg} / \mathrm{m}^{3}$ and $0.03 \mathrm{mg} / \mathrm{m}^{3}$, respectively. The $\mathrm{Al}$ oxides present in these dusts generally constitute approximately $25-$ $44 \%$ of the total Al. On average, the Søderberg particles were composed of $60 \%$ soot, $7.2 \%$ $\mathrm{Al}$ oxides, and cryolite $\left(\mathrm{NaAlF}_{6}\right)$ mixtures, $0.7 \%$ pure oxides, $12 \%$ silicates, $14 \%$ Ca sulfates and lesser amounts (3\%) of Ca fluorides. The Prebake particles were primarily (56\%) mixtures of $\mathrm{Al}$ oxides and cryolite, $36 \%$ soot, $1 \%$ silicates, $0.6 \%$ Ca fluorides, and $2.8 \%$ other materials. No pure cryolite particles were seen in either process. Under humid conditions (as in the respiratory tract) all these aerosols developed thin films of water over their surfaces and the $\mathrm{Al}$ oxides/cryolite particles agglomerated into larger water droplets. These observations are important because up to $10 \%$ of the airborne HF and $1 \%$ of the airborne $\mathrm{SO}_{2}$ dissolved into those liquid aerosols and their physical properties facilitated transfer of these acids into the deeper (alveolar) regions of the lung than when workers are exposed to the airborne acid alone. At the present time, however, it is not known if these factors increase the risk of local pulmonary irritation, edema, and hemorrhage or contribute to occupational respiratory disease (Weinbruch et al. 2010).

Lewis et al. (2011) compiled workplace area (> $120 \mathrm{~min}$ ) and breathing zone (> 30-543 min) measurements of $\mathrm{Al}_{2} \mathrm{O}_{3}$ and $\mathrm{Al}_{2} \mathrm{~S}_{3}$ in dust generated during handling of a powdered catalyst (zeolite with trace elements) used in crude oil fractionation. No efforts were expended to determine particle size distributions, but the literature sources suggested the mean diameter was $70-80 \mathrm{~mm}$. Personal and workplace area samples found the highest total dust $\left(540 \mathrm{mg} / \mathrm{m}^{3}\right)$ and $\mathrm{Al}$ oxide $\left(2.1 \mathrm{mg} / \mathrm{m}^{3}\right)$ concentrations during catalyst loading, but airborne $\mathrm{Al}_{2} \mathrm{~S}_{3}$ concentrations were always less than the analytical limit of detection.

Alumina and Al silicate nanoparticles ( $2-3 \mathrm{~nm}$ diameter) are used in pigments and cosmetics, fine polishing powders, and in microelectronics production. $\mathrm{Al}$ nanoparticles are generated during friction stir, flame, and solid-state welding on $\mathrm{Al}$ (Curwin and Bertke 2011, Dash and D'Arcy 2008, Gomes et al. 2012a, 2012b, Pfefferkorn et al. 2010), sanding painted surfaces (Koponen et al. 2010) and in electric arc thermal sprays (Bémer et al. 2010). The extent of Al nanoparticle exposure during welding depends on work practices, the temperature of the weld (as a function of electrical current) and operator distance to the welding front (Gomes et al. 2012). While concerns have been expressed over carcinogenic potential and other aspects of toxicity associated with occupational and environmental exposures to engineered nanospheres or nanodots, short- and long nanobelts, nanorods, nanowires, or nanotubes (Borm et al. 2006, Byrne and Baugh 2008, Nel et al. 2006, NIOSH 2011), it has proven complicated to assess health risks of nanoscale materials because the 
physiochemical properties and particle behavior can differ from those of ultrafine or bulk materials of the same chemical composition.

\section{Ambient air}

Boullemant (2011) compared collection methods used to capture total particulate matter $\left(\mathrm{PM}_{\text {total }}=\mathrm{PM}>0.3 \mathrm{~mm}\right.$ plus condensables), $\mathrm{PM}_{10}$ and $\mathrm{PM}_{2.5}$ in $\mathrm{Al}$ smelter emissions (e.g., anode baking furnace exhaust, potroom scrubber stacks, and potroom roof vents). Two primary Al smelters (both using prebake technologies) with different production rates (190 and $420 \mathrm{kt} / \mathrm{year}$ ) were studied. The uncontrolled roof vents were responsible for $85 \%$ of all smelter emissions and accounted for $71 \%$ of all smelter $\mathrm{PM}_{2.5}$. Aluminum comprised the majority of the $\mathrm{PM}_{2.5}$ mass fraction regardless of whether the sample was from ambient air $(1.74-4.05 \%)$ or from stacks at the gas treatment center (13\%). Scanning electron microscopy/energy dispersive $\mathrm{X}$-ray analyses confirmed these $\mathrm{Al}$ particles were related to those generated in the electyrolytic bath (chiolite, cryolite, $\mathrm{NaAlF}_{4}$, and fluorinated alumina).

Naturally occurring Al nanoforms are prominent in volcanic ash (Wada 1987) and in the fine fractions of clay soils ( $\mathrm{Li}$ et al. 2012a, Theng and Yuan 2008). 1-100 nm Al nanoplatelets, nanowires/nanotubes and/or nanodots are abundant in allophane (where nanotubes exist as individual 3.5-5.0 nm particles 30-50 $\AA$ in diameter), halloysite, hectorite, kaolinite and montmorillonite (Childs et al. 1990, Floody et al. 2009, Hall et al. 1985, Karube et al. 1996, Theng et al. 1982) and these materials are present in the dust suspended in ambient air.

\section{Absorption, distribution, and elimination}

\section{Ingestion}

Krewski et al. (2007) described the influence of Al chemical form and the influence of citrate and other carboxylic acids on oral absorption of Al. Ingested Al is absorbed primarily from the duodenum and small intestine via passive diffusion, pinocytosis, and transferrin/ vitamin D-dependent active transport (summarized in Crisponi et al. 2012). Parathyroid hormone (PTH) increases intestinal Al uptake by stimulating renal synthesis of 1, 25dihydroxycholecalciferol (1, 25-DHC) (Azik et al. 2011, Malluche and Faugere 1985). Dietary constituents that reduce $\mathrm{Al}$ uptake from the gut include phosphates that combine with Al to yield insoluble dialuminum triphosphate and Fe that competes for transferrin; dietary factors that enhance $\mathrm{Al}$ uptake include citric and other organic acids. Following absorption, $\mathrm{Al}^{+3}$ in serum is bound primarily ( $\left.\sim 90 \%\right)$ to transferrin and the remaining fraction is bound to low molecular weight molecules including citrate, phosphate, and citrate-phosphate complexes of which Al-citrate predominates (7-8\%) (Yokel and McNamara 2001).

Mujika et al. (2011b) studied the interaction between $\mathrm{Al}^{3+}$ and $\mathrm{Fe}^{3+}$ with serum transferrin. Iron bound to serum transferrin is normally released from the protein's closed conformation $\mathrm{N}$-lobe to the transferrin receptor 1 in peripheral (e.g., neurons, glial and blood-brain barrier) cells where it is internalized by endocytosis. The process is $\mathrm{pH}$-dependent in that the endosomal pH 5.5 is significantly less than serum $\mathrm{pH}$ (7.4). Trivalent $\mathrm{Al}$ does not compete 
effectively with ferric iron for serum Fe-binding sites. The successive stability constants for $\mathrm{Fe}^{3+}$ binding to transferrin $(\log \mathrm{K} 1=22.7$ and $\log \mathrm{K} 2=22.1)$ are much higher than those for $\mathrm{Al}^{3+}(\log \mathrm{K} 1=12.9$ and $\log \mathrm{K} 2=12.3)$. As $70 \%$ of serum metal binding sites are normally unoccupied by $\mathrm{Fe}^{+3}$, the transferrin protein can accommodate two $\mathrm{Al}^{+3}$ ions-first one binding at the $\mathrm{C}$-lobe and the second at the $\mathrm{N}$-lobe. Additional studies of serum transferrin $\mathrm{Al}^{+3}$ binding and release by Mujika et al. (2012a) revealed that only under conditions where Tyr188 is protonated do transferrin's conformational hinge-bending and hinge-twisting changes permit $\mathrm{Al}^{+3}$ release (Mujika et al. 2012a).

Citrate is important not only because it increases gastrointestinal Al bioavailability (Krewski et al. 2007, Priest 2004, 2010a, 2010b, Wu et al. 2012b) and 7-8\% of the $\mathrm{Al}$ in plasma is bound to citrate (Chen et al. 2010b, Krewski et al. 2007), but it has been suggested that Alcitrate is also taken up by the monocarbonate transporter (MCT) and that it might serve as a substrate for the organic anion-transporting polypeptide (OATP) enabling brain brain influx (Crisponi et al. 2012, Yokel 2006), where it constitutes approximately $90 \%$ of the $\mathrm{Al}$ in cerebrospinal fluid (Yokel and McNamara 2001). Based on Al citrate uptake into immortalized rat cells in the presence of ligands for the sodium-independent L-glutamate/Lcysteine exchanger system $\mathrm{Xc}^{-}$, Nagasawa et al. (2005) suggested that system may also mediate $\mathrm{Al}$ citrate uptake into the brain.

The EFSA (2011) reviewed the Al gastrointestinal bioavailability results by Priest (2010a). This study examined Sprague-Dawley rats given a single oral 50-mg intubation of ${ }^{26} \mathrm{Al}$ citrate $\left(1.47 \mathrm{ng}^{26} \mathrm{Al}\right), \mathrm{AlCl}_{3}, \mathrm{Al}\left(\mathrm{NO}_{3}\right)_{3}$, or $\mathrm{Al}_{2}\left(\mathrm{SO}_{4}\right)_{3}$ in water or $17 \mathrm{mg}$ of $\mathrm{Al}(\mathrm{OH})_{3}$ or 23 $\mathrm{mg}$ of $\mathrm{Al}_{2} \mathrm{O}_{3}$ in carboxymethycellulose or $6.9 \mathrm{mg}$ metallic $\mathrm{Al}$ particles in honey. At 7 days after intubation, whole body $(\mathrm{WB})^{26} \mathrm{Al}$ retention (following removal of the pelt, gut, paws, tail and head in an effort to reduce external contamination) after an oral dose was compared to that after iv injection of $0.19 \mathrm{ng}{ }^{26} \mathrm{Al}$ citrate. The mean ${ }^{26} \mathrm{Al}$ fraction remaining at 7 days after iv Al citrate $(0.079 \pm 0.006 \%)$ was substantially less than the $0.3-1.49 \%$ gastrointestinal uptake reported previously for rats (Froment et al. 1989, Schönholzer et al. 1997, Yokel et al. 2001). It is possible this difference is due to Al elimination during the 7 days after administration. Among the salts $\mathrm{Al}_{2}\left(\mathrm{SO}_{4}\right)_{3}$ had the highest oral absorbed fraction $(0.21 \pm 0.079 \%)$ and $\mathrm{Al}(\mathrm{OH})_{3}$ had the lowest $(0.025 \pm 0.041 \%)$. Retention of ${ }^{26} \mathrm{Al}$ after an oral dose of metallic $\mathrm{Al}(<0.015 \%)$ was less than the analytical limit of detection.

Yokel and associates (2008) measured gastrointestinal uptake of ${ }^{26} \mathrm{Al}$ by fasted male F344 rats from $1 \mathrm{~g}$ of processed cheese containing $1.5 \%$ or $3 \%$ basic sodium aluminum phosphate (SALP). Comparing the area under the serum concentration: time curve after 60-h intravenous infusion with $100 \mu \mathrm{g} \mathrm{Al} / \mathrm{kg}$-h (as $\left.\mathrm{AlK}\left(\mathrm{SO}_{4}\right)_{2}\right)$ to the serum ${ }^{26} \mathrm{Al}$ concentrations after feeding cheese, peak circulating $\mathrm{Al}$ was achieved at 8.0-8.6 $\mathrm{h}$ and the highest concentration was seen in rats that consumed the lower (1.5\%) SALP cheese. Total oral Al bioavailability was 3 times greater in rats consuming cheese with the higher $\mathrm{Al}$ content than in those consuming the lower Al level cheese. Yokel and Florence (2008) then compared oral bioavailability (to $60 \mathrm{~h}$ ) of ${ }^{26} \mathrm{Al}$ in $\mathrm{F} 344$ rats using serum concentration: time profiles after an intravenous infusion of $\mathrm{AlK}(\mathrm{SO} 4)_{2}$ at $100 \mu \mathrm{g} \mathrm{Al} / \mathrm{kg}$-hr over $14 \mathrm{~h}$. Total gastrointestinal uptake of Al from tea was 0.37\% (Flaten 2002, Yokel and Florence 2008), a 
value higher than the Al uptake measured in rats fed cheese containing SALP $(0.10-0.29 \%)$ or after rats were fed acidic SALP in baked goods (0.12\%) (Yokel and Florence 2006).

Poirier et al. (2011) compared the relative oral Al uptake and distribution after repeated 7 or 14 days oral gavage with $30 \mathrm{mg} / \mathrm{kg}$-day of either $\mathrm{Al}$ citrate, $\mathrm{Al}_{2}\left(\mathrm{SO}_{4}\right)_{3}, \mathrm{AlCl}_{3}, \mathrm{Al}(\mathrm{OH})_{3}$, or $\mathrm{Al}\left(\mathrm{NO}_{3}\right)_{3}$ dissolved in deionized water $(<2 \mu \mathrm{g} \mathrm{Al} / \mathrm{L})$ in rats. Whole blood $\mathrm{Al}$ concentrations were similar at Day 7 for all $\mathrm{Al}$ forms. Whole blood $\mathrm{Al}$ concentrations declined on Day 14 compared to those measured on Day 7 despite the continued daily oral dosing. The highest Al concentrations were present in liver, kidney, and bone.

The Poirier et al. (2011) conclusions with $\mathrm{Al}_{2}\left(\mathrm{SO}_{4}\right)_{3}$ and $\mathrm{Al}(\mathrm{OH})_{3}$ contrast with the relative WB Al bioavailability (0.025-0.21\%) after a single oral 50-mg intubation in groups of six adult female Sprague-Dawley rats with ${ }^{26} \mathrm{Al}$ labeled $\mathrm{Al}_{2}\left(\mathrm{SO}_{4}\right)_{3}>\mathrm{Al}$ citrate $>\mathrm{AlCl}_{3}>$ $\mathrm{Al}\left(\mathrm{NO}_{3}\right)_{3}>\mathrm{Al}(\mathrm{OH})_{3}(\mathrm{EFSA} 2011)$. The comparatively low value $(0.025 \pm 0.041 \%)$ listed by EFSA (2011) for $\mathrm{Al}(\mathrm{OH})_{3}$ is perhaps due to the smaller $17 \mathrm{mg}$ dose given as a suspension in carboxymethylcellulose which may alter uptake compared to the aqueous vehicle used for the other congeners.

The factors relating to bioavailability and tissue accumulation of Al citrate are complicated. Mujika et al. (2012b) examined $\mathrm{Al}^{+3}$ binding with citrate and determined four pKa values $\left(2.9,4.3,5.6\right.$, and 11.6/14.4). Citrate binds $\mathrm{Al}^{+3}$ at three coordination sites and three labile water molecules occupy the remaining positions in an octahedron. Depending on $\mathrm{pH}$, unprotonated citrate binds $\mathrm{Al}^{+3}$ at two terminal carboxylic and one alkoxy group; as $\mathrm{pH}$ increases, a second then a third ionization of carboxyl then alkoxy groups commences and $\mathrm{Al}^{+3}$ binding shifts the citrate $\mathrm{pKa}$ values. This binding and deprotonation of the trivalent Al-citrate coordination complex contributes to its high uptake from the gut. Binding and deprotonation also contribute to $\mathrm{Al}$ interaction with MCT and OATP transporters, $\mathrm{Al}$ sequestration in different intracellular compartments and to $\mathrm{Al}$ efflux from the central nervous system (Crisponi and Nurchi 2011, Yokel 2002).

The bioavailability of ingested $\mathrm{Al}$ depends in large measure on the aqueous solubility of the particular physical and chemical form. Krewski et al. (2007) concluded that gastrointestinal bioavailability of $\mathrm{Al}(\mathrm{OH})_{3}$ is $0.1 \%$ or less and that $\mathrm{Al}$ uptake from foods ranges between 0.1 and $0.3 \%$. The data from Poirier et al. (2011) and Priest (2010a) support the conclusion that ingested citrate enhances $\mathrm{Al}$ uptake from the gut.

\section{Percutaneous}

Krewski et al. (2007) concluded that topical Al penetration into intact skin "is very shallow". This conclusion was based in part on the data by Flarend et al. (2001), who found $0.012 \%$ of a single topical ${ }^{26} \mathrm{Al}$-labeled $\mathrm{ACH}$ dose applied to the underarm of two volunteers was absorbed.

Mayeux et al. (2012) inspected $\mathrm{Al}$ deposition patterns in the stratum corneum following 1 or 7 days repeated application of aqueous $5 \% \mathrm{AlCl}_{3}$ on the forearms of volunteers. A total of 37 volunteers of both genders (aged, 21-59 years) participated. The $\mathrm{AlCl}_{3}$ solution was applied on skin of the volar aspect of the forearm and after air drying, biometrological 
measurements were performed at rest and after a moderate 10-min physical exercise on a cycloergometer. The $\mathrm{AlCl}_{3}$-treated skin was documented using two ultraviolet light-emitting cameras to record subtle variations or changes related to $\mathrm{AlCl}_{3}$ deposition and/or local effects. After a single application of $\mathrm{AlCl}_{3}, \mathrm{Al}$ deposits on skin were observed predominantly inside the microrelief lines and at their crossings. After daily applications of $\mathrm{AlCl}_{3}$ for 1 week, $\mathrm{Al}$ deposits were evident within the plateaus delimited by the microrelief lines. No information regarding local irritation following single or repeated applications of $\mathrm{AlCl}_{3}$ or after physical exercise compared with the resting condition was provided.

The Mayeux protocol also included corneoxenometry to predict local $\mathrm{AlCl}_{3}$ irritation (Goffin et al. 2000, Piérard-Franchimont et al. 2010). Briefly, CSSS were dipped into $\mathrm{AlCl}_{3}$ solutions at 5,20, and $40 \%$ for $2 \mathrm{~h}$ and these samples were then dried and stained with toluidine blue and basic fuchsin for $3 \mathrm{~min}$. After rinsing, the color of the samples was measured and the staining intensity of the stratum corneum was calculated. No significant differences in the median or range of staining intensity were detected at any concentration compared to the concurrent water control. Mayeux et al. (2012) suggested these data were indicative of low irritant potential for $\mathrm{AlCl}_{3}$ under the conditions of their study. Among the limitations of this study are: little information was available on the study participants, test compound (chemical characteristics and purity), no information regarding $\mathrm{pH}$ of the administered $\mathrm{AlCl}_{3}$ solutions, or the $\mathrm{pH}$ of the skin after exposure and the report provided no details on the application technique (e.g. duration of contact, occlusion condition).

Yanagishita et al. (2012) studied localization of $\mathrm{Al}$ in palm skin after topical $20 \% \mathrm{AlCl}_{3}$ treatment for palmar hyperhidrosis. The study included 127 patients (no other details available) who received a daily solution without occlusion (once each day) for one month. No mention was made of the $\mathrm{pH}$ of the solution or whether any of the participants complained of local irritation or other clinical signs. The mean rate of sweat production after 30 days of $\mathrm{AlCl}_{3}$ applications was reduced significantly. Hematoxylin-eosin staining of the stratum corneum found that prior to $\mathrm{AlCl}_{3}$ treatment the eccrine sweat ducts were intact, but after treatment those ducts were filled with an amorphous polysaccharide/cytokeratincontaining cast. Histologic study of $5 \mu \mathrm{m}$ sections of treated palm skin found that an $\mathrm{Al}$ complex was present on the surface of the stratum corneum and in casts that accumulated in the sweat duct. There was no evidence of $\mathrm{Al}$ accumulation in either the eccrine sweat duct or in the sweat gland.

In a report that measured $\mathrm{Al}$ retention beneath the epidermis, Guillard et al. (2012) measured $\mathrm{Al}$ in a dermatofibrosarcoma taken from a 45-year-old woman at 5-12 years after im injection of an $\mathrm{Al}(\mathrm{OH})_{3}$ adjuvant-containing vaccine. Skin $\mathrm{Al}(768 \mathrm{mg} / \mathrm{kg}$ dry weight) was elevated compared to that in the skin of two untreated volunteers (40-44 mg/kg dry weight). However, the high Al concentration was traced to the Al-containing tattoo paste ( $35 \mathrm{mg}$ $\mathrm{Al} / \mathrm{kg}$ ) used to mark the biopsy site.

Pineau et al. (2012) used Franz ${ }^{\circledR}$ diffusion cells to measure $\mathrm{Al}$ transdermal movement from topical $\mathrm{ACH}$ at $37^{\circ} \mathrm{C}$ for $6-24 \mathrm{~h}$. Abdominal skin biopsies ( $513 \mu \mathrm{m}$ thick) from five healthy Caucasian (29-52 years) volunteers were treated with either a $14.5 \% \mathrm{ACH}$ emulsion $(8 \mathrm{mg})$, a $21.2 \% \mathrm{ACH}$ "stick" (4.5 mg) or a $38.5 \% \mathrm{ACH}$ aerosol base $(2.6 \mathrm{mg})$. The mean thickness 
of the materials applied to the skin was $1402 \pm 348 \mu \mathrm{m}$. Blanks applied to tape-stripped skin were of similar thickness. Because of its high viscosity, a higher dose of the aerosol base could not be applied to the test cells. After incubation, the superficial horny layer was removed and the skin was dissected to separate epidermis and dermis. Regardless of the $\mathrm{ACH}$ formulation, the highest mean $\mathrm{Al}$ concentration $\left(2.24-4.43 \mu \mathrm{g} / \mathrm{cm}^{2}\right)$ was present in the horny layer. The epidermis had the highest mean Al concentration $\left(9.42 \pm 7.82 \mathrm{mg} / \mathrm{cm}^{2}\right)$ after it was in treated with the $21.2 \%$ "stick". The most salient observation was the fact that the $\mathrm{Al}$ concentrations in the Franz ${ }^{\circledR}$ receptor fluid were less than $0.1 \mu \mathrm{g} / \mathrm{cm}^{2}$ and corresponded to only $0.012 \%(1 / 10,000)$ of the applied Al. The Pineau et al. (2012) in vitro assays used abdominal skin and the experimental conditions were such that personal habits and conditions (e.g., frequent repeated underarm shaving) and individual rates of $\mathrm{Al}$ application (e.g., diaper rash, prickly heat, insect stings, Tinea pedis) (reviewed in Krewski et al. 2007) could not be taken into account.

One case of systemic hyperaluminemia (plasma $\mathrm{Al}=104.7 \mu \mathrm{g} / \mathrm{L}$ ) presenting with complaints of bone pain after 4 years of daily $\mathrm{ACH}$ deodorant application has been described (Guillard et al. 2004). In light of that report, Yokel (2012) calculated the highest systemic Al uptake after routine topical application of a commercial 20\% $\mathrm{Al}$ zirconium glycine or a $25 \% \mathrm{ACH}$ deodorant was no more than $0.1 \mathrm{mg} / \mathrm{kg}$-day.

\section{Inhalation}

Aluminum workers can encounter a mixture of Al fumes and inhalable (aerodynamic diameter $\leq 100 \mu \mathrm{m})$, thoracic $(<28 \mu \mathrm{m})$, and respirable $(<10 \mu \mathrm{m}) \mathrm{Al}$ particulates in the occupational environment. These materials can be deposited in the respiratory tract where a fraction is absorbed from the lung and above 95\% is eliminated in urine (reviewed in ATSDR 2008, Krewski et al. 2007). The magnitude of these exposures and their associated Al urinary concentrations depend upon the particular industrial operations (such as bauxite mining, $\mathrm{Al}$ refining, reduction, casting, fettling, slagging, welding, and $\mathrm{AlF}_{3}$ production) and the $\mathrm{Al}$ forms encountered. Krewski et al. (2007) estimated that inhalation of $\mathrm{Al}$ dust and fume by refinery workers and welders yields a daily intake on the order of $6 \times 10^{-3} \mathrm{mg} / \mathrm{kg}$ day.

\section{Intramuscular injection}

Systemic uptake of $\mathrm{Al}$ from a vaccine depot in skeletal muscle depends upon the chemical form of the Al adjuvant (Flarend et al. 1997, Verdier et al. 2005). Krewski et al. (2007) examined $\mathrm{Al}$ absorption and distribution profiles of $\mathrm{Al}(\mathrm{OH})_{3}$ (present as poorly crystallized $\mathrm{AlO}(\mathrm{OH})$ ) and $\mathrm{AlPO}_{4}$ (present as $\left.\mathrm{HAlO}_{5} \mathrm{P}\right)(\mathrm{Hem}$ and White 1995, Shirodkar et al. 1990) and concluded that $100 \%$ of the injected $\mathrm{Al}$ is eventually absorbed. This conclusion was based in part on results by Verdier et al. (2005) who found that Al concentrations in muscle at 3-6 months after a single im injection of $\mathrm{AlO}(\mathrm{OH})$ in macaques were 4-fold higher than after equivalent injection of $\mathrm{AlPO}_{4}$. Muscle $\mathrm{Al}$ concentrations declined to less than the analytical limit of detection ( $\leq 25 \mu \mathrm{g} / \mathrm{g}$ ) within 12 months.

Intramuscular $\mathrm{AlO}(\mathrm{OH})$ is more rapidly taken up into rabbit blood than $\mathrm{AlPO}_{4}$. Within $1 \mathrm{~h}$ of a single im injection of $0.85 \mathrm{mg} \mathrm{Al}$ as ${ }^{26} \mathrm{Al}(\mathrm{OH})_{3}$ plasma ${ }^{26} \mathrm{Al}$ peaked at $2 \mathrm{ng} / \mathrm{ml}$ (Flarend 
et al. 1997). The maximum $\mathrm{Al}$ concentration represented approximately $7 \%$ of the normal $\mathrm{Al}$ level in rabbit plasma $(30 \mathrm{ng} / \mathrm{ml})$. Total ${ }^{26} \mathrm{Al}$ uptake from the injection ranged from 13 to $22 \%$ and was distributed to all organs examined (kidney> spleen $>$ liver $>$ heart $>$ lymph nodes $>$ brain). The initial plasma ${ }^{26} \mathrm{Al}$ concentrations after $\mathrm{AlO}(\mathrm{OH})$ injection were thrice those after equivalent injection of $\mathrm{AlPO}_{4}$, but by 28 days mean peripheral tissue ${ }^{26} \mathrm{Al}$ concentrations were 3-fold greater in rabbits given $\mathrm{AlPO}_{4}$ compared to those in rabbits given $\mathrm{AlO}(\mathrm{OH})$. Aluminum uptake from the depot continued for more than 28 days at which time only $6 \%$ of the injected ${ }^{26} \mathrm{AlO}(\mathrm{OH})$ had been eliminated in urine compared to $22 \%$ of the injected ${ }^{26} \mathrm{AlPO}_{4}$. Flarend et al. (1997) extrapolated the rabbit plasma concentration:time profile to humans and concluded that the $\mathrm{Al}$ dose associated with a single im adjuvant injection represented $0.8 \%$ or lesser increase above the normal $(2.7-6.2 \mu \mathrm{g} \mathrm{Al} / \mathrm{L})$ range (Krewski et al. 2007).

\section{Mechanisms of action}

Understanding mechanism of action and compound-specific bioavailability is key to the evaluation and interpretation of the health risks posed by exposure to the many different physical and chemical forms of Al. Mechanistic studies with the soluble Al salts point to $\mathrm{Al}^{+3}$ as the entity responsible for tissue damage whereas studies with the non-reactive $\mathrm{Al}$ oxides demonstrate adverse effects of particulates that are separate and distinct from the actions of ionized Al. Under some conditions (e.g., Al welding, fettling, refining) mixed exposures to soluble, sparingly soluble, and insoluble $\mathrm{Al}$ forms occur.

Fraga et al. (1990), Gutteridge et al. (1985), Savory et al. (1999), Tomljenovic (2011) and Zatta et al. (2002) concluded that elevated $\mathrm{Al}^{+3}$ concentrations induce cytotoxicity as a result of oxidative damage. Mailloux et al. (2011) traced the biochemical events contributing to (soluble) Al-induced toxicity in cultured HepG2 cells and advanced the hypothesis that disruption of "mitochondrial metabolism is the main site of the toxicological action of Al" due to interference with "Fe-dependent redox sensitive enzymes in the tricarboxylic acid (TCA) cycle and oxidative phosphorylation". Initial changes (apparently initiated via $\mathrm{Al}^{+3}$ binding with protein and competition for Fe-binding sites) include depletion of mitochondrial $\mathrm{Fe}$ and generation of $\mathrm{H}_{2} \mathrm{O}_{2}, \mathrm{O}_{2}{ }^{-}$and $\mathrm{OH}^{*}$. These changes result in a cellular metabolic shift from oxidative ATP production to anaerobic glycolysis (seen with the increased activity of LDH, pyruvate kinase, and glyceraldehyde-3-phosphate dehydrogenase) resulting in increased $a$-ketoglutarate and succinate and reduced L-carnitine due to diversion of a-ketoglutarate to scavenging ROS. These changes are reflected in reduced fatty acid $\beta$-oxidation that further facilitates increased peroxidation.

Data from cultured murine primary cortical astrocytes treated with $\mathrm{Al}$ glycinate do not necessarily support the hypothesis that mitochondrial membranes are the primary $\mathrm{Al}^{+3}$ target. Aremu et al. (2011) found no indication of mitochondrial-mediated apoptosis after astrocyte incubation with $0.1 \mathrm{mM} \mathrm{Al}$ glycinate for $12-24 \mathrm{~h}$ (followed by maintenance in fresh media for 7 days) or after culture with 0.1 or $1.0 \mathrm{mM} \mathrm{Al} \mathrm{glycinate} \mathrm{for} 48 \mathrm{~h}$. Not only were there no detectable alterations in $B c l 2, B a x$, or $B c l 2$ binding component 3/p53 (3bc3/ $P U M A$ ) expression, but there was no influence on cytochrome $c$ release. Aluminum 
treatment up-regulated Ire $1 \beta$, a response that was considered indicative of stress within the endoplasmic reticulum (Aremu et al. 2011).

Trivalent $\mathrm{Al}$ is a promoter of Fe-mediated (Gutteridge et al. 1985, Lemire and Appanna 2011) and non-Fe superoxide radical anion-mediated biological oxidation (Exley 2004, Kong et al. 1992, Mendez-Alvarez et al. 2002). Several theories advanced the concept that $\mathrm{Al}^{+3}$ binding with phospholipids leads to peroxidation and altered membrane fluid dynamics as responsible for $\mathrm{Al}$ toxicity. Ghribi et al. (2001a, 2001b, 2002) suggested the primary site of $\mathrm{Al}$ damage was within the endoplasmic reticulum leading to cytochrome $c$ release from mitochondria and activation of apoptotic demise. Free energy calculations and the physical chemistry of trivalent $\mathrm{Al}$ in water and its complex with $\mathrm{O}_{2}{ }^{-}$demonstrate displacement of a water molecule $\left[\mathrm{Al}\left(\mathrm{H}_{2} \mathrm{O}\right)_{6}{ }^{+3}+\mathrm{O}_{2}{ }^{\cdot-} \rightarrow\left[\mathrm{Al}\left(\mathrm{O}_{2}{ }^{*}\right)\left(\mathrm{H}_{2} \mathrm{O}_{5}\right)\right]^{+2}+\mathrm{H}_{2} \mathrm{O}\right]$ to produce bidentate superoxides (Mujika et al. 2011a). Thus, reaction of $\mathrm{Al}^{+3}$ with its first microsolvation shell generates an $\mathrm{Al}^{+3}$ superoxide semireduced radical $\left[\mathrm{AlO}_{2}{ }^{\circ}\right]^{+2}$ via $\left[\mathrm{Al}\left(\mathrm{H}_{2} \mathrm{O}\right)_{6}\right]^{+3}$. Formation of these radicals, together with $\mathrm{Al}^{+3}$ potentiation of $\mathrm{Fe}^{+2} / \mathrm{Fe}^{+3}$ redox and non-heme-mediated $\mathrm{OH}^{\bullet}$ formation, appear to account for the oxidant activity of $\mathrm{Al}^{+3}$ in biological systems.

Some the earliest genomic changes induced by $\mathrm{Al}^{+3}$ appear to involve increased $\mathrm{p} 53$ (Johnson et al. 2005) followed by Bax translocation, increased Bax reactivity in the endoplasmic reticulum (Ghribi et al. 2001a), reduced endoplasmic reticulum (Ghribi et al. 2001a, 2001b), and mitochondrial (Ghribi et al. 2001c) Bcl-2 and perturbation of the Bcl-2/Bax ratio (Savory et al. 1999). These events are followed by activation of caspase-3 (Ghribi et al. 2001a) and caspase-12 (Ghribi et al. 2001b). The intrinsic apoptotic pathway responds to oxidative stress and this is apparent in the $\mathrm{Al}^{+3}$-induced release of mitochondrial cytochrome $c$ (Ghribi et al. 2001a, 2001c) into the cytosol. The initial oxidative changes that lead to DNA fragmentation (Ghribi et al. 2001c) and the genomic response that occur at the lowest $\mathrm{Al}^{+3}$ concentration and at the earliest key metabolic juncture responsible for cytotoxicity remain to be confirmed (Crisponi et al. 2012).

Unlike the soluble salts, insoluble $\mathrm{Al}$ materials elicit dose-dependent pulmonary damage as a consequence of accumulation of nonreactive particles. At neutral $\mathrm{pH}$ the $\mathrm{Al}$ oxides and oxyhydroxides are chemically stable. After 60 days incubation of $565 \mathrm{mg} / \mathrm{L} \mathrm{Al}_{2} \mathrm{O}_{3}$ in $\mathrm{pH}$ 5.3-8.2 deionized or saline water at room temperature, Batten and Lafayette (undated) found the concentration of soluble $\mathrm{Al}^{+3}$ undetectable. Pauluhn (2009a) reported pulmonary inflammation after rats inhaled $\gamma-\mathrm{AlO}(\mathrm{OH})$ for 4 weeks. There was no evidence for either $\mathrm{Al}$ translocation from the lung or increased urinary Al. Those data are consistent with the observations by de Kom et al. (1997) who found no significant difference in serum Al among bauxite (gibbsite $\left[\mathrm{Al}(\mathrm{OH})_{3}\right]$, boehmite $[\gamma-\mathrm{AlO}(\mathrm{OH})]$, and diaspora $[\mathrm{a}-\mathrm{AlO}(\mathrm{OH})]$ ) miners compared to wood workers. Prolonged inhalation of bauxite dust increased the risk of simple and complex pneumoconiosis (Shaver's disease) (Beach et al. 2001, Donoghue et al. 2014, Friesen et al. 2009, Gartner 1952, Taiwo 2014). These conditions are related to inert particle accumulation and lung overload (Oberdörster 1995). 


\section{Organ systems and function}

\section{Nervous system}

The $\mathrm{AD}$ and $\mathrm{Al}$ literatures remain linked in reports from some researchers (Bondy 2010, Campdelacreu 2012, Tomljenovic 2011, Walton 2012b) yet others conclude factors distinct from $\mathrm{Al}$ are responsible for $\mathrm{AD}$ (reviewed in Lidsky 2014, Willhite et al. 2012). A primary feature of $\mathrm{AD}$ pathogenesis is $\beta$-amyloid precursor protein (APP) catabolism by the actions of $\alpha$-and $\beta$-secretase that yield the amyloid $\beta$-peptides $(A \beta)$. While $A \beta$ is constitutively produced from APP, normally it is degraded immediately; failing that, $A \beta$ polypeptides can mis-fold and self-aggregate in the brain leading to insoluble 'senile' plaques.

$A \beta_{1-40}$ is the major form present in biological fluids and $A \beta_{1-42}$ is the major insoluble form present in neuronal plaques. These plaques consist of an amorphous core surrounded by amyloid adjacent to degenerating neurons and glial cells. The plaques accumulate, neurofibrillary tangles develop, intraneuronal (argyrophilic) granulovacuolar lesions appear and progressive atrophy (shrinkage) of the brain follows. The amyloid cascade hypothesis seeks to explain the excessive $A \beta$ accumulation and it is believed the relative rates of $A \beta$ generation and degradation are key to $\mathrm{AD}$. The $\mathrm{Al} / \mathrm{AD}$ hypothesis has three distinct aspects: Al participation in $A \beta$ aggregation (perhaps via cross-linking hyperphosphorylated protein); $\mathrm{Al}$ induction of $\mathrm{A} \beta$ integration into $\beta$-sheet proteins found in the cores of senile plaques and Al-mediation of abnormal Fe-catalyzed oxidation, increased free radical generation, increased lipid peroxidation (LPO), inflammation and neuronal apoptosis.

At least four physiological factors contribute to the increased susceptibility of the brain to oxidative insult: its high rate of $\mathrm{O}_{2}$ consumption, the abundance of polyunsaturated fatty acids, its elevated Fe content and its relatively low antioxidant capabilities. Aluminum binds to phospholipids (Verstraeten et al. 1997a), stimulates Fe-initiated LPO (Toda and Yase 1998, Xie and Yokel 1996) and it reacts with $\mathrm{O}_{2}{ }^{-}$to form $\mathrm{Al}^{-} \mathrm{O}_{2}{ }^{-}$that increases oxidation of amino acids leading to generation of protein carbonyls (Exley 2004, Sánchez-Iglesias et al. 2009, Yokel 2000). These reactions reduce the activity of antioxidant enzymes (e.g., glutathione peroxidase (GPx), superoxide dismutase (SOD), and catalase) (Chaitanya et al. 2012, Shrivastava 2012, Verstraeten et al. 1997b, Yuan et al. 2012).

It is well known that $\mathrm{Al}^{+3}$ and other metal ions (notably $\mathrm{Cu}^{+2}, \mathrm{Fe}^{+3}$ and $\mathrm{Zn}^{+2}$ ) can bind proteins including $A \beta$ and that those reactions (at least in vitro) can lead to conformation changes, reduced $\mathrm{A} \beta$ solubility and can promote spontaneous $\mathrm{A} \beta(1-42) \mathrm{Al}^{+3}$ oligomerization, aggregation, and precipitation. $\mathrm{Zinc}^{+2}$ and $\mathrm{Cu}^{+2}$ accelerate amorphous $\mathrm{A} \beta$ aggregation whereas $\mathrm{Al}^{+3}$ and $\mathrm{Fe}^{+3}$ tend to promote $\mathrm{A} \beta$ fibril and oligomer formation (Kawahara 2005, Kawahara and Kato-Negishi 2011, Ricchelli et al. 2005). SanMartín et al. (2012) interpreted the elevated concentrations of $\mathrm{Al}, \mathrm{Cu}, \mathrm{Fe}$, and $\mathrm{Zn}$ in human neurofibrillary tangles and senile plaques along with their in vitro acceleration of $\mathrm{A} \beta$ fibril and amyloid $\beta$ oligomer formation as consequences of oxidative stress.

Data on the presence and accumulation of $\mathrm{Al}$ in amyloid fibers and $\mathrm{AD}$ plaques vary. A number of reports (e.g., Bjertness et al. 1996, Landsberg et al. 1992, Makjanic et al. 1998) failed to find $\mathrm{Al}$ accumulation in either whole $\mathrm{AD}$ brain or neuritic cores and neurofibrillary 
tangles. Strozyk et al. (2009) found no correlation between $\mathrm{Al}$ and $\mathrm{A} \beta_{42}$ in the cerebrospinal fluid of AD patients. In contrast, Yumoto et al. (2009) used EDX spectroscopy to measure $\mathrm{Al}$ in amyloid fibers of senile $\mathrm{AD}$ plaques in the human hippocampus and temporal lobe. Identification of senile plaque cores by TEM found $\mathrm{A} \beta$ peptides in senile plaque cores where $\mathrm{Al}, \mathrm{P}$ and $\mathrm{Ca}$ co-located. The Yumoto et al. (2009) findings are consistent with earlier data by Good et al. (1992) and Perl and Moalem (2006) who found Al in tangle-bearing neurons of the AD hippocampus, but none of those data defined whether the presence of $\mathrm{Al}$ occurs as a result of the $\mathrm{AD}$ pathophysiological process or whether elevated $\mathrm{Al}$ concentrations initiate or accelerate $\mathrm{A} \beta$ fibril and/or amyloid $\beta$ oligomer formation.

Kawahara and Kato-Negishi (2011) collated data on A $\beta$ structural alterations and Thinakaran and Koo (2008) reviewed the human $\mathrm{APP}^{3}$ gene and intracellular proteolytic APP processing. These authors listed $25+$ APP mutations considered causal in early onset familial $\mathrm{AD}$ (EOFAD) and hereditary cerebral angiopathy. EOFAD is associated with mutations in the presenilin one (PS1) or two (PS2) genes found on chromosomes 14 and 1, respectively. More than 230 APP/Ps1/PS2 mutations have been associated with EOFAD; however, EOFAD accounts for less than $1 \%$ of all AD cases (Wu et al. 2012d).

For the more common late onset $\mathrm{AD}$ (LOAD) the major genetic risk factor identified thus far is the inheritance of the apolipoprotein E4 gene (apoE4) (Verghese et al. 2011). Inheritance of the apoE4 allele has been linked to enhanced aggregation of $A \beta$ and to reduced $A \beta$ clearance from the brain (Potter and Wisniewski 2012). From studies with more than 16,000 subjects, four new $\mathrm{A} \beta$ genetic determinants for sporadic late onset $\mathrm{AD}$ have been identified and these include the PICALM (phosphatidyl inositol binding clathrin assembly protein), CLU (clusterin), CR1 (complement component receptor 1) and $\mathrm{BIN}_{1}$ (bridging integrator 1) genes (Harold et al. 2009, Lambert and Amouyel 2011). Results of functional assays suggest that LOAD is associated with impaired clearance of the A $\beta$ peptide where CR1 participates in A $\beta$ clearance, PICALM apparently alters synaptic vesicle cycling, BIN $_{1}$ appears to alter neuronal membranes and formation of synaptic vesicles and CLU enhances amyloid plaque formation. Together with apoE, CLU influences the structure and accumulation of A $\beta$. Of the many recent reports concerning $\mathrm{Al}$ neurotoxicity, those judged more informative are described below.

Neurotoxicity in humans-Exley and House (2011) tabulated literature reports on the Al content of human brain. In general the normal range is between 0.1 and $4.5 \mu \mathrm{g} / \mathrm{g}$ dry wt. with the higher values (> $2 \mu \mathrm{g} / \mathrm{g}$ dry wt.) measured in brains of non-demented elderly, AD patients (up to $11.5 \mu \mathrm{g} / \mathrm{g}$ dry wt.), dialysis encephalopathy (up to $14.1 \mathrm{mg} \mu \mathrm{g} / \mathrm{g}$ dry wt.), congophilic amyloid angiopathy (CAA) (up to $23.0 \mu \mathrm{g} / \mathrm{g}$ dry wt.) and other encephalopathies (up to $47.4 \mu \mathrm{g} / \mathrm{g}$ dry wt.).

House et al. (2012) measured $\mathrm{Al}$ in the temporal, frontal, occipital, and parietal lobes of brains from older donors ( $n=60$, aged 70-103 years) (described in Wharton et al. 2011). The $\mathrm{Al}$ content ranged from 0 (after subtraction of method blank values) to $33 \mu \mathrm{g} / \mathrm{g}$ dry wt ( $n$ $=713$ tissue digests). The median $\mathrm{Al}$ value was $1.02 \mu \mathrm{g} / \mathrm{g}$ dry wt. and $75 \%$ of all values were less than $2.01 \mu \mathrm{g} / \mathrm{g}$ dry wt. All these $\mathrm{Al}$ concentrations were within the "normal" range $(0.1-$ $4.5 \mu \mathrm{g} / \mathrm{g}$; Exley and House 2011) for aged brain. 
Akatsu et al. (2011) studied Al concentrations in the hippocampus and amygdala from people with $\mathrm{AD}$ (15 and 18 patients, respectively) or dementia with Lewy bodies (DLB) (11 and 11 patients, respectively) and compared those values to samples from brains of people with no history of dementia. The average $\mathrm{Al}$ concentrations in the hippocampus $(n=12)$ and amygdala $(n=16)$ of non-demented people were $2.8 \pm 2.0$ and $6.0 \pm 6.5 \mu \mathrm{M}$ wet tissue, respectively. The average $\mathrm{Al}$ concentrations in the hippocampus $(n=15)$ and amygdala $(n=$ 18) from $\mathrm{AD}$ patients were $4.4 \pm 3.8$ and $6.4 \pm 5.5 \mu \mathrm{M}$ wet weight, respectively. The average Al concentrations in the hippocampus $(n=11)$ and amygdala $(n=11)$ from people with DLB were $5.6 \pm 6.1$ and $6.9 \pm 5.9 \mu \mathrm{M}$ wet weight, respectively. Akatsu et al. (2011) found no significant differences in total $\mathrm{Al}$ concentrations in the hippocampus and amygdala between demented and non-demented individuals.

Rusina et al. (2011) measured $\mathrm{Al}$ in brains from 29 deceased patients (mean age 79 years, women to men ratio 20:9) with neuropathologically confirmed AD. All these samples fulfilled the National Institute of Aging (Hyman et al. 2012, McKhann et al. 2011) and Reagan Institute (Newell et al. 1999) AD diagnostic criteria. The 27 subjects (12 women and 15 men, mean age 76 years) in the referent group had no signs of $\mathrm{AD}$ or other degenerative dementias on autopsy. Different statistical approaches used by Rusina et al. (2011) provided somewhat different results: higher mean $\mathrm{Al}$ concentrations in the hippocampus were found in AD patients compared with the healthy individuals ( $0.357 \mathrm{vs} 0.090 \mu \mathrm{g} / \mathrm{g} ; p=0.039$ ) after Box-Cox data transformation, but not after standard logarithmic transformation to correct deviations from normality.

Walton (2010) examined $\mathrm{Al}$ in corticolimbic tissue from brains of five deceased older $\mathrm{AD}$ patients (4 males and 1 female) compared to five non-demented referents (4 males and 1 female). Autopsy confirmed diagnoses were made according to criteria established by the Neuropathology Task Force of the Consortium to Establish a Registry for Alzheimer's Disease (Mirra et al. 1991). Ten-micron paraffin sections from the corticolimbic region were examined after histological staining for Al (using the modified Walton (2004) method) and immunostaining with anti-PHF1 antibody for hyperphosphorylated tau. Nine of the 10 subjects exhibited pre-tangle cells. The remaining AD subject had extensive CA1 cell loss. The pre-tangle granules did not stain positively for $\mathrm{Al}$; one referent and one AD case had CA1 pyramidal cells with distinctive cytoplasmic pools that stained for both $\mathrm{Al}$ and hyperphosphorylated tau. Walton (2010) reported a few NFT development pre-tangle stage 1 (early 1a and late 1b), mature NFT stage 2 and extracellular NFT stage 3 in AD and nondemented subjects. Early pre-tangle (stage 1a) cells contained small cytoplasmic granules that were distributed throughout the cytoplasm that immunostained for hyperphosphorylated tau. These cells were observed frequently in both aged demented and non-demented humans. Late pre-tangle (stage $1 \mathrm{~b}$ ) cells had grainy-textured cytoplasmic pools that stained for $\mathrm{Al}$ and hyperphosphorylated tau and these were visible as cytoplasmic filaments. There was no evidence for $\mathrm{Al}$ accumulation in cells at the early pre-tangle stage. The presence of early pre-tangle cells was observed in four of the AD cases and in one referent. Walton (2010) suggested that the lack of Al staining during the early stage could indicate either an absence of $\mathrm{Al}$ or that $\mathrm{Al}$ levels were below the staining threshold. Mature (stage 2) NFTs were observed as densely packed filaments that stained for both $\mathrm{Al}$ and hyperphosphorylated tau; in these cases, the nuclei of affected cells were displaced to the cell periphery and in some of 
these cells no cytoplasm at all could be seen given the extent of the large NFTs. Mature NFTs were observed in all AD cases and in three of the five referents. Extracellular (stage 3) NFTs stained for both $\mathrm{Al}$ and hyperphosphorylated tau; in most of these cases, the glial cells were associated with extracellular NFTs. Stage 3 NFTs were commonly observed in AD cases and less often in the referents. After Al de-staining and re-staining for hyperphosphorylated tau, the Al/hyperphosphorylated tau complexes were evident in the cytoplasm during the late pre-tangle stage, mature and extracellular stages. Overall the Walton (2010) report provides indications of colocalization of $\mathrm{Al}$ with hyperphosphorylated tau during NFT formation in the late pre-tangle stage, mature, and extracellular stages. While these observations could be taken as evidence for Al contributions to NFT formation, neither Al levels nor NFT presence show clear relations with AD clinical pathology or pathogenesis (Armstrong 2013, De-Paula et al. 2012, Hamdy 1990, Mizoroki et al. 2007). In spite of the reported sensitivity and specificity of the Walton (2004) method for identifying $\mathrm{Al}$ and NFTs in brain, there has been no independent validation of the Walton staining technique.

Ionized $\mathrm{Al}$ and other ionized inorganics bind protein and it is not inconsistent that metals (including $\mathrm{Cu}$, non-heme $\mathrm{Fe}, \mathrm{Zn}$ and $\mathrm{Al}$ ) are colocated with $\mathrm{A} \beta_{40 / 42}$ in cerebral amyloid angiopathy (reviewed in Kawahara and Kato-Negishi 2011). As such, Al is not the only inorganic element implicated in AD (Bolognin et al. 2011, Grasso et al. 2011) and recent studies point to reduced $\mathrm{Cu}$ status and elevated AD risk (Schrag et al. 2011). Baum et al. (2010) measured $\mathrm{Al}$ and 11 other inorganic elements by ICP-MS in the serum of $44 \mathrm{AD}$ and 41 healthy referent subjects who lacked symptoms of neurologic disease. All AD patients had NINCDS-ADRDA (National Institute of Neurological and Communicative Disorders and Stroke-Alzheimer's Disease and Related Disorders Association) diagnosis of probable or possible AD (McKhann et al. 1984). These individuals were recruited from geriatric outpatient clinics $(n=35)$ and long-term care facilities $(n=9)$. The authors administered the Cantonese Mini-Mental Status Examination (MMSE, maximum score 30; Chiu et al. 1994) to $43 \mathrm{AD}$ and one healthy subject (rationale was not given for lack of MMSE assessment for the remaining 40 referents). Three statistical models were tested: (1) one metal at a time with age and sex as additional control covariates; (2) all metals in one model along with age and sex; and (3) a model with variables selected from model (2) by forward stepwise selection ( $p=0.05$, likelihood ratio test). Using the unadjusted comparisons, the $\mathrm{AD}$ patients had significantly higher serum $\mathrm{Al}(905 \pm 630 \mathrm{nmol} / \mathrm{L}$ or $24 \pm 17 \mu \mathrm{g} / \mathrm{L})($ median \pm interquartile range) than healthy referents $(580 \pm 620 \mathrm{nmol} / \mathrm{L}$ or $15 \pm 16 \mu \mathrm{g} / \mathrm{L})$. Using the unadjusted comparisons, the AD patients had lower $(p=0.0001)$ serum Zn $(10,900 \pm 1600$ $\mathrm{nmol} / \mathrm{L})$ than healthy referents $(12,300 \pm 1600 \mathrm{nmol} / \mathrm{L})$. After adjustment for age and gender (model 1), serum Al was increased ( $p=0.002)$ and serum $\mathrm{Zn}$ was reduced $(p=0.0007)$ in AD patients compared to their healthy referents. These conclusions depended on statistical procedures; in the simultaneous model adjusted for all metals ( $\mathrm{Al}, \mathrm{As}, \mathrm{Be}, \mathrm{Cr}, \mathrm{Co}, \mathrm{Cu}, \mathrm{I}, \mathrm{Fe}$, $\mathrm{Mn}, \mathrm{Ni}, \mathrm{Se}$, and $\mathrm{Zn}$ ) (model 2), only $\mathrm{Cr}$, Se and $\mathrm{Zn}$ were significantly different with only $\mathrm{Se}$ and $\mathrm{Zn}$ differing after Bonferroni adjustment. In a forward stepwise regression (model 3), only $\mathrm{Zn}$ was reduced $(p=0.005)$. Since serum $\mathrm{Zn}$ was reduced significantly in all models, Baum et al. (2010) suggested that $\mathrm{Zn}$ induced $A \beta$ aggregation (Bush and Tanzi 2002). The Cantonese MMSE results correlated significantly with serum $\mathrm{Al}$ and As concentrations. The 
serum $\mathrm{Al}$ data show marked variability and those values are elevated for the healthy participants (perhaps associated with $\mathrm{Al}$ antacid consumption) compared to the normal median $(0.12 \mu \mathrm{M}$ or $3.2 \mu \mathrm{g} / \mathrm{L}$ with an upper limit of $6 \mu \mathrm{g} / \mathrm{L}$ ) concentration (reviewed in Krewski et al. 2007). Those observations and the fact that only one healthy referent was subject to MMSE scoring reduce the confidence that can be placed in the authors' conclusions.

Baum et al. (2010) also suggested that the increased serum Al in AD patients might be associated with more efficient uptake of dietary $\mathrm{Al}$ in patients with $\mathrm{AD}$, but that the reason(s) for this difference in Al uptake were unknown (Miu et al. 2004, Roberts et al. 1998). The Baum et al. (2010) suggestion that $\mathrm{Al}$ gastrointestinal uptake is greater among people with AD than in otherwise healthy people is consistent with Moore et al. (2000), but it is at odds with the results presented by Molloy et al. (2007) who found there was no difference in $\mathrm{Al}$ (consumed as $\mathrm{Al}(\mathrm{OH})_{3}$ with citrate) uptake by $\mathrm{AD}$ patients and/or healthy people with apoE alleles compared to that by those who did not carry the apoE $\varepsilon 4$ allele. Rather, the differences in serum $\mathrm{Al}$ might reflect reduced renal $\mathrm{Al}$ clearance as a consequence of declines in kidney function with age.

Following a similar line of inquiry, Exley et al. (2012) compared $\mathrm{Al}, \mathrm{Fe}$, and $\mathrm{Cu}$ concentrations to the $A \beta$ content in senile plaques and in areas of amyloid angiopathy in brains from 38 women and 22 men (ages 70-103 years). There was no significant correlation between $\mathrm{Al}$ or $\mathrm{Fe}$ and senile plaques or amyloid angiopathy. The Exley et al. (2012) data do not support the hypothesis that elevated brain $\mathrm{Al}$ is associated with enhanced $\mathrm{A} \beta_{42}$ in senile plaques and/or focal CAA.

A pan-Canadian outbreak of hyperaluminemia occurred during 2005 among patients on peritoneal dialysis (PD). This was traced to a high $\mathrm{Al}$ content in dialysate solutions (1.3 $\mu \mathrm{mol} / \mathrm{L}$, current maximum recommended $<0.742 \mu \mathrm{mol} / \mathrm{L}$ ). Yue et al. (2011) examined 83 of those patients exposed to Al-contaminated dialysate and found the mean serum $\mathrm{Al}$ was 1.77 $\pm 0.74 \mu \mathrm{mol} / \mathrm{L}(47 \mu \mathrm{g} / \mathrm{L}$ ) compared to a normal upper limit of $6 \mu \mathrm{g} / \mathrm{L}$ (reviewed in Krewski et al. 2007).

Sandhu et al. (2011) carried out retrospective analyses of quarterly serum Al determinations for $589 \mathrm{HD}$ patients with end-stage renal disease. A total of 5,674 $\mathrm{Al}$ measurements for 589 patients were made and of those $32(0.5 \%)$ had $\mathrm{Al}$ concentrations $20 \mu \mathrm{g} / \mathrm{L}$ or higher. The overall mean $\mathrm{Al}$ concentration was $10 \mu \mathrm{g} / \mathrm{L}$ (range: $2-28 \mu \mathrm{g} / \mathrm{L}$ ). Out of 589 (4.2\%) patients, 25 patients experienced increased serum $\mathrm{Al}$ at some point in the study. The reason for increased serum $\mathrm{Al}$ was identified for only two of the participants (Al-containing antacids).

In a small clinical study, Elshamaa and associates (2010) found a significant ( $p=0.0001$ ) correlation between serum $\mathrm{Al}$ and EPO dose among 22 boys and 21 girls ( $11 \pm 3.3$ years) with end-stage renal disease. These children were on long-term HD and renal dialysate was eliminated as a source of excess $\mathrm{Al}$ inasmuch as the filtered deionized water contained $10 \mu \mathrm{g}$ $\mathrm{Al} / \mathrm{L}$ or lesser. None were given Al-containing phosphate binders. The HD patients were moderately anemic and weekly subcutaneous EPO injections were given to maintain a 28$31 \%$ hematocrit. Serum $\mathrm{Al}(\leq 30 \mu \mathrm{g} / \mathrm{L}$ ) was significantly higher among HD patients than in 
healthy referents, but there were no significant differences between HD boys and HD girls and HD duration had no influence on serum Al. There was a significant $(p=0.0001)$ linear correlation $(r=0.77)$ between serum $\mathrm{Al}$ and EPO dose. While the data suggest EPO was the source of the elevated Al, Elshamaa et al. (2010) did not quantify Al in the EPO given to these patients. This failure and the facts that the study was relatively small and confined to a single institution detract from the conclusions reached.

Albizzati et al. (2012) compared $\mathrm{Al}$ concentrations in blood, urine, and hair for 17 autistic children (ages $6-16$ years; mean $11.5 \pm 3.2$ years; 15 males and 2 females) to those for nonautistic subjects (ages $6-16$ years; mean: $10.4 \pm 3.2$ years; 15 males and 2 females). There were no significant differences in $\mathrm{Al}$ between the two groups.

Bakar et al. (2010) evaluated drinking water $\mathrm{Al}$ concentrations in relation to cognitive function among residents of the Kirazli region of the Biga Peninsula, northwest Turkey. The Kirazli region was included in the study as it has acidic drinking water and its $\mathrm{Al}$ concentration exceeds the WHO $(1984,2004)$ recommended maximum $(0.2 \mathrm{mg} \mathrm{Al} / \mathrm{L})$. Of 201 Kirazli inhabitants 73 agreed to participate; the referent group included 164 selected from 921 residents of a Ciplak-Halileli village in the same province. A neurologist administered the MMSE using face-to-face interviews and performed clinical examinations. All subjects obtained their drinking water from groundwater networks in their regions and a total of 237 people from both regions participated in the study. Drinking water collected in both regions revealed higher Al concentrations in Kirazli (13-16 mg/L) than in the referent region $(0.005-0.010 \mathrm{mg} / \mathrm{L})$. Despite the differences in Al levels in their drinking water, no significant differences were detected between serum Al levels, the MMSE scores or the incidence of clinical neuropathy between the two regions.

Studies of Akila et al. (1999), Bowler et al. (2003), Flaten et al. (1996), Hanninen et al. (1994), and Riihimaki et al. (2000) described subtle deficits in cognition associated with chronic occupational exposure to $\mathrm{Al}$ fume. It is those observations that apparently prompted the reduction in the $\mathrm{TLV}^{\circledR}$ for $\mathrm{Al}$ welding fume (ACGIH 2008). Those observations contrast with Kiesswetter et al. $(2007,2009)$ who found no changes in neurobehavioral parameters or motor performance compared to production or construction workers of similar average age.

Giorgianni et al. (2012) measured serum Al and performance on the Wechsler Memory Scale, attention matrix test and the color-word (Stroop) test for 86 non-smoking (apparently healthy) male $\mathrm{Al}$ welders ( $38.45 \pm 6.34$ years). Those results were compared to the results for 90 (38.29 \pm 7.14 years) male clerical workers who had no history of occupational Al exposure. Study participants had similar years of formal education and all were employed at the same shipyard for similar durations (mean $=15.5-15.8$ years). Employees who used Alcontaining antacids, experienced occupational Mn exposure or who had a history of diabetes, kidney disease, or cerebrovascular conditions were excluded. Work station (presumably area sampling) concentrations of airborne $\mathrm{Al}$ fume averaged $19.5 \mathrm{mg} / \mathrm{m}^{3}$ and this was attributed to "soldering operations performed inside large and medium-size hulls with double-bottoms and limited air circulation". Serum Al among the welders (24.2 \pm 9.9 $\mu \mathrm{g} / \mathrm{L})$ was four times that in the clerical workers $(6.93 \pm 1.95 \mu \mathrm{g} / \mathrm{L})$. Performance of welders on the Wechler and Stroop tests was reduced and older welders displayed reduced attention 
spans compared to the office staff; welders with longer employment generally had poorer scores. Giorgianni et al. (2012) concluded that chronic exposure (e.g., $\geq 16$ years) to Al welding fume not only resulted in markedly elevated circulating $\mathrm{Al}$, but that those concentrations over many years were associated with impaired cognition. The Giorgianni et al. (2012) data were qualitatively consistent with observations made by Akila et al. (1999), Bast-Petterson et al. (1994, 2000), Bowler et al. (2003), Hanninen et al. (1994), Riihimäki et al. (2000), and Sjogren et al. (1990). However, the confined space welding operations, apparent lack of fume control, absence of comprehensive exposure data (including frequency, duration and peak concentrations) taken together with the very high mean airborne Al levels do not permit quantitative comparisons among the different studies.

Kiesswetter et al. (2007) conducted a 4-year longitudinal repeated measures study of $20 \mathrm{Al}$ welders exposed to $5-8 \mathrm{mg} / \mathrm{m}^{3}$ total dust in their breathing zone. There was no relation between symptoms, verbal intelligence, logic, psychomotor performance, memory or attention, and urinary (88-140 $\mu \mathrm{g} / \mathrm{g}$ creatinine) or plasma (13-16 $\mu \mathrm{g} / \mathrm{L})$ Al. Kiesswetter et al. (2009) conducted a similar study in a second plant of 92 welders with an average of 11 years $\mathrm{Al}$ fume exposure. Personal samples found these men were exposed to $0.5-0.8 \mathrm{mg} / \mathrm{m}^{3}$ total dust and that their urinary $\mathrm{Al}(23-43 \mu \mathrm{g} / \mathrm{g}$ creatinine) and plasma $\mathrm{Al}(5-9 \mu \mathrm{g} / \mathrm{L})$ concentrations were somewhat lower than those measured in the first cohort. There were no differences on neurobehavioral or motor performance tests by these welders compared to those by 50 construction workers of similar age not employed in $\mathrm{Al}$ welding. Kiesswetter et al. (2009) concluded, "The repeated measurement models of both studies show no adverse effects of Al welding."

The review by Riihimäki and Aitio (2012) concluded that workers exposed to fine or ultrafine $\mathrm{Al}$ particulates while engaged in MIG/MAG Al welding, production and use of $\mathrm{Al}$ powders, plasma cutting, grinding, polishing, and thermal spraying were at risk for Alinduced cognitive deficit. Riihimäki and Aitio (2012) found "The mainstream of studies over the past two decades on workers exposed to fine particles of sparsely soluble aluminum have revealed exposure-related subclinical disturbances of cognitive functions and associated subjective symptoms". These are mixed exposures in that $\mathrm{Al}$ accounted for approximately $30 \%$ of the fume generated from AlMg 4.5 Mn welding wire, $\mathrm{Mg}$ accounted for $3 \%$ and $\mathrm{Cu}$, $\mathrm{Mn}, \mathrm{Pb}$, and $\mathrm{Zn}$ each represented 0.2\% (Riihimaki and Aitio 2012). Results by Buchta et al. (2005), Meyer-Baron et al. (2007), Polizzi et al. (2002), and Riihimäki et al. (2000) differ. Buchta et al. (2005) concluded that their neurobehavioral results with 44 welders who had a mean 11 years exposure to $\mathrm{Al}$ fume were no different from those of 37 production workers of similar age who had no opportunity for exposure to Al welding fume. Meyer-Baron et al. (2007) examined 9 studies of 449 workers employed in Al welding, smelting and electrolysis compared to 315 control workers. Although Meyer-Baron et al. (2007) concluded that urinary $\mathrm{Al}$ less than $135 \mu \mathrm{g} / \mathrm{L}$ "might have an effect on cognitive performance" measured using six different neuropsychological tests with 10 variables (including the symbol-digit and digit span forward/backward tests), when one of the nine studies with uncertain $\mathrm{Al}$ exposure was omitted from their meta-analysis there was no statistically significant difference between the Al-exposed and control workers. These studies are difficult to reconcile because of differences in worker age, Al exposure history, education, native intelligence and life style (including ethanol consumption). In addition, use 
of Al-containing over-the-counter pharmaceuticals results in urinary $\mathrm{Al}$ levels that are equal to or greater than those associated with routine occupational Al exposures. Riihimäki and Aitio (2012) opined that in spite of the preliminary, variable and incomplete evidence for changes in cognition among welders exposed to poorly soluble Al particulate, those reports could not be discounted.

Neurotoxicity in laboratory animals-Table 1 summarizes recent observations concerning Al-induced neurotoxicity in rodents and rabbits; many of these studies examined $\mathrm{Al}$ exposures that are much higher than those experienced by humans. Data considered more relevant to published guidance and regulatory limits are described below.

Shati et al. (2011) studied Al-induced biochemical and molecular changes in the brain of adult $\mathrm{Balb} / \mathrm{c}$ and $\mathrm{C} 57 \mathrm{BL} / 6$ mice given $\mathrm{AlCl}_{3}$ by repeated ip injections over 45 days. Li et al. (2012a) compared APP expression in the brain and selected internal organs of rats after ip injection of $\mathrm{AlCl}_{3}$ at $1 \mathrm{mg} \mathrm{Al} / \mathrm{kg}$ once every other day over 60 days. Abdel-Aal et al. (2011a) gave daily ip injections of $\mathrm{AlCl}_{3}$ at $100 \mathrm{mg} / \mathrm{kg}$-day for 60 days to male Wistar albino rats. Common limitations include only a single $\mathrm{Al}$ dose level, no details on clinical signs, food or drinking water consumption or the chemical purity of the test material and the $\mathrm{pH}$ of the administered $\mathrm{AlCl}_{3}$ solution or the $\mathrm{Al}$ content in the laboratory stock diet and drinking water were not reported. No controls given equimolar doses of $\mathrm{HCl}$ were included in any of these repeated ip $\mathrm{AlCl}_{3}$ injection studies. No neurobehavioral assessment (Shati et al. 2011) or only limited details of the conditions during the behavioral and neuromotor assays (e.g., blind examination) detract from these reports. Results from the Abdel-Aal et al. (2011a) study suggest that high-dose $\mathrm{AlCl}_{3}$ injections over a prolonged period can reduce locomotor and cognitive functions in rats, but the reductions in cognitive function and physical activity occurred at doses that also reduced body weight gain suggesting that repeated $\mathrm{AlCl}_{3}$ injections induced systemic toxicity.

Three recent studies examined the potential toxicity of ingested $\mathrm{Al}$ in novel protocols that gave mice $\mathrm{AlCl}_{3}$ or $\mathrm{Al}$ lactate for at least 90 days (Akiyama et al. 2011, Ribes et al. 2010, 2011). These assays are unique in that transgenic mice with increased amyloid $\beta$-protein $(\mathrm{A} \beta)$ deposition as a result of human $\mathrm{A} \beta$ precursor protein (A $\beta P P)$ mutations $(\mathrm{Tg} 2576)$ and (P301L) at the tau protein (Tg2576tau) were examined. The $\mathrm{Tg} 2576$ mouse carries the Lys670 $\rightarrow$ Asn,Met671 $\rightarrow$ Leu mutation and by six months of age they develop a 5 -fold increase in $A \beta(1-40)$ and a 14 -fold increase in $A \beta(1-42 / 43)$. The Ribes et al. $(2010,2011)$ protocols compared the responses seen in the $\operatorname{Tg} 2576$ mouse with those seen in wild-type mice. None of these studies examined more than one $\mathrm{Al}$ dose level.

Akiyama et al. (2011) followed the development of AD-like pathology in female ABPPsw

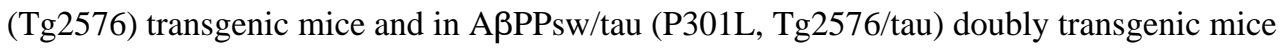
after long-term ingestion of Al. Akiyama et al. (2011) gave 5- to 8-month-old single transgenic Tg2576 mice or double A $\beta$ PPsw/tau (P301L) (Tg2576/tau) transgenic mice 400 $\mathrm{mg} \mathrm{Al} / \mathrm{L}$ in their drinking water as $\mathrm{AlCl}_{3}$ ad libitum for $4-10$ months. Assuming a body weight of $20 \mathrm{~g}$ and consumption of $5 \mathrm{ml}$ drinking water/day (http://www.informatics.jax.org/ mgi-home/other/mouse_facts1.shtml), the authors estimated the daily Al dose was $100 \mathrm{mg}$ $\mathrm{Al} / \mathrm{kg}$ bw. The first groups (six mice per group) of heterozygote A $\beta P P s w$ transgenic mice 
were given deionized water or $\mathrm{AlCl}_{3}$-treated drinking water for a total of 4 months (from ages 8-12 months) and subsequent groups were given identical treatments from age 8 months for ten months. The doubly transgenic ( $\mathrm{Tg} 2576 / \mathrm{tau}$ ) mice were maintained on the $\mathrm{AlCl}_{3}$-treated drinking water beginning at 5 months of age until 14 months. Histopathology was examined in serial sections from whole brains of two or three mice per group. Amyloid$\beta(A \beta)$ in all of the surviving mice and tau in the Tg2576/tau mice were determined using immunohistochemistry and quantitative image analyses. The $A \beta$ was present as diffuse and consolidated deposits in the cerebral cortex and hippocampus. Variability between hemispheres and also within age groups was evident, but there was a consistent increase in A $\beta$ deposition in the 18-month-old mice compared with the 12-month-old Tg2576 and 14month-old $\mathrm{Tg} 2576 /$ tau mice. In the 18-month-old mice, $A \beta$ deposition was widespread and the frontal and temporal cortices had the highest accumulations. The differences in $\mathrm{A} \beta$ deposition between the different treatment groups were not significant for the $\mathrm{AlCl}_{3}$-treated group and the distilled water controls. Deposition of $A \beta$ was not significantly different between treatment groups in the 14-month-old $\mathrm{Tg} 2576 /$ tau mice given $\mathrm{AlCl}_{3}$ versus those given distilled water. Abnormally phosphorylated tau in the brains of the 14-month-old Tg2576/tau mice was assessed using AT8 immunostaining; quantitative comparisons between sections with the highest tau accumulation found no significant differences between groups. Concentrations of soluble $A \beta$ increased with age, but no significant differences were observed between the different groups.

In sum, Akiyama et al. (2011) described brain pathology and A $\beta$ deposition in transgenic mice and found an absence of excess tau in genetically susceptible mice given $100 \mathrm{mg}$ $\mathrm{Al} / \mathrm{kg}$-day for nine months. Akiyama et al. (2011) concluded that $\mathrm{Al}$ ingestion failed to influence the amount of soluble $A \beta$ or $A \beta$ oligomer $(A \beta * 56)$ or accelerate or potentiate the pathogenesis of AD-type lesions in mouse brain. The authors also concluded that their results "did not show any significant effect of long-term intake of $\mathrm{Al}$ on the amount of $\mathrm{A} \beta$ accumulation in $\operatorname{Tg} 2576$ or of $A \beta$ and tau accumulation in $\operatorname{Tg} 2576 /$ tau mice" and that "our results failed to demonstrate that excess $\mathrm{Al}$ in drinking water, a form which is considered to be more bioavailable than $\mathrm{Al}$ in food, increases $\mathrm{AD}$ pathology in transgenic mouse models." While Akiyama et al. (2011) did not measure $\mathrm{Al}$ in the different brain areas, the authors cited the work of Gómez et al. (2008) who found feeding $\mathrm{Al}$ (as the lactate) at $1 \mathrm{mg} / \mathrm{g}$ in rodent chow for six months (equivalent to $1.3 \mathrm{mg} \mathrm{Al} / \mathrm{kg}$-day) to female $\mathrm{Tg} 2576$ mice increased $\mathrm{Al}$ concentrations in the hippocampus, cortex and cerebellum. It is noteworthy that Gómez et al. (2008) found no differences in the $\mathrm{Al}$ content of these brain regions between wild-type and $\operatorname{Tg} 2576$ mice.

In related protocols, Ribes et al. (2010) fed Al lactate in a stock rodent chow to male wildtype and Tg2576 transgenic mice for 210 days. Ribes et al. (2011) followed those studies by feeding dietary $\mathrm{Al}$ lactate to 15 male wild-type and $17 \mathrm{Tg} 2576$ transgenic mice for 3 months. Ribes et al. (2011) measured $\mathrm{Al}$ in the cerebellum and frontal cortex and counted the numbers of amyloid plaques (double immunofluorescence staining for $\mathrm{A} \beta$ and glial fibrillary protein) in the hippocampus and in the parietal and temporal cortex. These results were then correlated with results of behavioral assessments using a functional observational battery (FOB) along with measures of habituation, training, and memory retention. 
Ribes et al. (2010) evaluated learning, memory, and neurogenesis in 40 male wild-type and transgenic $\mathrm{Tg} 2576$ mice. Until 5 months of age, the animals had free access to laboratory chow containing $27 \mathrm{mg} \mathrm{Al} / \mathrm{kg}$ and tap water containing $14 \mu \mathrm{g} \mathrm{Al} / \mathrm{L}$. Starting from 5 months of age, 10 wild-type and $10 \mathrm{Tg} 2576$ transgenic mice were fed the stock diet supplemented with $\mathrm{Al}$ (1.1 mg Al lactate/g) for 210 days. Ten wild-type and ten transgenic mice (control) were fed the stock diet. Body weight, food intake, and water consumption were measured monthly during treatment, but the daily Al dose was not defined. After 7 months learning and memory were evaluated in a Morris Water Maze without habituation. Neurogenesis (proliferation, survival and differentiation of hippocampal cells) was assessed two days after behavioral testing. Primary bromo-2-deoxyuridine (BrdU) antibodies, NeuN and GFAP were used for immunochemistry. Optic microscopy was used to count BrdU, BRdU-NeuN, and BrdU-GFAP positive cells in the granular cell layer and hilus of the right and left hippocampus and dentate gyrus of coronal sections of six mice from each group. No significant effects of genotype or $\mathrm{Al}$ treatment were observed in relation to long-term retention (one week after the acquisition) and there were no differences between genotype/ treatment groups in proliferation, survival, and differentiation of hippocampal cells. The authors concluded "we were unable to observe a clear effect from the Al factor" and that there was no effect of dietary $\mathrm{Al}$ or genotype on cell proliferation in the hippocampus. The authors measured body weight and food consumption once in every month, but the results were not given in the publication. Assuming average food consumption of $4.4 \mathrm{~g} / \mathrm{day}$ by a 30$\mathrm{g}$ adult male mouse (Bachmanov et al. 2002), the daily Al consumption may have been on the order of approximately $160 \mathrm{mg} \mathrm{Al} / \mathrm{kg}$-day. Verification of the dietary $\mathrm{Al}$ concentration was not mentioned and this is of concern due to an error in the amount of $\mathrm{Al}$ in the diet reported in an earlier publication by this same group (Gomez et al. 2008).

Ribes et al. (2011) fed 15 wild-type and 17 Tg2576 transgenic female mice (7-8 per group) dietary $\mathrm{Al}$ lactate $(1 \mathrm{mg} \mathrm{Al} / \mathrm{g})$ ad libitum from six until nine months of age. Control mice received a stock chow (Hanlan, Barcelona). No data on body weight, or food and drinking water consumption were provided. The dietary concentrations correspond to $3.4 \mathrm{mg} \mathrm{Al} / \mathrm{kg}$ bw/day in mice given the stock diet and $54 \mathrm{mg} \mathrm{Al} / \mathrm{kg}$-day in the treated mice (Gomez et al. 2008). After treatment a number of behavioral endpoints were evaluated in a FOB and the results were scored on a scale from 1 (normal) to 4 (severely abnormal). A novel object recognition test examined the numbers of rearings, distance traveled, and total time spent exploring. After behavioral testing, $\mathrm{Al}$ levels in cerebellum and frontal cortex were measured using a computer-controlled ICP-AES (detection limit $=1.0 \mu \mathrm{g} / \mathrm{kg}$ ) and serum corticosterone was measured. Because Tg2576 mice develop amyloid plaques, $\beta$-amyloid plaques were determined in $\mathrm{Tg} 2576$ mice only: the total number of $\mathrm{A} ß$ deposits was counted in the parietal and temporal cortex surrounding the hippocampus and in the hippocampus of both Al-treated and control Tg2576 mice. Two-way ANOVA revealed a significant Al effect (diminished) on climbing in both Al-treated wild-type and $\operatorname{Tg} 2576$ mice $[\mathrm{F}(1,32)=8.724, \mathrm{p}$ $=0.006)]$ with lower activity in the Al-exposed Tg2576 group ( $\mathrm{p}<0.05$, Mann-Whitney test). There was a significant $\mathrm{Al}$ effect $[\mathrm{F}(1,32)=10.702, \mathrm{p}=0.003]$ on piloerection (increase) in both of the Al-exposed groups compared to the controls. No effect of genotype or $\mathrm{Al} \times$ genotype interaction was found. There were no significant effects of $\mathrm{Al}$ ingestion on corticosterone levels or $\mathrm{Al}$ concentrations in frontal cortex and cerebellum of the wild-type 
and $\operatorname{Tg} 2576$ mice. $B$-amyloid plaque depositions were observed in both the $\mathrm{Al}$-fed and control Tg2576 animals with a higher number of plaques in the controls compared to the Altreated $\mathrm{Tg} 2576$ mice, but there were no significant differences between these groups. Ribes et al. (2011) found that subchronic ingestion of Al lactate was associated with increased piloerection and diminished home cage activity in both Al-treated wild-type and $\mathrm{Tg} 2576$ mice. The Al-treated $\mathrm{Tg} 2576$ mice spent less time exploring new objects and this was taken as evidence for impaired long-term memory in the Tg2576 mice. Ribes et al. (2011) also concluded that increased B-amyloid plaques in Tg2576 transgenic mice had no correlation with deficits in recognition memory. Perhaps the most important conclusions were that "neither Al treatment nor genotype had any noticeable effect on Al concentrations in frontal cortex and cerebellum of mice" and that "Al did not alter the recognition memory and bamyloid plaque loads in Tg2576 mice."

The Akiyama et al. (2011) and Ribes (2010, 2011) data demonstrate that repeated high-dose $\mathrm{Al}$ ingestion increased brain $\mathrm{Al}$ concentrations, but increased brain $\mathrm{Al}$ failed to potentiate abnormal accumulation of $A \beta$, tau, or neuritic $\beta$-amyloid plaques in transgenic mouse models of AD. Since Al-induced pathology in rodent brain is different from that seen in AD (Wisniewski 1997, Klatzo et al. 1965), extrapolation of studies in transgenic rodents to assessment of human health risks posed by $\mathrm{Al}$ is limited.

Neurobehavioral studies in humans-Olabanji et al. (2011) measured Al in hair and whole blood from 43 healthy adults compared to 60 adults of whom 43 were diagnosed with schizophrenia, 8 who were bipolar, 7 who were diagnosed with non-specific mental illness, and 2 who suffered from post-partum depression. The authors suggested that the Al concentrations were higher in patients with behavioral disorders than in the referent group, but the authors admitted the higher values "may be due to considerable contamination during sample preparation". The investigators were not blinded to the patient and referent samples and the admitted contamination is such that no useful information can be gained from the Olabanji et al. (2011) publication.

In a retrospective evaluation of 8 men and 22 women who had histologically confirmed focal $\mathrm{Al}$ accumulation on skeletal muscle biopsy and who were diagnosed with vaccine-induced macrophagic myofasciitis (MMF), Passeri et al. (2011) assessed visual memory, left ear extinction for interhemispheric connection using dichotic listening and signs of dysexecutive syndrome (characterized by generalized loss of autonomy, impaired planning ability, impaired abstract thinking, impaired social skills, repetitive actions, and poor impulse control). Participant emotional status was measured using the Montgomery/Asberg Depression Rating Scale and the Centre for Epidemiologic Studies Depression (CES-D) self-reporting system. Participants were evaluated using the Wechsler Adult Intelligence Scale, Digit Span test, the California Verbal Learning test, Grober \& Buschke test, Benton Visual Retention test, Rey-Ostereith Complex Figure Recall, Verbal Fluency and Trail Making tests, Zazzo's Cancellation Test for attention, and the Picture Naming DO 80 test.

Seventeen subjects were considered non-amnestic and ten were considered amnestic, but none were classified as demented. Depression tended to increase in $13(72 \%)$ who had "severe" signs of "mild cognitive impairment" (MCI) compared to those classified as pre- 
MCI (11\%) or with clear MCI (17\%). When these 30 patients were given MRI scans, five had cortical atrophy and three had callosal atrophy, but the imaging results found no correlation between brain anomalies and performance on any of these cognitive tests. Despite the authors' contention that "most people with MCI progress to dementia, mostly AD”, no assessment of patient apoE $\varepsilon 4$ allele (Mui et al. 1996, Rao et al. 1996) or PICALM, CIU, CR1 and BIN1 (Harold et al. 2009, Lambert and Amouyel 2011) was undertaken. The Passeri et al. (2011) study is biased in subject selection, failure to include age-matched referents, and lack of investigator blinding to subject history.

Neurobehavioral studies in laboratory animals-Recent neurobehavioral studies in rodents with $\mathrm{Al}$ are presented in Table 2 and the more informative reports are discussed below. Common problems with these studies include: failure to justify the dose, frequency and duration of exposure and only a single concentration was examined (so there is no opportunity to determine dose-response); there were limited or no details on clinical signs, food and drinking water consumption, body weight, the chemical purity of the test material, verification of administered dose, and the $\mathrm{pH}$ of the injected, oral gavage, or drinking water solutions. Most of these reports had no information on the Al content in the laboratory stock diet or drinking water. No concurrent controls treated with equimolar doses of $\mathrm{HCl}$ were included in any of these studies (e.g., Ali et al. 2008). Providing extraordinarily high $\mathrm{AlCl}_{3}$ concentrations results in acidic water of low palatability and this can lead to dehydration, reduced food consumption and reduced body weight gain. There was no report of evaluations of plasma urea or creatinine concentrations or other indicators of kidney function. Those parameters are important given the variable findings of renal toxicity reported in some intermediate and chronic duration Al exposure studies (ATSDR 2008). Most of the recent publications provide limited details on conduct of the behavioral and neuromotor assays and only a few include circulating or peripheral tissue $\mathrm{Al}$ concentrations.

Liu et al. (2010) evaluated memory, cerebral cortex, and hippocampus excitatory amino acids (glutamate and aspartate) and brain acetylcholinesterase (AChE) activity in male Kunming mice. Intraperitoneal $\mathrm{AlCl}_{3}$ was given at $100 \mathrm{mg} / \mathrm{kg}$ once every other day for 60 days. Control mice received the same ip volume of water once every other day for 60 days. Learning and memory were assessed using a single trial passive avoidance task. Reduced performance on tests for memory, reduced glutamate, and aspartate levels and increased AChE activity in the Al-treated mice were reported. A related study by Kakkar and Kaur (2011) investigated subchronic oral gavage with $100 \mathrm{mg} \mathrm{AlCl} / 3 / \mathrm{kg}$-day $\mathrm{AlCl}_{3}$ in relation to escape latency, hippocampus and cortex histology, brain LPO, SOC, GSH, catalase, and $\mathrm{AChE}$ activity in mice. Kumar et al. (2011) gave male rats $\mathrm{AlCl}_{3}$ by oral gavage at 100 $\mathrm{mg} / \mathrm{kg}$-day for 42 weeks. It is not clear to what extent the reported changes in behavior, brain chemistry, edema, and neuron degeneration in the hippocampus and cortex may be due to the acidic properties of high-dose $\mathrm{AlCl}_{3}$ and the influence of $\mathrm{HCl}$ on peritoneal tissues, drinking water consumption, hydration, and health of the animals.

Other recent studies suffer from similar limitations. Abu-Taweel et al. (2011b) gave adult male Swiss mice daily treatment "by oral route" with $\mathrm{AlCl}_{3}$ at 0,300 , or $600 \mathrm{mg} / \mathrm{kg}$-day in distilled water over 20 days. Dose-dependent reductions in social investigations, numbers of attacks, and numbers of fights were seen along with significant increases in latency to threat, 
latency to attack, rears, and non-social investigations. The authors reported significant reductions in circulating T in both Al-treated groups. Significant declines in serotonin (5HT) were seen at the high dose and declines in dopamine (DA) were reported at 300 and 600 $\mathrm{mg} / \mathrm{kg}$-day. Whole brain acetylcholine (Ach) was reduced at the low dose, but Ach was increased at the high dose. The authors concluded that daily $\mathrm{AlCl}_{3}$ ingestion resulted in neurobehavioral impairment associated with reduced brain 5-HT and DA. There were no details on the purity or $\mathrm{pH}$ of the dosing solution; the numbers of mice per group was not identified and clinical observations, food and water consumption and body weight gain data were not provided. Neither pair-fed controls nor concurrent controls given equimolar doses of $\mathrm{HCl}$ were included in the study design.

Thirunavukkarasu et al. (2012) gave groups of eight rats $100 \mathrm{mg} / \mathrm{kg}$-day of $\mathrm{AlCl}_{3}$ in drinking water for 90 days and evaluated anxiety and memory. Aluminum concentrations in the cerebral cortex and hippocampus increased 13- and 6-fold, respectively, compared to the controls. Rats given $\mathrm{AlCl}_{3}$ had an 8.5-fold increase in the number of escape trials and significant reductions in cortex and hippocampus $\mathrm{AChE}$ activity. Ingestion of $\mathrm{AlCl}_{3}$ was associated with behavioural alterations, significant reductions in brain SOD, catalase, glutathione peroxidase (GPx) and, reduced GSH compared to the controls."Shrunken" neuronal cells with vacuolated cytoplasm and massive cellular depletion along with severe necrosis were noted in the cerebral cortex and hippocampus. The changes in brain histology might reflect the increased $\mathrm{Al}$ levels in the cerebral cortex and hippocampus and behavioral changes; however, as no histologic evaluation of the gut and no data on food or water consumption were provided, it is difficult to determine whether the changes in behaviour and oxidative stress reflect direct consequences of $\mathrm{Al}$ or whether the changes were secondary to the acidic water.

Wang et al. (2010a) described the consequences of high-dose $\mathrm{Al}$ on memory in rats given 0 , 2000, 4000, or $6000 \mathrm{mg} / \mathrm{L} \mathrm{AlCl}_{3}$ in distilled drinking water for 90 days. Body weights and drinking water consumption were monitored, but no results were provided. Assessments of memory and learning ability were measured using the step-down test, synaptic plasticity in the hippocampus was evaluated using long-term potentiation (LTP), expression of protein kinase $\mathrm{C}$, assays of mitogen-activated protein kinase (MAPK), and measures of extracellular signal-regulated kinases (ERK1/2) and $\mathrm{Ca}^{+2}$ calmodulin-dependent protein kinase II (CaMKII)) expression. Absolute and relative brain weights and $\mathrm{Al}$ levels in whole brain and blood were measured. The average daily water intake declined as the $\mathrm{AlCl}_{3}$ concentration increased; animals given 2000, 4000, or $6000 \mathrm{mg} / \mathrm{L} \mathrm{AlCl} 3$ consumed $25 \pm 2,20 \pm 2$, and 15 $\pm 2 \mathrm{ml}$ per rat per day, respectively. By comparison, the control rats consumed $50 \pm 2 \mathrm{ml}$ of distilled water per day. These $\mathrm{AlCl}_{3}$ concentrations in drinking water were associated with $4-16 \%$ reductions in body weight.

A significant concentration-dependent increase in the numbers of mistakes and reduced latency (indicators of memory) in the $\mathrm{AlCl}_{3}$-treated rats were observed. Absolute (8-16\%) and relative brain weights (6-11\%) were reduced in the $\mathrm{AlCl}_{3}$-treated groups. Wang et al. (2010a) concluded that ingestion of $\mathrm{AlCl}_{3}$ reduced memory, impaired hippocampal synaptic plasticity, and decreased LTP induction-related kinases MAPK, ERK1/2, and CAMKII. As in studies by Erazi et al. (2011) and Thirunavukkarasu et al. (2012), the $\mathrm{pH}$ of the drinking 
water was not reported and no concurrent controls given equimolar concentrations of $\mathrm{HCl}$ were included.

In a study similar to Wang et al. (2010a), Cui et al. (2012) investigated the influence of prolonged $\mathrm{Al}$ ingestion on learning and memory of rats by studying changes in the Ras/Raf/ERK signal transduction pathway. Young Wistar rats given 2000, 4000, or 6000 $\mathrm{mg} / \mathrm{L} \mathrm{AlCl} 3$ in drinking water for 90 days had increased brain $\mathrm{Al}$, reduced brain weight, and reduced LTP amplitude in the hippocampus. Ras protein and mRNA expression increased and Raf1, ERK2, and CREB declined. The authors concluded that subchronic Al exposure during early life may affect learning and memory as a result of Al-induced changes in the Ras/ERK signal pathway.

Xiao et al. (2011) gave $\mathrm{AlCl}_{3}$ in distilled water to female Kunming mice at 0 or $20 \mathrm{mg} / \mathrm{kg}$ day by gavage for 10 weeks. Learning and memory were measured using the Morris water maze. Whole brain Ach and choline acetyltransferase (ChAT) and AChE activities along with amyloid $B(\mathrm{~A} \beta)$ and hyperphosphorylated tau (HFT) were determined at 8 and 10 weeks of exposure and after six weeks of recovery (i.e., 16 weeks from the beginning of the study). Histologic examination of senile plaque (SP)-like and neurofibrillary tangle (NFT)like structures was conducted and $A ß$ was measured using mouse anti- $A \beta_{1-42}$ antibody. After eight weeks there were no significant differences in escape latency, probing time in the target quadrant, or in brain Ach, ChAT and AChE activities. There were no detectable SPlike or NFT-like structures in the cortex or in the hippocampus. After 10 weeks there was a significant increase in escape latency among the $\mathrm{AlCl}_{3}$-treated rats compared to the controls, but there were no significant differences in Ach, AChT, and AChE activities and no SP-like or NFT-like structures in the cortex or hippocampus. At 16 weeks (10 weeks of treatment + 6 weeks withdrawal) there were no significant differences in escape latency, probing time, brain Ach, AChT, and AChE activities or SP-like and NFT-like structures in the cortex or hippocampus. Similar to the Cui et al. (2012), Thirunavukkarasu et al. (2012), Wang et al. (2010a) reports, Xiao et al. (2011) provided no rationale for dose selection, examined only a single $\mathrm{Al}$ dose level and the $\mathrm{pH}$ of the $\mathrm{AlCl}_{3}$ solution was not reported. Xiao et al. (2011) made no mention of $\mathrm{Al}$ concentrations in blood or brain or changes in body weight, food and drinking water consumption or clinical signs.

By and large the most recent laboratory reports (Tables 1 and 2) concerned with Al-induced neurotoxicity and neurobehavioral disorders have not identified exposures or outcomes that alter previous conclusions (ATSDR 2008, Krewski et al. 2007, Willhite et al. 2012). Some of the recently published studies support the plausibility that prolonged high-dose $\mathrm{Al}$ exposure can induce neurobehavioral disorders in rodents, but most of the recent studies that employed oral administration and high doses of $\mathrm{Al}$ (administered as $\left.\mathrm{AlCl}_{3}\right)$ were such that increased mortality (Kakkar and Kaur 2011) and/or systemic toxicity (e.g., reduced body weight) (Cui et al. 2012, Wang et al. 2010a) complicate interpretation of the results. The majority of the recent reports in rats used different strains, doses, routes, durations and frequency of exposure, and make no mention of clinical signs, body weight change and drinking water or food consumption. Given the lack of consistency in experimental design and protocols, comparisons between results are problematic. Based on studies with SpragueDawley rats injected with $\mathrm{AlCl}_{3}$ at $100 \mathrm{mg} / \mathrm{kg}$-day for 16 weeks, Elsaid et al. (2011) 
suggested that increased brain LPO and reduced brain AChE were "a major factor responsible for the memory deficit in AD". Kaizer et al. (2008) found increased hypothalamus and striatum AChE and reduced cerebellar, hippocampus and cortex AChE after chronic $\mathrm{Al}$ exposures in mice, but reported reduced hypothalamus AChE activity in the Kaizer et al. (2005) publication. Reduced rat brain AChE activity was also reported by Bhadauria (2012), Chakrabarty et al. (2012), Shrivastava (2012), Stevanović et al. (2011), and Thirunavukkarasu et al. (2012); however, Ahmed et al. (2011), Bihaqi et al. (2009), Kakkar and Kaur (2011), Kumar et al. (2011), Liu et al. (2010), and Sharma et al. (2009) all reported increased brain AChE activity, but Xiao et al. (2011) found no significant effect of prolonged oral $\mathrm{AlCl}_{3}$ on mouse brain AChE. Since there are no signs of cholinergic stimulation or inhibition seen after high acute doses of any $\mathrm{Al}$ form, the clinical significance of changes in AChE activity (if any) are not clear. Whether these differences are due to dose, duration or strain or species cannot be determined given the absence of brain $\mathrm{Al}$ concentration: time profiles. Similar discrepancies between the results of other rodent neurobehavioral assays after $\mathrm{Al}$ exposures were noted previously (Willhite et al. 2012).

Several studies were identified that examined exposure of laboratory animals to watersoluble $\mathrm{Al}$ materials with durations that spanned from 1 to nearly 6 months (Tables 1 and 2). Some of these studies used parenteral injections and others examined changes after $\mathrm{Al}$ (primarily $\mathrm{AlCl}_{3}$ ) by repeated oral (gavage) administration or via drinking water. The objective of some of these studies was to investigate the neuroprotective effects of various drugs or plant extracts (Kumar et al. 2011, Thirunavukkarasu et al. 2011, 2012) on Alinduced toxicity or to investigate mechanisms of Al neurotoxicity (Cui et al. 2012, Wang et al. 2010a, Xiao et al. 2011) following prolonged Al administration. Only Akiyama et al. (2011) and Ribes et al. (2010, 2011) provided a rationale for duration of exposure and some (González-Muñoz et al. 2008a, 2008b) lacked concurrent vehicle controls. Many of these studies used a single level of $\mathrm{Al}$ (administered as the chloride or lactate) and examined sexually mature male or female rats (Erazi et al. 2011, Kumar et al. 2011, Thirunavukkarasu et al. 2012) or mice (Kakkar and Kaur 2011, Xiao et al. 2011). Cui et al. (2012) and Wang et al. (2010a) studied young rodents; Abu-Taweel et al. (2011a, 2011b), Abd El-Rahman et al. (2011), Kakkar and Kaur (2011), and Xiao et al. (2011) studied mature mice. The majority of these studies gave Al via gavage (Abu-Taweel et al. 2011, Ahmed et al. 2011, BelaidNouria et al. 2012, Bihaqi et al. 2009, Kakkar and Kaur 2011, Kumar et al. 2011, Thirunavukkarasu et al. 2012, Xiao et al. 2011) and others employed drinking water (AbdElghaffar et al. 2007, Cui et al. 2012, Wang et al. 2010a); only two of the studies examined more than a single dose level (Cui et al. 2012, Wang et al. 2010a). Six of the recent studies presented measurements of $\mathrm{Al}$ in the brain and blood and included brain histology along with results of neurobehavioral testing (Chakrabarty et al. 2012, Cui et al. 2012, Erazi et al. 2011, Kakkar and Kaur 2011, Kumar et al. 2011, Wang et al. 2010a).

Data showing increased brain LPO in rodents (Ahmed et al. 2011, Belaid-Nouria et al. 2012) and rabbits (Abd-Elghaffar et al. 2007) after repeated oral dose $\mathrm{Al}$ are abundant. In addition to alterations in the activity of brain antioxidant enzymes (Table 3), Wu et al. (2012a) listed consistent features of the $\mathrm{Al}$ neurotoxic mode of action: disturbances in Fe and other metal homeostasis, impaired mitochondrial function as a result of increased mitochondrial $\mathrm{O}_{2}{ }^{--}$ and $\bullet \mathrm{OH} / \mathrm{H}_{2} \mathrm{O}_{2}$ and alterations in NF- $\mathrm{kB}, \mathrm{p} 53$, and JNK pathways that promote apoptosis. 
The cerebral atrophy and neuronal necrosis in rabbits described by Abd-Elghaffar et al. (2007) were consistent with previous reports by Rabe et al. (1982) and Yokel (1989) who found Al-induced neurodegeneration and neurofibrillary changes in rabbits, but the Ahmed et al. (2011) report of neurofibrillary tangles in Sprague-Dawley rat brain after 4 months of daily $\mathrm{AlCl}_{3}$ intubation and the Sun et al. (2009) report of increased cortex and hippocampus $\mathrm{A} \beta$ in Kunming mice after three months of daily $\mathrm{AlCl}_{3}$ injections are novel and unlike the neurofibrillary damage described by Shrivastava (2012). Nevertheless, recent histopathological observations in the brain of laboratory animals after $\mathrm{Al}$ administration via oral or parenteral routes have not confirmed the neuritic plaques seen in human $\mathrm{AD}$ and the recent results are not sufficient to conclude that the damage seen in animals treated with high $\mathrm{Al}$ doses $\mathrm{Al}$ is equivalent to that seen in $\mathrm{AD}$ (Klatzo et al. 1965, Wisniewski and Wen 1992; reviewed in Kawahara and Kato-Negishi 2011).

None of the laboratory studies reviewed here met the current international test guidelines and most failed to specify the source and chemical purity of the test material. The experimental designs of the majority were limited to only one dose level and observations were performed at a single time point. Given the paucity of details and the absence of clinical chemistry parameters and urine analyses, it is difficult to determine the health of the animals and their renal function. In most of these recent publications blood and tissue Al levels were not measured; therefore, the absorbed and distributed doses cannot be identified and compared to those of other animal and human studies. Overall, none of the recent animal studies that examined $\mathrm{Al}$ oral administration provided clear indications of neurologic damage in the absence of systemic toxicity. While several studies on Al-induced neurotoxicity in laboratory animals have appeared, none of the recently published studies in animals are adequate upon which to base oral RfD or DNEl values for metallic $\mathrm{Al}$, its oxides or the common $\mathrm{Al}$ salts.

Neurotoxicity in vitro-A number of in vitro studies focused on mechanisms of Alinduced neurotoxicity (Table 3). A brief overview of the laboratory data considered most relevant to $\mathrm{Al}$ hazard identification is provided below.

Niedowicz et al. (2011) described assembly of amyloid- $\beta$ (A $\beta$ ) and the hyperphosphorylated pathologically folded microtubule tau polymers of the neurofibrillary tangles that together make up the neuritic plaques. In an effort to understand the self-aggregation of soluble amyloid $\beta$-peptide $(A ß)$ responsible for the protein mis-folding that leads to development of insoluble "senile" plaques, Atwood et al. (1998) incubated $10 \mu \mathrm{M}$ synthetic human $\mathrm{A} \beta_{1-40}$ with 0.6 or $30 \mu \mathrm{M} \mathrm{Al}^{3+}$ at $\mathrm{pH} 6.6,6.8$, or 7.4. No detectable $\mathrm{Ab}_{1-40}$ aggregation was observed over the $\mathrm{pH}$ range tested in the absence of $\mathrm{Al}^{3+}$ or other metal ions. Incubation of $\mathrm{A} \beta_{1-40}$ with $0.6 \mu \mathrm{M} \mathrm{Al}^{3+}$ increased protein sedimentation as $\mathrm{pH}$ declined; incubation of synthetic human $\mathrm{A} \beta_{1-40}$ with $30 \mu \mathrm{M} \mathrm{Al}^{3+}$ induced partial aggregation at $\mathrm{pH}$ 6.6, but there was no significant aggregation at $\mathrm{pH}$ 7.4. Atwood et al. (1998) interpreted their data as reflecting subtle changes in $A \beta_{1-40}$ conformation that account for metal ion-induced $A \beta$ assembly mediated by $\left[\mathrm{H}^{+}\right]$.

The Atwood et al. (1998) observations were consistent with previous reports (Barrow and Zagorski 1991, Burdick et al. 1992, Fraser et al. 1991, Kirshenbaum and Daggett 1995, 
Wood et al. 1996, Zagorski and Barrow 1992) on Al concentration, $\mathrm{pH}$ and $\mathrm{A} \beta$ aggregation; as $\mathrm{Al}$ concentrations increased, there was an increase in $\mathrm{Al}^{+3}$-induced $\mathrm{A} \beta$ conformational change. Atwood et al. (1998) found that addition of $\mathrm{Cu}^{2+}$ and $\mathrm{Zn}^{2+}$ also induced $\mathrm{A} \beta_{1-40}$ aggregation at $\mathrm{pH}$ 6.8-7.4 and that the reaction was completely reversible with chelation or at higher pH. The Atwood et al. (1998) data could be taken as support for the suggestion that metabolic acidosis (Yates et al. 1990) associated with inflammation (Akiyama et al. 2000), impaired energy metabolism (Small et al. 2000) or increased oxidative stress coupled with the actions of ionized metals might contribute to the pathogenesis of $\mathrm{AD}$ and/or other neurologic disorders.

Many mechanistic studies (Table 3) are not directly relevant to Al hazard identification, but some offer (curious and/or conflicting) insights into $A \beta$ and its interactions with Al. For example, Nday et al. (2010) cultured Sprague-Dawly rat hippocampal cells with 0, 10, 100, or $500 \mu \mathrm{M} \mathrm{Al}^{+3}$ (as $\mathrm{AlCl}_{3}$ ). Neuronal dendrite skrinkage and lethality increased with concentration and duration of exposure and neurons were far more susceptible than glial cells. In a companion effort, cultured mouse neuroblastoma N2a cells expressing the amyloid precursor protein APP695 were used to produce a supernatant that contained $8.2 \mathrm{pg}$ $\mathrm{A} \beta_{1-40} / \mathrm{ml}$. Addition of $750 \mu \mathrm{l}$ of that supernatant to $96 \mathrm{~h}$ cultures of rat neuronal and glial cells reduced their survival 26 and $14 \%$, respectively. However, when $500 \mu \mathrm{M} \mathrm{Al}^{+3}$ was incubated along with the same concentration of $A \beta$-bearing $N 2 a$ supernatant, neuronal and glial cell survival was no different from that in cultures treated with the $A \beta$ supernatant alone. When $A \beta$ alone was added (4 days) to cultured neurons there was a significant reduction in polymerized tubulin, yet when $50 \mu \mathrm{M} \mathrm{Al}^{+3}$ was added to neurons cultured under identical conditions there was no change in polymerized tubulin compared to cultures treated with $\mathrm{Al}^{+3}$ alone. The most important conclusion was that there was no significant interaction between $\mathrm{A} \beta_{1-40}$ and $\mathrm{Al}^{+3}$ in cultured rat neurons and glial cells.

The Nday et al. (2010) conclusion appears to conflict with that by Drago et al. (2007) who reported reduced survival of cultured rat endothelial cells after treatment with rat or human $A \beta_{1-42}$ and that cytotoxicity was enhanced after exposure to human $A \beta-A 1$. The Nday (2010a) conclusion is also at odds with that by Drago et al. (2008) who compared the viability and morphology of cultured human neuroblastoma cells treated with synthetic $A \beta_{1-42}$ or $A \beta-A l, A \beta-C u, A \beta-F e$ or $A \beta-Z n$ conjugates (prepared via $A \beta$-binding with bare ions to yield monometalated molecules). Unlike Nday et al. (2010) who found native $A \beta_{1-40}$ was cytotoxic for rat primary hippocampal neurons after $96 \mathrm{~h}$ incubation, Drago and associates (2008) found no significant toxicity of synthetic $A \beta_{1-42}$ in transformed human neuroblastoma cells after $24 \mathrm{~h}$ in culture. Notably, of the $A \beta_{1-42}$ metal conjugates only the $\mathrm{A} \beta$ - $\mathrm{Al}$ reduced cell survival. It is not clear whether the differences between the results from Nday et al. (2010) and Drago et al. (2008) are due to the specific nature of the N2a-produced $A \beta_{1-40}$ compared to the synthetic $A \beta_{1-42}$, to different culture conditions and durations of exposure, or to differential uptake of $A \beta_{1-40}$ and $A \beta_{1-42}$ by primary and transformed cells. While $A \beta_{1-40}$ incubation with rat neurons and glial cells was prolonged (4 days) and fluorescent stains were used to measure polymerized tubulin, Nday et al. (2010) made no confirmation by ElISA or other means to determine the extent of mouse N2a-generated $\mathrm{A} \beta_{1-40}$ uptake into cultured rat hippocampal cells. 
Bolognin et al. (2011) expanded on the Drago et al. $(2007,2008)$ efforts and found both A $\beta$ $\mathrm{Al}$ and $\mathrm{A} \beta-\mathrm{Fe}$ induced annular protofibrils and fibrillar oligomers in cultured human neuroblastoma cells, yet only $\mathrm{A} \beta-\mathrm{Al}$ triggered production of the amyloid precursor protein and tau 181 (Table 3). The latter observations were not consistent with the in vivo results presented by Ribes et al. (2011) and Akiyama et al. (2011) who found not only that prolonged ingestion of 54 or $100 \mathrm{mg} \mathrm{Al} / \mathrm{kg}$-day failed to increase the numbers of $\beta$-amyloid plaques or influence the amount of soluble $A \beta$ or $A \beta * 56$ oligomer, but also failed to influence the levels of abnormally phosphorylated tau in the brains of susceptible transgenic mice. In follow-up studies with cultured human neuroblastoma cells to ascertain $A \beta$, Bolognin et al. (2011) measured aggregated $A \beta$ and $A \beta$-metal conjugates with conformation-specific antibodies to aggregated $A \beta$, but no direct immunoreactivity for monomeric $A \beta$ was included in that protocol. Given the notable activity of small oligomeric $A \beta$ species that readily diffuse through cell membranes, Bolognin et al. (2011) suggested that in contrast to the historical specific focus on $A \beta$ it may be that prefibrillar and/or fibrillar $A \beta$ oligomers are the primary targets of concern.

In another example, Gatta et al. (2011) examined the influence of $A \beta_{1-42}$ or the $A \beta_{1-42}-A l$ complex on gene expression in cultured human SHSY5Y neuroblastoma cells and compared those results to gene expression profiles in cultures with $A \beta_{1-42}$ or $\mathrm{Al}$ alone. At $4^{\circ} \mathrm{C}$ the $\mathrm{A} \beta$ self-aggregated into short irregular protofibrils, but the $\mathrm{A} \beta-\mathrm{Al}$ complex was present as oligomers. Media was replaced every 2 days and the SH-SY5Y cells were incubated with $0.5 \mu \mathrm{M} A \beta_{1-42}$ or $\mathrm{A} \beta_{1-42}-\mathrm{Al}$ complex for $24 \mathrm{~h}$. Other cultures were incubated under identical conditions with $5 \mu \mathrm{M} \mathrm{Al}$ (10-fold higher than that used in the $\mathrm{A} \beta_{1-42}-\mathrm{Al}$ complex) as $\mathrm{Al}\left(\mathrm{C}_{3} \mathrm{H}_{5} \mathrm{O}_{3}\right)_{3}$ alone. Culture with the $\mathrm{A} \beta_{1-42} \mathrm{Al}$ complex induced different gene expression patterns compared to the patterns induced after similar exposures to $\mathrm{A} B$ or $\mathrm{Al}$ alone. Of a total of 28,676 transcripts, exposure to the $\mathrm{A} ß-\mathrm{Al}$ complex promoted upregulation of 1535 genes and down-regulation of 1815 genes. A gene subset correlated with clinical AD was identified from 584 AD-related genes of which 29 were up-regulated and 23 were down-regulated. Ingenuity pathway analyses revealed that these genes were involved in the modulation of $\mathrm{Ca}^{+2}$ homeostasis as well as regulation of glutamatergic transmission and synaptic plasticity. Microarrays of 35,129 genes were conducted to investigate changes induced via exposure to the $A \beta_{1-42}-\mathrm{Al}(\mathrm{A} \beta-\mathrm{Al})$ complex on the expression profile. Downregulated genes included those involved in cell-cell signaling, inflammation and free radical scavenging; up-regulated genes included those involved in amino acid and lipid metabolism and DNA replication. Based on these results, Gatta et al. (2011) concluded that the Aß-Al complex might be involved in regulation of neuronal as well as synaptic function/ dysfunction and that its presence might modulate AD-related pathways including glutamatergic transmission, $\mathrm{Ca}^{+2}$ homeostasis, oxidative stress, inflammation and neuronal apoptosis. Limitations identified for the Gatta et al. (2011) study include the fact that cultured transformed neuroblastoma cells have limited relevance to normal neurons (Lidsky 2014). As with all of the in vitro assays (Table 3), Aremu et al. (2011), Castorina et al. (2010), Gatta et al. (2011), Nday et al. (2010), and Yang et al. (2011) provided no justification for the $\mathrm{Al}$ concentrations used in their assays. None of the authors compared their $\mathrm{Al}$ concentrations examined in vitro (Table 3 ) to the $\mathrm{Al}$ concentrations measured in human brain or other tissues (e.g., Akatsu et al. 2011, House et al. 2012, Rusina et al. 2011). 
There is evidence to show that the tangles found in $\mathrm{AD}$ patients are associated with elevated brain Al (reviewed in Exley and House 2011, Walton 2010), but there is no consistency in the results of historical (Kasa et al. 1965) or recent studies of brain Al concentrations in patients with AD. Some studies involving bulk analyses of brain samples provide evidence of increased brain $\mathrm{Al}$ concentrations in $\mathrm{AD}$ patients compared to non-demented controls, while other studies do not. Similarly, there is no agreement between the results of different studies examining $\mathrm{Al}$ accumulation in senile plaques and neurofibrillary tangles. Different measurement techniques and their inherent limitations, variations in sampling strategies and sample handling and possible laboratory $\mathrm{Al}$ contamination may contribute the explanations for the conflicting data (reviewed in Krewski et al. 2007, Willhite et al. 2012). While Al can be present in senile plaques, this observation alone does not imply a direct role for $\mathrm{Al}$ in the pathogenesis of AD (Exley and House 2011, Walton et al. 2010). Wu et al. (2012a) summarized the current state of the science as follows:

"The controversy whether $\mathrm{Al}$ has a direct link to common human neurodegenerative diseases, such as $\mathrm{AD}$, has been debated for decades. Conflicting data exist in the literature (Mizoroki et al. 2007, Savory and Ghribi 2007, Savory et al. 2006). Although it is relatively certain that $\mathrm{Al}$ displays multifaceted and complicated neurotoxicity at low dosages, some of which appears relevant to AD disease, there is still no evidence to link $\mathrm{Al}$ as a high risk factor for $\mathrm{AD}$ as happening in the general population."

The data published to date do not support identification of $\mathrm{Al}$ accumulation in brain as the etiologic basis of AD (summarized in Wu et al. 2012a, Lidsky 2014). With respect to the $\mathrm{Al}$ hypothesis for AD (Graves et al. 1990, Kawahara and Kato-Negishi 2011, Krewski et al. 2007, Perl and Moalem 2006, Rusina et al. 2011, Tomljenovic 2011, Walton 2010, 2012a, 2012b), it remains unclear why Al welders and other Al workers (Akila et al. 1999, Giorgianni et al. 2012, Graves et al. 1998, Gun et al. 1997, Hanninen et al. 1994, Rossbach et al. 2006, Salib and Hillier 1996, Santibáñez et al. 2007) or people who experience very high prolonged $\mathrm{Al}$ exposures via PN, renal dialysis, and/or Al phosphate binders (Jenkins et al. 1989, Klein et al. 1984, Ott et al. 1982, Pei et al. 1992, 1995, Salusky et al. 1984, 1990, 1991, Smith et al. 1986) who accumulate substantial Al body burdens (serum Al 30-40 to $\geq$ $100 \mu \mathrm{g} / \mathrm{L}$ ) and who show clinical signs of $\mathrm{Al}$ intoxication do not experience elevated $\mathrm{AD}$ risk.

Since AD shows heritability of up to $79 \%$ and the apolipoprotein A (apoE e4) gene increases $\mathrm{AD}$ risk, contemporary $\mathrm{AD}$ research focuses on the different functional loci involved in lipid processing (apoE, $\mathrm{ClU}$, and $\mathrm{ABCA}_{7}$ ), cell membrane integrity (PICALM, $\mathrm{BIN}_{1}, \mathrm{CD}_{33^{\prime}}$, and $\left.\mathrm{CD}_{2} \mathrm{AP}\right)$, and the immune system (CLU, $\mathrm{CR}_{1}, \mathrm{ABCA}_{7}, \mathrm{CD}_{33}$, and $\left.\mathrm{EPHA}_{1}\right)$ all of which play roles in A $\beta$ clearance and confer increased AD susceptibility (Carrasquillo et al. 2011, Hollingworth et al. 2011). Other research that demonstrated "seeding" small soluble oligomers of human $A \beta$ (complexed with other macromolecules) or aggregates of mutant P301S tau induced misfolding and filamentation of wild-type tau and AD pathology in naïve mice suggests infectious or prion-like actions in the pathogenesis of $\mathrm{AD}$ (reviewed in Guest et al. 2011). 


\section{Respiratory}

Kongerud and Søyseth (2014) summarized factors related to development of "potroom asthma" among Al smelter workers. Donoghue et al. (2010) studied occupational asthma among employees in Al pre-bake smelters. Regular medical surveillance, including respiratory questionnaires and spirometry, was conducted at all smelters with intervals from 3 months to 2 years. No information was available on ages of the workers, gender or length of employment. Asthma cases were identified by surveillance and a few of the cases were diagnosed by family physicians. Pre-placement criteria and assessment of individual suitability for jobs with exposure to potroom dust, fumes, and gases were introduced before the study period; these criteria evolved over the course of the study and these criteria were not uniform at all smelters. Reported parameters included a history of asthma beyond childhood, reduced forced expiratory ratio and evidence of reversible airway obstruction. In some smelters, assessment of non-specific bronchial hyperresponsiveness using methacholine challenge was performed. Incidence rates for occupational asthma were calculated for each smelter and for all smelters combined and the data were presented for each year of the study. All cases of occupational asthma identified among smelter employees (regardless of job category) were divided by the total number of smelter employees (regardless of job category) and the incidence rates were expressed as the number of cases per 1,000 employees per year. Employees who worked "in close proximity to pot fume or bath material for several hours a week as part of their normal job" (e.g., potrooms, potroom services, rodding, potlining, cryolite recovery, scrubbing, and alumina) were defined as the highly "bath exposed" workers. Personal sampling of inhalable particulate, respirable particulate, particulate fluoride (F), gaseous hydrogen fluoride (HF), and total F were conducted for potroom employees. The study design was such that use of personal respiratory protection was not taken into account.

A total of 329 cases of occupational asthma were identified and the highest rate in 1992 (9.46/1,000 per year) declined to $0.36 / 1,000$ per year in 2006. Of the 329 cases, 180 (55\%) occurred in potroom employees and 243 of those occurred among employees assigned to the "bath exposed" areas. A number of control measures were implemented and as a result, the concentrations of inhalable particulate, respirable particulate, particulate F, gaseous HF, and total F in the workers' breathing zone declined over the study period. Significant correlations were observed between reductions in asthma and reductions in total respirable particulate, total F, particulate F, and gaseous HF.

In contrast, Martin and Larivière (2014) described a study of 5000 employees of Canadian Al smelters in which the incidence of post-hire asthma was no different between fumeexposed workers and non-exposed workers. Another study that collated symptoms among 490 male employees (36.75 \pm 6.9 years) of three $\mathrm{Al}$ industries (mean duration 12.3 years) found that $77 \%$ complained of back, shoulder and other pain, but there was no indication of respiratory or any other health issues (Aghilinejad et al. 2012).

\section{Mechanistic data}

Aluminum added as $\mathrm{AlCl}_{3}$ at $1,5,10,50$, or $100 \mu \mathrm{M}$ to cultured human transformed HaCat epidermal keratinocytes or primary human dermal fibroblasts for two or three days, 
respectively, failed to induce significant proliferation. Based on these in vitro observations, Jenkins et al. (2011) suggested that the (conflicting) reports of pulmonary fibrosis in workers exposed to fine dusts of alumina, Al pyro powders or bauxite (reviewed in ATSDR 2008) were not due to Al-induced proliferation of fibroblasts.

\section{Hematology and cardiovascular}

Elevated $\mathrm{Al}$ reduces the erythrocyte lifespan and interferes with hemoglobin synthesis; these factors contribute to the microcytic hypochromic anemia that develops after prolonged $\mathrm{Al}$ exposure in patients with compromised kidney function (Lin et al. 1996, Rosenlof et al. 1990, Touam et al. 1983). This Fe—resistant anemia is due to reduced erythrocyte membrane integrity, inhibition of $\delta$-aminolevulinic dehydratase, reduced Fe uptake by Al•transferrin, down-regulation of transferrin receptor expression and impaired intracellular delivery of Fe from transferrin (McGregor et al. 1990, Niemoeller et al. 2006, Rosenlof et al. 1990).

Elshamaa et al. (2010) compared serum $\mathrm{Al}$ in 43 children on chronic renal dialysis (where dialysate $\mathrm{Al}$ was less than $10 \mu \mathrm{g} / \mathrm{L}$ ) to serum $\mathrm{Al}$ in 43 healthy children. The dialysis patients used $\mathrm{Ca}$ acetate or carbonate to control circulating phosphate, and none of these children received Al-containing phosphate binders. Serum Al was significantly higher (18.4 \pm 4.3 $\mu \mathrm{g} / \mathrm{L})$ in renal patients than in healthy referents $(6.5 \pm 1.6 \mu \mathrm{g} / \mathrm{L})$. The source of the elevated serum $\mathrm{Al}$ in these cases appeared to be erythropoietin (EPO).

In a cross-sectional study of whole blood $\mathrm{Al}$ determined in men and women with a history of cardiovascular incidents or diabetes or who had taken diuretics, aspirin, antihyperlipidemics, or "any regular drug", Lind et al. (2011) found a significant non-linear (inverted U-shape) relation between $\mathrm{Al}$ and the prevalence of ultrasound-confirmed atherosclerotic plaques in the carotid artery. This relation remained after adjusting for gender, waist circumference, body mass index, fasting blood glucose, systolic and diastolic blood pressure, HDL and LDL cholesterol, serum triglycerides, smoking, antihypertensives or statins, diabetes mellitus and coronary heart disease. Lind et al. (2011) offered the suggestion that development of carotid plaques might be associated with Al-catalyzed oxidation of low-density lipoproteins.

After male Wistar rats (200-230 g) were given repeated ip injections of $\mathrm{AlCl}_{3}$ at $15 \mathrm{mg} / \mathrm{kg}$ day for ten days, Cheng et al. (2012) found significant reductions in erythrocyte counts, hemoglobin concentrations, mean corpuscular volume, mean corpuscular hemoglobin and hematocrit. These animals also developed increased brain LPO and reduced GST and SOD; however, no mechanistic data were presented to explain the anemia. The Cheng et al. (2012) study is compromised by study of only one exposure level and failure to provide justification for the relatively high $\mathrm{AlCl}_{3}$ dose. Neither the $\mathrm{pH}$ of the test solution, mention of concurrent controls given equimolar injections of HCL, nor necropsy results of the peritoneal cavity were reported. Reductions in erythrocyte counts were also seen after rats consumed 430 $\mathrm{mg} / \mathrm{L} \mathrm{AlCl}{ }_{3}$ in their drinking water for $90-150$ days (Zhang et al. 2011a). Prolonged exposure to this high concentration also reduced body weight gain and the limitations to the Zhang et al. (2011a) report are similar to those for Cheng et al. (2012). 
There are at least two recent publications concerning the influence of elevated $\mathrm{Al}$ on vascular cells. After $0.001-100 \mu \mathrm{g} / \mathrm{ml} \mathrm{Al}_{2} \mathrm{O}_{3}(39.7 \mathrm{~nm}$ ) particles were cultured with human cardiac microvascular endothelial cells for $24 \mathrm{~h}$, there was no evidence for cytotoxicity, ROS generation, increased cell permeability or inflammatory markers (Sun et al. 2011b). Compared to the potent cytolethality of $\mathrm{Cu}, \mathrm{Mg}$, and $\mathrm{Zn}$ oxide nanoforms in vitro, Sun et al. (2011a) attributed the reduced toxicity of this nano $\mathrm{Al}$ oxide to its larger specific surface area. Mikkelsen et al. (2012) compared the toxicity of particulate platelet or 30-75 nm kaolinite $\left(\mathrm{Al}_{2} \mathrm{SiO}_{5}\right)$ interior wall paint dust in cultured human umbilical vein endothelial cells to the toxicity of crystalline $\mathrm{Al}_{2} \mathrm{O}_{3}(20-40$ to $1930 \mathrm{~nm})$. Cytotoxicity was significant only after exposure to the highest concentration $(100 \mu \mathrm{g} / \mathrm{ml})$ of kaolinite. The Mikkelsen results confirm that toxicity depends on the particular Al physical and chemical form.

Of the recent mechanistic reports that by Vota et al. (2012) is one of the more informative. Since high $\mathrm{Al}$ concentrations interfere with heme synthesis and disrupt the EPO receptor (Vittori et al. 2005), fresh human erythrocytes were cultured in $\mathrm{pH} 7.3$ medium at $4^{\circ} \mathrm{C}$ for 21 days (during which time media was refreshed every two days) in the presence of $100 \mu \mathrm{M}$ $\mathrm{AlCl}_{3} \bullet 6 \mathrm{H}_{2} \mathrm{O}$ (equivalent to $11 \mu \mathrm{M} \mathrm{Al}$ or $298 \mu \mathrm{g} \mathrm{Al} / \mathrm{L}$ ). By way of comparison, plasma and serum $\mathrm{Al}$ concentrations in healthy humans range from less than 1.6 to $6 \mu \mathrm{g} / \mathrm{L}$ (median $=3.2$ $\mu \mathrm{g} / \mathrm{L}$ or $0.12 \mu \mathrm{M}$ ) and very high $\mathrm{Al}$ concentrations (to $255 \mu \mathrm{g} / \mathrm{L}$ or $94 \mu \mathrm{M}$ ) occur in seriously ill renal patients (Krewski et al. 2007). These culture conditions increased the numbers of acanthocytes and stomatocytes, but failed to induce hemolysis. These conditions also increased the concentrations of $\mathrm{O}_{2} \bullet^{-}$and $\mathrm{OH} \bullet$ three-fold, increased intracellular $\mathrm{Ca}$ and reduced significantly the intracellular levels of GSH. These changes and the eryptosis were abolished in parallel assays that included $5 \mathrm{mM}$ of the antioxidant thiol $\mathrm{N}$-acetylcysteine. The Vota et al. (2012) results implicate the pro-oxidant properties of $\mathrm{Al}^{+3}$ in its adverse effects on erythrocytes.

\section{Musculoskeletal}

Humans-Gherardi and Authier (2012) presented evidence for Al oxyhydroxide $[\mathrm{AlO}(\mathrm{OH})]$-induced MMF after its use as an adjuvant in French hepatitis and tetanus vaccines. The time that elapsed from vaccination until patient presentations ranged from 0.5 to 84 months with most MMF diagnoses made long after the initial onset of symptoms. One remarkable feature was that although ultrastructual examination of muscle at the injection site confirmed macrophages with agglomerations of submicron/micron $\mathrm{Al}$ inclusions, almost never was muscle pain or tenderness associated with the injection site, but these symptoms occurred either in the legs or were non-specific and diffuse. Gherardi and Authier (2012) suggested that uptake by antigen-presenting cells of nano-size $(\sim 13 \mathrm{~nm}) \mathrm{AlO}(\mathrm{OH})$ particles as submicron aggregates facilitated $\mathrm{Al}$ translocation to organs distant from the muscle via the lymphatics. However, the current literature search found no independent definitive characterization of the proposed MMF or ASIA (autoimmune syndrome induced by adjuvants) (Shoenfeld and Agmon-Levin 2011) condition.

Laboratory animals—del Pilar Martínez et al. (2011) compared $\mathrm{Al}(\mathrm{OH})_{3}$-induced reductions in bone strength in young Sprague-Dawley rats to that caused by reduced atmospheric pressure (hypobaric hypoxia). Two of four groups were given $20 \%$ glycerol as a 
control and two groups were given three ip injections of $27 \mathrm{mg} \mathrm{Al} / \mathrm{kg}$ as $\mathrm{Al}(\mathrm{OH})_{3}$ per week for three months. One Al-treated and one vehicle control group were maintained at sealevel barometric pressure; one Al-treated and one vehicle control group were exposed to simulated hypoxia (506 mbar equivalent to $5484 \mathrm{~m}$ altitude) $18 \mathrm{~h} /$ day for 30 days. Bone $\mathrm{Al}$ increased 14-15x among the $\mathrm{Al}(\mathrm{OH})_{3}$-treated groups compared to the vehicle controls.

Repeated $\mathrm{Al}(\mathrm{OH})_{3}$ injections also reduced the mean hematocrit and increased the percent reticulocytes in both the ambient and hypobaric groups. Hypoxia increased erythropoiesis, hematocrit, and reticulocyte counts. Body weights and femur length and width were reduced with prolonged hypobaric exposures, and the reductions in bone strength (ultimate, elastic load, and elastic energy absorption) after hypoxia were more pronounced than after repeated $\mathrm{Al}$ injections. The effect of combined $\mathrm{Al}$ and simulated high altitude on bone was no greater than hypobaric conditions alone.

$\mathrm{Li}$ et al. (2010) studied $\mathrm{Al}$ ingestion in relation to $\mathrm{Al}$ levels in bone and cartilage in rats. Healthy rats were given drinking water (free access) containing $400 \mathrm{mg} / \mathrm{L} \mathrm{AlCl} 3$ and control rats were given distilled water during 150 days. Ten rats from each group were sacrificed on Days 30, 60, 90,120, and 150 at which times $\mathrm{Al}$ in serum, bone and cartilage was measured. The body weights of the treated rats were significantly less than the controls beginning at Day 60 and the serum, cartilage, and femur $\mathrm{Al}$ concentrations were significantly higher in the Al-treated rats. The $\mathrm{Li}$ et al. (2010) study examined the influence of $\mathrm{Al}$ on bone metabolism during the primary phases of skeletal growth, but failures to justify the single high $\mathrm{AlCl}_{3}$ concentration, report $\mathrm{Al}$ levels in the diet, report the $\mathrm{pH}$ of the drinking water, record drinking water consumption and the absence of precautions to avoid sample contamination by environmental $\mathrm{Al}$ detract from the study. The relatively high serum $\mathrm{Al}$ levels in the control group suggest that external $\mathrm{Al}$ contamination may have occurred or that background serum $\mathrm{Al}$ levels were elevated due to the diet or other factors.

$\mathrm{Li}$ et al. (2011a) examined the influence of drinking water (pH 5.6) containing $100 \mathrm{mg} / \mathrm{L}$ $\mathrm{AlCl}_{3} \cdot 6 \mathrm{H}_{2} \mathrm{O}$ (99\% purity) on bone $\mathrm{Al}, \mathrm{Ca}$, and $\mathrm{P}$ content during growth of young rats. A concurrent control group was given distilled drinking water ( $\mathrm{pH}$ 7.0) for the same 150 days under the same conditions. All rats had free access to water and standard pellet diet (no details regarding the $\mathrm{Al}$ content of the diet or the control drinking water were reported). The body weights of the Al-treated rats were significantly lower than the controls from Day 60 until Day 150. The serum $\mathrm{pH}$ of the Al-treated rats was reduced $(\mathrm{p}<0.05)$ on Day 150. The mean $\mathrm{Al}$ content in femurs was significantly higher than the controls beginning at Day 30 . Bone $\mathrm{Ca}$ and $\mathrm{P}$ concentrations were reduced significantly in the Al-treated group compared to the controls at Day 150. Li et al. (2011a) concluded that long-term ingestion of high Al concentrations in drinking water led to $\mathrm{Al}$ accumulation in bone, inhibition of bone formation, and bone loss in rats.

Li et al. (2011b) then conducted a follow-up investigation on the influence of 150-day consumption of $430 \mathrm{mg} / \mathrm{L} \mathrm{AlCl}_{3}$ in drinking water on $\mathrm{Ca}, \mathrm{P}$, and $\mathrm{Mg}$ during rat bone formation. Ten rats from each group were killed every 30 days and the $\mathrm{Al}$ content in right femurs was measured. The body weights in the Al-treated group were significantly less than the controls from Day 60. The mean $\mathrm{Al}$ content in bone increased significantly compared to the control on Days 30-150 and the $\mathrm{Ca}, \mathrm{Mg}$, and P levels were significantly lower in the Al- 
treated group compared to the controls on Days 120-150. The results were similar to those reported by $\mathrm{Li}$ et al. (2011a) where a $100 \mathrm{mg} / \mathrm{L} \mathrm{AlCl}_{3}$ concentration in drinking water was also associated with reduced bone $\mathrm{Ca}, \mathrm{Mg}$, and $\mathrm{P}$. Li et al. (2011b) suggested that prolonged consumption of $\mathrm{AlCl}_{3}$ in drinking water increased $\mathrm{Al}$ levels in rat bone and inhibited bone mineralization through disruption of trace element metabolic pathways. The major limitations to the Li et al. (2011b) study are similar to those described for the Li et al. (2011a) study.

Hirayama et al. (2011) studied the influence of age on the endogenous or "background" concentrations of $\mathrm{Al}$ in rat femur. Groups of five female Wistar rats were reared from 4 weeks to 113 weeks on a laboratory stock diet and tap water. Elemental Al concentrations in the stock diet and in tap water were $60 \mathrm{mg} / \mathrm{kg}$ and $0.038 \mathrm{mg} / \mathrm{L}$, respectively. Five rats were sacrificed at $5,9,13,17,21,25,33,42,50,59,68,77,85,95,105$, and 113 weeks of age (4 rats at 113 weeks). The mean $\mathrm{Al}$ concentration in bone at 17 weeks was $0.31 \mu \mathrm{g} / \mathrm{g}$ and for all ages the mean was $0.53 \mu \mathrm{g} / \mathrm{g}$. Uptake rates of $\mathrm{Al}$ into bone varied among individual rats and the values were broadly distributed.

Unlike healthy humans where bone $\mathrm{Al}$ increases with age (Hellstrom et al. 2005, Priest 2004), accumulation of Al in rat bone is limited. The Hirayama et al. (2011) data are consistent with those of Slanina et al. (1984) who found little change in the Al content of adult rat bone even after daily oral dosing with $100 \mathrm{mg} \mathrm{Al}(\mathrm{OH})_{3}$ for nine weeks. Very young rats accumulate $\mathrm{Al}$ in bone, but older rats tend to accumulate $\mathrm{Al}$ in their kidneys (Greger and Radzanowski 1995). This response depends on exposure in that rats can accumulate sufficient $\mathrm{Al}$ in bone to elicit osteomalacia after repeated injections of very high $\mathrm{Al}$ doses (Goodman et al. 1984, Robertson et al. 1983).

In vitro-When transparent $\mathrm{Al}$ ceramic $\left(\mathrm{Al}_{23} \mathrm{O}_{27} \mathrm{~N}_{5}\right.$ and $\left.\mathrm{MgAl}_{2} \mathrm{O}_{4}\right)$ discs (99.7-99.8\% pure) were incubated for five days with human fetal osteoblasts, cultures with $\mathrm{MgAl}_{2} \mathrm{O}_{4}$ discs had higher mitotic rates than cells cultured on $\mathrm{Al}_{23} \mathrm{O}_{27} \mathrm{~N}_{5}$ discs. Other than these differences in proliferation there was no evidence of cytotoxicity associated with these $\mathrm{Al}$ ceramics (Bodhak et al. 2011).

\section{Digestive tract}

Lindquist et al. (2011) compared the effects of reduced fat milk (pH 6.6), tap water (pH 7.0), carbonated mineral water $(\mathrm{pH} 7.0)$, gum Arabic and $1.1 \mathrm{~g}$ of a commercial $\mathrm{Al}(\mathrm{OH})_{3}$ gastric antacid tablet on neutralization of $10 \mathrm{ml}$ of dilute $\mathrm{HCl}(\mathrm{pH} 1$ or 2) in the mouths of 11 volunteers ( $33 \pm 9.3$ years). Volunteers used a series of two min oral rinses after each one min $\mathrm{HCl}$ rinse (to mimic the $\mathrm{pH}$ of acid reflux) and the acid: base balance in the mouth was followed for $30 \mathrm{~min}$. There was no mention of irritation or other effects of any of the solutions, but overall the results with $\mathrm{Al}(\mathrm{OH})_{3}$ were consistent with those of Meurman et al. (1988) who found chewing an $\mathrm{Al}(\mathrm{OH})_{3}$ tablet was an effective means to combat dental softening and erosion due to chronic acid regurgitation.

Maghraoui and coworkers (2012) examined $\mathrm{Al}$ deposition in the gastric mucosa of rats. At two $\mathrm{h}$ after a single gastric intubation of $\mathrm{Al}\left(\mathrm{NO}_{3}\right)_{3}$ at $70 \mathrm{mg} / \mathrm{kg}$, $\mathrm{Al}$ was retained in the 
cytoplasm and lysosomes of the mucosal parietal cells similar to that seen in lysosomes of human gastric mucosal cells after ingestion of $\mathrm{Al}(\mathrm{OH})_{3}$ (Florent et al. 1991). There was no suggestion of histologic or ultrastructural damage to the liver or gastric mucosa after ingestion of either $\mathrm{Al}\left(\mathrm{NO}_{3}\right)_{3}$ or $\mathrm{Al}(\mathrm{OH})_{3}$.

\section{Renal}

Patients with compromised kidney function are at increased risk for systemic Al toxicity (Hou et al. 2010, Jenkins et al. 1989, Yokel 2012, 2013). Azik and associates (2011) compared circulating $\mathrm{Al}, \mathrm{P}, \mathrm{Ca}$, and PTH concentrations in six girls and four boys diagnosed with urinary tract disease (reflux nephropathy, glomerulosclerosis, glomerulonephritis, and neurogenic bladder) to those parameters in 12 healthy girls and 8 boys. Of the 10 children who were in kidney disease stages $2-4,3$ were on peritoneal dialysis (mean $=44$ months) and one was on HD (1 month). Mean circulating $\mathrm{Al}(27.2 \mu \mathrm{g} / \mathrm{L})$ was significantly greater in those with renal disease than in the healthy referents $(2.5 \mu \mathrm{g} / \mathrm{L})$. Since PTH increases Al uptake by stimulating synthesis of 1, 25-DHC in the kidney, Azik et al. (2011) gave these children a four-week course of 1, 25-DHC at 15-45 ng/kg-day. Circulating Al declined promptly after dosing with 1,25 -DHC.

Mahieu et al. (2003) examined renal function in relation to histology and oxidative stress in rats given ip injections of $\mathrm{Al}$ lactate thrice/week at $5.7 \mathrm{mg} / \mathrm{kg}$-day over 90 days. These injections failed to influence glomerular filtration or renal clearance. Repeated ip injections reduced GSH and GST and increased LPO in proximal tubule cells. These cells developed toxicity consistent with oxidative damage induced by $\mathrm{Al}^{+3}$ as seen in other studies (Bhaduria 2012, Kaneko et al. 2004, Viezeliene et al. 2011, 2012).

\section{Hepatic}

Signs of systemic $\mathrm{Al}$ intoxication are manifest in skeletal and neurological damage and microcytic anemia, but there are few data to suggest liver disease (e.g., fatty degeneration, apoptosis, necrosis) in humans as a result of either acute or chronic high-dose $\mathrm{Al}$ exposure (ATSDR 2008, Krewski et al. 2007, Willhite et al. 2012). Nevertheless, studies of the liver in Al-treated animals and of hepatocytes in vitro have provided valuable insights into ROS and apoptosis (reviewed in Percy et al. 2011, Mailloux et al. 2011).

\section{Humans}

Gatti et al. (2011) measured Al concentrations in maternal blood and in fetal liver and kidney (characterized as micro- and nano-scale particles) in eight aborted fetuses (21-23 weeks gestation) afflicted with spina bifida. Those concentrations were compared to $\mathrm{Al}$ from eight referent fetuses without defects of the neural tube. Aluminum concentrations in all maternal blood samples were less than the analytical limit of detection (data not shown). Aluminum concentrations were elevated significantly in the malformed fetuses. Routine pathology found no anomalies in the liver or kidney of any of the abortuses. 


\section{Laboratory animals}

Alemmari et al. (2011) studied intravenous $\mathrm{AlCl}_{3}$ at $1.5 \mathrm{mg} / \mathrm{kg}$-day in newborn piglets (1978 $\pm 257 \mathrm{~g}$ ) as a model of neonatal human PN. The dose given to piglets was substantially greater than the mean $\mathrm{Al}(15.2 \pm 8.0 \mu \mathrm{g} / \mathrm{kg}$-day $)$ received by 10 human neonates from PN solutions (Bohrer et al. 2010, Poole et al. 2008). This $1.5 \mathrm{mg} / \mathrm{kg}$-day dose was 750x the maximum $\mathrm{Al}$ recommended for adults ( $2 \mathrm{mg} / \mathrm{kg}$-day) by the ASCN/ASPEN (1991) and it was up to 300x higher than the 4-5 $\mu \mathrm{g} \mathrm{Al} / \mathrm{kg}$-day dose recognized by US FDA (2013) above which $\mathrm{Al}$ accumulates and produces systemic toxicity (Fewtrell et al. 2009, Smith et al. 2007). Groups of four piglets each received $\mathrm{AlCl}_{3}$ for one, two, three or four days or an equivalent volume of saline via an indwelling venous catheter. Although Alemmari et al. (2011) acknowledged the magnitude of their Al exposure compared to humans, the authors based their study design on Klein et al. (1987) who found elevated serum bile acids and increased hepatic lysosomes in piglets subjected to identical doses. Serial timed sacrifice was made and blood, urine, bile, and liver samples were collected in Al-free containers. Serum, urinary, and hepatic Al concentrations increased as duration of exposure increased. There was a direct correlation between total bile acids and urinary Al levels with hepatic $\mathrm{Al}$ concentrations. Transmission electron microscopy confirmed dilated bile caniculi, inflammatory infiltrate and increased numbers of Al-containing hepatic lysosomes.

In discussing these data Alemmari et al. (2012) stated that small-volume parenterals are the main $\mathrm{Al}$ source providing typical infant doses of 10-60 $\mu \mathrm{g} \mathrm{Al} / \mathrm{kg}$-day. The authors noted that more than $80 \%$ of the $\mathrm{Al}$ in infant $\mathrm{PN}$ comes from $\mathrm{Ca}$ gluconate and that if an $\mathrm{Al}$-free $\mathrm{Ca}$ gluconate was to be used daily infant $\mathrm{Al}$ exposures could be reduced $85 \%$. Those estimates were confirmed in Yucatan miniature piglets given an $\mathrm{Al}$-free $98 \%$ pure Ca gluconate PN solution that delivered $6 \mu \mathrm{g} \mathrm{Al} / \mathrm{kg}$-day compared to a standard PN that delivered $38 \mu \mathrm{g}$ $\mathrm{Al} / \mathrm{kg}$-day (Alemmari et al. 2012). Neonatal injury induced by $\mathrm{Al}$ in PN solutions is a multifaceted medical issue (Wier and Kuhn 2012) involving Al-contaminated nutrients (soluble vitamins, lipid emulsions, trace elements, and amino acids) (Popinska et al. 2010), bags, burettes and syringes (de Oliveira et al. 2010), prematurity, duration of exposure, lack of enteral feeding and the need to sterilize PN solutions.

Other reports of Al-associated hepatotoxicity in animals are confounded by selection of the particular Al salt, route of administration and magnitude of the dose. After a single ip injection of $32.5 \mathrm{mg} / \mathrm{kg} \mathrm{Al}\left(\mathrm{NO}_{3}\right)_{3}$, increased serum AlT and AST, reduced hepatic GSH and catalase activities and increased LPO were evident in the liver, kidneys, and brains of adult rats (Bhaduria 2012). In another example, gross necropsy of male gerbils after five day per week ip injections of $10.4 \mu \mathrm{mol} / \mathrm{kg}\left(1.33 \mathrm{~g} / \mathrm{kg}\right.$-day) of $\mathrm{AlCl}_{3}$ found accumulations of "white deposits" on the surface of the liver, kidneys, mesentery and throughout the peritoneum (Garrosa et al. 2011). These accumulations were accompanied by peritoneal irritation, diffuse granulomas, focal hepatocellular degeneration, and periportal inflammation. Garrosa et al. (2011) compared their results to those of Fiejka et al. (1996) who found no signs of peritonitis after repeated 233-265 mg/kg-day ip injections of $\mathrm{Al}(\mathrm{OH})_{3}$ in Pzh:SFIS strain mice. Aluminum chloride is a potent irritant (Krewski et al. 2007) and the development of chronic peritonitis after repeated injections of neat $\mathrm{AlCl}_{3}$ can be attributed to its hydrolysis product $\mathrm{HCl}$ (ATSDR 2008). Garrosa et al. (2011) qualified their experiment in that "the 
particular properties of $\mathrm{AlCl}_{3}$ solution, such as its lower $\mathrm{pH}$, might account for the appearance of peritonitis, adherences and portal inflammation, rather than the intrinsic toxic effect of Al".

Zhu et al. (2013) gave $\mathrm{AlCl}_{3}$ in drinking water to rats at concentrations sufficient to deliver $0,64.18,128.36$, or $256.72 \mathrm{mg} / \mathrm{kg}$-day for 120 days. These exposures resulted in a dosedependent increase in liver $\mathrm{Al}$, reduced body weights, reduced liver: body weight ratios, decreased hepatic microsomal protein and reduced hepatic cytochrome P450 enzymes. As neither drinking water nor food consumption were measured and given that no concurrent controls given equimolar doses of $\mathrm{HCl}$ were included, it is difficult to determine whether the changes were due to the actions of ingested $\mathrm{Al}$ or were consequences of chronic dehydration/inanition associated with avoidance of acidic drinking water.

A number of laboratories identified Al-induced oxidative stress as a major or contributing factor to damage in the liver and other organs (reviewed in Krewski et al. 2007). In a series of studies by Viezeliene et al. $(2011,2012)$ concerning potential amelioration of $\mathrm{Al}-$ induced liver damage by selenite, BALB/C mice were given ip injections of $25 \mathrm{mg} / \mathrm{kg} \mathrm{AlCl}$ and $1.25 \mathrm{mg} / \mathrm{kg} \mathrm{Na}_{2} \mathrm{SeO}_{3}$; selenite injection was made $20 \mathrm{~min}$ prior to administration of $\mathrm{AlCl}_{3}$. At 16-h post-injection there was an increase in hepatic protein synthesis and serum ALT, but $\mathrm{Na}_{2} \mathrm{SeO}_{3}$ injection alone had no influence on ALT. When $\mathrm{Na}_{2} \mathrm{SeO}_{3}$ was given prior to $\mathrm{AlCl}_{3}$ serum ALT was no different from that after $\mathrm{AlCl}_{3}$ alone. Hepatic GSH was reduced significantly after $\mathrm{AlCl}_{3}$, but when selenite was given prior to $\mathrm{AlCl}_{3}$ the levels of oxidized glutathione (GSSG) and GSH in the liver were no different from the controls. Thus, parenteral $\mathrm{Al}$ reduced both hepatic GSH and the GSH/GSSG ratio. The authors interpreted these changes as indicative of $\mathrm{Al}$-induced oxidative stress in mouse hepatocytes secondary to $\mathrm{Al}$ disruption of hepatocyte membranes and/or interference with $\mathrm{PO}_{4}$ and ATP generation. Limitations to the Viezeliene et al. $(2011,2012)$ reports include the absence of doseresponse descriptions and measures of $\mathrm{Al}$ and $\mathrm{Se}$ in blood or liver.

These observations of Al-induced oxidative stress were consistent with those made in liver (El-Demerdash 2004, González et al. 2007, Yousef 2004), testes (Guo et al. 2009), kidney (Kaneko et al. 2004), and brain (Chakrabarty et al. 2012, Gómez et al. 2005, Kaiser et al. 2005, Kumar et al. 2009a, 2009b, Savory et al. 1999). Mechanistic studies with ip $\mathrm{AlCl}_{3}$ have also been conducted in adult male CF-1 mice by El-Sayed et al. (2011) and in BALB/c and C57BL/6 mice by Shati et al. (2011). Among mice given a single $25 \mathrm{mg} / \mathrm{kg}$ injection, there was a significant increase in serum ALT and TNF-a at $24 \mathrm{~h}$; hepatic MDA and reduced catalase, GST, GPx and NADPH-quinone oxidoreductase were increased compared to saline controls. However, there was no change in overall hepatic glutathione levels. Pretreatment of identical mice with taurine at $100 \mathrm{mg} / \mathrm{kg}$-day for five days abolished the reductions in hepatic catalase, GST and GPx and the authors speculated taurine acted by scavenging free radicals to prevent lipid peroxidation. The observations by Shati et al. (2010) are consistent with El-Sayed et al. (2011) in that repeated ip injection of $\mathrm{AlCl}_{3}$ in saline (pH 6.8) at 40 $\mathrm{mg} / \mathrm{kg}$-day for 45 days increased serum ALT, AST, and bilirubin in both mouse strains. The liver damage was consistent with increased hepatic LPO and increased circulating triglycerides and total cholesterol. 
In keeping with the Al metabolic disruptions articulated by Mailloux et al. (2011), Bhasin et al. (2012) examined the influence of supplemental $\mathrm{Zn}$ (given as $\mathrm{ZnSO}_{4}$ ) on $\mathrm{AlCl}_{3}$-induced hepatotoxicity in rats. Controls were given tap water ad libitum for 2 months; a second group was given $\mathrm{AlCl}_{3}$ by oral gavage at $100 \mathrm{mg} / \mathrm{kg}$-day; a third group was given drinking water sufficient to provide 1-2 $\mathrm{mg} \mathrm{Zn/kg-day} \mathrm{and} \mathrm{a} \mathrm{fourth} \mathrm{group} \mathrm{was} \mathrm{given} \mathrm{Zn}$ along with $\mathrm{AlCl}_{3}$. Histologic study of the $\mathrm{AlCl}_{3}$-treated rats found increased vacuolization of hepatocytes. Gavage with $\mathrm{AlCl}_{3}$ increased cytosolic ALT and AST and reduced hepatic catalase and GST. Supplemental Zn restored catalase and GST activity to control levels. Catalase contains four porphyrin heme $\left(\mathrm{Fe}^{+3}\right)$ groups and Bhasin et al. (2012) suggested (consistent with Mailloux et al. 2011) that the reduced catalase may be due to Al substitution for $\mathrm{Fe}$ or that $\mathrm{Zn}$ induction of metallothionine acted as a free radical scavenger. However, no kinetic or other mechanistic studies on Al inhibition of catalase or GST were included, and no data on hepatic $\mathrm{Al}$ or $\mathrm{Zn}$ concentrations were provided.

\section{Development and reproduction}

Humans-The hazards associated with excessive $\mathrm{Al}$ in neonates and young children are well known (Bozynski et al. 1989, Chedid et al. 1991, Crisponi et al. 2011, Freundlich et al. 1985, 1986, 1990, IPCS 1997, Klein 1995, Klein et al. 1982, Klein and Coburn 1994).

Historical $\mathrm{Al}$ concentrations in commercial PN solutions ranged from less than 50 to as high as $300 \mu \mathrm{g} / \mathrm{L}$, but those levels declined over time (Arnold et al. 2003) primarily as a result of substitution of crystalline amino acids for casein hydrolysate. Calcium gluconate continues to be a source of Al contamination in PN solutions (Koo et al. 1986, Hernández-Sández et al. 2013), but elevated $\mathrm{Al}$ is also due to contamined inorganic $\mathrm{PO}_{4}$ and cysteine $\mathrm{HCl}$ (Hernández-Sández et al. 2013) and it leaches from glass containers during storage and autoclaving (Poole et al. 2011). Beaney and Smeaton (2010) reported 4925-6160 $\mu \mathrm{g} \mathrm{Al} / \mathrm{L}$ in commercial $10 \%$ Ca gluconate packaged in glass ampules for compounding PN injections compared to $30-33 \mu \mathrm{g} \mathrm{Al} / \mathrm{L}$ when packaged in plastic.

Patients who receive repeated intravenous doses sufficient to supply higher than 4-5 $\mu \mathrm{g}$ $\mathrm{Al} / \mathrm{kg}$-day can accumulate sufficient body $\mathrm{Al}$ burdens so as to elicit encephalopathy, impaired neurologic development, and osteomalacia (Bates et al. 1985, Bishop et al. 1997, Klein 1995, Klein et al. 1991). Popinska et al. (2010) examined 24 patients on chronic PN (2-14.7 years) and found their $\mathrm{Al}$ intake was $5.8-29.6 \mu \mathrm{g} / \mathrm{kg}$-day. United States regulations [21 CFR 201.323] intended to control Al concentrations in large volume parenterals (25 $\mu \mathrm{g} / \mathrm{L}$ ) were issued years ago (US FDA 1998, 2003), but there is currently no limit on the Al content of pharmacy bulk packages or small volume parenterals (US FDA 2013). Excessive iatrogenic $\mathrm{Al}$ exposure among neonates continues (Bishop et al. 1997, Bohrer et al. 2010, Fewtrell et al. 2009, 2011, Poole et al. 2008, 2011). Poole and associates (2008) examined records for 13,384 in-patient days for premature neonates, children with reduced renal function and children on prolonged PN. Using the Al content printed on the manufacturer's labels for PN constituents, Poole et al. (2008) calculated daily exposures for those with body weights less than $3 \mathrm{~kg}$ (who represented nearly $50 \%$ of all patients) at 30-60 $\mu \mathrm{g} \mathrm{Al} / \mathrm{kg}$-day or 6-12x the recommended maximum $5 \mu \mathrm{g} \mathrm{Al} / \mathrm{kg}$-day. Compliance with the recommended maximum $\mathrm{Al}$ dose using standard PN solutions could be realized only in older children with body weights more than $50 \mathrm{~kg}$. Poole et al. (2010) then compared empirical Al 
concentrations in 40 different PN solutions and 16 different components used to formulate those products to the US FDA $25 \mu \mathrm{g} / \mathrm{L}$ limit on $\mathrm{Al}$ for large-volume parenterals. Using patient body weights to calculate daily $\mathrm{Al}$ exposure, the highest dose ( $23 \mu \mathrm{g} \mathrm{Al} / \mathrm{kg}$-day) was received by the smallest infants ( $\leq 1 \mathrm{~kg}$ ). After comparing the $\mathrm{Al}$ content in PN solutions, the daily Al dose was 3-5x the US FDA (2013) maximum. Investigation of constituents used to formulate the PN solution found that $\mathrm{Ca}$ gluconate and the $\mathrm{K}$ and Na phosphates accounted for the majority of the $\mathrm{Al}$ present in hospital pharmacy-formulated PN solutions.

In a similar effort, Bohrer et al. (2010) studied 10 preterm hospitalized infants who received total PN over 5-10 days. The mean total Al dose given by infusion was $186 \pm 106 \mu \mathrm{g}(15 \pm 8$ $\mu \mathrm{g} / \mathrm{kg}$-day; range: $5-27 \mu \mathrm{g} / \mathrm{kg}$-day). Only two of ten patients received $\mathrm{Al}$ at less than 5 $\mu \mathrm{g} / \mathrm{kg}$-day. Although the study was restricted to a small number of premature babies (32-36 weeks gestation), the daily $\mathrm{Al}$ exposure was such that a majority received thrice the maximum tolerable dose.

Fewtrell et al. (2009) followed the long-term consequences of $\mathrm{Al}$ exposure on bone in young people. Among 59 adolescents, 26 had received neonatal PN that provided $45 \mu \mathrm{g} \mathrm{Al} / \mathrm{kg}$-day and 33 were given 4.0-4.5 $\mu \mathrm{g} \mathrm{Al} / \mathrm{kg}$-day. The origin of the elevated $\mathrm{Al}$ in these solutions was traced to $\mathrm{Al}$ leachate from glass bottles used to store $\mathrm{Ca}$ gluconate. Children afflicted with neurologic conditions or who had a prior Bailey score less than 85 were excluded from the study. Participants were matched for birth weights, gestation, and duration of intravenous nutrition. Dual-energy radiograph absorptiometry was used to measure bone mineral content (BMC), bone area (BA), and bone mineral density at the lumbar spine (LS), hips, and WB. Total neonatal Al exposure, as a continuous and categorical variable $(<55 \mu \mathrm{g} / \mathrm{kg}$ vs. $>55 \mu \mathrm{g} /$ $\mathrm{kg}$ ), was examined in relation with adolescent bone mass after adjusting for potential confounders including duration of PN and severity of neonatal illness.

Mean Al intake was significantly higher for those given the standard PN solution as compared with those given PN with low Al. The bone density measurements tended to be higher in the low $\mathrm{Al}$ group, but significant differences were observed only for BMC and BA at the LS (44.9 vs. $39.8 \mathrm{~g}$ and 40.5 vs. $37.8 \mathrm{~cm}^{2}$, respectively). The increase in LS BMC may be attributable to increased bone size in the low $\mathrm{Al}$ group, as no difference between the groups in LS BMC was seen after adjusting for height, weight, and LS BA.

After adjusting for relevant neonatal variables in a nonrandomized analysis, total $\mathrm{Al}$ exposure as a continuous variable was not a significant predictor of adjusted BMC at any site. When $\mathrm{Al}$ exposure was categorized using the median $(55 \mu \mathrm{g} / \mathrm{kg})$ as a cut-off, children with high exposure had significantly lower (7.6\%) hip BMC. Children who experienced higher $\mathrm{Al}$ exposure as neonates had significantly reduced lower hip BMC than children whose neonatal $\mathrm{Al}$ exposures were some ten-fold lower.

Fewtrell et al. (2011) expanded the presentation and explained the results from Bishop et al. (1997) wherein 227 premature (gestational age < 34 weeks) infants who received either standard PN $(25 \mu \mathrm{g} \mathrm{Al} / \mathrm{dl})$ or reduced $\mathrm{Al}(2.2 \mu \mathrm{g} / \mathrm{dl}) \mathrm{PN}$ (equivalent to daily $\mathrm{Al}$ of $19 \pm 8$ or 3 $\pm 1 \mu \mathrm{g} / \mathrm{kg}$-day) beginning at postnatal day 2 or 3 that continued for a median 10 days. There were marked individual variations in the daily $\mathrm{Al}$ dose. For 157 of these infants (with no 
signs of neuromotor delay at 18 months), their $\mathrm{Al}$ doses were associated with a one point per day decline on the Bayley Mental Development Index. Those declines were considered materially significant and children exposed to elevated $\mathrm{Al}$ in PN solutions were at increased risk for cognitive problems and educational difficulties. Of the 59 adolescents followed at 15 years of age, no consistent differences in academic achievement, memory, intelligence and ability to solve complex problems (e.g., planning and organizational behavior) could be detected. Fewtrell et al. (2011) noted the main limitation to their conclusion was the small number of children available for assessment.

Zeager and associates (2012) surveyed 23 clinical laboratories in the United States that measure $\mathrm{Al}$ in serum and urine and found these facilities use different criteria. The reference ("background") concentrations used to compare different patients depended on whether the laboratory used atomic absorption or ICP-MS. When Zeager et al. (2012) attempted to align biological monitoring data with Al-induced pathology, they concluded "there is currently a lack of data to support a correlation between $\mathrm{Al}$ exposure doses, $\mathrm{Al}$ levels measured in biological samples and adverse clinical outcomes". Krewski et al. (2007) described time lines for $\mathrm{Al}$ measures in plasma, serum and urine from non-exposed healthy individuals and in people who consume $\mathrm{Al}$ antacids, in people given $\mathrm{PN}$ and in occupational cohorts. Plasma collected from volunteers with no known $\mathrm{Al}$ exposure generally contains $\leq 2.7 \mu \mathrm{g} / \mathrm{L}$ (with an upper normal limit of $\sim 6 \mu \mathrm{g} / \mathrm{L}$ ), serum generally contains up to approximately $3 \mu \mathrm{g} / \mathrm{L}$ and urine generally contains approximately $1-9 \mu \mathrm{g} / \mathrm{L}$. The Zeager et al. (2012) conclusion is not consistent with others who have used blood and urinary Al to monitor HD patients (Pei et al. 1992, 1995), Al welders and other industrial workers (DFG 2007, Riihimaki et al. 2008, Riihimaki and Aitio 2012).

Two studies (Yu and Zhang 2011, Huang et al. 2011) were identified that examined associations between environmental $\mathrm{Al}$ exposures and the risk of neural tube defects (NTDs). Yu and Zhang (2011) collected samples of soil, water, and food from an area with elevated congenital defects (study area) and from an area with lower rates. Regression analyses revealed a significant correlation between lower Al levels in surface and groundwater and elevated rates of certain birth defects. Huang et al. (2011) examined associations between $\mathrm{Al}$ in soil and NTD risk in an area that had the highest prevalence of NTDs in China. Aluminum concentrations were measured in soil from 112 villages and those values were matched with village records of birth defects. The association between NTDs and soil Al levels was evaluated using the maximum likelihood method. Huang et al. (2011) concluded that higher Al concentrations in soil were associated with increased NTD risk. However, no actual $\mathrm{Al}$ exposure data were presented and no efforts were made to quantify maternal folate status (Bower et al. 1993, Czeizel and Dudas 1992) or related genetic factors (e.g., defects in the gene for 5, 10-methylenetetrahydrofolate reductase, folate receptor-a) (Finnell et al. 1998, Ou et al. 1996, van der Put et al. 1995, Whitehead et al. 1995). Nevertheless, based on the results of controlled intervention studies (Czeizel and Dudas 1992, Wald 1993), Oakley $(1993,2002)$ concluded that up to $60 \%$ of all NTDs in China could be reduced with supplemental dietary folate. Given these deficiencies, the results of the Huang et al. (2011) study are not considered reliable. 
Bell et al. (2010) conducted a county-wide ecological study wherein ambient air particulate matter $\left(\mathrm{PM}_{2.5}\right)$ exposures were calculated for mothers of 76,788 Connecticut and Massachusetts infants on a per week basis. The weekly exposures were extrapolated to total particulate exposure by trimester. The mothers were primarily Caucasian, married and had a mean age of 29.3 years; tobacco was used by not more than $13 \%$ and ethanol was used by not more than $1.8 \%$ of the mothers. Relative $\mathrm{PM}_{2.5}$ as $\mathrm{Al}$ was associated primarily with roadway dust, but the dust also contained $\mathrm{Si}, \mathrm{Ca}, \mathrm{Fe}, \mathrm{Mn}$, and Ti whereas regional ambient air $\mathrm{PM}_{2.5}$ also contained $\mathrm{Na}, \mathrm{S}, \mathrm{V}, \mathrm{Ni}$ and chloride (due apparently to road salt). Linear regression was used to relate birth weight to $\mathrm{PM}_{2.5}$ total mass, sources and constituents and the results were presented as change in birth weight (grams) and increased risk of small-atterm birth per quartile range (IQR) by source, PM 2.5 and constituent. The mean ambient air Al concentration $\left(0.042 \pm 0.02 \mu \mathrm{g} / \mathrm{m}^{3}\right)$ corresponded to an IQR of $0.03\left(\mu \mathrm{g} / \mathrm{m}^{3}\right)$ and this was associated with an $11 \%$ increased risk (3-20\%; 95\% CI) for low birth weight. Strengths of the Bell et al. (2010) study stem from the large numbers of births and adjusting for gestational length, infant gender, prenatal care, maternal age, ethnicity, education, and tobacco and ethanol consumption during pregnancy. However, the protocol did not account for other constituents in ambient air (e.g., $\mathrm{CO}, \mathrm{NO}, \mathrm{NO}_{2}, \mathrm{NOx}$, elemental carbon, and $\mathrm{PM}_{2.5}$ from motor vehicle exhaust) or for maternal conditions (e.g., low pre-pregnancy weight, anemia, antibiotics, cardiovascular disease, multiple offspring, and low socioeconomic status) that are associated with low birth weight (Wilhelm et al. 2012, Yu et al. 2013). Moreover, the chemical form of $\mathrm{Al}$ in the airborne dust was not identified and no personal sampling was conducted. Given the mixed exposures it is not possible to conclude that one or another individual constituent in roadway dust was responsible for the results.

Giaccio et al. (2011) measured semen volume, $\mathrm{pH}$, sperm concentrations, sperm motility, total sperm counts, and sperm $\mathrm{Al}$ for 600 infertile men. No mention was made concerning tobacco and ethanol use among the subjects. There was no correlation between soil $\mathrm{Al}$ and reduced fertility among these men.

Laboratory animals-The reproductive and developmental toxicity of $\mathrm{Al}$ was examined by Hirata-Koizumi et al. (2011a) in a two-generation study with $\mathrm{Al}_{2}\left(\mathrm{SO}_{4}\right)_{3}(98.5 \%)$ administered to $\mathrm{Crl}: \mathrm{CD}(\mathrm{SD})$ rats. A preliminary range-finding study was conducted with drinking water containing $0,1000,3000,10,000$, and 30,000 $\mathrm{mg} \mathrm{Al}_{2}\left(\mathrm{SO}_{4}\right)_{3} / \mathrm{L}$. Males were dosed for 7 weeks, beginning 14 days before mating, and females were dosed for 6-8 weeks beginning 14 days before mating and until PND 4. Administration of $\mathrm{Al}_{2}\left(\mathrm{SO}_{4}\right)_{3}$ reduced water consumption, reduced body weight gain and reduced food consumption at concentrations $3000 \mathrm{mg} / \mathrm{L}$ or higher. Among litters from dams given 10,000 mg/L Al $2\left(\mathrm{SO}_{4}\right)_{3}$ or higher there was a significant reduction in pup body weights on PND 4. The rats given $30,000 \mathrm{mg} / \mathrm{L}$ were euthanized within 2 weeks of initial exposure due to dehydration and marked reductions in body weight. Macroscopic examination found thickening of the limiting ridge in the stomach and atrophy of the thymus and spleen in rats given 10,000 $\mathrm{mg} / \mathrm{L}$. The relative liver, thymus, and spleen weights were reduced in females given 3000 or $10,000 \mathrm{mg} / \mathrm{L}$.

Based on the preliminary results, the concentrations of $\mathrm{Al}_{2}\left(\mathrm{SO}_{4}\right)_{3}$ selected for the main study were $0,120,600$, and $3000 \mathrm{mg} / \mathrm{L}$ (equivalent to total $\mathrm{Al}$ daily doses from food and 
water of $1.62-2.35,2.96-4.72,8.06-14.0$ and $31.2-55.6 \mathrm{mg} \mathrm{Al} / \mathrm{kg}$-day). The $\mathrm{pH}$ of the drinking water was 3.57-4.20. Twenty-four animals per sex and group (F0 generation) were given $\mathrm{Al}_{2}\left(\mathrm{SO}_{4}\right)_{3}$ in deionized drinking water beginning at 5 weeks of age for 10 weeks until mating, during mating, throughout gestation and lactation. The control animals received only deionized water under the same conditions. Drinking water provided to the F1 offspring contained the identical $\mathrm{Al}_{2}\left(\mathrm{SO}_{4}\right)_{3}$ concentrations as those of their parents. Endpoints included clinical signs, drinking water and food consumption, and body weights. Parameters recorded at parturition included the number of live and dead offspring, sex ratio and the numbers and types of gross malformations. The F1 and F2 pups were observed daily for clinical signs of toxicity, and the body weights of live pups were recorded. Developmental parameters included sex ratios, neonatal body weights, pinna unfolding, anogenital distance (AGD), incisor eruption, eye opening, surface righting reflex, negative geotaxis and mid-air righting reflex. In the F1 pups selected as parents, the males were observed for timing of preputial separation and the females were observed for timing of vaginal opening.

Spontaneous locomotor activity was assessed at four weeks of age and at six weeks of age a water-filled multiple T-maze test was administered.

Reproductive success was evaluated based on copulation index (\%), percentage of motile and progressively motile sperm, sperm swimming speed and pattern, sperm counts per gram epididymal tissue, the percentage of morphologically abnormal sperm, precoital interval, fertility index, gestation index, gestation length, delivery index, estrous cycle numbers of litters and numbers of pups. There were no clinical signs, but drinking water consumption was reduced significantly in all treated groups. Body weights and food consumption of the F0 males and females given $3000 \mathrm{mg} / \mathrm{L}$ were reduced significantly during the first few weeks of the study. No treatment-related changes were observed in the numbers of litters, numbers of pups delivered, sex ratios or viability on PND 0, 4, and 21. Gross examination found no differences in the incidence of malformations in either the F1 or F2 generations.

There were no significant treatment-related effects on age at completion of pinna unfolding, age at incisor eruption, eye opening, or AGD in the F1 and F2 male pups and in the F1 female pups. In the female F2 pups, the completion time of pinna unfolding on PND 2 was delayed in those given $600 \mathrm{mg} / \mathrm{L}$. There were no treatment-related differences in the time to F1 preputial separation and there were no significant differences in righting reflex (PND 5), negative geotaxis reflex (PND 8), or mid-air righting reflex (PND 18). In the F1 females vaginal opening was delayed in those given $3000 \mathrm{mg} / \mathrm{L}$ ( $31.4 \pm 1.7$ days vs. $29.5 \pm 2.1$ days in the concurrent controls). At the time of vaginal opening, the body weight "was slightly heavier than the control" $(119.0 \pm 13.3 \mathrm{~g}$ vs. $109.6 \pm 11.6 \mathrm{~g})$ in the $3000 \mathrm{mg} / \mathrm{L}$ group. No significant differences were observed in male and female F1 rats regarding spontaneous locomotor activity or in their performance on the water-filled T-maze test.

Ingestion of $\mathrm{Al}_{2}\left(\mathrm{SO}_{4}\right)_{3}$ failed to influence the oestrus cycle in either the $\mathrm{F} 0$ or $\mathrm{F} 1$ generation. Following the F0/F1 or F1/F2 matings there were no significant differences in copulation, fertility index, gestation index, precoital interval, gestation length, numbers of implantations, pups delivered or delivery index (i.e., number of pups/number of implantations). There were no significant differences regarding sperm parameters with the exception of a reduction in the absolute number of sperm in the F0 males given $3000 \mathrm{mg} / \mathrm{L}$, but this change was not 
significant when expressed as per gram of tissue. Necropsy of the F0 and F1 parents found no treatment-related lesions or alterations in the reproductive organs. The results provide no evidence for adverse effects of daily $\mathrm{Al}_{2}\left(\mathrm{SO}_{4}\right)_{3}$ ingestion on ovarian or testicular function in $\mathrm{Crl}: \mathrm{CD}(\mathrm{SD})$ rats.

Despite the lower relative liver and spleen weights in the F1 males, examination of the F1 and F2 weanlings showed no treatment-related histopathology in the liver or spleen. The primary changes observed in rats consuming $3000 \mathrm{mg} / \mathrm{L} \mathrm{Al} 2\left(\mathrm{SO}_{4}\right)_{3}$ were the reductions in pup body weight on PND21 (F1 males and females and F2 females) and a slight delay in vaginal opening (F1 females). However, interpretation of developmental landmarks is difficult due to treatment-related reductions in drinking water and food consumption. HirataKoizumi et al. (2011a) found it was not possible to separate the effects of the reduced drinking water consumption and dehydration from the possible influence of $\mathrm{Al}$ on offspring body weight. Hirata-Koizumi et al. (2011a) assigned a conservative LOAEL for parental systemic toxicity and reproductive/developmental toxicity of $3000 \mathrm{mg} / \mathrm{L}(31.2 \mathrm{mg} \mathrm{Al} / \mathrm{kg}$ bw/day or $188 \mathrm{mg} \mathrm{Al} 2\left(\mathrm{SO}_{4}\right)_{3} / \mathrm{kg}$ bw/day) and identified a NOAEL of $600 \mathrm{mg} / \mathrm{L}(8.06 \mathrm{mg}$ $\mathrm{Al} / \mathrm{kg}$ bw/day or $41.0 \mathrm{mg} \mathrm{Al}{ }_{2}\left(\mathrm{SO}_{4}\right)_{3} / \mathrm{kg}$ bw/day. Grip strength was not measured, precluding comparisons with previous studies that found significant alterations in forelimb and hindlimb grip strength in rodents born to Al-treated dams (reviewed in ATSDR 2008).

The reproductive and developmental toxicity of ingested $\mathrm{Al}$ was also examined by HirataKoizumi et al. (2011b) in a two-generation reproductive toxicity study of $\mathrm{Al}$ ammonium sulfate $\left[\mathrm{NH}_{4} \mathrm{Al}\left(\mathrm{SO}_{4}\right)_{2}, 99.5 \%\right]$ administered to $\mathrm{Crl}: \mathrm{CD}(\mathrm{SD})$ rats in drinking water. The study design complied with OECD TG 416. A preliminary range finding study was conducted with deionized drinking water containing $\mathrm{NH}_{4} \mathrm{Al}\left(\mathrm{SO}_{4}\right)_{2}$ (AAS) at $0,300,1000,3000$, or $10,000 \mathrm{mg} / \mathrm{L}$. Administration of AAS reduced water consumption in all groups and at concentrations $3000 \mathrm{mg} / \mathrm{L}$ or higher water avoidance was associated with reduced body weights. Gross necropsy found thickening of the gastric limiting ridge at $10,000 \mathrm{mg} / \mathrm{L}$, but there were no changes in any reproductive or developmental parameter. Based on the results of the preliminary study, the AAS concentrations for the definitive study were $0,50,500$, and $5000 \mathrm{mg} / \mathrm{L}$ (equivalent to total $\mathrm{Al}$ daily doses from food and water of 1.56-2.39, 1.98$3.10,5.35-9.36$, and 36.3-61.1 $\mathrm{mg} \mathrm{Al} / \mathrm{kg}$-day). The $\mathrm{pH}$ of the drinking water was not specified. The study design and parameters measured were the same as those described for Hirata-Koizumi et al. (2011a).

No treatment-related deaths or clinical signs of toxicity were observed. Water consumption among treated rats was reduced in males and females of both generations in a concentrationdependent manner. In the F1 males and females given $5000 \mathrm{mg} / \mathrm{L}$, body weights were reduced during the first 1-2 weeks of treatment. Food consumption was reduced among the F0 females of the 500 and $5000 \mathrm{mg} / \mathrm{L}$ groups during the first week of treatment and during the second and third weeks of lactation in both F0 and F1 dams given $5000 \mathrm{mg} / \mathrm{L}$.

There were no treatment-related differences in the numbers of implantations, delivery index, incidence of malformations, sex ratio, or viability index. No gross abnormalities were found and there were no differences in birth weights. Reduced body weights were noted among the F1 offspring at $5000 \mathrm{mg} / \mathrm{L}$, but no such change was seen at the lower concentrations. There 
were no treatment-related effects on pinna unfolding, incisor eruption, eye opening, or AGD. There were no differences in age at preputial separation, but a significant delay in vaginal opening was evident in the $\mathrm{F} 1$ females given $5000 \mathrm{mg} / \mathrm{L}$ ( $32.3 \pm 1.8$ days vs. $30.2 \pm 2.1$ days in controls). There were no changes in estrous cyclicity or weight or histology of the weanling and adult reproductive organs among rats given $5000 \mathrm{mg} / \mathrm{L}$. There were no significant differences in surface righting response times or negative geotaxis reflex. There were no consistent differences in behavioral parameters by gender, generation, or dose. No treatment-related changes were detected on the water-filled T-maze or in spontaneous locomotor activity.

No treatment-related gross lesions were found. Changes in body weights and in absolute and/or relative seminal vesicle, epididymis, testis, ovary, uterus, kidney, adrenal, liver, thymus, brain and pituitary weights were observed at 500 and $5000 \mathrm{mg} / \mathrm{L}$, but there were no dose-response relations. Hirata-Koizumi et al. (2011b) considered these findings secondary to the reduced body weights and attributed the reductions in growth and development of the offspring to "the astringent taste of AAS which would decrease the palatability of drinking water in the AAS-treated groups". There were no treatment-related histologic changes in the male or female reproductive organs.

Hirata-Koizumi et al. (2011b) identified a LOAEL of $5000 \mathrm{mg} / \mathrm{L}$ for AAS-induced parental toxicity and developmental toxicity based on the reduced body weight gains and delayed sexual development in the F1 females. The LOAEL corresponds to $305 \mathrm{mg}$ $\mathrm{NH}_{4} \mathrm{Al}\left(\mathrm{SO}_{4}\right)_{2} / \mathrm{kg}$-day or $36.3 \mathrm{mg} \mathrm{Al} / \mathrm{kg}$-day. The NOAEL corresponds to $33.5 \mathrm{mg}$ $\mathrm{NH}_{4} \mathrm{Al}\left(\mathrm{SO}_{4}\right)_{2} / \mathrm{kg}$-day or $5.35 \mathrm{mg} \mathrm{Al} / \mathrm{kg}$ bw per day. However, due to the clear treatmentrelated reductions in drinking water consumption taken together with the decreased food consumption by the F0 and F1 dams during the later stages of lactation, it is difficult to determine whether reduced growth was a direct effect of $\mathrm{Al}$ or whether reduced growth was due to dehydration, inanition, and/or decreased nursing by dehydrated dams. The strengths and limitations of the Hirata-Koizumi et al. (2011b) study are similar to those noted for Hirata-Koizumi et al. (2011a). Grip strength was not measured in this study, which limits comparison of the results with other studies that reported changes in neuromuscular parameters (ATSDR 2008).

Poirier et al. (2011) conducted a combined developmental toxicity/chronic toxicity study with Al citrate in deionized drinking water (pH 6-7) administered to Sprague-Dawley rats using a design based on OECD TG 426. Doses were selected based on the results of a 90day pilot drinking water study and the highest concentration was based on the maximum solubility of $\mathrm{Al}$ citrate in water. The study design included groups given deionized water, $\mathrm{Na}$ citrate in deionized water or $\mathrm{Al}$ citrate (equivalent to 30, 100, or $300 \mathrm{mg} \mathrm{Al} / \mathrm{kg}$-day). Fresh solutions were prepared each week and the $\mathrm{Al}$ concentrations in water were verified by independent ICP-MS. The study covered continuous exposure from 6 days post-conception until one year after birth. Behavioral endpoints (motor activity, T-maze, auditory startle, a FOB targeting autonomic, and sensimotor function and physical activity, neuromuscular and physiological function and cognition as measured on the Morris swim maze), brain weights, clinical chemistry, hematology, neuropathology, and Al concentrations in blood, liver, femur, brain cortex, cerebellum, brainstem, and cervical and thoracic spinal cord were measured. 
Whole blood $\mathrm{Al}$ concentrations in the water controls, the Na citrate controls and the lowdose $\mathrm{Al}$ citrate males and females were similar. By Day 23 of Al citrate exposure the highest $\mathrm{Al}$ concentration was present in whole blood $(800 \mu \mathrm{g} / \mathrm{ml})$ and $\mathrm{Al}$ concentrations declined as blood $>$ brainstem $>$ femur $\sim$ thoracic and cervical spinal cord $>$ cerebellum $>$ liver $>$ cerebral cortex. The high-dose Al citrate rats developed a low-grade microcytic anemia (reduced hematocrit, mean cell hemoglobin, and mean cell volume) and elevated serum alkaline phosphatase. The most notable observation was hydronephrosis. Several animals developed distended abdomens, only to become hypothermic and die (due to apparent hyperkalemia). Morbidity was elevated among the high-dose Al citrate males and the survivors were euthanized on study day 98 .

Body weights of Na citrate-treated male and female offspring were depressed compared to the low- and mid-dose $\mathrm{Al}$ citrate groups; pup development (measured as time to vaginal opening and preputial separation) was delayed in the Na citrate-treated group compared to those given deionized drinking water, but the developmental delay was longer in those given the highest $\mathrm{Al}$ citrate concentration. Treatment of identical rats with $\mathrm{Na}$ citrate alone reduced pre-weaning body weights in both sexes and there were consistent reductions in postweaning body weights among the female pups. Poirier et al. (2011) considered the delayed sexual development treatment-related, but whether the effect was secondary to growth retardation as evidenced by reduced body weight is not clear. Drinking water consumption was greater among those given $\mathrm{Na}$ citrate alone, but this could be due to the elevated $\mathrm{Na}$ content of the drinking water as contrast to the citrate concentration since circulating $\mathrm{Na}$ was elevated.

The highest dose ( $300 \mathrm{mg} / \mathrm{kg}$-day) exceeded the maximum tolerated dose in that at PND 84 pup mean body weights were $30 \%$ less than control. At $100 \mathrm{mg} / \mathrm{kg}$-day, Poirier et al. (2011) found no adverse effects of ingested $\mathrm{Al}$ citrate on memory or learning, but stated that neuromuscular functions (hind limb grip strength and foot splay) were impaired in the midand high-dose $\mathrm{Al}$ citrate groups. There was no significant difference in any FOB parameter for neonatal males or females. Poririer et al. (2011) assigned a LOAEL of $100 \mathrm{mg} \mathrm{Al} / \mathrm{kg}$-day and a NOAEL of $30 \mathrm{mg} \mathrm{Al} / \mathrm{kg}$-day based on deficits in grip strength and foot splay in the mid-dose group. Poirier et al. (2011) qualified their conclusion in that "the high dose of Al citrate is therefore considered to have had an adverse effect on body weights of male pups" and that "Al may affect neuromuscular performance in a dose-dependent manner, either primarily or secondarily to its effects on body weight in the mid- to high-dose groups." While the authors considered delayed development related to ingested $\mathrm{Al}$, this delay also occurred in the reference citrate group without $\mathrm{Al}$ exposure and this speaks to a relation between high citrate consumption and delayed development. Aluminum concentrations among the high-dose rats were increased in the cerebral cortex, cerebellum, brainstem, and thoracic spinal cord, but whether the changes in hind limb grip strength and foot splay were the result of $\mathrm{Al}$ accumulation in those tissues or were secondary to reductions in body weight is not clear. The high citrate concentration in the Al-treated groups and the similar delays in sexual maturity in the Na citrate-treated rats "due to alterations in water and/or food consumption" cloud the contribution of $\mathrm{Al}$ to the changes reported. 
Prenatal and perinatal toxicity studies-Erazi et al. (2011) evaluated the effects of $\mathrm{AlCl}_{3}$ administration in drinking water at 0 or $0.3 \%(3000 \mathrm{mg} / \mathrm{L})$ among four groups of five male and female Wistar rats in two separate protocols. In the first study, rats were given $\mathrm{AlCl}_{3}$ beginning at 3 months of age and this continued for 4 months. In the second study, maternal rats were given $\mathrm{AlCl}_{3}$ from mating through gestation, parturition and lactation. Newborns were not treated directly. After weaning the offspring were given $\mathrm{AlCl}_{3}$ in their drinking water until 3 months of age. The authors measured tyrosine hydroxylase (TH) immunoreactive neurons using a TH-specific antibody at four months of age. Prenatal, lactational, and perinatal exposure of rats to $\mathrm{AlCl}_{3}$ reduced the numbers of $\mathrm{TH}$ reactive neurons within the substantia nigra, reduced immunostaining in the substantia nigra and reduced locomotor activity in the offspring. Erazi et al. (2011) suggested that Al-associated changes in neurologic parameters were more pronounced in rats exposed to $\mathrm{AlCl}_{3}$ from conception to maturity compared to rats given $\mathrm{AlCl}_{3}$ as adults.

The Erazi et al. (2011) report cannot be relied upon due to limitations in experimental design and conduct: the authors failed to account for the physical condition of their rats as neither body weights nor food or drinking water consumption were recorded and there were no measures of the $\mathrm{pH}$ of the $\mathrm{AlCl}_{3}$ solution. High $\mathrm{AlCl}_{3}$ concentrations result in acidic drinking water of low palatability, leading to dehydration, inanition, reduced body weight gain, and poor nursing. Since only a single concentration was examined it is not possible to determine dose-response. The study design included neither pair-fed controls given equivalent volumes of drinking water nor controls given equimolar $\mathrm{HCl}$ in their drinking water. The very small numbers of rats per group (20 litters/dose group are normally required) compromise the study. No effort was made to quantify either circulating or tissue Al. Failure to document maternal and offspring body weights and to measure drinking water and food consumption leaves open the possibility that changes in TH immunoreactive neurons were due to impaired health of these animals as contrast to an Al-specific effect. The reported reduced spontaneous locomotor activity among rats given $\mathrm{AlCl}_{3}$ in their drinking water is not consistent with Hirata-Koizumi et al. (2011a) who found no such changes in male and female $\mathrm{Crl}: \mathrm{CD}(\mathrm{SD})$ rats given drinking water with $3000 \mathrm{mg} / \mathrm{L}$ $\mathrm{Al}_{2}(\mathrm{SO} 4)_{3}$ (up to $338 \mathrm{mg} / \mathrm{kg}$-day) from conception until four weeks of age.

Abu-Taweel et al. (2011a) investigated neurobehavioral changes after $\mathrm{AlCl}_{3}$ was given in drinking water to pregnant Swiss-Webster mice. Mated females were provided tap water or 300 or $600 \mathrm{mg} / \mathrm{L} \mathrm{AlCl}_{3}$ in tap water ad libitum from gestation day 1 through PND 15. Significant concentration-dependent reductions in postnatal body weight gain, locomotor activity, learning ability, and cognitive performance were reported. Delays in eye opening, hair growth and sensory motor reflex were also reported. Significant concentration-related reductions in dopamine and serotonin were observed in homogenized forebrain (including hippocampus and cerebral cortex) from PND 7 until PND 36. The authors suggested that prenatal and lactational exposure to high $\mathrm{Al}$ levels can cause developmental toxicity in mice The $\mathrm{pH}$ of the $\mathrm{AlCl}_{3}$-treated drinking water was not specified and drinking water consumption was not measured; the authors acknowledged: "It is likely that the present high concentrations of $\mathrm{Al}$ used in the drinking water might have affected total fluid intake due to its astringent properties, but no efforts were made to assess any such differences in total fluid 
intake specifically." Abu-Taweel et al. (2011a) assumed based on rat (Yumoto et al. 2001, 2003) and rabbit (Yokel and McNamara 1985) data that Al administered to the mother was passed to the pups via milk, but there were no significant changes in the reflexes of Altreated pups compared to the controls at the end of lactation. The authors suggested body weight, learning and memory declined in the post-weaning period, but given the astringent properties of high-concentration $\mathrm{AlCl}_{3}$ in drinking water it is possible avoidance of the water and dehydration may have contributed to the reported changes.

Moselhy et al. (2011) investigated changes in rat testes after $34 \mathrm{mg} / \mathrm{kg} \mathrm{AlCl} \mathrm{Al}_{3}$ was given (apparently by daily gavage) to 45 sexually mature Wistar rats for 60 days. Five rats from each group were sacrificed on Days 30,45, and 60 of treatment. No significant changes were observed in testis, epididymis, prostate gland, and seminal vesicle weights compared with the controls. Significant reductions in serum testosterone were seen in the treated rats at 30, 45, and 60 days of exposure. Testicular MDA levels were increased $163 \%$ after 60 days and sperm motility was reduced significantly at 30,45 , and 60 days. The percentages of live spermatozoa were reduced and the numbers of total sperm abnormalities increased 304, 211, and $283 \%$ compared to the controls at 30,45 , and 60 days.

Histological examination of the $\mathrm{AlCl}_{3}$-treated rats revealed degeneration of spermatogenic cells with exfoliation into the lumen "arrows" at 30 days. At 45 days those changes progressed to thinning and disorganization of the seminiferous germinal epithelium. By 60 days degeneration and necrosis of spermatogenic cells were abundant. No differences were seen in the epididymis between the treated and control groups at 30 days post-exposure, but Moselhy et al. (2011) noted desquamation and vacuolation of some epithelial cells along with diminished amounts of intraluminal sperm at 45 days. By 60 days the damage progressed to the point of complete lack or only very few sperm in the epididymal lumen. No significant histological changes were seen in the prostate at 30 days post-exposure, but by 45 days the size of the prostatic acini without intra-luminal secretions was reduced. By 60 days the epithelium became thin with multiple calcified intraluminal deposits.

Limitations of the Moselhy et al. (2011) study include failure to justify the dose, study of only a single dose level and absence of information on clinical signs, body weights or food and drinking water consumption. There was no mention of the $\mathrm{pH}$ of the $\mathrm{AlCl}_{3}$ solution. Thirunavukkarasu et al. (2010) described damage in the seminiferous tubules and vascular degeneration in the spermatogenic epithelium and Sertoli cells of rats given $\mathrm{AlCl}_{3}$ at $100 \mathrm{mg}$ $\mathrm{AlCl}_{3} / \mathrm{kg}$-day by gavage for 90 days. The strain, age, and numbers of rats were not provided. The strength of the study rests with the subchronic duration of exposure, but there was no effort made to study the reproductive performance of these rats and the single dose level precludes dose-response. Limited details on body weight and food and water consumption as indicative of general health of these rats limit interpretation of the Thirunavukkarasu et al. (2010) report. Given the absence of testicular toxicity seen in the guideline-compliant Hirata-Koizumi et al. (2011a, 2011b) repeated oral (2-8x higher Al) dose studies with $\mathrm{Al}_{2}\left(\mathrm{SO}_{4}\right)_{3}$ and AAS in rats, confidence in the Moselhy et al. (2011) and Thirunavukkarasu et al. (2010) conclusions is reduced.

Wang et al. (2012a) gave 40 female Wistar (5 weeks old) rats free access to drinking water with $\mathrm{AlCl}_{3}$ to provide $0,64.18,128.36$, or $256.72 \mathrm{mg} \mathrm{AlCl} / \mathrm{kg}$-day for 120 days. These 
doses were extrapolated based on generic mean water consumption for a $100 \mathrm{~g}$ rat whereas rats that survived to 120 days weighed $250-300 \mathrm{~g}$. Serum and ovarian Al concentrations, estrogen (E2), progesterone (P), testosterone (T), follicle-stimulating hormone (FSH), and luteinizing hormone $(\mathrm{LH})$ were measured at termination. There were significant concentration-related reductions in body weight among the treated groups beginning on Day 30 and these decrements became more pronounced by Day 120 . The authors reported $\mathrm{E}(2)$, $\mathrm{P}, \mathrm{FSH}$, and LH were reduced, that serum and ovarian $\mathrm{Al}$ concentrations were increased in all Al-treated groups and that ovarian $\mathrm{Al}$ concentrations were greater than those in serum. Testosterone concentrations were significantly higher in the low- and medium-dose groups, but not in the high-dose group compared with controls. Wang et al. (2012a) gave no information on $\mathrm{pH}$ of the $\mathrm{AlCl}_{3}$ drinking water and food and water consumption was not measured. No studies of fertility or reproductive performance of the $\mathrm{AlCl}_{3}$-treated rats were included. Wang et al. (2012a) also reported changes in reproductive hormones of $\mathrm{AlCl}_{3}$ treated female rats, but those conclusions failed to account for avoidance of acidic drinking water leading to possible dehydration and inanition as contributors to the reductions in body weight gain and hormonal disruptions.

This same laboratory gave 40 young male Wistar rats $\mathrm{AlCl}_{3}$ at $0,64,128$, or $257 \mathrm{mg} / \mathrm{kg}$-day in drinking water ad libitum for 120 days. Circulating levels of T and LH in the mid- and high-dose groups were significantly lower than in controls, but no significant changes in FSH were detected. Androgen receptor (AR) protein expression and the levels of AR mRNA expression in mid- and high-dose groups were reduced. A positive dose-response relation was evident between $\mathrm{AlCl}_{3}$ exposure and $\mathrm{AR}$ protein expression. Sun et al. (2011b) considered their serum T results consistent with those of Reza and Palan (2006) and Guo et al. $(2001,2005)$ who treated male rats and male mice, respectively, with daily ip $\mathrm{AlCl}_{3}$ injections at up to $175 \mathrm{mg} / \mathrm{kg}$-day for 20 or 12-16 days. Sun et al. (2011b) gave no measures of drinking water consumption so it is difficult to determine how the $\mathrm{Al}$ doses were determined. No pair-fed controls, concurrent control $\mathrm{HCl}$ group, drinking water $\mathrm{pH}$ or body weight data were included. Sun et al. (2011b) did not evaluate reproductive performance or success of $\mathrm{AlCl}_{3}$-treated rats. The limitations to the Sun et al. (2011b) report are similar to those in the Wang et al. (2012a) report. In the absence of Al blood and tissue data, it is difficult to relate results with repeated high-dose $\mathrm{AlCl}_{3}$ injections in rodents compared to the far lower environmental $\mathrm{Al}$ exposures experienced by humans.

Overall, the non-guideline studies provide limited details on test material, study design, and exposure conditions (e.g., the actual doses cannot be established). Common features include failure to account for or control the astringent properties of the acidic $\mathrm{Al}$ salts in relation to drinking water consumption and failure to account for dehydration and reduced body weights in relation to the parameters examined. Other than the iatrogenic skeletal toxicity induced by excessive $\mathrm{Al}$ in neonates (Bohrer et al. 2010) and impaired neurological development in premature infants given standard $\mathrm{PN}$ solutions with elevated $\mathrm{Al}$ (Bishop et al. 1997), a direct causative role of $\mathrm{Al}$ in production of adverse effects on reproduction and development has not been demonstrated. It is noteworthy the (variable) reductions in grip strength seen in offspring of Al maltolate-treated mice (Golub et al. 2000) were consistent with the reductions in grip strength seen in the offspring of Al citrate-treated rats (Poirier et al. 2011). 


\section{Endocrine}

Following up on a 1989 report concerning $21 \mathrm{Al}$ workers with reduced circulating thyrotropin (TSH) and prolactin at 12-18 months after initial employment (that subsequently resolved; Alessio et al. 1989), Orihuela (2011) gave $7 \mathrm{mg} \mathrm{Al} / \mathrm{kg}$-day as Al lactate in saline by ip injection to adult male Wistar rats for 6 weeks. Serum concentrations of TSH, triiodothyronine (T3), thyroxine (T4), and $\mathrm{Al}$ were measured along with thyroid $\mathrm{Al}$ and ${ }^{125 \mathrm{I}}$ uptake. Among the Al-injected rats mean serum $\mathrm{Al}$ increased 4500x compared to the salineinjected controls and there was a significant increase in mean thyroid $\mathrm{Al}$ and thyroid gland IPO. There was no influence of repeated daily Al lactate injections on circulating TSH or T4. Thyroid ${ }^{125} \mathrm{I}$ uptake was diminished in treated rats at $25 \mathrm{~h}$ after $\mathrm{Al}$ injection compared to that in controls, but by $50-100 \mathrm{~h}^{125} \mathrm{I}$ uptake was no different between the two groups. No justification of dose, route or duration of exposure was offered and only a single dose level was examined, precluding dose-response or identification of a NOAEL. Regardless, the authors stated: "We can conclude that in adult rats the Al would not act as a thyroid disruptor."

Contini et al. (2011) compared the effects of repeated (3/week for 12 weeks) ip doses of $\mathrm{Al}$ lactate $(5.75 \mathrm{mg} \mathrm{Al} / \mathrm{kg}$ at each injection) in 8-week-old intact and ovariectomized Wistar rats. There were no differences in food or drinking water consumption, serum $\mathrm{E}_{2}$ or estrous cycles for the intact rats and none of the animals showed clinical signs of $\mathrm{Al}$ intoxication (other than body weight reductions in ovariectomized rats who remained in permanent diestrus). Among the Al-injected rats, serum, renal, and hepatic Al increased 150-, 19- and 30 -fold, respectively. There was no influence of repeated $\mathrm{Al}$ injections on serum $\mathrm{Na}$ or $\mathrm{K}$ concentrations despite the fact that both intact and ovariectomized Al-treated rats had significantly higher serum aldosterone levels than rats that remained untreated. There were no differences in serum osmolality, urinary $\mathrm{K}$ excretion, or glomerular filtration rates between the groups. Consistent with reports by Bhadauria (2012), El-Demerdash (2004), González et al. (2007), Kaneko et al. (2004), Mahieu et al. (2003), Prabhakar et al. (2011) and Yousef (2004), Contini et al. (2011) found that hepatic LPO increased and catalase activity declined in the livers and kidneys of Al-injected rats compared to the untreated controls.

Citing the report by Alessio et al. (1989) and describing reductions in prolactin after high $\mathrm{Al}$ exposures in lambs, rats and mice, Calejo et al. (2010) cultured $\mathrm{AlCl}_{3}$ at $300 \mathrm{nM}-3 \mathrm{mM}$ with primary lactrophic cells isolated from the anterior pituitary of male Wistar rats for 1-4 days. The highest concentration tested represented the limit of $\mathrm{AlCl}_{3}$ solubility in culture media. After incubation with up to $3 \mu \mathrm{M} \mathrm{AlCl}_{3}$, there was no influence on cell viability. Identical culture with $300 \mu \mathrm{M}$ or $3 \mathrm{mM}$ caused cell death within $30 \mathrm{~min}$. Calejo et al. (2010) noted their data were consistent with the apoptotic cell death in cultured human lymphocytes treated with $25 \mathrm{mg} / \mathrm{L} \mathrm{AlCl}{ }_{3}$ (Banasik et al. 2005) and deformation of human erythrocytes treated with 10-100 $\mu \mathrm{M} \mathrm{AlCl}_{3}$ (Niemoeller et al. 2006), but none of these studies accounted for the influence of elevated $\mathrm{HCl}$ on cultured cells.

Calejo et al. (2011) followed up their earlier work by observing 14-46\% reductions in prolactin secreted from cultured Wistar rat pituitary lactotroph cells exposed for $24 \mathrm{~h}$ to a 
sub-lethal $30 \mu \mathrm{M} \mathrm{AlCl}_{3}$ concentration. This reduction was associated with reduced exocytosis as a result of reduced membrane capacitance, perhaps related to reductions in the diameter of the fusion pore size. Calejo et al. (2011) suggested the spectrum of clinical signs seen in chronic $\mathrm{Al}$ intoxication include prolactin depletion, but other than the one report of a transient change in prolactin among $\mathrm{Al}$ workers (Alessio et al. 1989), no confirmation of that possible connection could be located. As with their previous study, Calejo et al. (2011) failed to report media $\mathrm{pH}$ or include concurrent $\mathrm{HCl}$ controls.

\section{Skin}

Controversy continues over whether $\mathrm{Al}$ in cosmetics and personal care products presents health risks (AFSSAPS 2011). While case reports cannot be utilized to assess quantitative health risk, those observations when aggregated can provide insights for more formal investigation. No guideline-compliant studies in animals were located that reported dermal reactions after acute or short-term repeated topical exposure to Al compounds. Clinical trials, recent case reports and in vitro assays support $\mathrm{Al}$ dermal irritation after application of Al-containing deodorants. This local irritation is usually mild, sensitization is rare and only a small fraction of the $\mathrm{Al}$ applied to intact healthy skin is available for uptake.

Swaile et al. (2012) described use of a $6.5 \% \mathrm{AlCl}_{3}$ solution in anhydrous ethanol to treat profuse underarm perspiration. This solution acts by diffusion into the eccrine sweat gland where reactions with $\mathrm{OH}^{-}$, lactic acid, and protein generate $\mathrm{Al}(\mathrm{OH})_{3}$ that blocks sweat movement to the skin surface. At the same time, $\mathrm{HCl}$ liberated from $\mathrm{AlCl}_{3}$ can cause local irritation, pain, and erythema. When 35 healthy males were treated with $\mathrm{AlCl}_{3}$ or a commercial underarm deodorant with $\mathrm{Al}$ zirconium trichlorohydrate glycine using a randomized block (paired comparison) design, about 10\% developed irritation by Day 7 and Day 10, 20\% had objective skin irritation.

Consistent with observations that $\mathrm{Al}^{+3}$ binds structurally diverse anions, including histidine and hydroxyl-containing amino acids (Rezabal et al. 2007), polypeptides (Hollender et al. 2006, Zuo et al. 2005) and protein (Bhasin et al. 2012, Tomljenovic 2011), Swaile et al. (2012) noted that men with unshaven axillae experienced less local irritation than those with shaved skin because $\mathrm{Al}^{+3}$ bound to underarm hair. Streker et al. (2010) found that among 20 patients ( $26.9 \pm 4.3$ years) with excessive idiopathic axillary hyperhidrosis who used a commercial under-arm deodorant each day for 42 days, six experienced local skin irritation. Based on the incidence and nature of the response, the authors concluded that daily application of an $\mathrm{AlCl}_{3}$ antiperspirant was "an effective, safe and inexpensive treatment" for idiopathic hyperhidrosis.

Garg et al. (2010) described the case of a 28-year-old woman who presented at the hospital with eczema in both axillae. The patient complained that her condition occurred after the use of deodorants that contained ACH. Patch testing was performed to the British Contact Dermatitis Society baseline series, in addition to a fragrance series and $\mathrm{AlCl}_{3}$. The results were scored according to International Contact Dermatitis Research Group criteria. This patient responded with a $3+$ reaction to $2 \% \mathrm{AlCl}_{3}$ (in petrolatum), but there was no skin 
reaction after contact with an 8-mm Aluminum Finn Chamber ${ }^{\circledR}$. After she avoided all Alcontaining deodorants, her eczema cleared completely.

Watson et al. (2012) evaluated whether the use of Al-based antiperspirants while receiving external beam radiotherapy for Stage 0, I, or II breast cancer could exacerbate local irritation to damaged axilla skin. A total 198 participants were randomized to either the antiperspirant or a standard care-wash only control group. The skin reactions in both groups were measured weekly and at two weeks after cessation of treatment using the National Cancer Institute Common Toxicity Criteria Adverse Events (version 3) criteria. No significant differences were observed between the antiperspirant group and the control group.

Wooley-Lloyd and Valins (2009) (as described in Yanagishita et al. 2011) investigated topical exposure to $\mathrm{Al}$ chloride hexahydrate in a salicylic acid gel for treatment of hyperhidrosis. Local irritation with transient itching was evident after repeated gel application, but it should be noted that topical antiperspirants contain not only Al salts, but other active non-ionic and ionic agents (Quatrale 1985). As such, the Yanagishita et al. (2012) observations did not quantify the irritant potential of $\mathrm{Al}$ constituents present in commercial underarm deodorants.

\section{Immunology and vaccine adjuvants}

Aluminum adjuvants (often the oxyhydroxide and/or phosphate) are included in vaccines to enhance and extend the immune response (Exley et al. 2010, Kool et al. 2011). After Al adjuvant injection, Al-containing particles are taken up via phagocytosis by an antigenpresenting cell. These actions increase the immune response by delivery of antigen to T-cells in the lymph nodes (Rimaniol et al. 2004, Sokolovska et al. 2007). Immunopotentiation was originally attributed to the formation of a depot of antigen at the inoculation site (Glenny et al. 1926) suggesting it provided prolonged exposure of the antigen to the immune system resulting in higher antibody titers than antigen alone; adsorption of the antigen with the Al adjuvant has been regarded as essential to this mechanism (Gupta 1998). However, a direct correlation between the persistence of antigen at the inoculation site and the resulting antibody response has never been demonstrated (Hutchison et al. 2012).

Noe et al. (2010) studied the relation between depot formation and immunopotentiation by comparing the retention of antigen at the inoculation site with antibody production in rats. A labeled alpha casein (IDCAS) antigen was adsorbed onto either $\mathrm{Al}(\mathrm{OH})_{3}$ or $\mathrm{AlPO}_{4}$ adjuvant, or onto a non-adsorbed IDCAS with phosphate-treated $\mathrm{AlPO}_{4}$ (PTAP). The response after inoculation of those preparations was compared with that after injection of an adjuvant-free IDCAS solution. The final Al concentration in all of these formulations was $1.7 \mathrm{mg} / \mathrm{ml}$. When incubated with human plasma in vitro, approximately $90 \%$ of the IDCAS eluted from $\mathrm{AlPO}_{4}$ within $24 \mathrm{~h}$ while only $25 \%$ of the IDCAS eluted from $\mathrm{Al}(\mathrm{OH})_{3}$ at $72 \mathrm{~h}$. Those results suggested that antigen adsorption was higher with $\mathrm{Al}(\mathrm{OH})_{3}$ than with $\mathrm{AlPO}_{4}$. Antigen retention at the inoculation site was $\mathrm{Al}(\mathrm{OH})_{3}>\mathrm{AlPO}_{4}>$ non-adsorbed with PTAP. Adsorption with PTAP was equivalent to that seen with the adjuvant-free IDCAS solution. However, the $\mathrm{AlPO}_{4}$-adsorbed IDCAS produced a significantly higher antibody titer in rats than did the $\mathrm{Al}(\mathrm{OH})_{3}$-adsorbed IDCAS. Antibody titers declined as: non-adsorbed PTAP = 
$\mathrm{AlPO}_{4}$ adsorbed $>\mathrm{Al}(\mathrm{OH})_{3}$ adsorbed solution. These data were consistent with Hansen et al. $(2007,2009)$ and Egan et al. (2009) who found that tight antigen binding to an Al-adjuvant inhibited antibody production by interfering with antigen processing in dendritic cells (DCs), resulting in reduced T-cell activation. Tight antigen binding may also reduce B-cell activation by reducing the amount of antigen available for B-cell recognition in the draining lymph node (Hansen et al. 2007). Noe et al. (2010) confirmed the concept that $\mathrm{Al}$ adjuvants are necessary for immunopotentiation, but that a "depot mechanism" was not supported by their results.

Following a similar line of inquiry De Veer et al. (2010) measured uptake of particulate antigen from an intradermal injection in sheep by lymphocytes in the presence or absence of $50 \mathrm{mg} \mathrm{Al}$ adjuvant (Rehydragel). De Veer et al. (2010) concluded that the Al adjuvanticity failed to correlate with slow antigen release, but that it correlated with retention of antigen at the injection site and $\mathrm{Al}$ increased uptake of particulate antigen by mature migratory DCs. Wagner et al. (2012) compared the immunogenicity of anthrax vaccine in CD-1 mice immunized once by ip injection of fresh $\mathrm{Al}$ hydrogel formulations to the same formulations stored at $25^{\circ}$ or $37^{\circ} \mathrm{C}$ for 3 weeks. Mice immunized with freshly prepared $\mathrm{Al}$ formulations developed significantly higher antibody titers compared to mice immunized with stored formulations. This difference might reflect the relative stability of $\mathrm{Al}$ adsorption over time or the influence of storage conditions on the vaccine itself.

Mechanisms of Al adjuvant actions-Although Al compounds have been used as human vaccine adjuvants for many decades, their mechanism of action is not completely understood. The influence of physico-chemical parameters on both the antigens and $\mathrm{Al}$ adjuvants and the associated immune response have only recently been investigated (Clapp et al. 2011). Early studies by Goto et al. (1997) and Naim et al. (1997) concluded that adjuvanticity of Al correlated with inflammation produced at the inoculation site. These inflammation-related pathways include: recruitment of phagocytic cells (including DCs) to the inoculation site (Guyton and Hall 2000), increased antigen uptake by DCs (Morefield et al. 2005), activation and maturation of DCs and macrophages (Kool et al. 2008a, Sokolovska et al. 2007), and release of DC cytokines (Kool et al. 2008a). Recent in vitro studies demonstrated direct activation by Al of the NIRP3 (also known as Nalp3 or cryopyrin) inflammasome complex leading to the processing of several pro-inflammatory cytokines including IL-1ß (Eisenbarth et al. 2008, Li et al. 2008). Some authors have pointed to indirect inflammasome activation via Al-induced release of uric acid crystals (Kool et al. 2008b, Lambrecht et al. 2009, Marrack et al. 2009) and their role in activation of DCs and macrophages (Eisenbarth et al. 2008). At the same time, others found no involvement of the NIRP3 pathway in macrophage (Kuroda et al. 2011), DC or lymphocyte activation by Al salts or adjuvants (Franchi and Núñez 2008, Li et al. 2008, McKee et al. 2009). These differences could be related to different $\mathrm{Al}$ adjuvants, test systems or the different conditions and protocols used in these studies.

Adverse outcomes with Al adjuvants-Recent randomised controlled trials, semirandomised controlled clinical trials, and comparative cohort studies that investigated the safety and immunogenicity of Al-containing vaccines are summarized in Table 4. Most of 
the recent studies did not include groups given only the Al adjuvant, but where concurrent Al referent groups were included those studies are described below.

Descamps et al. (2009) studied the safety of the human papilloma virus (HPV)-16/18 AS04adjuvanted cervical cancer vaccine (Cervarix ${ }^{\mathrm{TM}}$ ) in a cohort of almost 30,000 girls and women aged 10-14, 15-25 and above 25 years who received the same three-dose regimen at 0,1 , and 6 months. The AS04 adjuvant is comprised of $\mathrm{Al}(\mathrm{OH})_{3}(500 \mu \mathrm{g}$ per dose) and 3-Odesacyl-4' ${ }^{\prime}$-monophosphoryl lipid A (MPl) (50 $\mu$ g per dose). Reference groups were given equivalent injections of $\mathrm{Al}(\mathrm{OH})_{3}$ alone. Compliance was $93.4 \%$ for the HPV-16/18 group and $96.4 \%$ for the $\mathrm{Al}(\mathrm{OH})_{3}$ group. No immediate hypersensitivity reactions occurred and injection site pain (consistent with results from Chotpitayasunondh et al. (2008); Ehrlich et al. (2008); Romanowski et al. (2011) and Zhu et al. (2009) with other vaccines) was the most common acute complaint. Erythema and swelling at the injection site developed in those aged 15-25 and above 25 years during the 7 days after each vaccination and these were 2.4-3.2 times, respectively, higher in the groups given the HPV-16/18 vaccine compared to those given $\mathrm{Al}(\mathrm{OH})_{3}$ alone. Complaints of fatigue, headache, and myalgia were common among those given the vaccine. There were no differences between the HPV-16/18 vaccine group and the $\mathrm{Al}(\mathrm{OH})_{3}$ group with regard to fatigue, fever, gastrointestinal distress, headache, rash, arthralgia, myalgia, and urticaria. The overall rate of serious adverse effects (SAEs) after injection of $\mathrm{Al}(\mathrm{OH})_{3}$ was almost 10 times higher in women 15-25 years of age than among those above 25 years ( $8.4 \%$ compared with $0.9 \%$, respectively). A higher percentage of SAEs-including spontaneous abortion-was observed among the 15- to 25year olds in the $\mathrm{Al}(\mathrm{OH})_{3}$ group compared to HPV-16/18 vaccine group. Descamps et al. (2009) observed that the spontaneous abortion rate for these women was within the range reported for the United States and explained that the increase could be due to differences in the longer follow-up for those in given $\mathrm{Al}(\mathrm{OH})_{3}$ (5.5 years) compared to 1.5 years for those given the HPV-16/18 vaccine. A higher percentage of new cases of chronic asthma, urticaria and hypersensitivity among the 15 - to 25 -year olds in those given only $\mathrm{Al}(\mathrm{OH})_{3}$ was recorded compared to those given the HPV-16/18 vaccine (1.1\% compared with $0.3 \%$, respectively). There were no differences in the frequency of new cases of autoimmune disease at any age. The Descamps et al. (2009) analysis examined large sample sizes $(29,953$ subjects, 45,988 vaccine doses), gave separate presentations of outcomes for the vaccine and $\mathrm{Al}(\mathrm{OH})_{3}$ groups by age and it included follow-up observations at $0-7$ months, 7-12 months and more than 12 months.

Netterlid et al. (2013) conducted a randomized, controlled, single-blind study of Al contact allergy. This was a multicentre evaluation of children and adults that involved patch-testing with allergen extracts containing $\mathrm{Al}(\mathrm{OH})_{3}$ and $\mathrm{AlCl}_{3} \cdot 6 \mathrm{H}_{2} \mathrm{O}$ in white petrolatum at 2.0, 10.0, and $20.0 \%$ w/w. Seventy-eight children and 127 adults completed the study and positive results were found in eight (5/78 children and 3/127 adults). There were no positive reactions to the empty Finn Chamber, but seven tested positive to $10 \% \mathrm{AlCl}_{3} \cdot 6 \mathrm{H}_{2} \mathrm{O}$ and five tested positive to $2 \% \mathrm{AlCl}_{3} \cdot 6 \mathrm{H}_{2} \mathrm{O}$. Four members of the control group also tested positive to Al. Six of eight participants with contact allergy to $\mathrm{Al}$ reported previous atopic dermatitis and four of those six were in the exposed group. In sum, the Netterlid et al. (2013) study demonstrated a $3.9 \%$ proportion of $\mathrm{Al}$ contact allergy in atopic individuals with allergic 
disease. Among those who developed $\mathrm{Al}$-induced allergic reactions, children and adults with atopic dermatitis were more highly represented.

A syndrome known as MMF has been associated with prolonged $\mathrm{Al}$ retention (e.g., years) at the site of vaccinations that contained $\mathrm{Al}(\mathrm{OH})_{3}$ (Exley et al. 2009, Gherardi and Authier 2012). Aluminum-containing macrophages gather in the myofascii at the injection site and these accumulations have been confirmed in deltoid muscle biopsy (Siegrist 2005). A small proportion of vaccinated people present with delayed onset diffuse myalgia, chronic fatigue, and cognitive dysfunction. None of the clinical manifestations commonly associated with MMF (fever, myalgias, arthralgia, asthenia, and muscle weakness) are specific (Israeli et al. 2011, Gherardi and Authier 2012). A number of attempts have been made to link local vaccine reactions to those complaints; however, no firm etiological association with vaccination has been established (Lindblad 2004, Batista-Duharte et al. 2011) and these conditions as related to $\mathrm{Al}$ adjuvants remain uncertain (Shoenfeld and Agmon-Levin 2011).

A number of studies examined the potential of $\mathrm{Al}$ adjuvant-containing vaccines to elicit inflammation, attention deficit hyperactivity disorders, delays in speech or language development (Tomljenovic and Shaw 2011a, 2011b, 2012), neurodevelopmental delay (Dorea 2011, 2012a, 2012b) and impaired cognition (Couette et al. 2009). These concerns were highlighted by Dorea and Marques (2010) who reported that infants receiving immunizations were given 225-1750 $\mu \mathrm{g}$ Al per injection. On the other hand, Nøkleby (2007) and Mitkus et al. (2011) concluded that the risk of adverse effects including neurotoxicity posed by $\mathrm{Al}$ adjuvants received during childhood vaccinations was "low" and Ehrlich et al. (2008) observed only increased complaints of headache. In their study of 9600 people enrolled in 13 clinical trials of vaccines against influenze H5N1 virus, Manzoli et al. (2009) found no serious adverse events associated with $\mathrm{Al}$ adjuvants. Theeten et al. (2005) found that systemic adverse events were rare and a significant difference among $\mathrm{Al}$ study groups was found only for fatigue. The Global Advisory Committee on Vaccine Safety concluded there was no discernible relation between vaccinations and adverse outcomes (GACVS 2012, Kelso et al. 2012). Limitations to the published results include "incorrect assumptions about known associations of $\mathrm{Al}$ with neurological disease, uncertainty of the accuracy of the autism spectrum disorder prevalence rates in different countries, and accuracy of vaccination schedules and resulting calculations of Al doses in different countries" (GACVS 2012).

Twenty recent clinical studies of different Al-containing vaccines were available for review. Some of these studies reported a diminished or limited immunogenic role for $\mathrm{Al}(\mathrm{OH})_{3}$ adjuvant in certain vaccines (Brady et al. 2009, Keitel et al. 2009, Manzoli et al. 2011, Liang et al. 2010, Yin et al. 2011, Zhu et al. 2009). Depending on the vaccine and dose, Bresson et al. (2006) and Ehrlich et al. (2008) found that influenza vaccines with alum adjuvant were no more effective toward inducing an immune response than influenza vaccines without adjuvant. Zhu et al. (2009) found that influenza H1N1 vaccine without Al adjuvant was associated with fewer local reactions and greater immune response than vaccine with adjuvant. Theeten et al. (2005) suggested limited or possible stimulatory roles for $\mathrm{Al}(\mathrm{OH})_{3}$ in adsorbed DTaP vaccines, but there was no clear or consistent relation between immunogenicity and the $\mathrm{Al}$ quantity in the vaccine or total $\mathrm{Al}$ dose. The contributions of $\mathrm{Al}$ 
adjuvants to immune response after vaccination appear to vary with antigen as well as with patient age (Zhu et al. 2009).

Contact reactions (delayed-type hypersensitivity with painful erythematous and pruritic eruptions, edema, and blistering) to $\mathrm{Al}$ at injection sites do occur (Table 5), but they are rare (Bergfors et al. 2005, Ehrlich et al. 2008, Leventhal et al. 2012, Zhu et al. 2009). These reactions can develop weeks, months, or even years after injection of an Al-containing vaccine (Leventhal et al. 2012). Histological examinations of biopsies from the injection sites revealed granulomatous and foreign body reactions (Garcia-Patos et al. 1995) and people with hypersensitivity to Al-containing vaccines generally demonstrate positive patch testing to Al (Bergfors and Trollfors 2012, Beveridge et al. 2011, Lehman et al. 2008, Netterlid et al. 2013).

There is little consistency among the 20 studies regarding their designs, event definitions, event types, and the age categories examined. The diversity of protocols, vaccines, methods, and data presentation in these publications makes it difficult to determine the relative safety of different $\mathrm{Al}$ adjuvants present in the different vaccines. Given the absence of standardized quantitative measures designed to calculate the therapeutic ratio, the comparative safety and/or efficacy of $\mathrm{Al}$ adjuvants in these vaccines, especially in children and pregnant women (Wijnans et al. 2011), remains unknown. Moreover, no formal effort was identified to establish causality between the systemic reactions following immunization with an $\mathrm{Al}$ adjuvant. A number of recent case reports describe delayed hypersensitivity after vaccination with $\mathrm{Al}$ adjuvants (Table 5) and while those results are suggestive, case reports cannot be considered definitive evidence for or the circumstances under which $\mathrm{Al}$ adjuvant injections may elicit undesirable effects in humans. In a 2012 study, Yokel found that of the Al present in pediatric vaccines (125-330 $\mu \mathrm{g} / \mathrm{dose})$ the amount absorbed each day from the depot was approximately $0.07 \mu \mathrm{g} / \mathrm{kg}$ (assuming 30 injections over the first 6 years of life and a mean body weight of $20 \mathrm{~kg}$ ). The lack of suitable experimental models and standardized predictive methods, mixed exposures (Dorea 2010, 2012a, 2012b, Marques et al. 2010), issues in quantifying immunotoxicity and problems with detecting rare events make determination of causal relations between vaccines, their $\mathrm{Al}$ content and adverse outcomes difficult (BatistaDuharte et al. 2011).

Laboratory animals-Recent reports on immune system parameters in rats exposed orally to $\mathrm{Al}$ are summarized in Table 6. Details of the multi-generation bioassays by HirataKoizumi et al. (2011a, 2011b) with $\mathrm{Al}_{2}\left(\mathrm{SO}_{4}\right)_{3}$ and $\mathrm{NH}_{4}\left(\mathrm{Al}\left(\mathrm{SO}_{4}\right)_{2}\right.$ in rats are described at the preceding discussion of developmental toxicity. Findings there include reduced absolute and relative thymus and spleen weights after ingestion of $3000 \mathrm{ppm} \mathrm{Al}{ }_{2}\left(\mathrm{SO}_{4}\right)_{3}$ in drinking water, but necropsy found no dose-related histologic lesions in those organs. Interpretation of the reduced spleen and thymus weights is problematic due to the reductions in drinking water and food consumption. The Hirata-Koizumi et al. (2011b) study with $\mathrm{NH}_{4} \mathrm{Al}\left(\mathrm{SO}_{4}\right)_{2}$ also found reduced absolute and relative thymus and spleen weights. As these changes may be related to maternal dehydration and inanition the utility of these observations for health risk assessment is limited. 
There is some evidence that repeated exposure to high doses of different Al forms may stimulate (Lauricella et al. 2001, Yoshida et al. 1989) or suppress the immune response in rodents (Golub et al. 1993, Khalaf et al. 2008, Yoshida et al. 1989). Tsunoda and Sharma (1999) found no change in mRNA expression for cytokines TNF $\alpha$, IL-1 $\beta$, and INF $\gamma$ in peripheral cells of the immune system (TNF $a$ and IL-1 $\beta$ in splenic macrophages and INF $\gamma$ in splenic lymphocytes) of mice given $\mathrm{Al}_{2}\left(\mathrm{SO}_{4}\right)_{3}$ in their drinking water at $0,5,25$ or 125 $\mathrm{mg} / \mathrm{L}$ (equivalent to $0,0.95,4.3$, and $21 \mathrm{mg} \mathrm{Al} / \mathrm{kg}$-day) for one month. An effect of $\mathrm{Al}$ on the rodent immune response appears to vary with age, dose, onset, and duration of exposure (Glynn et al. 1999, Becaria et al. 2006), study design and/or physiological state (Khalaf et al. 2008, Yoshida et al. 1989). There is some evidence to suggest that changes in the immune system after high-dose $\mathrm{Al}$ exposure during development may be more pronounced in the offspring than in the dams (Khalaf et al. 2008). Zhu et al. (2012b) found decreased relative spleen weights in rats following ingestion of $\mathrm{AlCl}_{3}$ at up to $256 \mathrm{mg} / \mathrm{kg}$-day during 120 days and suggested that $\mathrm{Al}$ immunotoxicity could be due to disruption of $\mathrm{Fe}, \mathrm{Cu}$, and $\mathrm{Zn}$ in the spleen and interference with cytokines that regulate immune activation and homeostasis. Golub et al. (1993) suggested that Al-induced immunosuppression might result from a specific extrinsic effect, from a specific intrinstic deficit or from nonspecific disruption of physiological, hormonal or metabolic processes. At the present time, the underlying mechanisms associated with an immunological role for $\mathrm{Al}$ in rodents cannot be defined.

\section{Genotoxicity}

Krewski et al. (2007) concluded that $\mathrm{Al}$ compounds produced mostly negative results in standard short-term prokaryotic and eukaryotic test systems. Some of the early studies with soluble Al conducted in mice and rats produced mixed results. Recent data point to cell culture conditions and administration of excessively high (near-lethal) doses that contribute to the mixed results seen in the earlier reports.

Laboratory animals - Turkez et al. (2010) studied the clastogenic activity of Al in hepatocytes of adult male Sprague-Dawley rats (8-weeks old, 5 animals per group) after gavage with $34 \mathrm{mg} / \mathrm{kg}$ bw $\mathrm{AlCl}_{3}$ along with $50 \mathrm{mg} / \mathrm{kg}$ bw propolis for 30 days. Turkez et al. (2010) found that repeated gavage with $\mathrm{AlCl}_{3}$ induced a significant increase in the numbers of micronucleated hepatocytes (MNHEPs). Simultaneous administration of propolis attenuated the increased numbers MNHEPs induced by oral $\mathrm{AlCl}_{3}$. Repeated high oral doses of $\mathrm{AlCl}_{3}$ also caused a significant increase in alkaline phosphatase, transaminases (AST and ALT) and LDH and induced histopathological changes in the liver. The authors suggested the observed clastogenicity after oral $\mathrm{AlCl}_{3}$ may have been mediated, at least in part, by free radicals (Abubakar et al. 2003). Similar MNHEP results were obtained after four repeated daily ip injections of $5 \mathrm{mg} / \mathrm{kg}$ of $\mathrm{AlCl}_{3}$ in rats (Turkez et al. 2013). There was no justification for the doses examined, there was no study of dose-response and the genetic damage occurred after exposures that induced cytotoxicity. As written, it is not possible to exclude the possibility that the genetic damage was associated with oxidative stress in the liver as contrast to direct actions of trivalent $\mathrm{Al}$.

Geyikoĝlu et al. (2013) conducted a liver MN assay in adult male Sprague-Dawley rats given daily ip injections of $\mathrm{AlCl}_{3}$ at $5 \mathrm{mg} / \mathrm{kg}$-day for 10 weeks. A control group of six rats 
received daily ip injections of saline. The $\mathrm{MN}$ assay was performed in accord with methods described by Turkez et al. (2010). Daily injections of $\mathrm{AlCl}_{3}$ over 10 weeks resulted in a 4fold increase in the numbers of MNHEPs. Histopathology suggested that the clastogenicity might be a consequence of cytotoxicity. These findings mirrored those by Manna and Das (1972) who found increased CAs in mouse bone marrow following repeated ip injections of $\mathrm{AlCl}_{3}$. The Geyikoglu et al. (2013) report failed to identify the $\mathrm{pH}$ of the injected $\mathrm{AlCl}_{3}$ solution, there were no concurrent controls given equimolar injections of $\mathrm{HCl}$ and there were no measures of circulating or tissue $\mathrm{Al}$ concentrations.

Cytotoxicity and genotoxicity in vitro-Table 3 summarizes recent observations on $\mathrm{Al}$ toxicity in cultured cells. Data considered more relevant to weight of evidence comparisons are described below.

Turkez and Geyikoĝlu (2011) conducted CA and SCE assays with $\mathrm{Al}_{2}\left(\mathrm{SO}_{4}\right)_{3}$ in cultured human lymphocytes. Blood was collected from three healthy non-smoking donors with no history of exposure to genotoxic agents. The $\mathrm{Al}_{2}\left(\mathrm{SO}_{4}\right)_{3}$ concentrations tested were 0,10 , and $20 \mu \mathrm{g} / \mathrm{ml}$ (equivalent as $0,1.57$ and $3.15 \mu \mathrm{g} \mathrm{Al} / \mathrm{ml}$ ). Addition of $10 \mu \mathrm{g} / \mathrm{ml} \mathrm{Al}_{2}\left(\mathrm{SO}_{4}\right)_{3}$ failed to influence the frequency of SCEs or CAs; identical study with $20 \mu \mathrm{g} / \mathrm{ml}$ increased the frequency of SCEs per cell and CAs compared with controls, but the change was not biologically significant $(<2$-fold change in SCEs/cell as shown in publication Figure 1). There was no effect of $\mathrm{Al}_{2}\left(\mathrm{SO}_{4}\right)_{3}$ at $10 \mu \mathrm{g} / \mathrm{ml}$ on oxidative stress markers in erythrocytes, but treatment with $20 \mu \mathrm{g} / \mathrm{ml}$ reduced erythrocyte GSH and caused significant decrements in the activities of antioxidant enzymes (G-6-PDH, SOD and catalase). The authors suggested that the increased SCEs and CAs seen at $20 \mu \mathrm{g} / \mathrm{ml}$ were the result of reduced antioxidant enzyme activity. The Turkez and Geyikoglu (2011) protocol examined only one time point and no reference mutagen (positive control) was included. Only thirty well-spread metaphases were scored per sample for the CA assay whereas OECD Test Guideline \#473 requires at least 200 well-spread metaphases. The number of second cycle metaphases examined for SCEs was not reported. The highest Al concentration $(3,157 \mu \mathrm{g} / \mathrm{L})$ was $\sim 300 \mathrm{x}$ the $\mathrm{Al}$ concentrations $(1.9-10.3 \mu \mathrm{g} / \mathrm{L})$ present in normal human plasma and serum (Krewski et al. 2007). No control cultures treated with equimolar concentrations of $\mathrm{H}_{2} \mathrm{SO}_{4}$ were included, there was no mention of media $\mathrm{pH}$ and there was no mention of light microscopic evaluations of these cells. Structural CAs can occur as a result of cytotoxicity (Galloway et al. 2000) and in the presence of $>50 \%$ cytotoxicity, CA increases are most all artifactual and can represent false positives (Battersby 2007, Kirkland et al. 2007, Galloway 2000). Cytotoxicity, solubility of the compound in the test system, changes in $\mathrm{pH}$ and changes in osmolality must always be considered in selection of the highest test substance concentration in these assays (OECD Test Guideline 473). Overall, the results of the Turkez and Geyikoglu (2011) study are equivocal.

Sappino et al. (2012) investigated $0,10,100$ or $300 \mu \mathrm{M} \mathrm{AlCl} 3$ or $\mathrm{ACH}$ (purity $\geq 99 \%$ ) in cultured MCF-10A cells and in cultured human primary mammary epithelial cells. Sappino et al. (2012) suggested that "at the expected $\mathrm{pH}$ of the cell culture medium ( $\mathrm{pH} \sim 7.2), \mathrm{AlCl}_{3}$ and $\mathrm{ACH}$ yield the same dissociation product, aluminum hydroxide". There were no visual precipitates in these cultures and addition of $\mathrm{AlCl}_{3}$ had a minor effect on $\mathrm{pH}$. Incubation of MCF-10A cells with $100 \mu \mathrm{M} \mathrm{AlCl}_{3}$ for six weeks induced loss of contact inhibition and 
increased anchorage-independent growth. Culture of MCF-10A cells with 100 or $300 \mu \mathrm{M}$ $\mathrm{AlCl}_{3}$ reduced the numbers of cells, but there were no signs of apoptosis. Culture with 10, 100 or $300 \mu \mathrm{M} \mathrm{AlCl}_{3}$ increased the percentage of senescence-associated B-galactosidasepositive cells in proliferating MCF-10A cells after 7 days. At the same time, exposure to 100 or $300 \mu \mathrm{M} \mathrm{AlCl}{ }_{3}$ increased the expression of $\mathrm{p} 16 / \mathrm{INK} 4 \mathrm{a}$, a cyclin-dependent kinase inhibitor and tumour suppressor that enforces growth arrest (Baker et al. 2011). The addition of 10,100 and $300 \mu \mathrm{M} \mathrm{AlCl}_{3}$ increased DNA DSBs in a dose- and time-dependent manner in proliferating MCF-10A cells, but it had little or no effect on proliferating $\mathrm{HaCaT}$ keratinocytes. There was no influence of $\mathrm{AlCl}_{3}$ on X-ray induced DSB repair in MCF-10A cells, but there was upregulation of the p53/p21 pathway. Companion studies found no effects of $\mathrm{AlCl}_{3}$ on anchorage-independent growth in $\mathrm{HaCaT}$ keratinocytes or $\mathrm{C} 26 \mathrm{Ci}$ human colonic fibroblasts cultured for 17 weeks in the presence of $300 \mu \mathrm{M} \mathrm{AlCl}_{3}$. Based on their results with MCF-10A cells, Sappino et al. (2012) suggested that $\mathrm{AlCl}_{3}$ (at up to $300 \mu \mathrm{M}$ or $60 \mu \mathrm{M}$ as Al) induced proliferation, increased DSBs and accelerated senescence. According to the authors, the results indicated that induction of DSBs by $\mathrm{AlCl}_{3}$ treatment occurred slowly, suggesting that this effect was indirect and possibly cell specific.

A number of observations can be made with regard to the Sappino et al. (2012) report. There was no justification offered for the $\mathrm{Al}$ concentrations examined and no empirical data were provided to support the suggested correlations between $\mathrm{ACH}$ and $\mathrm{AlCl}_{3}$ exposures. The $\mathrm{Al}$ concentrations examined by Sappino et al. (2012) were 800-4200x the median 0.07-0.38 $\mu \mathrm{M}(<10 \mu \mathrm{g} / \mathrm{L})$ present in serum and plasma of healthy people (reviewed in Krewski et al. 2007). No positive control group was included, no equimolar $\mathrm{HCl}$ controls were included and it was not clear if the expected $\mathrm{pH}$ (7.3) was measured in fresh or long-term culture media. Since cytotoxicity increases after in vitro exposure to $\mathrm{HCl}$ and other acids (Morita et al. 1992) and weakly acidic conditions (pH 6.6-6.8) are mutagenic and clastogenic for cultured cells, it is possible that the Sappino et al. (2012) findings (even at non-cytotoxic concentrations) reflect oxidative stress (e.g., increased free radicals and ROS associated with LPO) associated with $\mathrm{HCl}$. While Sappino et al. (2012) pointed to positive results from other Al studies, exposure to acidic media in those older reports cannot be excluded (reviewed in Krewski et al. 2007). There is evidence to support the fact that acidic conditions in cultured human (Morita et al. 1992, Güngör et al. 2010) and rodent (Cifone et al. 1987, Morita et al. 1989, 1992) cells can increase the numbers of CAs (e.g., chromatid breaks and gaps). At neutral $\mathrm{pH} \mathrm{AlCl} \mathrm{Al}_{3}$ transforms to $\mathrm{Al}$ trihydroxide and $\mathrm{Al}$ oxidehydroxide and these hydroxides precipitate (Mayeux et al. 2012). While Sappino et al. (2012) stated that they did not observe visually-evident precipitates (detection method not reported), microscopic $\mathrm{Al}$ precipitates may have existed in these cultures (particularly at the highest concentration). Therefore, in the absence of data on cytotoxicity, it is possible that these cells were exposed to $\mathrm{HCl}$ and $\mathrm{Al}(\mathrm{OH})_{3}$ particulate and that the findings are associated with acidic media and particulates as contrast to a direct genotoxic effect of $\mathrm{Al}^{+3}$.

Lima et al. (2011) summarized older reports on the genotoxic activity of Al-containing atmospheric dust, $\mathrm{Al}(\mathrm{NO})_{3}, \mathrm{AlCl}_{3}$ and irradiated $\mathrm{Al}$ ions. Other reports examined treatment of cells from Parkinson's patients with $1 \mathrm{mM} \mathrm{Al}$ and study of waste materials from an $\mathrm{Al}$ products factory. These reports included results with cultured V79-4 Chinese hamster cells, cultured Balb c3T3 cells, Vicia faba and Allium cepa cells. The results with the waste 
materials are confounded by a positive response in $S$. typhimurium tester strains associated with aromatic amine contaminants. Based on polyploidy and clastogenesis in cultured human lymphocytes with 5-25 $\mu \mathrm{M} \mathrm{AlCl}_{3}$ (Lima et al. 2007), Lima et al. (2011) considered $\mathrm{AlCl}_{3}$ genotoxic. Lima et al. (2011) also noted cytotoxicity at those same concentrations and that gaps were included in the statistical comparisons of breaks and reduplications. Therefore, the Lima et al. (2007) conclusions regarding structural and numerical chromosome aberrations induced by $\mathrm{AlCl}_{3}$ may be called into question. Certainly all of the concentrations examined by Lima et al. (2007) are 42-360x higher than the mean or median $\mathrm{Al}$ concentrations in serum and plasma from healthy infants and adults $(1.9-10.3 \mu \mathrm{g} / \mathrm{L}$ or $0.07-0.38 \mu \mathrm{M})$ and in patients on PN $(15.9 \mu \mathrm{g} / \mathrm{L}$ or $0.59 \mu \mathrm{M})$. The $\mathrm{Al}$ concentrations employed by Lima et al. (2007) are consistent with serum Al concentrations (to $808 \mu \mathrm{g} / \mathrm{L}$ or $29.7 \mu \mathrm{M}$ ) in HD patients who died as a result of $\mathrm{Al}$ intoxication (reviewed in Krewski et al. 2007). The conclusions reached by Lima et al. (2011) contrast with those drawn by others based on results of standard short-term in vivo and in vitro assays with water-soluble $\mathrm{Al}$ salts (IPCS 1997, Krewski et al. 2007, Willhite et al. 2012).

After correlating $\mathrm{Al}$ concentrations with reductions in $\%$ adenine + thymine interphase (quiescent) heterochromatin in relation to $50-500 \mathrm{nM} \mathrm{Al}_{2}\left(\mathrm{SO}_{4}\right)_{3}$ inhibition of RNA polymerase II-mediated transcription in human neuronal glial cells, Lukiw (2010) formulated his 'Al compaction' hypothesis. This theory is based on $\mathrm{Al}^{+3}$ affinity for binding A-T nucleotides and suppression of regulatory promoter gene expression compared to $\mathrm{Al}^{+3}$ affinity for G-C rich templates. This theory recalls $\mathrm{Al}$ binding to nucleotide phosphates previously held responsible for in vitro binding of $\mathrm{Al}(\mathrm{OH})^{2+}$ to DNA and that was thought to reduce unwinding at pH 6-7.5 and contribute to DNA crosslinking (Karlik et al. 1980).

Lukiw (2010) presented neither in vivo nor other direct in vitro evidence to support the DNA binding theory in relation to Al-induced cytotoxic or genotoxic activity.

\section{Carcinogenicity}

It has been recognized for at least 30 years that exposures during $\mathrm{Al}$ production present an increased risk of lung and bladder cancer (IARC 1987). This increased risk has been attributed to the presence of known carcinogens including polynuclear aromatic hydrocarbons in those operations (ATSDR 2008). Gibbs and Labrèche (2014) confirmed those observations and noted that the airborne concentrations of benzo[a]pyrene are used as an index of exposure to carcinogenic (benzene-soluble) coal tar pitch volatiles. Krewski et al. (2007) concluded that experimental studies in animals failed to demonstrate carcinogenicity attributed solely to $\mathrm{Al}$ exposure. No reports of recent carcinogenicity bioassays or initiation/promotion protocols with any $\mathrm{Al}$ form were located in the open literature. Recent epidemiologic data and case reports are compared below with those summarized by Krewski et al. (2007).

Friesen et al. (2009) investigated associations between alumina and bauxite dust exposures with circulatory and respiratory disease mortality and cancer in employees of four bauxite mines and three alumina refineries. These individuals were employed on or after January 1, 1983. For people employed prior to the initial 1995-1996 survey, work history and smoking status were obtained from company records. Outcomes were determined by linkage with the 
national mortality database and the national and state cancer incidence registries.

Cumulative exposure to inhalable bauxite and alumina were estimated using a task-exposure matrix for those employed during 1995/1996. A less detailed job-exposure matrix was required for subjects who left employment before 1996. Before 1998, total dust was measured using a NIOSH cassette that was subsequently found to underestimate the inhalable fraction. Measurements taken after 1998 used an Institute of Medicine recommended device to quantify inhalable dust. The study cohort had a mean age of 32 \pm 10.5 years at entry, a mean duration of 14.1 years and a mean person-year (PY) contribution of $16.2 \pm 4.8$ years (equal to $93,420 \mathrm{PYs}$ of follow-up). A greater percentage of the bauxite-exposed workers were either current ( $29 \%$ vs $24 \%$ ) or former ( $29 \%$ vs $25 \%$ ) smokers compared to the unexposed referent group. The alumina-exposed workers and the unexposed workers did not differ with respect to smoking. The median, mean and maximum cumulative measures of bauxite dust among the bauxite-exposed workers were 5.7, 13.4, and $187 \mathrm{mg} / \mathrm{m}^{3}-\mathrm{yr}$, respectively. The median, mean and maximum cumulative measures of alumina dust among the alumina-exposed workers were $2.8,14.5$, and $210 \mathrm{mg} / \mathrm{m}^{3}-\mathrm{yr}$, respectively. Exposure categories were defined based on the tertiles in the few cases. The relative risk of death from non-malignant respiratory disease showed a significant trend (7 deaths; $\mathrm{p}<0.01$ ) with cumulative bauxite exposure after adjustments for age, calendar year and smoking. These deaths were due to chronic obstructive pulmonary disease, asbestosis, unspecified bronchopneumonia and interstitial pulmonary fibrosis. Cumulative alumina exposures showed a marginally significant trend with increased mortality from cerebrovascular disease (10 deaths; $p=0.04$ ). No notable associations or trends were observed for cancer. These analyses were based on only a few cases that accrued during the relatively short follow-up and adjustment for smoking was done using only a crude categorical variable. The absence of significant associations between occupational $\mathrm{Al}$ exposures and cancer risk by Friesen et al. (2009) are consistent with the conclusions reached by Fritschi et al. (2008), IARC (1987) and ATSDR (2008).

Pan et al. (2011) investigated residential proximity to Canadian Al smelters and risk of female breast cancer in a population-based case-control study using data collected by the National Enhanced Cancer Surveillance System. This study was based on individual data collected from 21,020 Canadians diagnosed with one of 19 types of cancers and it included 5039 population controls (aged 20-76 years). The study examined 2343 incident cases of breast cancer ( 863 premenopausal and 1480 postmenopausal) compared to 2467 controls. Breast cancer cases were identified by the population-based provincial cancer registries and all cases were verified by pathology reports. Breast cancer was defined as C50 according to the International Classification of Diseases for Oncology and questionnaires were sent to 3013 cases and 2982 cases were contacted. Completed questionnaires were received from 2362 cases, representing $78.4 \%$ of cases. Questionnaires were also mailed to 3847 women without diagnosis of cancer and these women were selected as potential controls using a random sample stratified by age group. In total, 2492 women without diagnosis of cancer completed and returned the questionnaire (representing 64.8\% of the ascertained controls). These self-administered questionnaires collected information on education, average family income over the last five years, marital status, ethnic group, height, weight, physical activity, alcohol consumption, diet and vitamin and mineral supplements for the past 20 years. These 
questionnaires also gathered smoking history, menstrual and reproductive history (including menopausal status), a lifetime residential and employment history, the distance between a residence and an industrial source and the number of years of proximity. Assessments also included dietary frequency, patterns and portion sizes for each of 69 foods consumed during the two years before interview. Distance to an industrial source was estimated using the locations and years of production for $\mathrm{Al}$ smelters and nine other major industries: copper smelters and refineries, lead smelters, nickel smelters and refineries, zinc smelters and refineries, petroleum refineries, paper mills, pulp mills, steel mills, and thermal power plants. Distance was categorized as less than $0.8 \mathrm{~km}$ (0.5 mile), 0.8-3.2 km (0.5-2 miles), and more than $3.2 \mathrm{~km}$ (>2 miles). The change-in-point estimate approach was used to assess potential confounding factors: age, educational level, family income, alcohol consumption, smoking, body mass index, total calorie intake, recreational physical activity level, menopausal status, and number of live births. The final multivariate models were adjusted for age (years, continuous), province of residence, education (years, continuous), number of live births (none, 1, 2, 3, and $\geq 4$ ), age at menarche (years, continuous), alcohol consumption (servings per week, continuous), pack-years of smoking (continuous), total caloric intake (kilocalories per week, continuous), and employment in the specific industry under consideration (yes or no). For postmenopausal women, the models were also adjusted for body mass index and recreational physical activity. In order to evaluate the trends for all models of categorized data, the different categories were treated as a single ordinal variable. The risk of breast cancer associated with residential proximity to $\mathrm{Al}$ industrial facilities was estimated based on odds ratios and corresponding $95 \%$ confidence intervals using unconditional logistic regression.

Data from 2343 breast cancer cases (863 premenopausal cases and 1480 postmenopausal cases) and 2467 controls ( 835 premenopausal controls, 1604 postmenopausal controls, and the menopausal status unknown for 28 controls) were used. The premenopausal cancer patients were older, had slightly higher family income, started menstruation at an earlier age and had longer menstruation compared with their controls. The postmenopausal women were slightly younger, had higher education, consumed more alcohol and tobacco, had higher body mass index, started menstruation at an earlier age and had fewer live births and more years of menstruation compared with their controls. The results indicated no increased risk of breast cancer among premenopausal or postmenopausal women living within 0.8-3.2 $\mathrm{km}$ of an $\mathrm{Al}$ smelter. After adjustment for age, province of residence, education, smoking pack-years, alcohol consumption, number of live births, age at menarche, total energy intake, and employment in the industry under consideration, the odds ratios were not statistically significant for premenopausal breast cancer among women living $0.8-3.2 \mathrm{~km}$ from $\mathrm{Al}$ smelters compared to the controls ( 8 breast cancer patients and 13 controls; OR = 0.52 [0.21-1.31]) or for those living less than $0.8 \mathrm{~km}$ from smelters (two breast cancer patients and one control; OR = 2.08 [0.18-23.72]). After adjustment for age, province of residence, education, smoking pack years, alcohol consumption, numbers of live births, age at menarche, total energy intake and employment in the industry under consideration, the odds ratios for postmenopausal breast cancer patients were not statistically significant for women living 0.8-3.2 km from Al smelters compared to the controls (19 breast cancer patients and 14 control; $\mathrm{OR}=1.06$ [0.50-2.23]) or for those living less than $0.8 \mathrm{~km}$ from 
smelters (six breast cancer patients and six controls; OR $=0.97$ [0.27-3.41]). For both preand postmenopausal breast cancer patients, the odds ratios for those living greater than 3.2 $\mathrm{km}$ from an $\mathrm{Al}$ smelter were all unity.

Among the strengths of the Pan et al. (2011) population-based study are the relatively large sample sizes and the length of time that participants had lived near Al smelters. A number of potential confounders were controlled, including employment in the specific industry under consideration. The Pan et al. (2011) inquiry has a number of limitations including no information on the ages of the women when they resided near a plant; information was not available for all patients on family history of breast cancer, benign breast disease, BRCA1/2 status or use of oral contraceptives or estrogen replacements. No exposure measures for $\mathrm{Al}$ or any other airborne material were provided.

Donoghue and Coffey (2014) described community health risk assessments for five Australian $\mathrm{Al}$ smelters with $\mathrm{NO}_{2}, \mathrm{SO}_{2}, \mathrm{PM}_{10}$, arsenic, and cadmium emissions that found arsenic accounted for $75 \%$ of the total incremental cancer risk $\left(1.2 \times 10^{-6}\right) 3 \mathrm{~km}$ downwind of these facilities. The 0.3-1.1 acute hazard index for those residents was due to airborne $\mathrm{PM}_{10}$, formaldehyde, $\mathrm{NO}_{2}, \mathrm{SO}_{2}, \mathrm{CO}$, and mercury, but the elevated risk was not related to Al.

Darbre $(2001,2006)$ declared that Al underarm antiperspirants and cosmetics cause human breast cancer, a conclusion based in part on a data from a Comet assay with cultured canine cells (Yiu 2004). However, Yiu (2004) evaluated complex mixtures (e.g., Secret Platinum ${ }^{\circledR}$ for women, Old Spice ${ }^{\circledR}$ for men and Crystal Natural ${ }^{\circledR}$ ) and the Darbre conclusion (2001 (2006) ignored the absence of $\mathrm{AlCl}_{3}$ and $\mathrm{Al}_{2}\left(\mathrm{SO}_{4}\right)_{3}$ mutagenic activity in standard assays (reviewed in IPCS 1997, Krewski et al. 2007, Willhite et al. 2012). Notable among the oftcited reports concerning $\mathrm{Al}$ - induced clastogenesis are those by Banasik et al. (2005) and Lima et al. (2007) who cultured human peripheral lymphocytes for $72 \mathrm{~h}$ with $\mathrm{AlCl}_{3}$. The Lankoff et al. (2006) study with cultured human lymphocytes examined $\mathrm{AlCl}_{3} \bullet 6 \mathrm{H}_{2} \mathrm{O}$ at 4.15-103.75 $\mu \mathrm{M}$ (equivalent to $0.8-21 \mu \mathrm{M} \mathrm{Al}^{+3}$ ) where the higher concentrations induced apoptotic death. The DNA damage occurred after exposure to $40 \mu \mathrm{M} \mathrm{AlCl}_{3}$ (equivalent as 8 $\mu \mathrm{M} \mathrm{Al}^{+3}$ ), a concentration that was at least $67 \mathrm{x}$ normal median human blood $\mathrm{Al}$ concentrations (3.2 $\mu \mathrm{g} / \mathrm{L}$ or $0.12 \mu \mathrm{M})$ (Krewski et al. 2007). These in vitro results are difficult to interpret due to the high $\mathrm{AlCl}_{3}$ concentrations and whether the apoptosis and increased $\mathrm{MN}$ at cytotoxic concentrations were due to $\mathrm{Al}^{+3}$ or to $\mathrm{HCl}$. Nevertheless, reversible $\mathrm{Al}(\mathrm{OH})^{2+}$ binding with DNA bases can occur in vitro, and Al-DNA binding can be attenuated by chelators; these changes are related to $\mathrm{Al}^{+3}$ binding with nucleotide phosphates and these reactions can precipitate DNA crosslinks in vitro (reviewed in Willhite et al. 2012).

Exley et al. (2007b) measured $\mathrm{Al}$ in mastectomy tissues from 17 patients treated for breast cancer. Defatted dry weight Al concentrations were between 4-437 nmol/g. Exley et al. (2007b) suggested 'within-individual trends' were seen for $\mathrm{Al}$ in mammary adipose tissue, but neither those distributions nor the total $\mathrm{Al}$ concentration in mammary fat were significant. No comparisons were made between the Al concentrations in these patients and Al concentrations in mammary adipose tissue from healthy matched donors. Exley et al. 
(2007a) concluded: "we have no direct evidence that the aluminum measured in these breast biopsies originated from antiperspirant".

Mannello et al. (2011) compared $\mathrm{Al}$ concentrations in nipple aspirate from 16 healthy women $(131 \pm 9.6 \mu \mathrm{g} / \mathrm{L})$ to those in 19 women diagnosed with breast cancer $(268 \pm 28.1$ $\mu \mathrm{g} / \mathrm{L})$. Based on the highly significant $(\mathrm{p}<0.0001)$ difference, Mannello et al. (2011) suggested that either human breast tissue accumulates $\mathrm{Al}$ or that the elevated $\mathrm{Al}$ concentrations were related to use of $\mathrm{Al}$-containing underarm antiperspirants. Following up on that suggestion, Darbre et al. (2011) cultured human mammary adenocarcinoma MCF-7 cells with 0 or $0.0001 \mathrm{M}(100 \mu \mathrm{M}) \mathrm{ACH}$ (equivalent to $31 \mu \mathrm{M} \mathrm{Al})$ for 21 weeks. There was no influence of $\mathrm{ACH}$ on cell proliferation, but 50 genes (including mRNAs for five Cabinding proteins) were up-regulated and 57 were down-regulated. No protein synthesis data were included, no effort was made to establish concentration-response relationships and the single concentration examined was $>250 \mathrm{x}$ the median $\mathrm{Al}(0.12 \mu \mathrm{M})$ present in plasma from healthy humans (reviewed in Krewski et al. 2007).

There are at least two large epidemiology studies that examined antiperspirant/deodorant use and risk of female breast cancer, one of which was a population-based case-control study that found no relation whatsoever (Mirick et al. 2002). The second suggested an earlier age for diagnosis of the disease with increasing antiperspirant use (McGrath 2003). McGrath (2009) suggested a novel, indirect potential [but not empirically-verified] observation between topical Al-containing antiperspirant use and human breast and prostate cancer and put forward the idea that $\mathrm{Al}(\mathrm{OH})_{3}$ obstruction of sweat glands in an as-yet unidentified manner increased systemic uptake of "sex hormones and phermones (androgens) from apocrine sweat glands".

Fakri et al. (2006) compared antiperspirant use by 54 women who presented with breast cancer to that of 50 healthy women of similar age; $82 \%$ of the healthy women reported antiperspirant use compared to $51.8 \%$ of those with the disease. Fakri et al. (2006) concluded that underarm antiperspirant use had no association with risk of female breast cancer, but that family history and oral contraceptive use were related to excess risk. However, neither Fakri et al. (2006), Darbre (2001, 2006, 2011) nor McGrath (2003, 2009) accounted for BRCA1/2 mutations, the dose and duration of oral contraceptives or addressed other well-known risk factors for human breast cancer (Lee et al. 2008).

Namer et al. (2008) identified 59 studies published to 2007 in an effort to determine a) whether existing biological data support an association between the use of underarm deodorants/antiperspirants and female breast cancer, b) whether use of those products increased breast cancer risk and c) whether data exist to support a causal relation between use of underarm deodorants/antiperspirants and increased risk for breast cancer. Of the 59 candidate studies, 19 were judged appropriate to evaluate the hypothesis. Namer et al. (2008) concluded that there was "no scientific evidence to support the hypothesis" that use of Al-containing antiperspirants increased the incidence of human mammary upper outer quadrant gland cancer. 
Alumina-on-alumina total hip arthroplasty has been popular for at least three decades (Hannouche et al. 2011) during which time at least three case reports of soft tissue sarcoma have appeared (Ingram 1988). Yoon et al. (2011) described the case of an 80-year-old woman who received a titanium hip prosthesis with an alumina-on-alumina bearing. At five years after surgery, she developed a palpable cystic mass around her greater trochanter. Upon resection the mass was identified as a malignant fibrous histiocytoma and metastatic nodules were present in her lungs and axillary lymph nodes; her death was attributed to multiple lung metastases. Yoon et al. (2011) noted the similarities in their case to that detailed by Ryu et al. (1987) who noted the contribution of wear debris to sarcomatous degeneration.

\section{Nanomaterials}

Synthetic alumina, mixed $\mathrm{Al}$ silicate $\left(\mathrm{SiO}_{2} / \mathrm{Al}_{2} \mathrm{O}_{3}\right)$ and $\mathrm{Al}$ oxide nano materials have a host of industrial (Kaste and Rice 2004, Najafpour et al. 2012, Patra et al. 2012, Yu et al. 2011), agricultural (Costa et al. 2011, Stadler et al. 2010), consumer product (Maquire-Boyle et al. 2012, Sadiq et al. 2009) and medical (Monteiro-Riviere et al. 2010, Li et al. 2011c, Zhao and Castranova 2011) applications. Aluminum-reinforced carbon nanotubes and composites with $\mathrm{Al}$ oxide coatings are increasingly common (Gupta et al. 2011, Keshri et al. 2010, Seo et al. 2012).

Nanosized $\mathrm{Al}$ oxide particles are also generated during $\mathrm{Al}$ welding and corundum grinding (Curwin and Bertke 2011, Dasch and D'Arcy 2008, Gomes et al. 2012a, 2012b, Pfefferkorn et al. 2010). The $\mathrm{Al}$ nanoparticles generated during $\mathrm{Al}$ fettling, cutting and molding are comprised of metallic $\mathrm{Al}$ and $\mathrm{Al}$ oxides and as are those those generated during $\mathrm{Al}$ thermal spray (Bémer et al. 2010). The primary Al nanoparticles present in Al welding fume (10-75 $\mathrm{nm}$ ) agglomerate in air by adhesion into larger particles and the primary $\mathrm{Al}$ nanoparticles in corundum (crystalline $\mathrm{Al}_{2} \mathrm{O}_{3}$ ) dust (10-35 nm) also aggregate (Schneider et al. 2013).

Controversy exists over the (potential) toxicity of engineered nanotubes, nanocapsules, nanospheres, nano quantum dots and nanoshells (Card et al. 2011, Nel et al. 2006, Oberdörster et al. 2005, Powers et al. 2013, Yokel and MacPhail 2011). Some (Chen et al. 2008, Oesterling et al. 2008, Zhang et al. 2011b) have suggested nanoscale alumina is a more potent pro-oxidant than bulk or common micron-sized $\mathrm{Al}$ oxides whereas others (Radzium et al. 2011, Sun et al. 2011b) concluded that $\mathrm{Al}_{2} \mathrm{O}_{3}$ nanomaterials pose little hazard. Oesterling et al. (2008) observed that primary nano alumina agglomerated at physiological $\mathrm{pH}$ in serum-containing culture media giving rise to particles ranging from nano to micron size. The primary particles agglomerate in culture media due to hydrophobic and Van der Waals forces and binding with protein and polysaccharides (Powers et al. 2006).

Data that might be taken to support the view that $\mathrm{Al}$ nanoparticles may be of greater concern than similar micron-sized particles include those from Lordan et al. (2011) who cultured human HepG2 cells with different montmorillonite particles (one tactoid at 30-100 $\mu \mathrm{m}$ and one agglomerated at 3-35 $\mu \mathrm{m}$ ). After $24 \mathrm{~h}$ in culture these Al particles clumped into larger bundles to the point that the cultures were obscured and the cells could not be seen under a light microscope. At these concentrations there was an increase in intracellular reactive 
oxygen and viability was reduced $23-27 \%$, but there was no increase in caspase-3/7 activity. These particles were relatively non-toxic in that at $500-1000 \mu \mathrm{g} / \mathrm{ml}$ there was no or only a slight elevation in LDH release. Lordan et al. (2011) considered that the death of these cells was not due to apoptosis; death was attributed to necrosis, but no histologic or other data were presented to support that conclusion. Long-term dietary studies with refined montmorillonite and related Al silicate particles in humans (Afriyie-Gyawu et al. 2008) and rodents (Afriyie-Gyawu et al. 2005, Phillips 1999, Phillips et al. 2008, Wiles et al. 2004) found no evidence for particle accumulation or toxicity, but fatty hepatic degeneration occurred in mice after chronic feeding as a result of particle binding with choline in the intestine (Wilson 1953, 1954).

Prabhakar et al. (2011) compared the acute oral toxicity of bulk $\mathrm{Al}_{2} \mathrm{O}_{3}(99 \%)$ with that of 30 $\mathrm{nm}$ or $40 \mathrm{~nm} \mathrm{Al} \mathrm{O}_{3}$ in rats given $0,500,1000$ or $2000 \mathrm{mg} / \mathrm{kg}$. No adverse signs were evident and food consumption and organ weights were no different from those of the controls. Among rats given 30 or $40 \mathrm{~nm} \mathrm{Al}_{2} \mathrm{O}_{3}$ there was a significant increase in hepatic 1PO; catalase activity increased, reduced GSH declined and SOD activity decreased. These changes resolved by day 14 save in those given the highest dose. Intubation of 30 or $40 \mathrm{~nm}$ $\mathrm{Al}_{2} \mathrm{O}_{3}$ caused greater $\mathrm{GSH}$ reductions than did an equivalent dose of bulk $\mathrm{Al}_{2} \mathrm{O}_{3}$. Dilated central veins and distended portal tracts developed in rats given $2000 \mathrm{mg} / \mathrm{kg}$ of the nano $\mathrm{Al}_{2} \mathrm{O}_{3}$ whereas rats given an identical dose of bulk $\mathrm{Al}_{2} \mathrm{O}_{3}$ showed no anomalies. The extent of LPO was greater in rats given nano $\mathrm{Al}$ than in those given bulk $\mathrm{Al}$, but there was no significant difference in hepatic LPO between rats given the 30 or $40 \mathrm{~nm} \mathrm{Al}{ }_{2} \mathrm{O}_{3}$. Prabhakar et al. (2011) attributed the higher oxidant response in the liver after nano $\mathrm{Al}$ compared to bulk Al to a higher delivered dose but no empirical data were presented to support that conclusion.

Substantial differences exist regarding Al nanoparticle cytotoxicity in vitro. Many of these differences likely relate to the physical form(s) of these materials in culture media (Powers et al. 2006). There is no question that sufficiently high $(\mu \mathrm{M}-\mathrm{mM})$ concentrations of synthetic $\mathrm{Al}$ nanoparticles can kill cultured fibroblast, keratinocyte, melanoma, and mammary carcinoma cells (Maduray et al. 2012, Rocha et al. 2012). Rocha et al. (2012) attributed Al nanoparticle-induced cytotoxicity to generation of $\mathrm{O}_{2} \bullet^{-}, \mathrm{OH} \bullet$ and related free radicals. After cultured rat alveolar macrophages were exposed to nanoscale metallic $\mathrm{Al}$ at 100-250 $\mu \mathrm{g} / \mathrm{ml}$ for $24 \mathrm{~h}$ significant reductions in viability were observed. When macrophages were treated with $\mathrm{Al}_{2} \mathrm{O}_{3}$ nanoparticles under the same conditions, phagocytosis was impaired but only 'marginal' reductions in viability were seen (Wagner et al. 2007). In contrast, there was no evidence of cytotoxicity after $24 \mathrm{~h}$ culture of human epidermal keratinocytes with 50-80 $\mathrm{nm} \mathrm{Al}$ nanoparticles at $0.0004-4.0 \mathrm{mg} / \mathrm{L}$ (Monteiro-Riviere et al. 2010) and there was no significant toxicity in human lung fibroblasts (Zhang et al. 2011c), human lung epithelial 1929 and A549 carcinoma cells (Kim et al. 2010), human foreskin BJ and mouse fibroblasts (Radziun et al. 2011) or primary human brain microvascular endothelial (hCMEC/D3) cells (Chen et al. 2008). Extraordinarily high concentrations in vitro ( $\geq 100 \mu \mathrm{g} / \mathrm{ml}$ ) can reduce viability, increase cell shrinkage and promote apoptosis, but whether those changes are specific to $\mathrm{Al}^{+3}$ released from the particles or whether these represent non-specific particulate damage is not clear. Differences in nano $\mathrm{Al}$ cytotoxicity in vitro depend on 
particle behavior just as was the case in vivo after inhalation of 10 or $40 \mathrm{~nm} \gamma-\mathrm{AlOOH}$ (Pauluhn 2009a).

Neutral Al nanoparticles can bind purines and pyrimidines in vitro (Jin et al. 2012). High concentrations (5-10 mg/L) of $\mathrm{Al}_{2} \mathrm{O}_{3}$ nanoparticles increase $\mathrm{ROS}$, increase TNF- $\mathrm{a}$, increase IL-6 and induce cyclooxygenase- 2 in cultured murine macrophages (Nishanth et al. 2011). Aluminum nanoparticles increased micronuclei in cultured Chinese hamster ovary cells, but failed to increase the frequency of SCEs (Di Virgilio et al. 2010). These particles (20-30 $\mathrm{nm}$ ) were neither clastogenic for cultured human fibroblasts (Tsaousi et al. 2010) nor mutagenic in $S$. typhimurium strains TA 100 , TA 1535 , TA 98, TA97a or TA 102 either in the presence or absence of fortified rat liver S9 (Balasubramanyam et al. 2010, Pan et al. 2010).

Dong et al. (2011) compared the toxicity of four nano $\gamma$-aluminas to that of $\mathrm{Al}_{2} \mathrm{O}_{3}$ powder in cultured C17.2 neural stem cells (NSC). The study included cell morphology, viability, membrane integrity, necrosis, apoptosis and particle uptake. All of these primary nano $\gamma$ alumina particles were crystals; sample numbers 1, 2 and 4 were rods and sample 3 particles were of irregular shapes. The chemical purity was $99.9 \%$ and the mean primary particle size was $6.3-18.9 \mathrm{~nm}$. The agglomerated particle sizes in the media varied from $420-650 \mathrm{~nm}$. Particle solubility in the media ranged from less than the limit of detection for sample number 1 to $180 \mathrm{ng} \mathrm{Al} / \mathrm{ml}$ for sample number 2. Irregular micron size crystalline $\mathrm{Al}_{2} \mathrm{O}_{3}$ particulates $(402 \mathrm{~nm}$ ) were used as a reference and these had the highest solubility (920 ng $\mathrm{Al} / \mathrm{ml})$ of all of the forms.

Dong et al. (2011) cultured the NSC in 10\% fetal bovine serum and 5\% horse serum under humidified $5 \% \mathrm{CO}_{2}$ and $95 \%$ air at $37^{\circ} \mathrm{C}$ for $24 \mathrm{~h}$ with 0 or $10-500 \mu \mathrm{g} / \mathrm{ml}$ test material. All of the nano $\mathrm{Al}$ particles aggregated to the point that they had similar sizes in the media (450-650 nm). Concentration-dependent toxicity was observed after treatment with nano sample 4 at $72 \mathrm{~h}$. The duration of exposure (up to three days) failed to influence cell viability and there were no adverse effects of media pre-treated with alumina (to evaluate the influence of nutrient depletion) on viability. A concentration-related release of LDH was observed in all $\mathrm{Al}$ nano-treated cultures, but the differences between the four types of $\mathrm{Al}$ nano-forms were small. After $24 \mathrm{~h}$ many particles accumulated in the NSC cytoplasm, but there were no particles in the nucleus. There were no ultrastructural anomalies at 24 or $72 \mathrm{~h}$ culture with any of the Al nanoforms. A concentration-dependent increase in ROS was seen at $24 \mathrm{~h}$ following treatment with $100 \mu \mathrm{g} / \mathrm{ml} \mathrm{N} 1-\mathrm{N} 4$ and the increased ROS was consistent with concentration-dependent reductions in viability. There was no evidence of apoptosis following exposure to nanoAl (N1-N4) or $\mathrm{Al}_{2} \mathrm{O}_{3}$ at $24 \mathrm{~h}$. Dong et al. (2011) concluded that alumina particles were readily internalized by cultured cells but that the cytotoxicity of nano $\gamma$-alumina in cultured NSC cells was low. The Dong et al. (2011) study is important because it compared the toxicity of various agglomerated $\mathrm{Al}$ nanoparticles to that of conventional $\mathrm{Al}_{2} \mathrm{O}_{3}$ and found that none of the $\mathrm{Al}$ nanoforms were significantly more toxic than the bulk $\mathrm{Al}_{2} \mathrm{O}_{3}$. However, the brief durations of exposure and the in vitro nature of the study make extrapolations to in situ conditions tenuous. 
Definitive studies on the pulmonary toxicity of $\mathrm{Al}$ oxide nanoparticles are those by Pauluhn (2009a, 2009b, 2009c, 2011) and Adamcakova-Dodd et al. (2012). These studies point to general principles of the behavior of inhaled ultrafine $\mathrm{Al}$ particles. One goal of the Pauluhn (2009a) investigation was to "test whether the pulmonary effects (toxicity and fate) following exposure to aluminum oxyhydroxides of differing primary and agglomerated particle size are more dependent on the primary than agglomerated particle size". Pauluhn $(2009 \mathrm{~b}, 2009 \mathrm{c})$ then followed the initial observations with more detailed analyses of cumulative lung particle burden in relation to inhaled concentrations, particle volume, macrophage activity and pulmonary inflammation. The Pauluhn (2009a, 2009b, 2009c, 2011) series explains Al nanoparticle characteristics [primary particle size, chemical composition, shape, diameter and surface properties (e.g., smooth, thin) that determine relative flexibility/rigidity] in relation to agglomeration, deposition and retention in the respiratory tract. Among the generalizations that come from this and related work on the inhalation toxicology of poorly soluble ultrafine particulates include the observation that acute pulmonary inflammation after high dose exposure appears more closely related to particle surface area and reactivity, but the sustained inflammation seen after prolonged pulmonary retention depends more on particle volume than on particle surface area.

Pauluhn (2009a) exposed groups of 54 adult male Wistar Bor:WISW (SPF-Cpb) rats by nose-only inhalation $6 \mathrm{~h} /$ day, 5 days/week for 4 weeks to $0,0.4,3$ and $28 \mathrm{mg} / \mathrm{m}^{3}$ of 10 or 40 $\mathrm{nm}$ calcined $\mathrm{Al}$ oxyhydroxide $(\gamma-\mathrm{AlO}(\mathrm{OH})$ or boehmite $)$ crystals. The particle mass median aerodynamic diameter (MMAD) of one boehmite was $1.7 \mu \mathrm{m}$ (10 nm Dispersal ${ }^{\circledR}$ of 39.4\% $\mathrm{Al})$ and that of the other was $0.6 \mu \mathrm{m}\left(40 \mathrm{~nm}\right.$ Pural ${ }^{\circledR}$ of $\left.43.9 \% \mathrm{Al}\right)$. Despite the differences in primary particle size, the geometric diameters of the agglomerated particles in the inspired air were identical ( 2.7 and $2.6 \mu \mathrm{m}$, respectively). The post-exposure observation period was three months. An interim sacrifice was made on day 10 during exposure and post-exposure sacrifices were carried out one day after the end of exposure then at 12 days, 33 days and 91 days after termination of exposure. Twelve animals were exposed per concentration and time-point; six were subjected to bronchoalveolar lavage and histopathology and six were used in determination of $\mathrm{Al}$ tissue concentrations. Pulmonary inflammation was assessed by measuring total protein and total cell counts, numbers of neutrophilic granulocytes (PMNs) and LDH, $\gamma$-glutamyltransferase ( $\gamma$-GT) and $\beta$-N-acetylglucosaminidase ( $\beta$-NAG) activities in bronchoalveolar lavage fluid (BALF) and histopathological examination included all five lung lobes, bronchi, lung-associated lymph nodes, olfactory bulb, ethmoid turbinates and the olfactory nerve. Aluminum concentrations were measured in urine, brain, the right lung lobe, BAL cells, hilar lymph nodes, kidney and liver.

There were no deaths, clinical signs or treatment-related changes in body weight. As the concentration and duration of exposure increased, $\mathrm{Al}$ concentrations in the lung increased. The increase in lung $\mathrm{Al}$ was greater in rats that inhaled the $40 \mathrm{~nm}$ particulate than in rats that inhaled the $10 \mathrm{~nm}$ particulate. Rats that inhaled the $40 \mathrm{~nm}$ particulate consistently received higher daily $\mathrm{Al}$ doses $(1.85,15.7$ and $130 \mu \mathrm{g} /$ day) than rats that inhaled identical concentrations of the $10 \mathrm{~nm}$ particulate (1.06, 8.7 and $77.2 \mu \mathrm{g} /$ day). Pulmonary Al elimination $t_{1 / 2}$ values were similar for both particulates at the lower concentrations, but pulmonary elimination by rats inhaling $28 \mathrm{mg} / \mathrm{m}^{3}$ found the smaller $10 \mathrm{~nm}$ particulate had an $\mathrm{Al}$ elimination half-time that was more than twice that of the larger $40 \mathrm{~nm}$ particulate. 
There was no measurable increase in $\mathrm{Al}$ in lung-associated lymph nodes after rats inhaled 0.4 or $3 \mathrm{mg} / \mathrm{m}^{3}$ of either preparation and there were no time or concentration-dependent increases in brain, liver or kidney $\mathrm{Al}$. There were no changes in urinary $\mathrm{Al}$ associated with either duration or magnitude of exposure.

There were no significant differences in BALF cytology or biochemical parameters at 0.4 or $3 \mathrm{mg} / \mathrm{m}^{3}$ of either preparation, but after rats inhaled $28 \mathrm{mg} / \mathrm{m}^{3}$ was there an inflammatory response in the lung. Histology after four weeks of exposure to the highest concentration found particles within the alveoli and particle accumulation in enlarged, foamy alveolar macrophages. Slight to minimal focal septal thickening, increased numbers of epithelial cells and increased inflammatory infiltrate were evident. Increased LDH activity followed a similar profile for both the 10 and $40 \mathrm{~nm}$ boehmites and increased levels of $\beta-\mathrm{NAG}$, total protein and $\gamma$-GT followed increased total cell and PMN counts. Focal septal collagen increased only after rats inhaled $28 \mathrm{mg} / \mathrm{m}^{3}$ of either preparation. Even though measurable $\mathrm{Al}$ was present in lungs from rats inhaling 0.4 or $3 \mathrm{mg} / \mathrm{m}^{3}$, there were no adverse effects in the lung despite the sensitive endpoints employed to evaluate toxicity. Histopathological study of the bulbus olfactorius and ethmoid nasal passages found neither signs of local tissue alterations nor evidence for $\gamma-\mathrm{AlO}(\mathrm{OH})$ particle translocation. The results demonstrated that the size of the agglomerated $\gamma-\mathrm{AlO}(\mathrm{OH})$ particles was more closely related to total lung particle burden than was the size of the primary particle.

Lung $\mathrm{Al}$ concentrations increased after male C57B1/6 mice inhaled (WB exposure) 3.3 $\mathrm{mg} / \mathrm{m}^{3}$ of a dry aerosol of $2-4 \times 2800 \mathrm{~nm} \mathrm{Al}_{2} \mathrm{O}_{3}$ nanowhiskers, $4 \mathrm{~h} /$ day, 5 days/week for two or four weeks (Adamcakova-Dodd et al. 2012). Measures of particle size distribution found the primary particles formed $150 \mathrm{~nm}$ agglomerations with protruding nanowhiskers. Although pulmonary macrophage increased with duration of exposure, there were no signs of pulmonary damage or inflammation (based on LDH, IL-6, IFN- $\gamma$, MIP-1a, TNF-a and MIP-2 in BAlF) among treated mice compared to their controls. Methacholine challenge found no evidence for airway hyperreactivity and histology found no sign of airway remodeling, inflammation, lymphoid aggregates or fibrosis. The results from AdamcakovaDodd et al. (2012) are consistent with the results from Pauluhn (2009a), but the former is limited by examination of only a single concentration.

Pauluhn (2009b) extended his work to quantify exposure using the kinetics of inhaled 10 and $40 \mathrm{~nm} \gamma-\mathrm{AlO}(\mathrm{OH})$ particulates. The pulmonary elimination $\mathrm{t}_{1 / 2}$ values for $\gamma-\mathrm{AlO}(\mathrm{OH})$ increased as the particle concentrations in the inspired air increased. The $t_{1 / 2}$ was longer for the $10 \mathrm{~nm}$ (177 days) than for the $40 \mathrm{~nm}$ (94 days) particles and the elimination rates correlated with lung burden. The cumulative lung particle burden was proportional to the PM concentrations in the inspired air; rats that inhaled the highest $\gamma-\mathrm{AlO}(\mathrm{OH}) \mathrm{PM}$ concentrations accumulated the highest particle concentrations in their lungs. Rats that inhaled the $40 \mathrm{~nm}$ PM had higher pulmonary loads than those that inhaled an identical concentration of the $10 \mathrm{~nm}$ particles. Pulmonary inflammation (measured as relative PMN counts) was most closely correlated $(r=0.93-0.97)$ with mass-based measures of dose than with particle surface area. Pulmonary inflammation was not evident when lung particle loads did not impede normal macrophage clearance. These data point to the conclusion that the toxicity of $\gamma-\mathrm{AlO}(\mathrm{OH})$ in rat lung was not due to leaching or dissolution of $\mathrm{Al}^{+3}$ from these 
non-redox active agglomerates, but it was reflected in the capacity of pulmonary macrophages to clear these poorly-soluble particles.

The work by Pauluhn (2009c) builds on concepts of pulmonary particle overload and toxicity in the lung (Oberdörster 1995, Oberdörster et al. 2005). Pulmonary overload has been defined as a two- to four-fold reduction in alveolar clearance beginning when pulmonary macrophages accumulate a particle mass $\geq 60 \mu \mathrm{m}^{3}$ and become immobilized. This value is equivalent to a lung particle burden of $\sim 1 \mathrm{mg} / \mathrm{g}$ (ILSI 2000). In the case of 10 and $40 \mathrm{~nm} \gamma-\mathrm{AlO}(\mathrm{OH})$ particles, the size of their closely-packed, poorly soluble agglomerates leads to high composite volumes of phagocytized particles. A smaller total nanoparticle mass than that seen with larger microsized particles can exceed the volumetric overload limits of pulmonary macrophages. It is only after sufficient agglomerates are retained in immobilized macrophages that pulmonary inflammation was evident in rats that inhaled 10 or $40 \mathrm{~nm} \gamma-\mathrm{AlO}(\mathrm{OH})$. The work by Pauluhn (2009a, 2009b, 2009c) supports the concept that prolonged pulmonary retention and sustained inflammation depend upon particle volume as contrast to particle surface area.

Pauluhn (2011) extrapolated the $\gamma-\mathrm{AlO}(\mathrm{OH})$ data together with the results of other studies on ultrafine PM to calculate a generic OEL based on volume-based mass concentrations. This OEL $\left(0.54 \mu \mathrm{PM}_{\mathrm{resp}} / \mathrm{m}^{3}\right)$ is designed to preclude lung particle overload and prevent intraluminal pulmonary inflammation after exposure to poorly soluble nano- to submicronsize PM. Assumptions implicit to those calculations were that the inhaled Al PM presents no risk for neoplastic lung disease and that systemic uptake of the Al PM is insignificant. In the case of inhaled $\gamma-\mathrm{AlO}(\mathrm{OH})$ there was no evidence for extra pulmonary translocation (Pauluhn 2009a). Pauluhn (2011) advanced the concept of non-reactive lung particle overload as the determining factor in health risks posed by airborne Al nanoparticles. The potential for pulmonary inflammation and damage associated with exposure to airborne nanoscale aluminas is related primarily to the size and composite volume of the agglomerated material as contrast to the size of the primary crystals.

\section{Standards and guidelines}

Current standards and guidelines include German and United States regulations on $\mathrm{Al}$ in foods, the EFSA Tolerable Weekly Intake (TWI), the Minimal Risk level (ATSDR 2008), the WHO drinking water limit, the French deliberations on Al in cosmetics (AFSSAPS 2011) and Occupational Exposure limits (OELs) (Table 7). At the present time, there is no European Union OEL for metallic Al or its compounds (Health Council of the Netherlands 2010).

\section{Food standards}

The US FDA considers common Al compounds used as multiple purpose, sequestrant, anticaking, leavening and emulsifying agents in foods 'generally recognized as safe' (GRAS) (Yokel 2012). Stahl et al. (2011) summarized German regulations on the maximum permissible levels of $\mathrm{Al}$ in food. Australia and New Zealand (FSANZ 2011) as well as Brazil (Aparecida 2009) have adopted standards for the maximum Al content in foods. 
The United States has been content to require warning labels on PN materials that contain > $25 \mu \mathrm{g} \mathrm{Al} / \mathrm{L}$ (US FDA 1998, 2003). The United Kingdoma Medicines and Healthcare Regulatory Agency (2010a, 2010b) issued contraindications for Ca gluconate packaged in small-volume glass containers $(10 \mathrm{ml})$ used to compound PN solutions. The intent of the UK action is to reduce the adverse effects of parenteral $\mathrm{Al}$ on bone mineralization and neurological development in premature infants.

TWI

The European Commission has been considering directives to ensure that the EFSA recommended TWI (equivalent to $280 \mu \mathrm{g} / \mathrm{kg}$-day) (Benford et al. 2012) for dietary $\mathrm{Al}$ is not exceeded (EFSA 2011). In contrast to the EFSA (2011, 2013) assumption that gastrointestinal uptake of all ingested $\mathrm{Al}$ materials is equivalent to that measured for $\mathrm{Al}$ citrate, Berthon (2002) compared the different dietary constituents that either promote (e.g., ascorbate, citrate, glutamate, malate, oxalate, tartrate) or retard (e.g., phosphate, soluble silicates) Al uptake. Under current EFSA $(2011,2013)$ and Benford et al. (2012) guidance, Al exposures associated with consumption of trace levels of bentonite/montmorillonite $\left.\left([\mathrm{Na}, \mathrm{Ca})_{0.33}(\mathrm{Al}, \mathrm{Mg})_{2}\left(\mathrm{Si}_{4} \mathrm{O}_{10}\right)(\mathrm{OH})_{2} \bullet \mathrm{nH}_{2} \mathrm{O}\right]\right)$ in wine that are not systemically available (Wiles et al. 2004) are cumulative with total $\mathrm{Al}$ exposures from more water-soluble and bioavailable forms like $\mathrm{Al}_{2}\left(\mathrm{SO}_{4}\right)_{3}$ (van der Voet and de Wolff 1986-87).

MRL

ATSDR (2008) calculated an intermediate (15-364 day) minimal risk level (MRL) for ingested Al of $1.0 \mathrm{mg} / \mathrm{kg}$-day. The ATSDR (2008) identified a NOAEL of $26 \mathrm{mg} / \mathrm{kg}$-day and applied a total uncertainty factor of 100 and used a modifying factor of 0.3 (to account for differences in gastrointestinal uptake of $\mathrm{Al}$ lactate compared to the $\mathrm{Al}$ forms in drinking water and food) to calculate the intermediate MRL. The ATSDR (2008) also calculated a chronic ( 2365 day) MRL for ingested $\mathrm{Al}$ of $1.0 \mathrm{mg} / \mathrm{kg}$-day.

\section{Drinking water}

In 1984 the WHO recommended a maximum drinking water concentration of $0.2 \mathrm{mg} \mathrm{Al} / \mathrm{L}$ to control discoloration. This recommendation was based on consumer complaints of 'foul' or discolored water at $\mathrm{Al}$ concentrations $>0.1 \mathrm{mg} / \mathrm{L}$ (WHO 2004, 2010).

\section{Cosmetics}

The US FDA limits the concentrations of $\mathrm{Al}$ in cosmetics as the polymerized $\mathrm{Al}_{\mathrm{y}}(\mathrm{OH})_{3 \mathrm{y}-2} \mathrm{Cl}_{2} \cdot \mathrm{H}_{2} \mathrm{O}$ to $\leq 25 \%$ w/v and $\mathrm{Al}_{2} \mathrm{Cl}_{7} \mathrm{H}_{7} \mathrm{O}_{7} \mathrm{Zr}_{2}$ to $\leq 20 \%$ w/v (US DHHS 1982, 2003). The US FDA commented that underarm deodorants with higher Al concentrations (e.g., up to 35\%) can be skin irritants; increasing the concentrations of $\mathrm{Al}$ antiperspirant ingredients in these products "increases the acidity of the material and irritation of the skin". The final decision included epidemiologic data from Graves et al. (1990) and concluded: "The agency does not find the current evidence sufficient to conclude that aluminum from antiperspirant use results in Alzheimer's disease." 
On January 4, 2013 the European Commission limited the concentration of $\mathrm{AlxZr}(\mathrm{OH}) \mathrm{yCl}_{2}$ and $\mathrm{AlZrClOH}$ glycine complexes in cosmetics to not more than $20 \%$ and prohibited their use in aerosol spray dispensers (EC 2013).

Vaccines

Of the vaccines currently registered in the United States (Leventhal et al. 2012), 12 contain $\mathrm{Al}(\mathrm{OH})_{3}$ and 23 contain other $\mathrm{Al}$ compounds (Kelso et al. 2012). Standard adjuvants in diphtheria, tetanus, and pertussis (DTP) and other vaccines include alum $\left(\mathrm{AlK}\left(\mathrm{SO}_{4}\right)_{2}\right.$, $\mathrm{Al}_{2}\left(\mathrm{SO}_{4}\right)_{3}$, Adju-Phos $\left(\mathrm{Al}\left(\mathrm{PO}_{4}\right)_{3}\right)$ Imject Alum $\left(\mathrm{Al}(\mathrm{OH})_{3}+\mathrm{MgOH}\right)$ and alhydrogel $\left(\mathrm{Al}(\mathrm{OH})_{3}\right)($ Kelso et al. 2012, Marrack et al. 2009). The United States FDA limits the elemental $\mathrm{Al}$ content of a single vaccine injection to $0.85 \mathrm{mg}$ (Eickhoff and Mayers 2002), a value equivalent to $2.45 \mathrm{mg} \mathrm{Al}(\mathrm{OH})_{3}$ per dose.

\section{OELS}

Different OELs for Al have been adopted in different countries (ILO 2011, IFA 2011a, 2011b); some countries rely on OELs developed in the United States whereas others rely on those adopted by the Deutsche Forschungsgemeinshaft (DFG), Safe Work Australia, the United Kingdom Health \& Safety Executive, the Health Council of the Netherlands or by the Nordic Expert Group (Arbete Och Hälsa) (Table 7). Some OEls are legally enforceable limits (e.g., OSHA Permissible Exposure Limits (PELs), 1993, Institut für Arbietsschutz der Deutschen Gesetzlichen Unfallversicherung (IFA), 2011b). The enforceable limits may be identical to or may be substantially different from non-binding 'guidance' values for the same material (Deveau et al. 2014).

Riihimäki and Aitio (2012) reviewed occupational exposure to $\mathrm{Al}$ welding fume in relation to $\mathrm{Al}$ concentrations in urine and blood and concluded that urinary $\mathrm{Al}$ was a more sensitive indicator of Al uptake and body burden than serum Al. Yokel (2012) calculated daily Al uptake from the lung after exposure to workplace air containing $25-2500 \mu \mathrm{g} / \mathrm{m}^{3}$ and found that pulmonary uptake $(0.6-8 \mu \mathrm{g} / \mathrm{kg}$-day) was substantially greater than that received after swallowing airborne Al particles $(0.008-1.0 \mu \mathrm{g} / \mathrm{kg}$-day). The Finnish Institute of Occupational Health adopted a limit of $6 \mu \mathrm{mol} / \mathrm{L}$ for $\mathrm{Al}$ in pre-shift urine after two days without Al welding. The current German Biological Workplace Chemical Tolerance Value (BAT) is $2.2 \mu \mathrm{mol} \mathrm{Al} / \mathrm{g}$ creatinine (pre-or postshift) corresponding to the MAK maximum Al concentration in workplace air of $1.5 \mathrm{mg} / \mathrm{m}^{3}$ (respirable fraction). The Polish MAC for airborne $\mathrm{Al}_{2} \mathrm{O}_{3}$ dust $\left(1.05 \mathrm{mg} / \mathrm{m}^{3}\right)$ corresponds to $2.1 \mu \mathrm{mol} \mathrm{Al} / \mathrm{L}$ urine. Riihimäki and Aitio (2012) proposed a urinary Al 'action limit' of $3 \mu \mathrm{mol} / \mathrm{g}$ (corrected to a relative urine density of 1.021 or $2.3 \mu \mathrm{mol} \mathrm{Al} / \mathrm{g}$ creatinine) based on reports of impaired cognition in $\mathrm{Al}$ welders with many years of exposure to the fume. This proposed limit assumes workers do not consume Al-containing antacids or buffered aspirin and that diet and beverages do not contribute to elevated urinary Al.

The Health Council of the Netherlands (2010) considered the available data insufficient to derive health-based OELs for metallic $\mathrm{Al}$ or $\mathrm{Al}$ compounds other than $\mathrm{ACH}$. The Health Council assigned an OEL to ACH of $0.05 \mathrm{mg} / \mathrm{m}^{3}$ based on the development of multifocal granulomatous pneumonia and microgranulomas in the peribronchial lymph nodes of rats 
and guinea pigs inhaling ACH (Steinhagen et al. 1978). The Health Council of the Netherlands (2010) emphasized that except for $\mathrm{ACH}$, existing data are not adequate to recommend OELs for bulk Al metal or other Al compounds. The Nordic Expert Group (2011) concurred with the Health Council of the Netherlands (2010) in that the repeat exposure 'minimal' inhalation LOAEL $\left(0.061 \mathrm{mg} \mathrm{Al} / \mathrm{m}^{3}\right)$ was an appropriate point of departure for derivation of an OEL for ACH.

\section{Synthesis and conclusions}

The results of the present review demonstrate that health risks posed by exposure to inorganic $\mathrm{Al}$ depend on its physical and chemical forms and that the response varies with route of administration, magnitude, duration and frequency of exposure. These results support previous conclusions that there is little evidence that exposure to metallic $\mathrm{Al}$, the $\mathrm{Al}$ oxides or its salts increases risk for AD, genetic damage or cancer (Krewski et al. 2007). The present review also found that the notion that $\mathrm{Al}$ dose can be accounted for, measured by, and the data interpreted as 'total Al' (e.g., Sorenson et al. 1974), as contrast to chemicalspecific analyses (BASF 2011, Rödelsperger et al. 1987), can lead to possibly inappropriate conclusions regarding $\mathrm{Al}$ health risks.

The present review found that the majority of the rodent studies (Tables 2 and 3) are of limited relevance for $\mathrm{Al}$ human health risk assessment. The designs of exploratory studies (e.g., Abdel-Aal et al. 2011a, 2011b, Abu-Taweel et al. 2011a, 2011b, Akiyama et al. 2012, Cheng et al. 2012, Cui et al. 2012, Elsaid et al. 2011, Garrosa et al. 2011, Kumar et al. 2011, Moselhy et al. 2011, Sun et al. 2011b, Thirunavukkarasu et al. 2010, 2011, 2012, Viezeliene et al. 2011, 2012, Wang et al. 2010a, Xiao et al. 2011) and of even those that meet current regulatory guidelines (e.g., Hirata-Koizumi et al. 2011a, 2011b) failed to include concurrent controls treated in an identical manner with equimolar doses of the hydrolysis products (e.g., $\mathrm{HCl}, \mathrm{H}_{2} \mathrm{SO}_{4}$ ). It is clear these hydrolysis products confound the interpretation of in vivo (e.g., Hirata-Koizumi et al. 2011a) and in vitro (Castorina et al. 2010, Cifone et al. 1987, Güngör et al. 2010, Kamalov et al. 2011, Morita et al. 1989, 1992) data, particularly where media $\mathrm{Al}$ concentrations $\geq 10 \mu \mathrm{M}$ are equivalent to lethal or near-lethal serum $\mathrm{Al}$ concentrations in humans (Krewski et al. 2007). Only a handful of the relatively large numbers of published studies were designed for regulatory purposes. While ip injections and gastric intubations represent convenient routes of administration in the laboratory, inhalation and dietary studies are more appropriate for assessing human health risk.

The current pathways, sources and magnitude of current human $\mathrm{Al}$ exposures are broadly consistent with those measured four decades ago (reviewed in Krewski et al. 2007). Dietary $\mathrm{Al}$ intake depends on the age of the individual, soil characteristics (including $\mathrm{pH}$ ) and local dietary customs. These differences are reflected in $\mathrm{Al}$ doses that range from $1.61 \mu \mathrm{g} / \mathrm{kg}$ week for Russian infants to $8.47 \mathrm{mg} / \mathrm{kg}$-week for Russian adults, values that were consistent with or higher than those for adolescent boys living in the Czech Republic $(1.14 \mathrm{mg} / \mathrm{kg}$ week) or for those living in Washington, D.C., San Francisco and St. Louis (1.14-6.68 $\mathrm{mg} / \mathrm{kg}$-week) (Sorenson et al. 1974). Other surveys found Al dietary exposure was no greater than the $2 \mathrm{mg} / \mathrm{kg}$-week PTWI for those living in the United States, Western Europe and the Canary Islands (ATSDR 2008, EFSA 2008, González-Weller et al. 2010), but it was 
above the PTWI for toddlers living in the United Kingdom ( $2.4 \mathrm{mg} / \mathrm{kg}$-week) (Rose et al. 2010), Japan (2.0-3.0 mg/kg-week) (Sato et al. 2014) and the EU (11.3-156 mg/kg-week) (EFSA 2013). The PTWI is based on studies with the highly bioavailable Al citrate (Benford et al. 2012, EFSA 2011); however, the oral bioavailability of the soluble and sparinglysoluble $\mathrm{Al}$ forms varies at least 10-fold (EFSA 2011) and insoluble Al silicates present in foods and beverages demonstrate essentially no uptake (Willhite et al. 2012). The validity of the assumption that the gastrointestinal bioavailability of all forms of ingested $\mathrm{Al}$ is equivalent to that of $\mathrm{Al}$ citrate (EFSA 2013) warrants further consideration.

Aluminum contamination of PN solutions continues to be of concern (Bohrer et al. 2010, Fanni et al. 2014, Hernández-Sandez et al. 2013, Poole et al. 2008, 2010, 2011, Popinska et al. 2010, Wier and Kuhn 2012). Recent reports (Fewtrell et al. 2009, 2011) confirm previous observations that $\mathrm{Al}$ contamination in PN solutions presents serious health risks for infants and neonates (Bates et al. 1985, Bishop et al. 1997, Fanni et al. 2014, Klein 1995, Klein et al. 1991).

The results of the present review support previous conclusions that there were no clear associations between vaccinations using $\mathrm{Al}$ adjuvants and serious adverse events (GACVS 2012, Kelso et al. 2012). Nevertheless, Al adjuvants increased injection site pain and tenderness (Table 4) and elicited sensitization to the metal (Table 5). The present review also identified controlled trials wherein vaccination without $\mathrm{Al}$ adjuvant provided equivalent response to vaccination with adjuvant and that vaccination with different $\mathrm{Al}$ forms produced a different response. Other recent studies found a limited immunogenic role for $\mathrm{Al}(\mathrm{OH})_{3}$ adjuvant, or a diminished immune response to certain vaccines (Brady et al. 2009, Keitel et al. 2009, Manzoli et al. 2011, Liang et al. 2010, Yin et al. 2011, Zhu et al. 2009). Based on results with the relatively few published controlled trials with $\mathrm{Al}$ adjuvants it is not clear whether routine use of $\mathrm{Al}$ adjuvants represents best clinical practice. Where $\mathrm{Al}$ adjuvants provide demonstrable benefit, it is not clear which $\mathrm{Al}$ form(s) and dose(s) have the highest therapeutic ratio (Batista-Duharte et al. 2011).

Some (Byrne and Baugh 2008, Nel et al. 2006) have expressed concern that nanoparticles can be dangerous and that platelet and tubular Al nanoclays are cytotoxic (e.g., Lordan and Higginbotham 2012, Lordan et al. 2011, Verma et al. 2012, Wallace et al. 1985). However there is little correlation between $\mathrm{Al}$ nanoparticle toxicity in vitro and that observed in vivo, partly because the physical properties of the primary Al nanoparticles differ from the larger aggregates (Al nanoclusters) (Murdock et al. 2008) to which people are exposed. Acute oral (Prabhakar et al. 2011) and repeat exposure inhalation studies in rats (Pauluhn 2009a) and mice (Adamcakova-Dodd et al. 2012) with Al nanoparticles failed to identify adverse effects except at very high levels of exposure. Chronic occupational inhalation of nanoparticlecontaining bauxite and other non-reactive Al dusts (Altekruse et al. 1984, Beach et al. 2001, Donoghue et al. 2014, Edling 1961, Gibbs and Pooley 1994, Hale et al. 1956, Lynch and McIver 1954, Oldham 1983, Rawlings et al. 1983, Sakula 1961, Taiwo 2014, Waxweiler et al. 1988) was associated with pneumoconiosis in exposed workers. These conditions are related to excessive particle loading of lung macrophages and impaired pulmonary clearance (Oberdörster 1995). Given the results with controlled inhalation of $\gamma$-AlO(OH) in rats, it appears preliminary estimates of health risk based on aggregate $\mathrm{Al}$ nanoparticle pulmonary 
overload (Pauluhn 2011) are appropriate. The data suggest that the pulmonary response to inhaled engineered $\mathrm{Al}$ oxide nanoparticles will be similar to that seen after naturallyoccurring bauxite nanoparticles are inhaled.

There is considerable variation in the OELs for metallic $\mathrm{Al}$ and the $\mathrm{Al}$ oxides under similar frequency and durations of exposure (Table 7). Both the Health Council of the Netherlands (2010) and the Nordic Expert Group (2011) concluded that existing data for metallic $\mathrm{Al}$ and its oxides are inadequate upon which to derive evidence-based OEL values. There remain concerns about reduced attention span, impaired cognition and deficits in fine motor skills among workers exposed to Al fume for many years (reviewed in Riihimäki and Aitio 2012). Nine studies (Akila et al. 1999, Bast-Petterson et al. 1994, 2000, Bowler et al. 2003, Flaten et al. 1996, Giorgianni et al. 2012, Hannien et al. 1994, Polizzi 2002, Riihimäki et al. 2000, Sjogren et al. 1990) identified adverse effects of $\mathrm{Al}$ fume on worker cognition, but four other studies Buchta et al. 2005, Kiesswetter et al. 2007, 2009, Meyer-Baron et al. 2007) found no such changes. The reasons for these differences are unclear.

Of the many health risk issues discussed in this review, several in particular warrant further attention. These include consideration of relative bioavailability of different $\mathrm{Al}$ species in deriving human exposure guidelines, $\mathrm{Al}$ contamination of $\mathrm{PN}$ solutions, justification of the use of $\mathrm{Al}$ as vaccine adjuvants and the basis for and derivation of OELs for $\mathrm{Al}$ compounds. Resolution of these issues will require additional investigation, and the application of appropriate risk assessment methodologies to arrive at evidence-based risk management decisions (Landry and Sibbald 2001, Guzelian et al. 2005).

\section{Abbreviations}

$\mathbf{A} \beta$

$\mathrm{ACH}$

AChE

AD

$\mathbf{A E}$

AGD

Al

ALT

APP

apoE

AST

ATSDR

AUC amyloid $\beta$ peptide

aluminum chlorhydrate $\mathrm{Al}_{2} \mathrm{Cl}(\mathrm{OH})_{5} \cdot 2 \mathrm{H}_{2} \mathrm{O}$

acetylcholinesterase

Alzheimer's disease

adverse events

anogenital distance

aluminum

alanine aminotransferase

$\beta$-amyloid precursor protein

apolipoprotein E

aspartate aminotransferase

Agency for Toxic Substances and Disease Registry

area under concentration:time curve 


\begin{tabular}{|c|c|}
\hline BAT & Biologischer Arbeitsstoff-Toleranz-Wert \\
\hline Bax & proapoptotic Bcl-2 associated protein \\
\hline Bcl2 & anti-apoptotic B-cell lymphoma-2-protein \\
\hline BMC & bone mineral content \\
\hline CA & chromosomal aberration \\
\hline CAA & congophilic amyloid angiopathy \\
\hline DBCP & double-blind placebo-controlled \\
\hline DC & dendritic cells \\
\hline DFO & desferrioxamine \\
\hline DLB & dementia with Lewy bodies \\
\hline DNEL & derived no effect level \\
\hline DPT & diphtheria/pertussis/tetanus \\
\hline DSB & double strand breaks \\
\hline DTaP & diphtheria/tetanus acellular pertussis \\
\hline EC & European Commission \\
\hline EFSA & European Food Safety Authority \\
\hline EPO & erythropoietin \\
\hline ERER & erythrocyte rosette forming enhancing rate \\
\hline ERIR & erythrocyte rosette forming inhibitory rate \\
\hline FAO/WHO & $\begin{array}{l}\text { Food and Agriculture Organization of the United Nations/World Health } \\
\text { Organization }\end{array}$ \\
\hline FDA & Food and Drug Administration \\
\hline FOB & functional observational battery \\
\hline FSH & follicle stimulating hormone \\
\hline GD & gestational day \\
\hline GFAAS & graphite furnace atomic absorption spectrophotometry \\
\hline GLP & Good Laboratory Practice \\
\hline GPx & glutathione peroxidase \\
\hline GSH & reduced glutathione \\
\hline
\end{tabular}




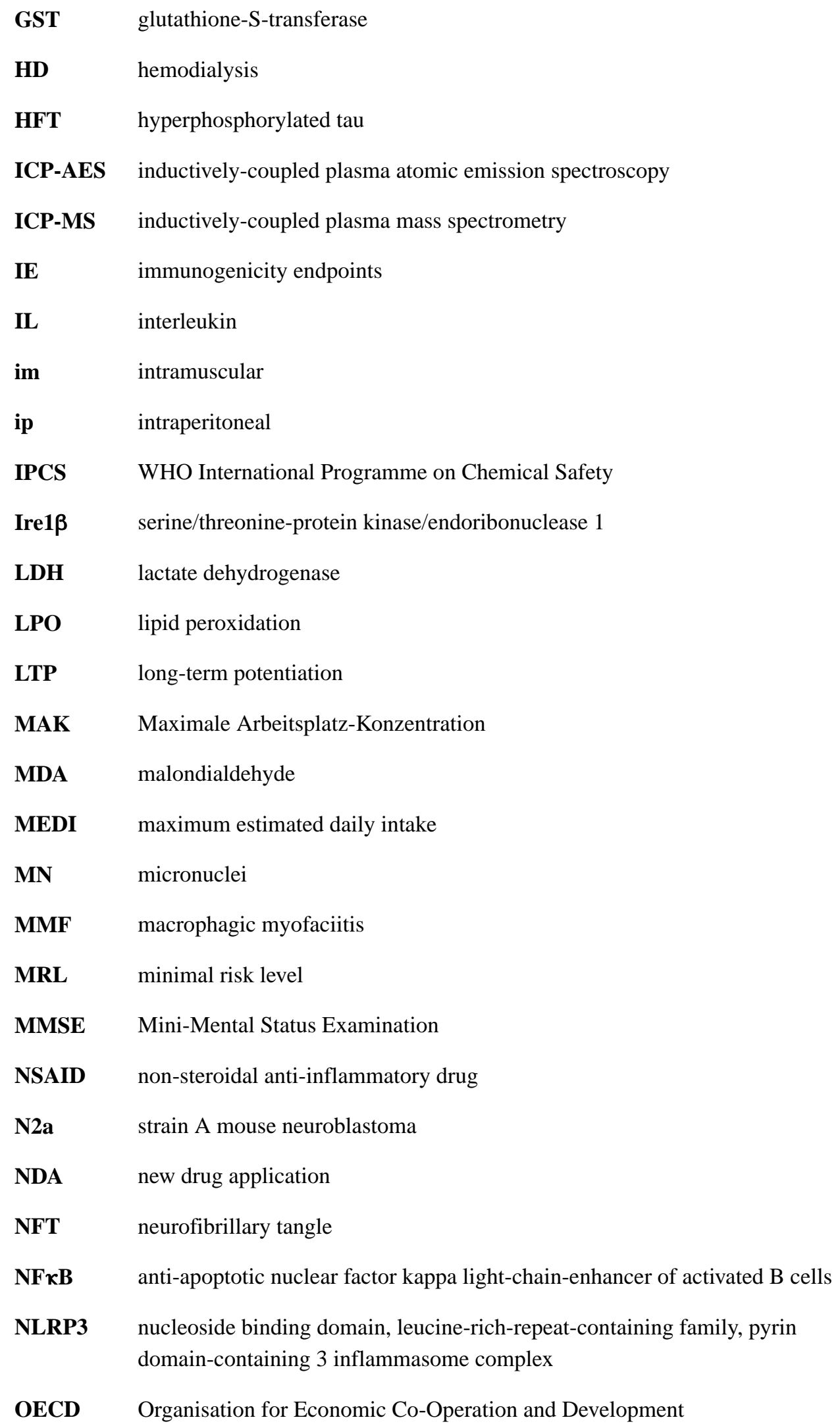


OEL Occupational Exposure Limit

OSHA Occupational Safety and Health Administration

PEL permissible exposure limit

PM particulate matter

PN parenteral nutrition

PND postnatal day

PS presenilin

RBC-C3bRRerythrocyte $\mathrm{C} 3 \mathrm{~b}$ receptor rate

RCT randomized control trial

PTWI provisional tolerable weekly intake

RBC-ICR erythrycyte C3B immune complex rosette rate

REL recommended exposure limit

RfD reference dose

ROS reactive oxygen species

SALP sodium aluminum phosphate

sc subcutaneous

SCE sister chromatid exchange

SEM scanning electron microscopy

SOD superoxide dismutase

T testosterone

TBARS thiobarbituric acid reactive substances

TEM transmission electron microscopy

THGA transversely heated graphic atomizer

$\mathbf{T L V}^{\circledR} \quad$ threshold limit value

TWA time-weighted-average

TWI tolerable weekly intake

UCL upper confidence limit 


\section{References}

Abd El-Rahman M, el-Khadragy MF, Abd-el HH, Gab-Allah DM. Effect of some cement components on ion contents in different brain areas of adult male albino mice. J Hazard Mate. 2011; 186:152740.

Abdel-Aal RA, Assi AA, Kostandy BB. Rivastigmine reverses aluminum-induced behavioral changes in rats. Eur J Pharmacol. 2011a; 659:169-76. [PubMed: 21440537]

Abdel-Aal RA, Assi AA, Kostandy BB. Memantine prevents aluminum-induced cognitive deficit in rats. Behav Brain Res. 2011b; 225:31-8. [PubMed: 21741993]

Abd-Elghaffar SKH, El Sokkary GH, Sharkawy AA. Aluminum-induced neurotoxicity and oxidative damage in rabbits: Protective effect of melatonin. Biogenic Amines. 2007; 21:225-40.

Abubakar MG, Taylor A, Ferns GA. Aluminium administration is associated with enhanced hepatic oxidant stress that may be offset by dietary vitamin E in the rat. Int J Exp Pathol. 2003; 84:49-54. [PubMed: 12694486]

Abu-Taweel GM, Ajarem JS, Ahmad M. Neurobehavioral toxic effects of perinatal oral exposure to aluminum on the developmental motor reflexes, learning, memory and brain neurotransmitters of mice offspring. Pharmacol Biochem Behav. 2011a; 101:49-56. [PubMed: 22115621]

Abu-Taweel GM, Ajarem JS, Ebaid H. Aluminum-induced testosterone decrease results in physiological and behavioral changes in male mice. Afr J Biotechnol. 2011b; 10:201-8.

ACGIH (American Conference of Governmental Industrial Hygienists). TLVs ${ }^{\circledR}$ and BEIs ${ }^{\circledR}$ Based on the Documentation of the Threshold limit Values for Chemical Substances and Physical Agents \& Biological Exposure Indices. Cincinnati: ACGIH; 2008.

ACGIH (American Conference of Governmental Industrial Hygienists). Documentation of the Threshold limit Values and Biological Exposure Indices. 6th. Cincinnati: ACGIH; 1991. p. 46-7.

Adamcakova-Dodd A, Stebounova LV, O'Shaughnessy PT, Kim JS, Grassian VH, Thorne PS. Murine pulmonary responses after subchronic exposure to aluminum oxide-based nanowhiskers. Part Fibre Toxicol. 2012; 9:22. [PubMed: 22713230]

Afriyie-Gyawu E, Ankrah NA, Heubner HJ, Ofosuhene M, Kumi J, Johnson NM, et al. NovaSil clay intervention in Ghanaians at high risk for aflatoxicosis. I. Study design and clinical outcomes. Food Addit Contam Part A Chem Anal Control Expo Risk Assess. 2008; 25:76-87. [PubMed: 17852392]

Afriyie-Gyawu E, Mackie J, Dash B, Wiles M, Taylor J, Huebner H, et al. Chronic toxicological evaluation of dietary NovaSil clay in Sprague-Dawley rats. Food Addit Contam. 2005; 22:259-69. [PubMed: 16019794]

AFSSAPS (Agence Francaise de Sécurité des Produits de Santé). Ěvaluation du Risque lié á l'utilisation de l'Aluminium dans les Produits Cosmétiques. Saint-Denis, France: AFSSAPS; 2011. p. 1-44.Available at: www.afssaps.frhttp://opac.invs.sante.fr./index.php? lul=notice_display\&id=5478 (denière consultation le 28/01/2011) Accessed on 10 June 2013

Agah H, Leermakers M, Elskens M, Rez Fatemi SM, Baeyens W. Accumulation of trace metals in the muscle and liver tissue of five fish species from the Persian Gulf. Environ Monit Assess. 2009; 157:499-514. [PubMed: 18850288]

Aghilinejad M, Javad Mousavi SA, Nouri MK, Ahmadi AB. Work-related musculoskeletal complaints among workers of Iranian aluminum industries. Arch Environ Occup Health. 2012; 67:98-102. [PubMed: 22524650]

Ahmed HH, Shousha WG, Hussien RM, Farrag ARH. Potential role of some nutraceuticals in the regression of Alzheimer's disease in an experimental animal model. Turk J Med Sci. 2011; 41:455-66.

Akatsu H, Hori A, Yamamoto T, Yoshida M, Mimuro M, Hashizume Y, et al. Transition metal abnormalities in progressive dementias. Biometals. 2011; 25:337-50. [PubMed: 22080191]

Akay C, Kalman S, Dündaröz R, Sayal A, Aydin A, Ozkan Y, Gül H. Serum aluminum levels in gluesniffer adolescent and in glue containers. Basic Clin Pharmacol Toxicol. 2008; 102:433-6. [PubMed: 18331391]

Akila R, Stollery BT, Riihimaki V. Decrements in cognitive function in metal inert gas welders exposed to aluminum. Occup Environ Med. 1999; 56:632-9. [PubMed: 10615297] 
Akiyama H, Barger S, Barnum S, Bradt B, Bauer J, Cole GM, et al. Inflammation and Alzheimer's disease. Neurobiol Aging. 2000; 21:383-421. [PubMed: 10858586]

Akiyama H, Hosokawa M, Kametani F, Kondo H, Chiba M, Fukushima M, Tabira T. Long-term oral intake of aluminium or zinc does not accelerate Alzheimer pathology in A $\beta P P$ and A $\beta P P / t a u$ transgenic mice. Neuropathol. 2012; 32:390-7.

Al-Ashmawy MAM. Prevalence and public health significance of aluminum residues in milk and some dairy products. J Food Sci. 2011; 76:T73-6. [PubMed: 21535864]

Albizzati A, Moré L, DiCandia D, Saccani M, Lenti C. Normal concentrations of heavy metals in autistic spectrum disorders. Minerva Pediatr. 2012; 64:27-31. [PubMed: 22350041]

Alemmari A, Miller GG, Arnold CJ, Zello GA. Parenteral aluminum induces liver injury in a newborn piglet model. J Pediatr Surg. 2011; 46:883-7. [PubMed: 21616246]

Alemmari A, Miller GG, Bertolo RF, Dinesh C, Brunton JA, Arnold CJ, Zello GA. Reduced aluminum contamination decreases parenteral nutrition associated liver injury. J Pediatr Surg. 2012; 47:889_ 94. [PubMed: 22595567]

Alessio L, Apostoli P, Ferioli A, Di Sipio I, Mussi I, Rigosa C, Albertini A. Behaviour of biological indicators of internal dose and some neuro-endocrine tests in aluminium workers. Med Lav. 1989; 80:290-300. [PubMed: 2593966]

Ali MA, Simin EV, Rahim C. Effect of oral aluminum chloride administration during lactation on short and long-term memory of their offspring. J Biol Sci. 2008; 8:767-72.

Alleyne T, Mohan N, Joseph J, Adogwa A. Unraveling the role of metal ions and low catalytic activity of cytochrome c oxidase in Alzheimer's disease. J Mol Neurosci. 2011; 43:284-9. [PubMed: 20725867]

Altekruse EB, Chaudhary BA, Pearson MG, Morgan WKC. Kaolin dust concentrations and pneumoconiosis at a kaolin mine. Thorax. 1984; 39:436-41. [PubMed: 6463912]

Andreoli SP, Bergstein JM, Sherrard DJ. Aluminum intoxication from aluminum containing phosphate binders in children with azotemia not undergoing dialysis. N Engl J Med. 1984; 310:1079-84. [PubMed: 6708989]

Andress DL, Maloney NA, Endres DB, Sherrard DJ. Aluminum-associated bone disease in chronic renal failure: High prevalence in a long-term dialysis population. J Bone Miner Res. 1986; 1:3918. [PubMed: 3503554]

ANSI/AAMI (American National Standards Institute). ANSI/AAMI RD52: 2004. Arlington, Virginia: Association for the Advancement of Medical Instrumentation; 2004. Dialysate for hemodialysis; $p$. 53

Aparecida, D. Exposicao a aditivos alimentares contend aluminio como fator de Risco a saude publica non Brasil, Diretoria regional de Brasilia, Fundacao Oswaldo cruz, 2009. Brazilian Ministry of Health, General Office of Food; 2009.

Aremu DA, Ezomo OF, Meshitsuka S. Gene expression in primary cultured astrocytes affected by aluminum: alteration of chaperons involved in protein folding. Environ Health Prev Med. 2011; 16:16-24. [PubMed: 21432213]

Arenas MD, Malek T, Gil MT, Moledous A, Núñez C, Alvarez-Ude F. Uso de captores aluminicos en hemodiálisis en la era del agua ultrapura. [Use of aluminum-based phosphate chelation in hemodialysis in the era of ultrapure water]. Nefrología. 2008; 28:168-73. [PubMed: 18454706]

Armstrong RA. What causes Alzhiemer's disease? Folia Neuropathol. 2013; 51:169-88. [PubMed: 24114635]

Arnich N, Sirot V, Riviere G, Jean J, Noel L, Guerin T, Leblanc JC. Dietary exposure to trace elements and health risk assessment in the 2nd French total diet study. Food Chem. 2012; 50:2432-49.

Arnold CJ, Miller GG, Zello GA. Parenteral nutrition-associated chloestasis in neonates: the role of aluminum. Nutr Rev. 2003; 61:306-10. [PubMed: 14552065]

ASCN/ASPEN (American Society for Clinical Nutrition Working Group on Standards for Aluminum Content of Parenteral Nutrition Solutions). Parenteral drug products containing aluminum as an ingredient or a contaminant: response to Food and Drug Administration notice of intent and request for information. J Parenter Enteral Nutr. 1991; 15:194-8.

ATSDR (Agency for Toxic Substances and Disease Registry). Toxicological Profile for Aluminum. Atlanta: U.S. Department of Health and Human Services, Public Health Service; 2008. p. 357 
Atwood CS, Moir RD, Huang X, Scarpa RC, Bacarra NM, Romano DM, et al. Dramatic aggregation of Alzheimer abeta by $\mathrm{Cu}(\mathrm{II})$ is induced by conditions representing physiological acidosis. J Biol Chem. 1998; 273:2817-26. [PubMed: 9446590]

Avcin S, Jazbec J, Jancar J. Subcutaneous nodule after vaccination with an aluminium- containing vaccine. Acta Dermatovenerol Alp Panonica Adriat. 2008; 17:182-4.

Azik FM, Ekim M, Sakallioglu O, Aydin A. A different interaction between parathyroid hormone, calcitriol and serum aluminum in chronic kidney disease; a pilot study. Intl Urol Nephrol. 2011; 43:467-70.

Bachmanov AA, Reed DR, Beauchamp GK, Tordoff MG. Food intake, water intake and drinking spout side preference of 28 mouse strains. Behav Genet. 2002; 32:435-43. [PubMed: 12467341]

Bakar C, Karaman HI, Baba A, Sengünalp F. Effect of high aluminum concentration in water resources on human health, case study: Biga Peninsula, northwest part of Turkey. Arch Environ Contam Toxicol. 2010; 58:935-44. [PubMed: 20012432]

Baker DJ, Wijshake T, Tchkonia T, LeBrasseur NK, Childs BJ, van de Sluis B, et al. Clearance of p16Ink4a-positive senescent cell delays ageing-associated disorders. Nature. 2011; 479:232-6. [PubMed: 22048312]

Balasubramanyam A, Sailaja N, Mahboob M, Rahman MF, Hussain SM, Grover P. In vitro mutagenicity assessment of aluminum oxide nanomaterials using the Salmonella/microsome assay. Toxicol In Vitro. 2010; 24:1871-6. [PubMed: 20624453]

Banasik A, Lankoff A, Piskulak A, Adamowska K, Lisowska H, Wojcik A. Aluminum-induced micronuclei and apoptosis in human peripheral-blood lymphocytes treated during different phases of the cell cycle. Environ Toxicol. 2005; 20:402-6. [PubMed: 16007643]

Barrow CJ, Zagorski MG. Solution structures of beta peptide and its constituent fragments: relation to amyloid deposition. Science. 1991; 253:179-82. [PubMed: 1853202]

Bast-Petterson R, Drablos PA, Goffeng LO, Thomassen Y, Torres CG. Neuropsychological deficit among elderly workers in aluminum production. Am J Ind Med. 1994; 25:649-62. [PubMed: 8030636]

Bast-Petterson R, Skaug V, Ellingsen D, Thomassen Y. Neurobehavioral performance in aluminum welders. Am J Ind Med. 2000; 37:184-92. [PubMed: 10615099]

BASF. Colloidal hydrated magnesium alumino-silicate. 2011. Available at: http://www.supmat.com/ downloadBASF/Attapulgite\%20Final\%2011.15.2007.pdf [Accessed on 10 June 2013]

Bates D, Parkinson IMS, Ward MK, Kerr DNS. Aluminum encephalopathy. Contr Nephrol. 1985; 45:29-41.

Batista-Duharte A, Lindblad EB, Oviedo-Orta E. Progress in understanding adjuvant immunotoxicity mechanisms. Toxicol Lett. 2011; 203:97-105. [PubMed: 21392560]

Batten, GL.; Lafayette, GK. Aluminum oxide, soluble aluminum and coral toxicity. (undated)Available at: www.seachem.com/support/AluminumSolubilityToxicity.pdf [Accessed on 19 May 2014]

Battersby, R. Fact Sheet 05: Health Risk Assessment Guidance for Metals: Mutagenicity. 2007. Available at: www.metalsriskassessment.org [Accessed on 10 June 2013]

Baum L, Chan IH, Cheung SK, Goggins WB, Mok V, Lam L, et al. Serum zinc is decreased in Alzheimer's disease and serum arsenic correlates positively with cognitive ability. Biometals. 2010; 23:173-9. [PubMed: 19911117]

Beach JR, de Klerk NH, Fritschi L, Sim MR, Musk AW, Benke G, et al. Respiratory symptoms and lung function in bauxite miners. Int Arch Occup Environ Health. 2001; 74:489-94. [PubMed: 11697452]

Beaney, AM.; Smeaton, I. Aluminium levels in parenteral nutrition - time to change to plastic ampoules of calcium gluconate? Group L Hospital Pharmacy Practice. 15th Anniversary Congress of the European Association of Hospital Pharmacists (EAHP); 24-26 March; Nice, France. 2010. p. 3

Becaria A, Lahiri DK, Bondy SC, Chen D, Hamadeh A, Li H, et al. Aluminum and copper in drinking water enhance inflammatory or oxidative events specifically in the brain. Neuroimmunol. 2006; 176:16-23. 
Belaid-Nouira Y, Bakhta H, Bouaziz M, Flehi-Slim I, Haouas Z, Ben CH. Study of lipid profile and parieto-temporal lipid peroxidation in $\mathrm{AlCl}(3)$ mediated neurotoxicity. Modulatory effect of fenugreek seeds. Lipids Health Dis. 2012; 11:16. [PubMed: 22280491]

Bell ML, Belanger K, Ebisu K, Gent JF, Lee HJ, Koutrakis P, Leaderer BP. Prenatal exposure to fine particulate matter and birth weight: variations by particulate constituents and sources. Epidemiology. 2010; 21:884-91. [PubMed: 20811286]

Bémer D, Régnier R, Subra I, Sutter B, Lecler MT, Morele Y. Ultrafine particles emitted by flame and electric arc guns for thermal spraying of metals. Ann Occup Hyg. 2010; 54:607-14. [PubMed: 20685717]

Benford, DJ.; Agudo, A.; Baskaran, C.; DINovi, M.; Folmer, D.; Leblanc, J-C.; Renwick, AG. Aluminium-containing food additives (addendum). Geneva: Food and Agriculture Organization of the United Nations/World Health Organization; 2012. WHO Additives Series 65: Safety Evaluation of Certain Food Additives and ContaminantsAvailable at: http://whqlibdoc.who.int/ publications/2012/9789241660655_eng.pdf [Accessed on 10 June 2013]

Berend K, Van Der Voet G, Boer WH. Acute aluminum encephalopathy in a dialysis center caused by a cement mortar water distribution pipe. Kidney Intl. 2001; 59:746-53.

Bergfors E, Björkelund C, Trollfors B. Nineteen cases of persistent pruritic nodules and contact allergy to aluminium after injection of commonly used aluminium-adsorbed vaccines. Eur J Pediatr. 2005; 164:691-7. [PubMed: 16044278]

Bergfors E, Trollfors B. Sixty-four children with persistent itching nodules and contact allergy to aluminium after vaccination with aluminium-adsorbed vaccines- prognosis and outcome after booster vaccination. Eur J Pediatr. 2012; 172:171-7. [PubMed: 23052615]

Berthon G. Aluminum speciation in relation to aluminum bioavailability, metabolism and toxicity. Coordin Chem Rev. 2002; 228:319-41.

Beveridge MG, Polcari IC, Burns JL, Adler A, Hendrickson B, Stein SL. Local vaccine site reactions and contact allergy to aluminum. Pediatr Dermatol. 2011; 29:68-72. [PubMed: 21854416]

Bhadauria M. Combined treatment of HEDTA and propolis prevents aluminum induced toxicity in rats. Food Chem Toxicol. 2012; 50:2487-95. [PubMed: 22251571]

Bhasin P, Singla N, Dhawan DK. Protective role of zinc during aluminum-induced hepatotoxicity. Environ Toxicol. 2012; 29:320-7. DOI: 10.1002/tox.21760 [PubMed: 22422511]

Bihaqi SW, Sharma M, Singh AP, Tiwari M. Neuroprotective role of Convolvulus pluricaulis on aluminium induced neurotoxicity in rat brain. J Ethnopharmacol. 2009; 124:409-15. [PubMed: 19505562]

Bishop NJ, Morley R, Day JP, Lucas A. Aluminum neurotoxicity in preterm infants receiving intravenous-feeding solutions. N Engl J Med. 1997; 336:1557-61. [PubMed: 9164811]

Bjertness E, Candy JM, Torvik A, Ince P, McArthur F, Taylor GA, et al. Content of brain aluminum is not elevated in Alzheimer's disease. Alzheimer Dis Assoc Disord. 1996; 10:171-4. [PubMed: 8876778]

Bodhak S, Balla VK, Bose S, Bandyopadhyay A, Kashalikar U, Jha SK, Sastri S. In vitro biological and tribological properties of transparent magnesium aluminate (Spinel) and aluminum oxynitride $\left(\mathrm{ALON}^{\circledR}\right)$. J Mater Sci Mater Med. 2011; 22:1511-19. [PubMed: 21562889]

Bohrer D, Bertagnolli DC, de Oliveira SM, do Nascimento PC, de Carvalho LM, Garcia SC, et al. Role of medication in the level of aluminium in the blood of chronic haemodialysis patients. Nephrol Dial Transplant. 2009; 24:1277-81. [PubMed: 19028749]

Bohrer D, do Nascimento PC, Binotto R, Becker E. Influence of the glass packing on the contamination of pharmaceutical products by aluminium. Part III: Interaction container chemicals during the heating for sterilization. J Trace Elem Med Biol. 2003; 17:107-15. [PubMed: 14531639]

Bohrer D, do Nascimento PC, Binotto R, Carlesso R. Influence of the glass packing on the contamination of pharmaceutical products by aluminium. Part II: amino acids for parenteral nutrition. J Trace Elem Med Biol. 2001; 15:103-8. [PubMed: 11787973]

Bohrer D, Oliveira SM, Garcia SC, Nascimento PC, Carvalho LM. Aluminum loading in preterm neonates revisited. J Pediatr Gastroenterol Nutr. 2010; 51:237-41. [PubMed: 20479688] 
Bolle F, Brian W, Petit D, Boutakhrit K, Feraille G, Van LJ. Tea brewed in traditional metallic teapots as a significant source of lead, nickel and other chemical elements. Food Addit Contam A. 2011; 28:1287-93.

Bolognin S, Messori L, Drago D, Gabbiani C, Cendron L, Zatta P. Aluminum, copper, iron and zinc differentially alter amyloid-A $\beta$ (1-42) aggregation and toxicity. Int J Biochem Cell Biol. 2011; 43:877-85. [PubMed: 21376832]

Bondy SC. The neurotoxicity of environmental aluminum is still an issue. Neurotoxicol. 2010; 31:575-81.

Bora T, Merdivan M, Hemamei C. Levels of trace and major elements in illicit heroin. Forensic Sci. 2002; 47:959-63.

Borm PJA, Robbins D, Haubold S, Kuhlbusch T, Fissan H, Donaldson K, et al. The potential risks of nanomaterials: a review carried out for ECETOC. Part Fibre Toxicol. 2006; 3:11. [PubMed: 16907977]

Boto de los Bueis A, Pereira Vega P, Sánchez Ramos JL, Maldonado Perez JA, Averbe Garcia RA, Garcia Jiménez DG, Pujol de la Llave E. Bronchial hyperreactivity in patients who inhale heroin mixed with cocaine vaporized on aluminum foil. Chest. 2002; 121:1223-30. [PubMed: 11948057]

Boullemant A. PM2.5 emissions from aluminum smelters: coefficients and environmental impact. J Air Waste Manage Assoc. 2011; 61:311-18.

Bower C, Stanley FJ, Nichol DJ. Maternal folate status and the risk for neural tube defects. Ann NY Acad Sci. 1993; 678:146-55. [PubMed: 8494257]

Bowler RM, Gysens S, Diamond E, Booty A, Hartney C, Roels HA. Neurophysiological sequelae of exposure to welding fumes in a group of occupationally exposed men. Int J Hyg Environ Health. 2003; 206:517-29. [PubMed: 14626899]

Bozynski MEA, Sedman AB, Naglie RA, Wright EJ. Serum, plasma and urinary aluminum levels and tissue loading in pre-term twins. J Parenter Enteral Nutr. 1989; 13:428-31.

Bradford-Hill A. The environment and disease: association or causation? Proc R Soc Med. 1965; 58:295-300. [PubMed: 14283879]

Brady RC, Treanor JJ, Atmar RL, Keitel WA, Edelman R, Chen WH, et al. Safety and immunogenicity of a subvirion inactivated influenza A/H5N1 vaccine with or without aluminum hydroxide among healthy elderly adults. Vaccine. 2009; 27:5091-5. [PubMed: 19577636]

Braganca VL, Melnikov P, Zanoni LZ. Trace elements in fruit juices. Biol Trace Elem Res. 2011; 146:256-61. [PubMed: 22068730]

Bresson JL, Perronne C, Launay O, Gerdil C, Saville M, Wood J, et al. Safety and immunogenicity of an inactivated split-virion influenza A/Vietnam 1194/2004 (H5N1) vaccine: phase I randomised trial. Lancet. 2006; 367:1657-64. [PubMed: 16714186]

Buchta M, Kiesswetter E, Schäper M, Zschiesche W, Schaller K, Kuhlmann A, Letzel S. Neurotoxicity of exposures to aluminium welding fumes in the truck trailer construction industry. Environ Toxicol Pharmacol. 2005; 19:677-85. [PubMed: 21783542]

Burdick D, Soreghan B, Kwon M, Kosmoski J, Knauer M, Henschen A, et al. Assembly and aggregation properties of synthetic Alzheimer's A41 beta amyloid peptide analogs. J Biol Chem. 1992; 267:546-54. [PubMed: 1730616]

Burrell SA, Exley C. There is (still) too much aluminium in infant formulas. BMC Pediatr. 2010; 10:63. [PubMed: 20807425]

Bush AI, Tanzi RE. The galvanization of $\beta$-amyloid in Alzheimer's disease. Proc Natl Acad Sci USA. 2002; 99:7317-19. [PubMed: 12032279]

Byrne JD, Baugh JA. The significance of nanoparticles in particle-induced pulmonary fibrosis. McGil J Med. 2008; 11:43-50.

Calejo AI, Jorgacevski J, Silva VS, Stenovec M, Kreft M, Goncalves PP, Zorec R. Aluminum-induced changes of fusion pore properties attenuate prolactin secretion in rat pituitary lactotrophs. Neuroscience. 2011; 201:57-66. [PubMed: 22123165]

Calejo AI, Rodriguez E, Silva VS, Jorgacevski J, Stenovec M, Kreft M, et al. Life and death in aluminum-exposed cultures of rat lactotrophs studied by flow cytometry. Cell Biol Toxicol. 2010; 26:341-53. [PubMed: 20052527] 
Campdelacreu J. Enfermedad de Parkinson y enfermedad de Alzheimer: factores de riesgo ambientales [Parkinson disease and Alzheimer disease: environmental risk factors]. Neurologia. 2012; [Epub ahead of print]. doi: 10.1016/j.nrl.2012.04.001

CAN/CSA-ISO (Canadian Standards Association). Water for haemodialysis and related therapies (adopted ISO 13959:2009; 1st edition 2009-04-15). Mississauga, Ontario: Canadian Standards Association; 2011.

Cannata JB, Briggs JD, Junor BJR, Fell GS. Aluminum hydroxide intake: Real risk of aluminum toxicity. Br Med J. 1983; 286:1937-8. [PubMed: 6407646]

Cao H, Qiao L, Zhang H, Chen J. Exposure and risk assessment for aluminium and heavy metals in Puerh tea. Sci Total Environ. 2010; 408:2777-84. [PubMed: 20413147]

Card JW, Jonaitis TS, Tafazoli S, Magnuson BA. An appraisal of the published literature on the safety and toxicity of food-related nanomaterials. Crit Rev Toxicol. 2011; 41:20-49.

Cárdenas O, Segura O, Puentes W, Sanabria M, Nava G, Torrenegra R. Aluminio en pacientes con terapia de reemplazo renal crónico con hemodiálisis en dos unidades renales en Bogotá. [Aluminuim in chronic renal replacement therapy patients undergoing haemodialysis in two renal units in Bogotá]. Rev Salud Pública. 2010; 12:669-81. [PubMed: 21340131]

Carrasquillo MM, Belbin O, Hunter TA, Ma L, Bisceglio GD, Zou F, et al. Alzheimer's Research UK (ARUK) consortium. Younkin SG. Replication of EPHA1 and CD33 associations with late-onset Alzheimer's disease: a multi-centre case-control study. Mol Neurodegener. 2011; 6:54. [PubMed: 21798052]

Castorina A, Tiralongo A, Giunta S, Carnazza Ml, Scapagnini G, D’Agata V. Early effects of aluminum chloride on $\beta$-secretase mRNA expression in a neuronal model of $\beta$-amyloid toxicity. Cell Biol Toxicol. 2010; 26:367-77. [PubMed: 20111991]

CDC (US Centers for Disease Control). Data Table of Infant Weight-for-Age Charts. National Center for Health Statistics; 2000. Available at: http://www.cdc.gov/growthcharts/html_charts/ wtageinf.htm [Accessed 10 June 2013]

CDC (Centers for Disease Control). Elevated serum aluminum levels in hemodialysis patients associated with use of electric pumps - Wyoming 2007. MMWR. 2008; 57:689-91. [PubMed: 18583956]

Chaitanya TV, Mallipeddi K, Bondili JS, Nayak P. Effect of aluminum exposure on superoxide and peroxide handling capacities by liver, kidney, testis and temporal cortex in rat. Indian J Biochem Biophys. 2012; 49:395-8. [PubMed: 23259328]

Chakrabarty M, Bhat P, Kumari S, D’Souza A, Bairy KL, Chaturvedi A, et al. Cortico-hippocampal salvage in chronic aluminum induced neurodegeneration by Celastrus paniculatus seed oil: Neurobehavioural, biochemical, histological study. J Pharmacol Pharmacother. 2012; 3:161-71. [PubMed: 22629092]

Chedid F, Fudge A, Teubner J, James SL, Simmer K. Aluminum absorption in infancy. J Paediatr Child Health. 1991; 27:164-6. [PubMed: 1888563]

Chen L, Yokel RA, Henning B, Toborek M. Manufactured aluminum oxide nanoparticles decrease expression of tight junction proteins in brain vasculature. J Neuroimmune Pharmacol. 2008; 3:286-95. [PubMed: 18830698]

Chen TJ, Cheng HM, Wang DC, Hung HS. Nonlethal aluminum maltolate can reduce brain-derived neurotrophic factor-induced Arc expression through interrupting the ERK signaling in SH-SY5Y neuroblastoma cells. Toxicol Lett. 2011a; 200:67-76. [PubMed: 21040763]

Chen TJ, Hung HS, Wang DC, Chen SS. The protective effect of Rho-associated kinase inhibitor on aluminum-induced neurotoxicity in rat cortical neurons. Toxicol Sci. 2010a; 116:264-72. [PubMed: 20395307]

Chen WT, Liao YH, Yu HM, Cheng IH, Chen YR. Distinct effects of Zn2+, Cu2+, Fe3+, and Al3 + on amyloid-beta stability, oligomerization, and aggregation: amyloid-beta destabilization promotes annular protofibril formation. J Biol Chem. 2011b; 286:9646-56. [PubMed: 21216965]

Chen BB, Zeng Y, Hu B. Study on speciation of aluminum in human serum using zwitterionic bile acid derivative dynamically coated C18 column HPLC separation with UV and on-line ICP-MS detection. Talanta. 2010b; 81:180-6. [PubMed: 20188906] 
Cheng D, Zhu C, Cao J, Jiang W. The protective effects of polyphenols from jujube peel (Ziziphus jujube Mill.) on isoproterenol-induced myocardial ischemia and aluminum-induced oxidative damage in rats. Food Chem Toxicol. 2012; 50:1302-8. [PubMed: 22306920]

Childs CW, Parfitt RL, Newman RH. Structural studies of Silica Springs allophane. Clay Miner. 1990; 25:329-41.

Chiu HFK, Lee HC, Chung WS, Kwong PK. Reliability and validity of the Cantonese version of the mini-mental state examination - a preliminary study. J Hong Kong Coll Psychiatrists. 1994; 4(Suppl 2):25-8.

Chotpitayasunondh T, Thisyakorn U, Pancharoen C, Pepin S, Nougarede N. Safety, humoral and cell mediated immune responses to two formulations of an inactivated, split-virion influenza A/H5N1 vaccine in children. PloS One. 2008; 3:e4028. [PubMed: 19112513]

Cifone MA, Myhr B, Eiche A, Boksfoldi G. Effects of pH shifts on the mutant frequency at the thymidine kinase locus in mouse lymphoma 15178 Y TK +/- cells. Mutat Res. 1987; 189:39-46. [PubMed: 3114628]

Clapp T, Siebert P, Chen D, Jones BL. Vaccines with aluminum-containing adjuvants: optimizing vaccine efficacy and thermal stability. J Pharm Sci. 2011; 100:388-401. [PubMed: 20740674]

Coburn JW, Mischel MG, Goodman WG, Salusky IB. Calcium citrate markedly enhances aluminum absorption from aluminum hydroxide. Am J Kidney Dis. 1991; 17:708-11. [PubMed: 2042654]

Colak S, Geyikoglu F, Keles ON, Turkez H, Topal A, Unal B. The neuroprotective role of boric acid on aluminum chloride-induced neurotoxicity. Toxicol Ind Health. 2011; 27:700-10. [PubMed: 21543463]

Contini del MC, Millen N, González M, Mahieu S. Melatonin prevents oxidative stress in ovariectomized rats treated with aluminium. Biol Trace Elem Res. 2011; 144:924-43. [PubMed: 21537923]

Costa C, Conte A, Buonocore GG, Del Nobile MA. Antimicrobial silver- montmorillonite nanoparticles to prolong shelf life of fresh fruit salad. Int J Food Microbiol. 2011; 148:164-7. [PubMed: 21684619]

Couette M, Boisse MF, Maison P, Brugieres P, Cesaro P, Chevalier X, et al. Long-term persistence of vaccine-derived aluminum hydroxide is associated with chronic cognitive dysfunction. $\mathrm{J}$ Inorg Biochem. 2009; 103:1571-8. [PubMed: 19748679]

Crisponi G, Nurchi VM. Thermodynamic remarks on chelating ligands for aluminium related diseases. J Inorg Biochem. 2011; 105:1518-22. [PubMed: 22099162]

Crisponi G, Nurchi VM, Bertolasi V, Remelli M, Faa G. Chelating agents for human disease related to aluminium overload. Coord Chem Rev. 2012; 256:89-104.

Crisponi G, Nurchi VM, Faa G, Remelli M. Human diseases related to aluminium overload. Montash Chem. 2011; 142:331-40.

Cui X, Wang B, Zong Z, Liu S, Xing W. The effects of chronic aluminum exposure on learning and memory of rats by observing the changes of Ras/Raf/ERK signal transduction pathway. Food Chem Toxicol. 2012; 50:315-19. [PubMed: 22079183]

Curwin B, Bertke S. Exposure characterization of metal oxide nanoparticles in the workplace. J Occup Environ Hyg. 2011; 8:580-7. [PubMed: 21936697]

Czeizel AS, Dudas I. Prevention of the first occurrence of neural tube defects by periconceptual vitamin supplementation. N Engl J Med. 1992; 327:1832-5. [PubMed: 1307234]

Dabeka R, Fouquet A, Belisle S, Turcotte S. Lead, cadmium and aluminum in Canadian infant formulae, oral electrolytes and glucose solutions. Food Addit Contam Part A Chem Anal Control Expo Risk Assess. 2011; 28:744-53. [PubMed: 21623498]

Dabeka RW, McKenzie AD. Aluminium levels in Canadian infant formulae and estimation of aluminium intakes from formulae by infants 0-3 months old. Food Addit Contam Part A Chem Anal Control Expo Risk Assess. 1990; 7:275-82.

Darbre PD. Underarm cosmetics are a cause of breast cancer. Eur J Cancer Prev. 2001; 10:389-93. [PubMed: 11711753]

Darbre PD. Metalloestrogens: an emerging class of inorganic xenoestrogens with potential to add to the oestrogenic burden of the human breast. J Appl Toxicol. 2006; 26:191-7. [PubMed: 16489580] 
Darbre PD, Pugazhendhi D, Mannello F. Aluminum and human breast diseases. J Inorg Biochem. 2011; 105:1484-8. [PubMed: 22099158]

Dasch J, D'Arcy J. Physical and chemical characterization of airborne particles from welding operations in automotive plants. J Occup Environ Hyg. 2008; 5:444-54. [PubMed: 18464098]

Da Silva SE, Jakubovic R, Pejović-Milić A, Heyd DV. Aluminum and strontium in calcium supplements and antacids: a concern to haemodialysis patients? Food Addit Contam Part A Chem Anal Control Expo Risk Assess. 2010; 27:1405-14. [PubMed: 20640960]

de Kom JF, Dissels HM, van der Voet GB, de Wolff FA. Serum aluminium levels of workers in bauxite mines. J Toxicol Clin Toxicol. 1997; 35:645-51. [PubMed: 9365435]

de Oliveira SR, Bohrer D, Garcia SC, do Nascimento PC, Noremberg S. Aluminum content in intravenous solutions for administration to neonates: Role of product preparation and administration methods. J Parenteral Enteral Nutr. 2010; 34:322-8.

De-Paula VJ, Radanovic M, Diniz BS, Forlenza OV. Alzheimer's disease. Subcell Biochem. 2012; 65:329-52. [PubMed: 23225010]

De Veer VM, Kemp J, Chatelier J, Elhay MJ, Meeusen EN. The kinetics of soluble and particulate antigen trafficking in the afferent lymph, and its modulation by aluminum-based adjuvant. Vaccine. 2010; 28:6597-602. [PubMed: 20678587]

del Pilar Martínez MM, Bozzini C, Olivera MI, Dmytrenko G, Conti MI. Aluminum bone toxicity in immature rats exposed to simulated high altitude. J Bone Miner Metab. 2011; 29:526-34. [PubMed: 21327886]

Demont M, Boutakhrit K, Fekete V, Bolle F, Van LJ. Migration of 18 trace elements from ceramic food contact material: influence of pigment, $\mathrm{pH}$, nature of acid and temperature. Food Chem Toxicol. 2012; 50:734-43. [PubMed: 22265939]

Descamps D, Hardt K, Spiessens B, Izurieta P, Verstraeten T, Breuer T, Dubin G. Safety of human papillomavirus (HPV)-16/18 AS04-adjuvanted vaccine for cervical cancer prevention: a pooled analysis of 11 clinical trials. Hum Vaccine. 2009; 5:332-40.

DFG (Deutsche Forschungsgemeinschaft). Commission for the Investigation of Health Hazards of Chemical Compounds in the Work Area. Weinheim: Wiley-VCH; 2007. List of MAK and BAT Values 2001 Aluminium - Aluminiumoxid - und Aluminiumhydroxid-haltige Stäube Maximum Concentrations and Biological Tolerance Values at the Workplace.

DFG (Deutsche Forschungsgemeinschaft). MAK- und BAT-Werte-Liste. 2013. Available at: http:// www.dfg.de/download/pdf/dfg_im_profil/gremien/senat/arbeitsstoffe/ mak_bat_werte_liste_2013.pdf [Accessed 10 June 2013]

Deveau M, Chen C-P, Johanson G, Krewski D, Maier MA, Niven KJ, et al. The global landscape of occupational exposure limits - implementation of harmonization principles to guide limit selection. J Occup Environ Hyg. 2014 (in press).

Di Virgilio AL, Reigosa M, de Mele MF. Response of UMR 106 cells exposed to titanium oxide and aluminum oxide nanoparticles. J Biomed Mater Res A. 2010; 92:80-6. [PubMed: 19165783]

Divine KK, Lewis JL, Grant PG, Bench G. Quantitative particle-induced X-ray emission imaging of rat olfactory epithelium applied to the permeability of rat epithelium to inhaled aluminum. Chem Res Toxicol. 1999; 12:575-81. [PubMed: 10409396]

DiVirgilio AL, Reigosa A, Arnal PM, Fernández Lorenzo de Mele M. Comparative study of the cytotoxic and genotoxic effects of titanium dioxide and aluminum oxide nanoparticles in Chinese hamster ovary (CHO-K1) cells. J Hazard Mater. 2010; 177:711-18. [PubMed: 20079968]

Dong E, Wang Y, Yang ST, Yuan Y, Nie H, Chang Y, et al. Toxicity of nano gamma alumina to neural stem cells. J Nanosci Nanotechnol. 2011; 11:7848-56. [PubMed: 22097496]

Donoghue AM, Frisch N, Ison M, Walpole G, Capil R, Curl C, et al. Occupational asthma in the aluminum smelters of Australia and New Zealand: 1991-2006. Am J Ind Med. 2010; 54:224-31. [PubMed: 21298697]

Donoghue AM, Frisch N, Olney D. Bauxite mining and alumina refining. Process description and health risks. J Occup Environ Med. 2014; 56(5S):S12-7. [PubMed: 24806720]

Dorea JG. More on low-level non-occupational mercury exposure and health concerns. Sci Total Environ. 2010; 408:2008-9. [PubMed: 20149921] 
Dorea JG. Integrating experimental (in vitro and in vivo) neurotoxicity studies of low-dose thimerosal relevant to vaccines. Neurochem Res. 2011; 36:927-38. [PubMed: 21350943]

Dorea JG. Multiple toxic heavy metals and neonatal neurobehavior in China require considering coexposure to thimerosal-ethylmercury and adjuvant-aluminum. Neurotoxicol Teratol. 2012a; 34:219. [PubMed: 21986370]

Dorea JG. Neurotoxic metal coexposures and neurodevelopment. Environ Health Perspect. 2012b; 120:A226-7. [PubMed: 22659231]

Dorea JG, Marques RC. Infants' exposure to aluminum from vaccines and breast milk during the first 6 months. J Expo Sci Environ Epidemiol. 2010; 20:598-601. [PubMed: 20010978]

Drago D, Betella M, Bolognin S, Cendron L, Scancar J, Milacic R, et al. Potential pathogenic role of beta-amyloid (1-42) aluminum complex in Alzheimer's disease. Int J Biochem Cell B. 2008; 40:731-46.

Drago D, Folin M, Baiquera S, Tognon G, Ricchelli F, Zatta P. Comparative effects of Abeta (1-42)-Al complex from rat and human amyloid on rat endothelial cell cultures. J Alzheimers Dis. 2007; 11:33-44. [PubMed: 17361033]

EC (European Commission). EUR 22766 EN European Union Risk Assessment Report cadmium oxide. In: Pakalin, S.; Munn, SJ.; Aschberger, K.; Cosgrove, O.; de Coen, W.; Paya-Perez, A.; Vegro, S., editors. Part II-Human Health. Vol 75. DG Joint Research Centre, Institute of Health and Consumer Protection, European Chemicals Bureau. Luxembourg: Office for Official Publications of the European Communities; 2005. p. 697-702.

EC (European Commission). Annex III. List of substances which cosmetic products may not contain except subject to restrictions laid down. EC Regulation (v.2). 2013. Available at http:// ec.europa.eu/consumers/cosmetics/cosing/index.cfm? fuseaction=search.results\&annex_v2=III\&search [Accessed 30 August 2013]

Edling NPG. Aluminum pneumoconiosis. A roentgendiagnostic study of five cases. Acta Radiol. 1961; 56:170-8. [PubMed: 13889219]

EFSA (European Food Safety Authority). Dietary exposure to aluminium-containing food additives; Supporting Publications 2013: EN-411. 2013. p. 17Available at: www.efsa.europa.eu/ publications [Accessed on 28 May 2014]

EFSA (European Food Safety Authority). On the evaluation of a new study related to the bioavailability of aluminium in food. EFSA J. 2011; 9:2157.

Egan PM, Belfast MT, Gimenez JA, Sitrin RD, Mancinelli RJ. Relationship between tightness of binding and immunogenicity in an aluminum-containing adjuvant-adsorbed hepatitis B vaccine. Vaccine. 2009; 27:3175-80. [PubMed: 19446188]

Ehrlich HJ, Müller M, Oh HML, Tambyah PA, Joukhadar C, Montomoli E, et al. A clinical trial of whole virus H5N1 vaccine derived from cell culture. N Engl J Med. 2008; 358:2573-84. [PubMed: 18550874]

Eickhoff TC, Mayers M. Workshop summary: aluminium in vaccines. Vaccine. 2002; 20:S1-4. [PubMed: 12184358]

Eisenbarth SC, Colegio OR, O'Connor W, Sutterwala FS, Flavell RA. Crucial role for the Nalp3 inflammasome in the immunostimulatory properties of aluminium adjuvants. Nature. 2008; 453:1122-6. [PubMed: 18496530]

El-Demerdash FM. Antioxidant effect of vitamin E and selenium on lipid peroxidation, enzyme activities and biochemical parameters in rats exposed to aluminum. J Trace Elem Med Biol. 2004; 18:113-21. [PubMed: 15487771]

Elsaid FG, Shati A, Hafez E. The protective role of coffea Arabica L. and Crocus sativus L. against the neurotoxicity induced by chronic administration of aluminium chloride. J Pharmacol Toxicol. 2011; 6:647-63.

El-Sayed WM, Al-Kahtani MA, Abdel-Moneim AM. Prophylactic and therapeutic effects of taurine against aluminum-induced acute hepatotoxicity in mice. J Hazard Mater. 2011; 192:880-6. [PubMed: 21703760]

Elshamaa MF, Sabry S, Mokhtar I, El-Saaid GS, Raafat M, Abd-El Haleem DA. Aluminum and lead abnormalities in children on haemodialysis: Relationship with some medications. Arch Med Sci. 2010; 6:420-9. [PubMed: 22371781] 
Erazi H, Ahboucha S, Gamrani H. Chronic exposure to aluminum reduces tyrosine hydroxylase expression in the substantia nigra and locomotor performance in rats. Neurosci Lett. 2011; 487:8-11. [PubMed: 20884324]

Erkan N, Özden Ö, Ulusoy S. Levels of trace elements in commercially important fish, crustaceans and mollusks from Istanbul fish market. Fresneius Environ Bull. 2009; 18:1307-11.

Exley C. The pro-oxidant activity of aluminum. Free Radic Biol Med. 2004; 36:380-7. [PubMed: 15036357]

Exley C, Ahmed U, Polwart A, Bloor RN. Elevated urinary aluminium in current and past users of illicit heroin. Addict Biol. 2007a; 12:197-9. [PubMed: 17508993]

Exley C, Begum A, Woolley MP, Bloor RN. Aluminum in tobacco and cannabis and smoking-related disease. Am J Med. 2006; 119:276.e9-11. [PubMed: 16490479]

Exley C, Burgess E, Day JP, Jeffery EH, Melethil S, Yokel RA. Aluminum toxicokinetics. J Toxicol Environ Health. 1996; 48:569-84. [PubMed: 8772799]

Exley C, Charles LM, Barr L, Martin C, Polwart A, Darbre PD. Aluminum in human breast tissue. J Inorg Biochem. 2007b; 101:1344-6. [PubMed: 17629949]

Exley C, House ER. Aluminum in the human brain. Montash Chem. 2011; 142:357-63.

Exley C, House E, Patel T, Wu L, Fraser PE. Human pro-islet amyloid polypeptide (ProIAPP(1-48)) forms amyloid fibrils and amyloid spherulites in vitro. J Inorg Biochem. 2010; 104:1125-9. [PubMed: 20579740]

Exley C, House E, Polwart A, Esiri MM. Brain burdens of aluminum, iron and copper and their relationships with amyloid $\beta$ pathology in 60 human brains. J Alzheimers Dis. 2012; 31:1-6. [PubMed: 22504318]

Exley C, Siesjö P, Eriksson H. The immunobiology of aluminium adjuvants: how do they really work? Trends Immunol. 2010; 31:103-9. [PubMed: 20153253]

Exley C, Swarbrick L, Gherardi RK, Authier FJ. A role for the body burden of aluminum in vaccineassociated macrophagic myofasciitis and chronic fatigue syndrome. Med Hypotheses. 2009; 72:135-9. [PubMed: 19004564]

Fakri S, Al-Azzawi A, Al-Tawil N. Antiperspirant use as a risk factor for breast cancer in Iraq. Mediterr Health J. 2006; 12:478-82.

Fanni D, Ambu R, Gerosa C, Nemolato S, Iacovidou N, Van Eyken P, et al. Aluminum exposure and toxicity in neonates: a practical guide to halt aluminum overload in prenatal and perinatal periods. World J Pediatr. 2014; 10:101-7. [PubMed: 24801228]

Fekete V, Deconinck E, Bolle F, Van LJ. Modelling aluminium leaching into food from different foodware materials with multi-level factorial design of experiments. Food Addit Contam A. 2012; 29:1322-33.

Felsenfeld AJ, Gutman RA, Llach F, Harrelson JM. Osteomalacia in chronic renal failure: A syndrome previously reported only with maintenance dialysis. Am J Nephrol. 1982; 2:147-54. [PubMed: 7180912]

Fernandez-Lorenzo FJR, Cocho JA, Rey-Goldar ML, Couce M, Fraga JM. Aluminum contents of human milk, cow's milk and infant formulas. J Pediatr Gastroenterol Nutr. 1999; 28:270-5. [PubMed: 10067727]

Fewtrell MS, Bishop NJ, Edmonds CJ, Isaacs EB, Lucas A. Aluminum exposure from parenteral nutrition in preterm infants: bone health at 15-year follow-up. Pediatrics. 2009; 124:1372-9. [PubMed: 19858156]

Fewtrell MS, Edmonds CJ, Isaccs E, Bishop NJ, Lucas A. Aluminum exposure from parenteral nutrition in preterm infants and later health outcomes during childhood and adolescence. Proc Nutr Soc. 2011; 70:299-304. [PubMed: 21781356]

Fiejka M, Fiejka E, Dlugaszek M. Effect of aluminum hydroxide administration on normal mice: Tissue distribution and ultrastructural localization of aluminium in liver. Pharmacol Toxicol. 1996; 78:123-8. [PubMed: 8882343]

Finnell RH, Greer KA, Barber RC, Piedrahita JA, Shaw GM, Lammer EJ. Neural tube and craniofacial defects with special emphasis on folate pathway genes. Crit Rev Oral Biol Med. 1998; 9:38-53. [PubMed: 9488247] 
Flarend R, Bin T, Elmore D, Hem SL. A preliminary study of the dermal absorption of aluminum from antiperspirants using aluminum-26. Food Chem Toxicol. 2001; 39:163-8. [PubMed: 11267710]

Flarend RE, Hem SL, White JL, Elmore D, Suckow MA, Rudy AC, Dandashli EA. In vivo absorption of aluminum-containing vaccine adjuvants using aluminum-26. Vaccine. 1997; 15:1314-18. [PubMed: 9302736]

Flaten TP. Aluminum in tea - concentrations, speciation and bioavailability. Coord Chem Rev. 2002; 228:385-95.

Flaten TP, Alfrey AC, Birchall JD, Savory J, Yokel RA. Status and future concerns of clinical and environmental aluminum toxicology. J Toxicol Environ Health. 1996; 48:527-41. [PubMed: 8772797]

Floody MC, Theng BKG, Reyes P, Mora ML. Natural nanoclays: applications and future trends - a Chilean perspective. Clay Min. 2009; 44:161-76.

Florent C, Desaint B, Legendre C, Chappuis P, Galle C, Giboudeau J, de Meynard C. Morphologic and ultrastructural effects of Maalox TC on human gastric and duodenal mucosa. J Clin Gastroenterol. 1991; 13:S139-44. [PubMed: 1940188]

Foglio E, Buffoli B, Exley C, Rezzani R, Rodella LF. Regular consumption of silicic acid-rich water prevents aluminum-induced alterations in nitrergic neurons in mouse brain: histochemical and immunohistochemical studies. Histol Histopathol. 2012; 27:1055-66. [PubMed: 22763878]

Fraga CG, Oteiza PI, Golub MS, Gershwin ME, Keen CL. Effects of aluminum on brain lipid peroxidation. Toxicol Lett. 1990; 51:213-19. [PubMed: 2330606]

Franchi L, Nuñez G. The Nlrp3 inflammasome is critical for aluminum hydroxide-mediated IL-1beta secretion but dispensable for adjuvant activity. Eur J Immunol. 2008; 38:2085-9. [PubMed: 18624356]

Frankowski M, Ziola-Frankowska A, Kurzyca I, Novotny K, Vaculovic T, Kanicky V, et al. Determination of aluminium in groundwater samples by GF-AAS, ICP-AES, ICP-MS and modelling of inorganic aluminium complexes. Environ Monit Assess. 2011; 182:71-84. [PubMed: 21274747]

Franzmann AW, Flynn A, Arseson PD. Moose milk and hair element levels and relationships. J Wildlife Dis. 1976; 12:202-7.

Fraser PE, Nguyen JT, Surewicz WK, Kirschner DA. pH-dependent structural transitions of Alzheimer amyloid peptides. Biophys J. 1991; 60:1190-201. [PubMed: 1760507]

Freundlich M, Zilleruelo G, Abitbol C, Strauss J, Faugere MC, Malluche HH. Infant formula as a cause of aluminum toxicity in neonatal uremia. Lancet. 1985; 2:527-9. [PubMed: 2863545]

Freundlich M, Zilleruelo G, Faugere MC, Abitol A, Strauss J, Malluche HH. Treatment of aluminum toxicity in infantile uremia with deferoxamine. J Pediatr. 1986; 109:140-3. [PubMed: 3723235]

Freundlich M, Zilleruelo G, Strauss J, Abitbol C, Malluche HH. More on aluminum toxic effects in children with uremia. J Pediatr. 1990; 117:1007-9. [PubMed: 2246681]

Friesen MC, Fritschi L, Del Monaco A, Benke G, Dennekamp M, de Klerk N, et al. Relationships between alumina and bauxite dust exposure and cancer, respiratory and circulatory disease. Occup Environ Med. 2009; 66:615-18. [PubMed: 19304667]

Friesen MS, Purssell RA, Gair RD. Aluminum toxicity following iv use of oral methadone solution. Clin Toxicol. 2006; 44:307-14.

Fritschi I, Hoving JL, Sim MR, Del Monaco A, MacFarlane E, McKenzie D, et al. All cause mortality and incidence of cancer in workers in bauxite mines and alumina refineries. Int J Cancer. 2008; 123:882-7. [PubMed: 18478567]

Froment DH, Buddington B, Miller NL, Alfrey AC. Effect of solubility on the gastrointestinal absorption of aluminum from various aluminum compounds. J Lab Clin Med. 1989; 114:237-42. [PubMed: 2769017]

FSANZ (Food Standards Australia New Zealand). 23rd Annual Australian Total Diet Study. 2011. Available at http://foodstandards.gov.au/_srcfiles/FSANZ\%2023rd\%20ATDS_v5.pdf [Accessed 10 June 2013]

GACVS (Global Advisory Committee on Vaccine Safety). Weekly epidemiological record. Aluminum adjuvants. Wkly Epidemiol Res. 2012; 87:282-3. 
Galloway SM. Cytotoxicity and chromosome aberrations in vitro: Experience in industry and the case for an upper limit on toxicity in the aberration assay. Environ Mol Mutagen. 2000; 35:191-201. [PubMed: 10737954]

Garcia EM, Lorenzo ML, Cabera C, Lopéz MC, Sanchez J. Trace element determination in different milk slurries. J Dairy Res. 1999; 66:569-78. [PubMed: 10612055]

Garcia-Patos V, Pujol RM, Alomar A, Cisteró A, Curell R, Fernández-Figueras MT, de Morgas JM. Persistent subcutaneous nodules in patients hyposensitized with aluminum-containing allergen extracts. Arch Dermatol. 1995; 131:1421-4. [PubMed: 7492132]

Garg S, Loghdey S, Gawkrodger DJ. Allergic contact dermatitis from aluminium in deodorants. Contact Dermatitis. 2010; 62:57-8. [PubMed: 20136883]

Garrosa M, Lianes F, Gayoso MJ. Histopathological changes in gerbil liver and kidney after aluminum subchronic intoxication. Histol Histopathol. 2011; 26:883-92. [PubMed: 21630218]

Gartner H. Etiology of corundum smelter's lung; (bauxite workers lung, Shaver's disease). Arch Ind Hyg Occup Med. 1952; 6:339-43.

Gatta V, Drago D, Fincati K, Valenti MT, Dalle CL, Sensi SL, Zatta P. Microarray analysis on human neuroblastoma cells exposed to aluminum, $\beta(1-42)$-amyloid or the $\beta(1-42)$-amyloid aluminum complex. PLoS One. 2011; 6:e15965. [PubMed: 21298039]

Gatti AM, Bosco P, Rivasi F, Bianca S, Ettore G, Gaetti L, et al. Heavy metals nanoparticles in fetal kidney and liver tissues. Front Biosci (Elite Ed). 2011; 3:221-6. [PubMed: 21196301]

Gault PM, Allen KR, Newton KE. Plasma aluminium: a redundant test for people on dialysis? Ann Clin Biochem. 2006; 42:51-4. [PubMed: 15802033]

Geyikoĝlu F, Turkez H, Bakir TO, Cicek M. The genotoxic, hepatotoxic, nephrotoxic, haematotoxic and histopathological effects in rats after aluminum chronic intoxication. Toxicol Ind Health. 2013; 29:780-91. [PubMed: 22421584]

Gherardi R, Authier F. Macrophagic myofasciitis: characterization and pathophysiology. Lupus. 2012; 21:184-9. [PubMed: 22235051]

Ghribi O, DeWitt DA, Forbes MS, Herman MM, Savory J. Co-involvement of mitochondria and endoplasmic reticulum in regulation of apoptosis: changes in cytochrome $c, B c l-2$ and $B a x$ in the hippocampus of aluminum-treated rabbits. Brain Res. 2001a; 903:66-73. [PubMed: 11382389]

Ghribi O, Herman MM, DeWitt DA, Forbes MS, Savory J. Abeta (1-42) and aluminum induce stress in the endoplasmic reticulum in rabbit hippocampus, involving nuclear translocation of gadd153 and NF-кB. Brain Res Mol Brain Res. 2001b; 96:30-8. [PubMed: 11731006]

Ghribi O, Herman MM, Forbes MS, DeWitt DA, Savory J. GDNF protects against aluminum-induced apoptosis in rabbits by upregulating $B c l-2$ and $B c l-X L$ and inhibiting mitochrondrial $B a x$ translocation. Neurobiol Dis. 2001c; 8:764-73. [PubMed: 11592846]

Ghribi O, Herman MM, Savory J. The endoplasmic reticulum is the main site for caspase-3 activation following aluminum-induced neurotoxicity in rabbit hippocampus. Neurosci Lett. 2002; 324:217-21. [PubMed: 12009527]

Giaccio L, Cicchella D, De Vivo B, Lombardi G, De Rosa M. Does heavy metals pollution affects semen quality in men? A case of study in the metropolitan area of Naples (Italy). J Geochem Explor. 2011; 112:218-25.

Gibbs GW, Labrèche F. Cancer risks in aluminum reduction plant workers: a review. J Occup Environ Med. 2014; 56(5S):S40-59. [PubMed: 24806725]

Gibbs AR, Pooley FD. Fuller's earth (montmorillonite) pneumoconiosis. Occup Environ Med. 1994; 51:644-6. [PubMed: 7951799]

Gies WJ. Some objections to the use of alum baking powder. J Am Med Assoc. 1911; 57:816-21.

Giorgianni CM, D’Arrigo G, Brocciaroli R, Abbate A, Spatari G, Tringali MA, et al. Neurocognitive effects in welders exposed to aluminium. Toxicol Ind Health. 2012; 30:347-56. [PubMed: 22914260]

Glenny AT, Pape CG, Waddington H, Wallace W. The antigenic value of the toxin-antitoxin precipitate of Ramon. J Pathol Bacteriol. 1926; 29:31-40.

Glynn AW, Sparen A, Danielsson LG, Sundstrom B, Jorhem L. Concentration-dependent absorption of aluminum in rats exposed to labile aluminum in drinking water. J Toxicol Environ Health A. 1999; 56:501-12. [PubMed: 10201636] 
Goffin V, Henry F, Pieŕard-Franchimont C, Piérard GE. Penetration enhancers assessed by corneoxenometry. Skin Pharmacol Appl Skin Physiol. 2000; 13:280-4. [PubMed: 10940818]

Golub MS, Germann SL, Han B, Keen CL. Lifelong feeding of a high aluminum diet to mice. Toxicology. 2000; 150:107-17. [PubMed: 10996667]

Golub MS, Takeuchi PE, Gershwin ME, Yoshida SH. Influence of dietary aluminum on cytokine production by mitogen-stimulated spleen cells, from Swiss Webster mice. Immunopharmacol Immunotoxicol. 1993; 15:605-19. [PubMed: 8301020]

Gomes JFP, Albuquerque PCS, Miranda RMM, Vieira MTF. Determination of airborne nanoparticles from welding operations. J Toxicol Environ Health A. 2012a; 75:747-55. [PubMed: 22788362]

Gomes JF, Albuquerque PC, Miranda RM, Santos TG, Vieira MT. Comparison of deposited surface area of airborne ultrafine particles generated from two welding processes. Inhal Toxicol. 2012b; 24:774-81. [PubMed: 22954401]

Gómez M, Esparza JL, Cabré MC, Garćia T, Domingo JL. Aluminum exposure through the diet: Metal levels in A $\beta$ PP transgenic mice, a model for Alzheimer's disease. Toxicology. 2008; 249:214-19. [PubMed: 18571827]

Gómez M, Esparza JL, Noqués MR, Giralt M, Cabré M, Domingo JL. Pro-oxidant activity of aluminum in the rat hippocampus: gene expression of antioxidant enzymes after melatonin administration. Free Radic Biol Med. 2005; 38:104-11. [PubMed: 15589378]

González MA, Roma M, Bernal C, Alvarez ML, Carrillo MC. Involvement of oxidative stress in the impairment of biliary secretory function induced by intraperitoneal administration of aluminum to rats. Biol Trace Elem Res. 2007; 116:329-48. [PubMed: 17709913]

González-Muñoz MJ, Meseguer I, Sanchez-Reus M, Schultz A, Olivero R, Benedi J, Sánchez-Muniz FJ. Beer consumption reduces cerebral oxidation caused by aluminum toxicity by normalizing gene expression of tumor necrotic factor alpha and several antioxidant enzymes. Food Chem Toxicol. 2008b; 46:1111-18. [PubMed: 18096288]

González-Muñoz MJ, Pena A, Meseguer I. Role of beer as a possible protective factor in preventing Alzheimer's disease. Food Chem Toxicol. 2008a; 46:49-56. [PubMed: 17697731]

González-Weller D, Gutierrez AJ, Rubio C, Revert C, Hardisson A. Dietary intake of aluminum in a Spanish population (Canary Islands). J Agric Food Chem. 2010; 58:10452-7. [PubMed: 20809646]

Good DP, Perl DP, Bierer LM, Schmeidler J. Selective accumulation of aluminum and iron in the neurofibrillary tangles of Alzheimer's disease: a laser microprobe (LAMMA) study. Ann Neurol. 1992; 31:286-92. [PubMed: 1637136]

Goodman WG, Gilligan J, Horst R. Short-term aluminum administration in the rat. Effects on bone formation and relationship to renal osteomalacia. J Clin Invest. 1984; 73:171-81. [PubMed: 6690476]

Goto N, Kato H, Maeyama J, Shibano M, Saito T, Yamaguchi J, Yoshihara S. Local tissue irritating effects and adjuvant activities of calcium phosphate and aluminium hydroxide with different physical properties. Vaccine. 1997; 15:1364-71. [PubMed: 9302746]

Grasso G, Pietropaolo A, Spoto G, Pappalardo G, Tundo GR, Ciaccio C, et al. Copper (I) and copper (II) inhibit Abeta peptides proteolysis by insulin-degrading enzyme differently: implications for metallostasis alteration in Alzheimer's disease. Chemistry. 2011; 17:2752-62. [PubMed: 21274957]

Graves AB, Rosner D, Echeverria D, Mortimer JA, Larson EB. Occupational exposures to solvents and aluminium and estimated risk of Alzheimer's disease. Occup Environ Med. 1998; 55:627-33. [PubMed: 9861186]

Graves AB, White E, Koepsell TD, Reifler BV, van Belle G, Larson EB. The association between aluminum-containing products and Alzheimer's disease. J Clin Epidemiol. 1990; 43:35-44. [PubMed: 2319278]

Greger JL, Goetz W, Sullivan D. Aluminum levels in foods cooked and stored in aluminum pans, trays and foil. J Food Prot. 1985; 48:772-7.

Greger JL, Radzanowski GM. Tissue aluminum distribution in growing, mature and ageing rats: Relationship to changes in gut, kidney and bone metabolism. Food Chem Toxicol. 1995; 33:86775. [PubMed: 7590531] 
Guerin T, Chekri R, Vastel Ch, Sirot V, Volatier J-L, Leblanc J-C, Noel L. Determination of 20 trace elements in fish and other seafood from the French market. Food Chem. 2011; 127:934-42. [PubMed: 25214081]

Guest WC, Silverman JM, Pokrtshevsky E, O’Neill MA, Grad LI, Cashman NR. Generalization of the prion hypothesis to other neurodegenerative diseases: an imperfect fit. J Toxicol Environ Health A. 2011; 74:1433-59. [PubMed: 22043906]

Guillard O, Fauconneau B, Olichon D, Dedieu G. Hyperaluminemia in a woman using an aluminiumcontaining antiperspirant for 4 years. Am J Med. 2004; 117:956-9. [PubMed: 15629736]

Guillard O, Fauconneau B, Pineau A, Marrauld A, Bellocq JP, Chenard MP. Aluminium overload after 5 years in skin biopsy following post-vaccination with subcutaneous pseudolymphoma. J Trace Elem Med Biol. 2012; 26:291-3. [PubMed: 22425036]

Gun RT, Korten AE, Jorm AF, Henderson AS, Broe GA, Creasey H, et al. Occupational risk factors for Alzheimer's disease: a case-control study. Alzheimer Dis Assoc Disord. 1997; 11:21-7. [PubMed: 9071441]

Güngör N, Knaapen AM, Munnia A, Peluso M, Haenen GR, Chiu RK, et al. Genotoxic effects of neutrophils and hypochlorous acid. Mutagenesis. 2010; 25:149-54. [PubMed: 19892774]

Guo CH, Huang CJ, Chen ST, Hsu G-SW. Serum and testicular testosterone and nitric oxide products in aluminum-treated mice. Environ Toxicol Pharmacol. 2001; 10:53-60. [PubMed: 11382556]

Guo CH, Lin CY, Yeh MS, Hsu G-SW. Aluminum-induced suppression of testosterone through nitric oxide production in male mice. Environ Toxicol Pharmacol. 2005; 19:33-40. [PubMed: 21783460]

Guo C-H, Hsu G-SW, Chuang C-J, Chen P-C. Aluminum accumulation induced testicular oxidative stress and altered selenium metabolism in mice. Environ Toxicol Pharmacol. 2009; 27:176-81. [PubMed: 21783936]

Gupta RK. Aluminum compounds as vaccine adjuvants. Adv Drug Deliv Rev. 1998; 32:155-72. [PubMed: 10837642]

Gupta VK, Agarwal S, Saleh T. Synthesis and characterization of alumina-coated carbon nanotubes and their application for lead removal. J Hazard Mater. 2011; 185:17-23. [PubMed: 20888691]

Gutteridge JMC, Quinlan GJ, Clark I, Halliwell B. Aluminum salts accelerate peroxidation of membrane lipids stimulated by iron salts. Biochim Biophys Acta. 1985; 835:441-7. [PubMed: 2861853]

Guyton, AJ.; Hall, JE. Textbook of Medical Physiology. 10th. London: WB Saunders; 2000.

Guzelian PS, Victoroff MS, Halmes NC, James RC, Guzelian CP. Evidence-based toxicology: a comprehensive framework for causation. Hum Exp Toxicol. 2005; 24:161-201. [PubMed: 15957536]

Hale LW, Gough J, King EJ, Nagelschmidt G. Pneumoconiosis of kaolin workers. Br J Ind Med. 1956; 13:251-9. [PubMed: 13364154]

Hall PL, Churchman GJ, Theng BKG. Size distribution of allophane unit particles in aqueous suspensions. Clays Clay Miner. 1985; 33:345-9.

Hamdy RC. Aluminum toxicity and Alzheimer's disease. Is there a connection? Postgrad Med. 1990; 88:239-40. [PubMed: 2216983]

Hanninen H, Matikainen E, Kovala T, Valkonen S, Riihimaki V. Internal load of aluminum in the central nervous system function of aluminium welders. Scand J Work Environ Health. 1994; 20:279-85. [PubMed: 7801073]

Hannouche D, Zaoui A, Zadegan F, Sedel L, Nizard R. Thirty years of experience with alumina-onalumina bearings in total hip arthroplasty. Int Orthop. 2011; 35:207-13. [PubMed: 21191579]

Hansen B, Belfast M, Soung G, Song L, Egan PM, Capen R, et al. Effect of the strength of adsorption of hepatitis B surface antigen to aluminum hydroxide adjuvant on the immune response. Vaccine. 2009; 27:888-92. [PubMed: 19071182]

Hansen B, Sokolovska A, HogenEsch H, Hem SL. Relationship between the strength of antigen adsorption to an aluminum-containing adjuvant and the immune response. Vaccine. 2007; 25:6618-24. [PubMed: 17681647]

Crit Rev Toxicol. Author manuscript; available in PMC 2016 August 25. 
Harold D, Abraham R, Hollingworth P, Sims R, Gerrish A, Hamshere ML, et al. Genome-wide association study that identifies variants of CLU and PICALM associated with Alzheimers disease. Nat Genet. 2009; 41:1088-93. [PubMed: 19734902]

Health Canada. Canadian Total Diet Study. Dietary Intakes of Contaminants and Other Chemicals for Different Age-Sex Groups of Canadians. Vancouver. 2007. Available at: http://www.hcsc.gc.ca/fn-an/surveill/total-diet/intake-apport/chem_age-sex_chim_2007-eng.php [Accessed 10 June 2013]

Health Canada. Aluminum chloride, aluminum nitrate, aluminum sulfate. Ottawa: Environment Canada; 2010. Priority Substances List Assessment Report. Follow-up to the State of Science Report 2000. Available at: http://www.ec.gc.ca/CEPARegistry/documents/subs_list/ Aluminium_Salts/final/A1_salts_toc.cfm [Accessed 10 June 2013]

Health Council of the Netherlands. Aluminium and aluminium compounds. Health-based recommended occupational exposure limit. Den Haag: Health Council of the Netherlands; 2010 Jul 15. Publ. No. 2010/050OSH

Hellstrom HO, Mjoberg B, Mallmin H, Michaelsson K. The aluminum content of bone increases with age, but it is not higher in hip fracture cases with and without dementia compared to controls. Osteoporos Int. 2005; 16:1982-8. [PubMed: 16047227]

Hem SL, White JL. Structure and properties of aluminum-containing adjuvants. Pharm Biotechnol. 1995; 6:249-76. [PubMed: 7551220]

Hermansen JE, Badsberg JH, Kristensen T, Gundersen V. Major and trace elements in organically or conventionally produced milk. J Dairy Res. 2005; 72:362-8. [PubMed: 16174368]

Hernández-Sánchez A, Tejada-González P, Arteta-Jiménez M. Aluminium in parenteral nutrition: a systematic review. Eur J Clin Nutr. 2013; 67:230-8. [PubMed: 23403874]

Hirata-Koizumi M, Fujii S, Ono A, Hirose A, Imai T, Ogawa K, et al. Two-generation reproductive toxicity study of aluminium sulfate in rats. Reprod Toxicol. 2011a; 31:219-30. [PubMed: 21094250]

Hirata-Koizumi M, Fujii S, Ono A, Hirose A, Imai T, Ogawa K, et al. Evaluation of the reproductive and developmental toxicity of aluminium ammonium sulfate in a two-generation study in rats. Food Chem Toxicol. 2011b; 49:1948-59. [PubMed: 21570446]

Hirayama M, Satoe I, Iwashita M, Akiyama S, Takaku Y, Yamazaki M, et al. Aging effects of major and trace elements in rat bones and their mutual correlations. J Trace Elem Med Biol. 2011; 25:73-84. [PubMed: 21514127]

Hollender D, Károly-Lakatos A, Forgó P, Körtvelyesi T, Dombi G, Majer Z, et al. Al (III) binding of an octapeptide and its phosphorylated derivative. J Inorg Biochem. 2006; 100:351-61. [PubMed: 16423403]

Hollingworth P, Harold D, Sims R, Gerrish A, Lambert JC, Carrasquillo MM, et al. Common variants in ABCA7, MS4A6A/MS4A4E, EPHA 1, CD33 and CD2AP are associated with Alzheimer's disease. Nat Genet. 2011; 43:429-35. [PubMed: 21460840]

Hou X-H, Lamberts LV, Guan G-J, D'Haese PC. Increased exposure to aluminum: Still a problem for chronic renal failure patients in East China? Trace Elem Electrolytes. 2010; 27:10-19.

House E, Esiri M, Forster G, Ince PG, Exley C. Aluminium, iron and copper in human brain tissues donated to the medical research council's cognitive function and ageing study. Metallomics. 2012; 4:56-65. [PubMed: 22045115]

HSE (Health and Safety Executive). EH40/2005 Workplace Exposure Limits. Containing the list of workplace exposure limits for use with the Control of Substances Hazardous to Health Regulations (as amended). 2011. p. 74Available at: http://www.sheffield/ac.uk.polopoly_fs/ 1.136647!/file/eh402011.pdf [Accessed 10 June 2013]

Huang J, Wu J, Li T, Song X, Zhang B, Zhang P, Zheng X. Effect of exposure to trace elements in the soil on the prevalence of neural tube defects in a high-risk area of China. Biomed Environ Sci. 2011; 24:94-101. [PubMed: 21565679]

Hull MJ, Abraham JL. Human aluminum welding fume-induced pneumoconiosis. Hum Pathol. 2002; 33:819-25. [PubMed: 12203215]

Hutchison S, Benson RA, Gibson VB, Pollock AH, Garside P, Brewer JM. Antigen depot is not required for alum adjuvanticity. FASEB J. 2012; 26:1272-9. [PubMed: 22106367] 
Hyman BT, Phelps CH, Beach TG, Bigio EH, Cairns NJ, Carrillo MC, et al. National Institute on Aging-Alzheimer's Association guidelines for the neuropathologic assessment of Alzeimer's disease. Alzheimers Dement. 2012; 8:1-13. [PubMed: 22265587]

IARC (International Agency for Research on Cancer). Aluminum production Overall evaluation of carcinogenicity: An updating of IARC Monographs. Vol. 1-41. Lyon: World Health Organization; 1987. p. 89-91.

IFA (Insitiut für Abreitsschutz der Deutschen Gesetzlichen Unfallversicherung). GESTIS International Limit Values. 2011a. Available at: http://limitvalue.ifa.dguv.de/WebForm_ueliste.aspx [Accessed 10 June 2013]

IFA (Insitiut für Abreitsschutz der Deutschen Gesetzlichen Unfallversicherung). Grenzwerteliste 2011. Sicherheit und Gesundheitsschutz am Arbeitsplatz. Spitzenverband. (Institute for Occupational Safety and Health of the German Social Accident Insurance, IFA). Berlin: Deutsche Gesetzliche Unfallversicherung; 2011b.

ILO (International Labour Organization). Chemical Exposure Limits. 2011. Available at: http:// www.ilo.org/safework/info/WCMS_151534/lang-en/index.htm\#P53_2427 [Accessed 10 June 2013]

ILSI (International Life Science Institute). The relevance of the rat lung response to particle overload for human risk assessment: a workshop consensus report - ILSI Risk Science Institute workshop participants. Inhal Toxicol. 2000; 12:1-17.

Ingram AJ. Soft tissue sarcoma associated with aluminum oxide ceramic total hip arthroplasty. Clin Orthop Relat Res. 1988; 235:311-12. [PubMed: 3416538]

IPCS (International Programme on Chemical Safety). Aluminum Environmental Health Criteria 194 United Nations Environment Programme. Geneva: World Health Organization; 1997. p. 1-214.Available at: http://www.inchem.org/documents/ehc/ehc/ehc194.htm. [Accessed 10 June 2013]

Israeli E, Agmon-Levin N, Blank M, Shoenfeld Y. Macrophagic myofaciitis a vaccine (alum) autoimmune-related disease. Clin Rev Allergy Immunol. 2011; 41:163-8. [PubMed: 20882368]

JECFA (Joint FAO/WHO Expert Committee on Food Additives). Seventy-fourth meeting. Summary and conclusions. Rome. 2011 Jun 14-23. JECFA/74/SC. Available at: http://www.fao.org/ag/agn/ agns/jecfa_index_en.asp [Accessed 10 June 2013]

Jefferson T, Rudin M, Di PC. Adverse events after immunisation with aluminium-containing DTP vaccines: systematic review of the evidence. Lancet Infect Dis. 2004; 4:84-90. [PubMed: 14871632]

Jenkins DAS, Gouldesbrough D, Smith GD, Cowie JF, Winney RJ. Can low dosage aluminum hydroxide control the plasma phosphate without bone toxicity? Nephrol Dial Transplant. 1989; 4:51-6. [PubMed: 2494599]

Jenkins W, Perone P, Walker K, Bhagavathula N, Aslam MN, DaSilva M, et al. Fibroblast response to lanthanoid metal ion stimulation: potential contribution to fibrotic tissue injury. Biol Trace Elem Res. 2011; 144:621-35. [PubMed: 21484406]

Jimenez PM, Douthat W, Orias M. Can aluminum-based binders be used safely? Semin Dial. 2011; 24:430-1. [PubMed: 21801208]

Jin P, Chen Y, Zhang SB, Chen Z. Interactions between Al1 2 X (X = Al, C, N and P) nanoparticles and DNA nucleobases/base pairs: implications for nanotoxicity. J Mol Model. 2012; 18:559-68. [PubMed: 21547548]

Johnson VJ, Kim S-H, Sharma RP. Aluminum-maltolate induces apoptosis and necrosis in neuro-2a cells: potential role for p53 signaling. Toxicol Sci. 2005; 83:329-39. [PubMed: 15537749]

Kaizer RR, Corrêa MC, Gris LR, da Rosa CS, Bohrer D, Morsch VM, Schetinger MR. Effect of longterm exposure to aluminum on the acetylcholinesterase activity in the central nervous system and erythorcytes. Neurochem Res. 2008; 33:2294-301. [PubMed: 18470612]

Kaizer RR, Corrêa MC, Spanevello RM, Morsch VM, Mazzanti CM, Goncalves JF, Schetinger MRC. Acetylcholinesterase activation and enhanced lipid peroxidation after long-term exposure to low levels of aluminum on different mouse brain regions. J Inorg Biochem. 2005; 99:1865-70. [PubMed: 16055195] 
Kakkar V, Kaur IP. Evaluating potential of curcumin loaded solid lipid nanoparticles in aluminum induced behavioural, biochemical and histopathological alterations in mice brain. Food Chem Toxicol. 2011; 49:2906-13. [PubMed: 21889563]

Kamalov J, Carpenter DO, Birman I. Cytotoxicity of environmentally relevant concentrations of aluminum in murine thymocytes and lymphocytes. J Toxicol. 2011; 2011:796719.doi: 10.115512011/796719 [PubMed: 21776265]

Kan W-C, Chien C-C, Wu C-C, Su S-B, Hwang J-C, Wang H-Y. Comparison of low-dose deferoxamine versus standard-dose deferoxamine for treatment of aluminium overload among haemodialysis patients. Nephrol Dial Transpl. 2010; 25:1604-8.

Kaneko N, Yasui H, Takada J, Suzuki K, Sakurai H. Orally administered aluminum-maltolate complex enhances oxidative stress in the organs of mice. J Inorg Biochem. 2004; 98:2022-31. [PubMed: 15541491]

Karlik SJ, Eichhorn GL, Crapper-Mclachlan DR. Molecular interactions of aluminum with DNA. Neurotoxicol. 1980; 1:83-8.

Karube J, Nakaishi K, Sugimoto H, Fujihira M. Size and shape of allophone particles in dispersed aqueous systems. Clays Clay Miner. 1996; 44:485-91.

Kasa P, Szerdahelyi P, Wisniewski HM. Lack of topographical relationship between sites of aluminum deposition and senile plaques in Alzheimer's disease brain. Acta Neuropathol. 1965; 90:526-31. [PubMed: 8560987]

Kaste PJ, Rice BM. Novel energetic materials for the future force: the Army pursues the next generation of propellant and explosives. AMPTIAC Q. 2004; 8:84-90.

Kawahara M. Effects of aluminum on the nervous system and its possible link with neurodegenerative diseases. J Alzheimers Dis. 2005; 8:171-82. [PubMed: 16308486]

Kawahara M, Kato-Negishi M. Link between aluminum and the pathogenesis of Alzheimer's disease: The integration of the aluminum and amyloid cascade hypotheses. Int J Alzheimers Dis. 2011; 2011:276-393.

Keitel WA, Dekker CL, Mink C, Campbell JD, Edwards KM, Patel SM, et al. Safety and immunogenicity of inactivated, Vero cell culture-derived whole virus influenza A/H5N1 vaccine given alone or with aluminum hydroxide adjuvant in healthy adults. Vaccine. 2009; 27:6642-8. [PubMed: 19773098]

Kelly BC, Ikonomou MG, Higgs DA, Oakes J, Dubetz C. Mercury and other trace elements in farmed and wild salmon from British Columbia. Environ Toxicol Chem. 2008; 27:1361-70. [PubMed: 18211126]

Kelso JM, Greenhawt MJ, Li JT, Nicklas RA, Bernstein DI, Blessing-Moore J, et al. Adverse reactions to vaccines practice parameter 2012 update. J Allergy Clin Immunol. 2012; 130:25-43. [PubMed: 22608573]

Keshri AK, Huang J, Singh V, Choi W, Seal S, Agarwal A. Synthesis of aluminum oxide coating with carbon nanotube reinforcement produced by chemical vapor deposition for improved surface fracture and wear resistance. Carbon. 2010; 48:431-42.

Khalaf AE, Morgan AM, Mekawy MM, Ali MF. Immunotoxicity following pre- and post-natal aluminum exposure in rats. Toxicol Res. 2008; 24:51-8.

Kiesswetter E, Schäper M, Buchta M, Schaller KH, Rossbach B, Scherhag H, et al. Longitudinal study on potential neurotoxic effects of aluminum: I. Assessment of exposure and neurobehavioral performanceof $\mathrm{Al}$ welders in the train and truck construction industry over, 4 years. Int Arch Occup Environ Health. 2007; 81:41-67. [PubMed: 17522885]

Kiesswetter E, Schäper M, Buchta M, Schaller KH, Rossbach B, Kraus T, Letzel S. Longitudinal study on potential neurotoxic effects of aluminum: II. Assessment of exposure and neurobehavioral performance of $\mathrm{Al}$ welders in the automobile industry over, 4 years. Int Arch Occup Environ Health. 2009; 82:1191-210. [PubMed: 19326140]

Kim IS, Baek M, Choi SJ. Comparative cytotoxicity of $\mathrm{Al} 2 \mathrm{O} 3, \mathrm{CeO} 2, \mathrm{TiO} 2$ and $\mathrm{ZnO}$ nanoparticles to human lung cells. J Nanosci Nanotechnol. 2010; 10:3453-8. [PubMed: 20358977]

Kirkland D, Pfuhler S, Tweats D, Aardema M, Aardema M, Corvi R, et al. How to reduce false positive results when undertaking in-vitro genotoxicity testing and thus avoidunnecessary 
followup animal tests: Report of an ECVAM workshop. Mutat Res. 2007; 628:31-55. [PubMed: 17293159]

Kirshenbaum K, Daggett V. pH-dependent conformations of the amyloid beta (1-28) peptide fragment explored using molecular dynamics. Biochemistry. 1995; 34:7629-39. [PubMed: 7779809]

Klatzo I, Wisniewski HM, Streicher E. Experimental production of neurofibrillary degeneration: 1. Light microscopic observation. J Neuropathol Exp Neurol. 1965; 24:187-99. [PubMed: 14280496]

Klein GL. Aluminum in parenteral solutions revisited - again. Am J Clin Nutr. 1995; 61:449-56. [PubMed: 7872206]

Klein GL, Coburn JW. Total parenteral nutrition and its effects on bone metabolism. Crit Rev Clin Lab Sci. 1994; 31:135-67. [PubMed: 7917007]

Klein GL, Alfrey AC, Shike M, Sherrard DJ. Parenteral drug products containing aluminum as an ingredient or a contaminant: response to FDA notice of intent. Am J Clin Nutr. 1991; 53:399_ 402. [PubMed: 1899171]

Klein GL, Berquist WE, Ament ME, Coburn JW, Millner NL, Alfrey AC. Hepatic aluminum accumulation in children on total parenteral nutrition. J Pediatr Gastroenterol Nutr. 1984; 3:740 3. [PubMed: 6438295]

Klein GL, Ott SM, Alfrey AC, Sherrard DJ, Hazlet TK, Miller NL, et al. Aluminum as a factor in the bone disease of long-term parenteral nutrition. Trans Assoc Am Physicians. 1982; 95:155-63. [PubMed: 6820740]

Klein GL, Sedman AB, Heyman MB, Marathe G, Battifora HA, Worrall JL, et al. Hepatic abnormalities associated with aluminum loading in piglets. J Parenter Enteral Nutr. 1987; 11:293-7.

Klimisch H-J, Andreae M, Tillmann U. A systematic approach for evaluating the quality of experimental toxicological and ecotoxicological data. Reg Toxicol Pharmacol. 1997; 25:1-5.

Kong S, Liochev S, Fridovich I. Aluminum (III) facilitates the oxidation of NADH by the superoxide anion. Free Radic Biol Med. 1992; 13:79-81. [PubMed: 1321073]

Kongerud J, Søyseth V. Respiratory disorders in aluminium smelter workers. J Occup Environ Med. 2014; 56(5S):S60-70. [PubMed: 24806727]

Koo WW, Kaplan LA, Krug-Wispe SK. Aluminum contamination of infant formulas. J Parenter Enteral Nutr. 1988; 12:170-3.

Koo WW, Kaplan LA, Horn J, Tsang RC, Steichen JJ. Aluminum in parenteral nutrition solution sources and possible alternatives. J Parenter Enteral Nutr. 1986; 10:591-5.

Kool M, Fierens K, Lambrecht BN. Alum adjuvant: Some of the tricks of the oldest adjuvant. J Med Microbiol. 2011; 61(Pt 7):927-34. [PubMed: 22174375]

Kool M, Petrilli V, De ST, Rolaz A, Hammad H, Van NM, et al. Cutting edge: alum adjuvant stimulates inflammatory dendritic cells through activation of the NALP3 inflammasome. J Immunol. 2008a; 181:3755-9. [PubMed: 18768827]

Kool M, Soullie T, Van NM, Willart MA, Muskens F, Jung S, et al. Alum adjuvant boosts adaptive immunity by inducing uric acid and activating inflammatory dendritic cells. J Exp Med. 2008b; 205:869-82. [PubMed: 18362170]

Koponen IK, Jensen KA, Schneider T. Comparison of dust released from sanding conventional and nanoparticle-doped wall and wood coatings. J Expos Sci Environ Epidemiol. 2010; 21:450-63.

Krewski D, Yokel RA, Nieboer E, Borchelt D, Cohen J, Harry J, et al. Human health risk assessment for aluminum, aluminum oxide and aluminum hydroxide. J Toxicol Environ Health B. 2007; 10(Suppl 1):1-269.

Kumar A, Prakash A, Dogra S. Neuroprotective effect of carvedilol against aluminium induced toxicity: possible behavioral and biochemical alterations in rats. Pharmacol Rep. 2011; 63:91523. [PubMed: 22001979]

Kumar V, Bal A, Gill KD. Susceptibility of mitochondrial superoxide dismutase to aluminum-induced oxidative damage. Toxicology. 2009a; 255:117-23. [PubMed: 19010380]

Kumar V, Bal A, Gill KD. Aluminum-induced oxidative DNA damage recognition and cell-cycle disruption in different regions of rat brain. Toxicology. 2009b; 264:137-44. [PubMed: 19464335] 
Kuroda E, Ishii KJ, Uematsu S, Ohata K, Coban C, Akira S, et al. Silica crystals and aluminum salts regulate the production of prostaglandin in macrophages via NALP3 inflammasome-independent mechanisms. Immunity. 2011; 34:514-26. [PubMed: 21497116]

Kushkuley J, Metkar S, Chan WK, Lee S, Shea TB. Aluminum induces neurofilament aggregation by stabilizing cross-bridging of phosphorylated c-terminal sidearms. Brain Res. 2010; 1322:118-23. [PubMed: 20132798]

Lambert JC, Amouyel P. Genetics of Alzheimers disease: new evidences for an old hypothesis? Curr Opin Genet Dev. 2011; 21:295-301. [PubMed: 21371880]

Lambrecht BN, Kool M, Willart MA, Hammad H. Mechanism of action of clinically approved adjuvants. Curr Opin Immunol. 2009; 21:23-9. [PubMed: 19246182]

Landry M, Sibbald W. From data to evidence: evaluative methods in evidence-based medicine. Respir Care. 2001; 46:1226-35. [PubMed: 11679144]

Landsberg JP, McDonald B, Watt F. Absence of aluminum in the neuritic plaque cores in Alzheimer's disease. Nature. 1992; 360:65-8. [PubMed: 1436075]

Lankoff A, Banasik A, Duma A, Ochniak E, Lisowska H, Kuszewski T, et al. A comet assay study reveals that aluminium induces DNA damage and inhibits repair of radiation-induced lesions in human peripheral blood lymphocytes. Toxicol Lett. 2006; 161:27-36. [PubMed: 16139969]

Lauricella AM, Garbossa G, Nesse A. Dissimilar behavior of lymph cells in response to the action of aluminium. In vitro and in vivo studies. Int Immunopharmacol. 2001; 1:1725-32. [PubMed: 11562064]

Leblanc JC, Guérin T, Noël L, Calamassi-Tran G, Volatier JL, Verger P. Dietary exposure estimates from the 1st French Total Diet Study. Food Addit Contam. 2005; 22:624-41. [PubMed: 16019838]

Lee E, Ma H, McKean-Cowdin R, Van Den Berg D, Bernstein L, Henderson BE, Ursin G. Effect of reproductive factors and oral contraceptives on breast cancer risk in BRCA1/2 mutation carriers and noncarriers: results from a population-based study. Cancer Epidemiol Biomarkers Prev. 2008; 17:3170-8. [PubMed: 18990759]

Lehman HK, Faden HS, Fang YV, Ballow M. A case of recurrent sterile abscesses following vaccination: delayed hypersensitivity to aluminum. J Pediatr. 2008; 152:133-5. [PubMed: 18154915]

Lemire J, Appanna VD. Aluminum toxicity and astrocyte dysfunction: A metabolic link to neurological disorders. J Inorg Biochem. 2011; 105:1513-7. [PubMed: 22099161]

Lemire J, Mailloux R, Darwich R, Auger C, Appanna VD. The disruption of L-carnitine metabolism by aluminum toxicity and oxidative stress promotes dyslipidemia in human astrocytic and hepatic cells. Toxicol Lett. 2011; 203:219-26. [PubMed: 21439360]

Leventhal JS, Berger EM, Brauer JA, Cohen DE. Hypersensitivity reactions to vaccine constituents: a case series and review of the literature. Dermatitis. 2012; 23:102-9. [PubMed: 22653170]

Lewis RC, Gaffney SH, Le MH, Unice KM, Paustenbach DJ. Airborne concentrations of metals and total dust during solid catalyst loading and unloading operations at a petroleum refinery. Int $\mathrm{J}$ Hyg Environ Health. 2011; 215:514-21. [PubMed: 22177528]

Li H, Li Y, Jiao J, Hu H-M. Alpha-alumina nanoparticles induce efficient autophagy-dependent crosspresentation and potent antitumor response. Nature Nanotechnol. 2011c; 6:645-50. [PubMed: 21926980]

Li W, He Y, Wu J, Xu J. Extraction and characterization of natural soil nanoparticles in Chinese soil. Eur J Soil Sci. 2012a; 63:754-61. DOI: 10.1111/j.1365-2389.2012.01480.x

Li X, Hu C, Zhu Y, Sun H, Li Y, Zhang Z. Effects of aluminum exposure on bone mineral density, mineral, and trace elements in rats. Biol Trace Elem Res. 2011b; 143:378-85. [PubMed: 20886309]

Li X, Zhang L, Zhu Y, Li Y. Dynamic analysis of exposure to aluminum and an acidic condition on bone formation in young growing rats. Environ Toxicol Pharmacol. 2011a; 31:295-301. [PubMed: 21787697]

Li XB, Zhang ZY, Yin LH, Schluesener HJ. The profile of beta-amyloid precursor protein expression of rats induced by aluminum. Environ Toxicol Pharmacol. 2012a; 33:135-40. [PubMed: 22209725] 
Li X-W, Zhang LC, Hu CW, Gu Q-Y, She Y, Li YF. Effects of chronic aluminum exposure on the collage metabolism of bone and cartilage in rats. The toxic effect of aluminum on bone and cartilage in rats. Fourth Intl Conf Bioinform Biomed Eng. 2010:4.

Li H, Willingham SB, Ting JP, Re F. Cutting edge: inflammasome activation by alum and alum's adjuvant effect are mediated by NIRP3. J Immunol. 2008; 181:17-21. [PubMed: 18566365]

Liang XF, Wang HQ, Wang JZ, Fang HH, Wu J, Zhu FC, et al. Safety and immunogenicity of 2009 pandemic influenza A H1N1 vaccines in China: a multicentre, double-blind, randomised, placebo-controlled trial. Lancet. 2010; 375:56-66. [PubMed: 20018364]

Lidsky TI. Is the aluminum hypothesis dead? J Occup Environ Med. 2014; 56(5S):S73-9. [PubMed: 24806729]

Lima P, Vasconcellos M, Montenegro R, Bahia M, Costa E, Antunes L, Burbano R. Genotoxic effects of aluminum, iron and manganese in human cells and experimental systems: A review of the literature. Hum Exp Toxicol. 2011; 30:1435-44. [PubMed: 21247993]

Lima PDL, Leite DS, Vasconcellos MC, Cavalcanti BC, Santos RA, Costa-Lotufo LV, et al. Genotoxic effects of aluminum chloride in cultured human lymphocytes treated in different phases of cell cycle. Food Chem Toxicol. 2007; 45:1154-9. [PubMed: 17321660]

Lin JL, Kou MT, Leu ML. Effect of long-term low-dose aluminum containing agents on hemoglobin synthesis in patients with chronic renal insufficiency. Nephron. 1996; 74:33-8. [PubMed: 8883017]

Lind PM, Olsen L, Lind L. Circulating levels of metals are related to carotid atherosclerosis in elderly. Sci Total Environ. 2011; 416:80-8. [PubMed: 22178028]

Lindblad EB. Aluminium compounds for use in vaccines. Immunol Cell Biol. 2004; 82:497-505. [PubMed: 15479435]

Lindquist B, Lingstrom P, Fandriks L, Birkhed D. Influence of five neutralizing products on intra-oral pH after rinsing with simulated gastric acid. Eur J Oral Sci. 2011; 119:301-4. [PubMed: 21726291]

Liu YQ, Xin TR, Liang JJ, Wang WM, Zhang YY. Memory performance, brain excitatory amino acid and acetylcholinesterase activity of chronically aluminum exposed mice in response to soy isoflavones treatment. Phytother Res. 2010; 24:1451-6. [PubMed: 20878693]

Lordan S, Higginbotham CL. Effect of serum concentration on the cytotoxicity of clay particles. Cell Biol Int. 2012; 36:57-61. [PubMed: 21883092]

Lordan S, Kennedy JE, Higginbotham CL. Cytotoxic effects induced by unmodified and organically modified nanoclays in the human hepatic HepG2 cell line. J Appl Toxicol. 2011; 31:27-35. [PubMed: 20677180]

Lukiw WJ. Evidence supporting a biological role for aluminum in chromatin compaction and epigenetics. J Inorg Biochem. 2010; 104:1010-12. [PubMed: 20684046]

Lynch KM, McIver FA. Pneumoconiosis from exposure to kaolin dust: kaolinosis. Am J Pathol. 1954; 30:1117-27. [PubMed: 13207315]

Maduray K, Odhav B, Nyokong T. In vitro photodynamic effect of aluminum tetrasulfophthalocyanines on melanoma skin cancer and healthy normal skin cells. Photodiagn Photodyn. 2012; 9:32-9.

Maghraoui S, Ayadi A, Audinot JN, Ammar AB, Jaafoura MH, Hili AE, et al. Role of parietal and principal gastric mucosa cells in the phenomenon of concentration of aluminum and indium. Microsc Res Tech. 2012; 75:182-8. [PubMed: 21761500]

Mahalakshmi M, Balakrishnan S, Indria K, Srinivasan M. Characteristic levels of heavy metals in canned tuna fish. J Toxicol Environ Health Sci. 2012; 4:43-5.

Mahieu ST, Gionotti M, Millen N, Elías MM. Effect of chronic accumulation of aluminum on renal function, cortical renal oxidative stress and cortical renal organic anion transport in rats. Arch Toxicol. 2003; 77:605-12. [PubMed: 12928767]

Mailloux RJ, Lemire J, Appanna VD. Hepatic response to aluminum toxicity: dyslipidemia and liver diseases. Exp Cell Res. 2011; 317:2231-8. [PubMed: 21787768]

Makjanic J, McDonald B, Li-Hsian Chen CP, Watt F. Absence of aluminum in neurofibrillary tangles in Alzheimer's disease. Neurosci Lett. 1998; 240:123-6. [PubMed: 9502219] 
Malluche HH, Faugere MC. Aluminum: toxin or innocent bystander in renal osteodystrophy. Am J Kidney Dis. 1985; 6:336-41. [PubMed: 3904426]

Manna GK, Das RK. Chromosome aberrations in mice induced by aluminum chloride. Nucleus. 1972; 15:180-6.

Mannello F, Tonti GA, Medda V, Simone P, Darbre PD. Analysis of aluminium content and iron homeostasis in nipple aspirate fluids for healthy women and breast cancer-affected patients. J Appl Toxicol. 2011; 31:262-9. [PubMed: 21337589]

Manzoli L, De VC, Salanti G, D'Addario M, Villari P, Ioannidis JP. Meta-analysis of the immunogenicity and tolerability of pandemic influenza A 2009 (H1N1) vaccines. PloS One. 2011; 6:e24384. [PubMed: 21915319]

Manzoli L, Salanti G, De Vito C, Boccia A, Ioannidis JP, Villari P. Immunogenicity and adverse events of avian influenza A H5N1 vaccine in healthy adults: multiple-treatments meta-analysis. Lancet Infect Dis. 2009; 9:482-92. [PubMed: 19628173]

Maquire-Boyle SJ, Liga MV, Li Q, Barron AR. Alumoxane/ferroxane nanoparticles for the removal of viral pathogens: the importance of surface functionality to nanoparticle activity. Nanoscale. 2012; 4:5627-32. [PubMed: 22864822]

Marques RC, Dorea JG, Bernardi JV. Thimerosal exposure (from tetanus-diphtheria vaccine) during pregnancy and neurodevelopment of breastfed infants at 6 months. Acta Paediatr. 2010; 99:9349. [PubMed: 20003103]

Marrack P, McKee AS, Munks MW. Towards an understanding of the adjuvant action of aluminium. Nat Rev Immunol. 2009; 9:287-93. [PubMed: 19247370]

Martin SC, Larivière C. Community health risk assessment of primary aluminum smelter emissions. J Occup Environ Med. 2014; 56(5S):S18-22.

Mayeux G, Xhauflaire-Uhoda E, Pierard GE. Patterns of aluminum hydroxychloride deposition onto the skin. Skin Res Technol. 2012; 18:64-9. [PubMed: 21438926]

McGrath KG. An earlier age of breast cancer diagnosis related to more frequent use of antiperspirants/ deodorants and underarm shaving. Eur J Cancer Prev. 2003; 12:479-85. [PubMed: 14639125]

McGrath KG. Apocrine sweat gland obstruction by antiperspirants allowing transdermal absorption of cutaneous generated hormones and phermones as a link to the observed incidence rates of breast and prostate cancer in the 20th century. Med Hypotheses. 2009; 72:665-74. [PubMed: 19307063]

McGregor SJ, Naves ML, Oria R, Brock JH. Effect of aluminum on iron uptake and transferrinreceptor expression by human erythroleukemia K562 cells. Biochem J. 1990; 272:377-82. [PubMed: 2268267]

McKee AS, Munks MW, Macleod MK, Fleenor CJ, Van Rooijen N, Kappler JW, Marrack P. Alum induces innate immune responses through macrophage and mast cell sensors, but these sensors are not required for alum to act as an adjuvant for specific immunity. J Immunol. 2009; 183:4403-14. [PubMed: 19734227]

McKhann G, Drachman D, Folstein M, Katzman R, Price D, Stadlan EM. Clinical diagnosis of Alzheimer's disease: report of the NINCDS-ADRDA work group under the auspices of Department of Health and Human Services task force on Alzheimer's disease. Neurology. 1984; 34:939-44. [PubMed: 6610841]

McKhann GM, Knopman DS, Chertkow H, Hyman BT, Jack CR Jr, Kawas CH, et al. The diagnosis of dementia due to Alzheimer's disease: recommendations from the National Institute on Aging Alzheimer's Association workgroups on diagnostic guidelines for Alzheimer's disease. Alzheimers Dement. 2011; 7:263-9. [PubMed: 21514250]

McKinnon AJ, Cattrall RW, Scollary GR. Aluminum in wine - its measurement and identification of major sources. Am J Enol Vitic. 1992; 43:166-70.

Mendez-Alvarez E, Soto-Otero R, Hermida-Ameijeiras A, Lopez-Real AM, Labandeira-Garcia JL. Effects of aluminum and zinc on the oxidative stress caused by 6-hydroxydopamine autoxidation: relevance for the pathogenesis of Parkinson's disease. Biochim Biophys Acta. 2002; 1586:15568. [PubMed: 11959457]

Meurman JH, Kuittinen T, Kangas M, Tuisku T. Buffering effect of antacids in the mouth - a new treatment for dental erosion? Scand J Dent Res. 1988; 96:412-17. [PubMed: 3201113] 
Meyer-Baron M, Schäper M, Knapp G, van Thriel C. Occupational aluminum exposure: evidence to support its neurobehavioral impact. Neurotoxicology. 2007; 28:1068-78. [PubMed: 17692380]

Mikkelsen L, Jensen KA, Koponen IK, Saber AT, Wallin H, Loft S, et al. Cytotoxicity, oxidative stress and expression of adhesion molecules in human umbilical vein endothelial cells exposed to dust from paints with or without nanoparticles. Nanotoxicol. 2012; 7:117-34.

Millour S, Noel L, Kadar A, Chekri R, Vastel Ch, Sirot V, et al. Pb, Hg, Cd, As, Sb and Al levels in foodstuffs from the 2nd French total diet study. Food Chem. 2011; 126:1787-99. [PubMed: 25213958]

Ministry of Agriculture, Fisheries and Food. Metals and other elements in infant foods. 1999. United Kingdom Food Surveillance Information Sheet No. 190http://archive.food.gov.uk/maff/archive/ food/infsheet/1999/no190/190htm [Accessed 3 July 2014]

Mirick DK, Davis S, Thomas DB. Antiperspirant use and the risk of breast cancer. J Natl Cancer Inst. 2002; 94:1578-80. [PubMed: 12381712]

Mirra SS, Heyman A, McKeel D, Sumi SM, Crain BJ, Brownlee LM, et al. The Consortium to Establish a Registry for Alzheimer's Disease (CERAD). Part II. Standardization of the neuropathologic assessment of Alzheimer's disease. Neurology. 1991; 41:479-86. [PubMed: 2011243]

Mitkus R, King D, Hess MA, Forshee R, Walderhaug MO. Updated aluminum pharmacokinetics following infant exposures through diet and vaccination. Vaccine. 2011; 29:9538-43. [PubMed: 22001122]

Miu AC, Olteanu AI, Miclea M. A behavioral and ultrastructural dissection of the interference of aluminum with aging. J Alzheimers Dis. 2004; 6:315-28. [PubMed: 15201486]

Mizoroki T, Meshitsuka S, Maeda S, Murayama M, Sahara N, Takashima A. Aluminum induces tau aggregation in vitro but not in vivo. J Alzheimers Dis. 2007; 11:419-27. [PubMed: 17656819]

Molloy DW, Standish TI, Nieboer E, Turnbull JD, Smith SD, Dubois S. Effects of acute exposure to aluminum on cognition in humans. J Toxicol Environ Health A. 2007; 70:2011-19. [PubMed: 17966072]

Monteiro-Riviere NA, Oldenburg SJ, Inman AO. Interactions of aluminum nanoparticles with human epidermal keratinocytes. J Appl Toxicol. 2010; 30:276-85. [PubMed: 20013751]

Moore PB, Day JP, Taylor GA, Ferrier IN, Fifield LK, Edwardson JA. Absorption of aluminum-26 in Alzheimer's disease, measured using accelerator mass spectrometry. Dement Geriatr Cogn Disord. 2000; 11:66-9. [PubMed: 10705162]

Morefield GL, Sokolovska A, Jiang D, HogenEsch H, Robinson JP, Hem SL. Role of aluminumcontaining adjuvants in antigen internalization by dendritic cells in vitro. Vaccine. 2005; 23:1588-95. [PubMed: 15694511]

Morita T, Nagaki T, Fukuda I, Okamura K. Clastogenicity of low $\mathrm{pH}$ to various cultured mammalian cells. Mutat Res. 1992; 268:297-305. [PubMed: 1379335]

Morita T, Watanabe Y, Takeda K, Okumura K. Effects of $\mathrm{pH}$ on the in vitro chromosome aberration test. Mutat Res. 1989; 225:55-60. [PubMed: 2913491]

Moselhy W, Helmy N, Abdel-Halim B, Nabil T, Abdel-Hamid M. Role of ginger against the reproductive toxicity of aluminum chloride in albino male rats. Reprod Domest Anim. 2011; 47:335-43. [PubMed: 21790801]

Mudge DW, Johnson DW, Hawley CM, Campbell SB, Isbel NM, van Eps CL, Petrie JJ. Do aluminium-based phosphate binders continue to have a role in contemporary nephrology practice? BMC Nephrol. 2011; 12:20. [PubMed: 21569446]

Mui S, Briggs M, Chung H, Wallace RB, Gomez-Isla T, Rebeck GW, Hyman BT. A newly identified polymorphism in the apolipoprotein E enhancer gene is associated with Alzheimer's disease and strongly with the $\varepsilon 4$ allele. Neurology. 1996; 47:196-201. [PubMed: 8710077]

Mujika JI, Lopez X, Rezabal E, Castillo R, Mart S, Moliner V, Ugalde JM. A QM/MM study of the complexes formed by aluminum and iron with serum transferrin at neutral and acidic $\mathrm{pH}$. J Inorg Biochem. 2011b; 105:1446-56. [PubMed: 22099154]

Mujika JI, Ruiperez F, Infante I, Ugalde JM, Exley C, Lopez X. Pro-oxidant activity of aluminum: stabilization of the aluminum superoxide radical ion. J Phys Chem A. 2011a; 115:6717-23. [PubMed: 21604694] 
Mujika JI, Ugalde JM, Lopez X. Aluminum speciation in biological environments. The deprotonation of free and aluminum bound citrate in aqueous solution. Phys Chem Chem Phys. 2012b; 14:12465-75. [PubMed: 22573198]

Mujika JI, Escribano B, Akhmatskaya E, Ugalde JM, Lopez X. Molecular dynamics simulations of iron- and aluminum-loaded serum transferrin: protonation of tyr188 is necessary for prompt metal release. Biochemistry. 2012a; 51:7017-27. [PubMed: 22873711]

Murdock RC, Bradydich-Stolle L, Schrand AM, Schlager JJ, Hussain SM. Characterization of nanomaterial dispersion in solution prior to in vitro exposure using dynamic light scattering technique. Toxicol Sci. 2008; 101:239-53. [PubMed: 17872897]

Nagasawa K, Ito S, Kakuda T, Nagai K, Tamai I, Tsuji A, Fujimoto S. Transport mechanism for aluminum citrate at the blood-brain barrier: kinetic evidence implies involvement of system Xcin immortalized rat brain endothelial cells. Toxicol lett. 2005; 155:289-96. [PubMed: 15603924]

Naim JO, van Oss CJ, Wu W, Giese RF, Nickerson PA. Mechanisms of adjuvancy: I. Metal oxides as adjuvants. Vaccine. 1997; 15:1183-93. [PubMed: 9286042]

Najafpour MM, Pashaei B, Nayeri S. Nano-sized layered aluminum or zinc-manganese oxides as efficient water oxidizing catalysts. Dalton Trans. 2012; 41:7134-40. [PubMed: 22565665]

Namer M, Luporsi E, Gligorov J, Lokiec F, Spielman M. L'utilisation de deodorants/antitranspirants ne constitue pas un risqué de cancer du sein. Bull Cancer. 2008; 95:871-80. [PubMed: 18829420]

National Kidney Foundation. K/DOQI clinical practice guidelines for bone metabolism and disease in chronic kidney disease. Am J Kidney Dis. 2003; 42:S1-202. [PubMed: 14520607]

Nayak P, Sharma SB, Chowdary NV. Augmentation of aluminum-induced oxidative stress in rat cerebrum by presence of pro-oxidant (graded doses of ethanol) exposure. Neurochem Res. 2010; 35:1681-90. [PubMed: 20640917]

Nayak P, Sharma SB, Chowdary NVS. Impact of coexposure to aluminum and ethanol on phosphoesterases and transaminases of rat cerebrum. J Med Biochem. 2011; 30:25-32.

Nday CM, Drever BD, Salifoglou T, Platt B. Aluminum does not enhance $\beta$-amyloid toxicity in rat hippocampal cultures. Brain Res. 2010; 1352:265-76. [PubMed: 20624378]

Nel A, Xia T, Mädler L, Li N. Toxic potential of materials at the nanolevel. Science. 2006; 311:622-7. [PubMed: 16456071]

Netterlid E, Hindsen M, Siemund I, Bjork J, Werne S, Jacobsson H, et al. Does allergen-specific immunotherapy induce contact allergy to aluminium? Acta Derm Venereol. 2013; 93:50-6. [PubMed: 22948339]

Newell KL, Hyman BT, Growdon JH, Hedley-Whyte ET. Application of the National Institute on Aging (NIA)-Reagan Institute criteria for the neuropathological diagnosis of Alzheimer's disease. J Neuropathol Exp Neurol. 1999; 58:1147-55. [PubMed: 10560657]

Niedowicz DM, Nelson PT, Murphy MP. Alzheimer's disease: pathological mechanisms and insights. Curr Neuropharmacol. 2011; 9:674-84. [PubMed: 22654725]

Niemoeller OM, Kiedaisch V, Dreischer P, Wieder T, Lang F. Stimulation of eryptosis by aluminum ions. Toxicol Appl Pharmacol. 2006; 217:168-75. [PubMed: 17055015]

NIOSH (National Institute for Occupational Safety and Health). Current Intelligence Bulletin 63: Occupational Exposure to Titanium Dioxide. Cincinnati: Department of Health and Human Services; 2011. p. 119

Nishanth RP, Jyotsna RG, Schlager JJ, Hussain SM, Reddanna P. Inflammatory responses of RAW 264.7 macrophages upon exposure to nanoparticles: role of ROS-NFKB signaling pathway. Nanotoxicology. 2011; 5:502-16. [PubMed: 21417802]

Noe SM, Green MA, HogenEsch H, Hem SL. Mechanism of immunopotentiation by aluminumcontaining adjuvants elucidated by the relationship between antigen retention at the inoculation site and the immune response. Vaccine. 2010; 28:3588-94. [PubMed: 20211692]

Nøkleby H. Neurological adverse events of immunization: experience with an aluminum adjuvanted meningococcal B outer membrane vesicle vaccine. Expert Rev Vaccines. 2007; 6:863-9. [PubMed: 17931164] 
Nordic Expert Group for Criteria Documentation of Health Risks from Chemicals and the Dutch Expert Committee on Occupational Safety. 145. Aluminium and aluminium compounds. Vol. 45. Arbete och Hälsa: Vetenskaplig skriftserie; 2011. p. 1-142.

NRC (National Research Council). Toxicity Testing in the 21st Century: A Vision and Assessment of Environmental Agents. Washington, D.C.: National Academies Press; 2007. p. 1-216.

Oakley GP. Folic acid-preventable spina bifida and anencephaly. J Am Med Assoc. 1993; 269:1292-3.

Oakley GP. Global prevention of all folic acid-preventable spina bifida and anencephaly by 2010 . Community Genet. 2002; 5:70-7. [PubMed: 14960902]

Oberdörster G. Lung particle overload: implications for occupational exposure to particles. Regul Toxicol Pharmacol. 1995; 21:123-35. [PubMed: 7784625]

Oberdörster G, Oberdörster E, Oberdörster J. Nanotoxicology: an emerging discipline evolving from studies of ultrafine particles. Environ Health Perspect. 2005; 113:823-39. [PubMed: 16002369]

Oesterling E, Chopra N, Gavalas V, Arzuaga X, Lim EJ, Sultana R, et al. Alumina nanoparticles induce expression of endothelial cell adhesion molecules. Toxicol Lett. 2008; 178:160-6. [PubMed: 18456438]

Ogimoto M, Suzuki K, Kabashima J, Nakazato M, Uematsu Y. [Aluminum content in foods with aluminum-containing food additives] (Japanese). Shokuhin Eiseigaku Zasshi. 2012; 53:57-62. [PubMed: 22450671]

Ohno K, Ishikawa K, Kurosawa Y, Matsui Y, Matsushita T, Magara Y. Exposure assessment of metal intakes from drinking water relative to those from total diet in Japan. Water Sci Technol. 2010; 62:2694-701. [PubMed: 21099058]

Olabanji O, Ngila JC, Msagati TAM, Oluyemi EA, Fatoye FO, Mamba BB. Effect of metal poisoning and the implications of gender and age on the elemental composition in patients with mental behavioural disorders. Afr J Biotechnol. 2011; 10:3585-93.

Oldham PD. Pneumoconiosis in Cornish china clay workers. Br J Ind Med. 1983; 40:131-7. [PubMed: 6830708]

Orihuela D. Aluminum effects on thyroid gland function: Iodide uptake, hormone biosynthesis and secretion. J Inorg Biochem. 2011; 105:1464-8. [PubMed: 22099156]

OSHA (Occupational Safety and Health Administration). Air contaminants. Final rule, 29 CFR Part 1910. Federal Register. 1993; 58:35338-51.

Ott SM, Maloney NA, Coburn JW, Alfrey AC, Sherrard DJ. The prevalence of bone aluminum deposition in renal osteodystrophy and its relation to the response to calcitriol therapy. N Engl J Med. 1982; 307:709-13. [PubMed: 6896740]

Ou CY, Stevenson RE, Brown VK, Schwartz CE, Allen WP, Khoury MJ, et al. 5, 10Methylenetetrahydrofolate reductase genetic polymorphism as a risk factor for neural tube defects. Am J Med Genet. 1996; 63:610-14. [PubMed: 8826441]

Pan SY, Morrison H, Gibbons L, Zhou J, Wen SW, DesMeules M, Mao Y. Breast cancer risk associated with residential proximity to industrial plants in Canada. J Occup Environ Med. 2011; 53:522-9. [PubMed: 21494158]

Pan X, Redding JE, Wiley PA, Wen L, McConnell JS, Zhang B. Mutagenicity evaluation of metal oxide nanoparticles by the bacterial reverse mutation assay. Chemosphere. 2010; 79:113-16. [PubMed: 20106502]

Passeri E, Villa Ch, Couette M, Itti E, Brugieres P, Cesaro P, et al. Long-term follow up on cognitive dysfunction in patients with aluminum hydroxide-induced macrophagic myofasciitis (MMF). J Inorg Biochem. 2011; 105:1457-63. [PubMed: 22099155]

Patra AK, Dutta A, Bhaumik A. Self-assembled mesoporous $\gamma$-A12O3 spherical nanoparticles and their efficiency for removal of arsenic from water. J Hazard Mater. 2012:201-202.

Pauluhn J. Pulmonary toxicity and fate of agglomerated 10 and $40 \mathrm{~nm}$ aluminum oxyhydroxides following 4-week inhalation exposure of rats: toxic effects are determined by agglomerated, not primary particle size. Toxicol Sci. 2009a; 109:152-67. [PubMed: 19251949]

Pauluhn J. Retrospective analysis of 4-week inhalation studies in rats with focus on fate and pulmonary toxicity of two nanosized aluminum oxyhydroxides (boehmite) and pigment-grade iron oxide (magnetite): The key metric of dose is particle mass and not particle surface area. Toxicology. 2009b; 259:140-8. [PubMed: 19428954] 
Pauluhn J. Comparative pulmonary response to inhaled nanostructures: considerations on test design and endpoints. Inhal Toxicol. 2009c; 21(S1):40-54. [PubMed: 19558233]

Pauluhn J. Poorly soluble particulates: searching for a unifying denominator of nanoparticles and fine particles for DNEL estimation. Toxicology. 2011; 279:176-88. [PubMed: 21074595]

Pechansky F, Kessler FH, Diemen L, Bumaquin DB, Surratt HL, Inciardi JA. Brazilian female crack users show elevated serum aluminum levels. Rev Bras Psiquiatr. 2007; 29:39-42. [PubMed: 17435927]

Pei Y, Hercz G, Greenwood C, Segre G, Manuel A, Saiphoo C, et al. Risk factors for renal osteodystrophy: A multivariant analysis. J Bone Miner Res. 1995; 10:149-56. [PubMed: 7747622]

Pei Y, Hercz G, Greenwood C, Sherrard D, Segre G, Manuel A, et al. Non-invasive prediction of aluminum bone disease in hemo- and peritoneal dialysis patients. Kidney Int. 1992; 41:1374-82. [PubMed: 1614052]

Pennington JA. Aluminum content of foods and diet. Food Addit Contam. 1987; 5:161-232. [PubMed: 3360205]

Pennington JA, Schoen SA. Estimates of dietary exposure to aluminium. Food Addit Contam. 1995; 12:119-28. [PubMed: 7758626]

Pepper R, Campbell N, Yaqoob MM, Roberts NB, Fan SL-S. Do oral aluminium phosphate binders cause accumulation of aluminium to toxic levels? BMC Nephrology. 2011; 12:55. [PubMed: 21992770]

Percy ME, Kruck TPA, Pogue AI, Lukiw WJ. Towards the prevention of potential aluminum toxic effects and an effective treatment for Alzheimer's disease. J Inorganic Biochem. 2011; 105:150512.

Perl DP, Good PF. Uptake of aluminum into central nervous system along nasal-olfactory pathways. Lancet. 1987; 1:1028. [PubMed: 2883359]

Perl DP, Moalem S. Aluminum and Alzhiemer's disease, a personal prespective after 25 years. J Alzheimer's Dis. 2006; 9:291-300. [PubMed: 17004365]

Pfefferkorn FE, Bello D, Haddad G, Park J-Y, Powell M, McCarthy J, et al. Characterization of exposures to nanoscale particles during friction stir welding of aluminum. Ann Occup Hyg. 2010; 54:486-503. [PubMed: 20453001]

Phillips TD. Dietary clay in the chemoprevention of aflatoxin-induced disease. Toxicol Sci. 1999; 52:118-26. [PubMed: 10630600]

Phillips TD, Afriyie-Gyawu E, Williams J, Huebner H, Ankrah NA, Ofori-Adjei D, et al. Reducing human exposure to aflatoxin through the use of clay: A review. Food Addit Contam. 2008; 25:134-45.

Piérard-Franchimont, C.; Arrese-Estrada, J.; Quatresooz, P.; Piérard, GE. Cyanoacrylate skin surface strippings. In: Farage, MA.; Miller, KW.; Maibach, HI., editors. Textbook of Aging Skin. Berlin: Springer Verlag; 2010. p. 393-9.

Pineau A, Guillard O, Fauconneau B, Favreau F, Marty MH, Gaudin A, et al. In vitro study of percutaneous absorption of aluminum from antiperspirants through human skin in the Franz diffusion cell. J Inorg Biochem. 2012; 110:21-6. [PubMed: 22459170]

Poirier J, Semple H, Davies J, Lapointe R, Dziwenka M, Hiltz M, Mujibi D. Double-blind, vehiclecontrolled randomized twelve month neurodevelopmental toxicity study of common aluminum salts in the rat. Neuroscience. 2011; 193:338-62. [PubMed: 21699960]

Polizzi S, Pira E, Ferrara M, Bugiani M, Papaleo A, Albera R, Palmi S. Neurotoxic effects of aluminum among foundry workers and Alzheimer's disease. Neurotoxicology. 2002; 23:761-74. [PubMed: 12520766]

Poole RL, Hintz SR, Mackenzie NI, Kerner JA. Aluminum exposure from pediatric parenteral nutrition: meeting the new FDA regulation. J Parenter Enteral Nutr. 2008; 32:242-6.

Poole RL, Pieroni KP, Gaskari S, Dixon TK, Park K, Kerner JA Jr. Aluminum in pediatric parenteral nutrition products: measured versus labeled content. J Pediatr Pharmacol Ther. 2011; 16:92-7. [PubMed: 22477831] 
Poole RL, Schiff L, Hintz SR, Wong A, Mackenzie N, Kerner JA Jr. Aluminum content of parenteral nutrition in neonates: measured versus calculated levels. J Pediatr Gastroenterol Nutr. 2010; 50:208-11. [PubMed: 20038851]

Popinska K, Ksiazyk J, Friedman-Gruszczynska J, Nowicka E, Migdal A, Pietraszek E. Aluminum concentration in serum of children on long-term parenteral nutrition and in parenteral nutrition solution components. E Spen Eur E J Clin Nutr Metab. 2010; 5:e18-20.

Potter H, Wisniewski T. Apolipoprotein E: essential catalyst of the Alzheimer amyloid cascade. Int J Alz Dis. 2012; 2012:489428.

Powers CM, Bale AS, Kraft AD, Makris SL, Trecki J, Cowden J, et al. Developmental neurotoxicity of engineered nanomaterials: identifying research needs to support human health risk assessment. Toxicol Sci. 2013; 134:225-42. [PubMed: 23708405]

Powers KW, Brown SC, Krishna VB, Wasdo SC, Moudgil BM, Roberts SM. Research strategies for safety evaluation of nanomaterials. Part VI. Characterization of nanoscale particles for toxicological evaluation. Toxicol Sci. 2006; 90:296-303. [PubMed: 16407094]

Prabhakar PV, Reddy UA, Singh SP, Balasubramanyam A, Rahman MF, Indu KS, et al. Oxidative stress induced by aluminum oxide nanomaterials after acute oral treatment in Wistar rats. J Appl Toxicol. 2011; 32:436-45. [PubMed: 22161306]

Precioso AR, Miraglia JL, Campos LM, Goulart AC, Timenetsky MC, Cardoso MR, et al. A phase I randomized, double-blind, controlled trial of 2009 influenza A (H1N1) inactivated monovalent vaccines with different adjuvant systems. Vaccine. 2011; 29:8974-81. [PubMed: 21945258]

Priest ND. The biological behaviour and bioavailability of aluminium in man, with special reference to studies employing aluminium-26 as a tracer: review and study update. J Environ Monit. 2004; 6:375-403. [PubMed: 15152306]

Priest, ND. The bioavailability of ingested aluminium and aluminium compounds in the rat:citrate; chloride; nitrate; sulphate; hydroxide; oxide; metal; pot electrolyte. Atomic Energy of Canada Ltd. Draft Report. 14 March. A study conducted at the request of the Aluminium REACH Consortium. Chalk River: Atomic Energy of Canada Ltd; 2010a.

Priest, ND. The bioavailability of ingested Al-26 labelled aluminium and aluminium compounds in the rat. General Nuclear Product GNP-121100-REPT-003. Chalk River: Atomic Energy of Canada Ltd; 2010b Jul.

Priest ND, Talbot JR, Austin JG, Day JP, King SJ, Fifield K, Cresswell RG. The bioavailability of ${ }^{26} \mathrm{Al}$-labelled aluminum citrate and aluminum hydroxide in volunteers. BioMetals. 1996; 9:2218. [PubMed: 8696074]

Quatrale RP. Mechanism of antiperspirant action. Cosmet Toiletries. 1985; 100:23-6.

Rabe A, Lee MH, Shek J, Wisniewski HM. Learning deficit in immature rabbits with aluminuminduced neurofibrillary changes. Exp Neurol. 1982; 76:441-6. [PubMed: 6896495]

Radzium E, Dudkiewicz-Wilczyńska J, KsiaŸek I, Nowak K, Anuszewska EL, Kunicki A, et al. Assessment of the cytotoxicity of aluminum oxide nanoparticles on selected mammalian cells. Toxicol In Vitro. 2011; 25:1694-700. [PubMed: 21835238]

Ranau R, Oehlenschläger J, Steinhart H. Aluminium levels of fish fillets baked or grilled in aluminum foil. Food Chem. 2001; 73:1-6.

Rao VS, Cupples LA, van Duijn CM, Kurz A, Green RC, Chui H, et al. Evidence for major gene inheritance of Alzheimer disease in families of patients with and without apoliprotein E4. Am J Hum Genet. 1996; 59:664-75. [PubMed: 8751868]

Rawlings W, Kennedy T, Menkes H, Morgan R. Pulmonary functions and respiratory symptoms in a population of Georgia kaolin workers. Am Rev Respir Dis. 1983; 127:215-20. [PubMed: 6830038]

Reza SM, Palan MJ. Effect of aluminum on testosterone hormones in male rat. J Med Sci. 2006; 6:296-9.

Rezabal E, Mercero JM, Lopez X, Ugalde JM. A theoretical study of the principles regulating the specificity for Al (III) against Mg (II) in protein cavities. Chem Phys Chem. 2007; 8:2119-24. [PubMed: 17712827] 
Ribes D, Colomina MT, Vicens P, Domingo JL. Impaired spatial learning and unaltered neurogenesis in a transgenic model of Alzheimer's disease after oral aluminum exposure. Curr Alzheimer Res. 2010; 7:401-8. [PubMed: 19939225]

Ribes D, Torrente M, Vicens P, Colomina MT, Gomez M, Domingo JL. Recognition memory and $\beta$ amyloid plaques in adult Tg2576 mice are not modified after oral exposure to aluminum. Alzheimer Dis Assoc Disord. 2011; 26:179-85. [PubMed: 21642811]

Ricchelli F, Drago D, Filippi B, Tognon G, Zatta P. Aluminum-triggered structural modifications and aggregation of $\beta$-amyloids. Cell Mol Life Sci. 2005; 62:1724-33. [PubMed: 15990957]

Riihimäki V, Aitio A. Occupational exposure to aluminum and its biomonitoring in perspective. Crit Rev Toxicol. 2012; 42:827-53. [PubMed: 23013241]

Riihimäki V, Hanninen H, Akila R, Kovala T, Kuosma E, Paakkulainen H, et al. Body burden of aluminum in relation to central nervous system function among metal inert-gas welders. Scand J Work Environ Health. 2000; 26:118-30. [PubMed: 10817377]

Riihimäki V, Valkonen S, Engstrom B, Tossavainen A, Mutanen P, Aitio A. Behavior of aluminum in aluminum welders and manufacturers of aluminum sulfate - impact on biological monitoring. Scand J Work Environ Health. 2008; 34:451-62. [PubMed: 19137207]

Rimaniol AC, Gras G, Verdier F, Capel F, Grigoriev VB, Porcheray F, et al. Aluminum hydroxide adjuvant induces macrophage differentiation towards a specialized antigen-presenting cell type. Vaccine. 2004; 22:3127-35. [PubMed: 15297065]

Roberts NB, Clough A, Bellia JP, Kim JY. Increased absorption of aluminum from a normal dietary intake in dementia. J Inorg Biochem. 1998; 69:171-6. [PubMed: 9629676]

Robertson JA, Felsenfeld AJ, Haygood CC, Wilson P, Clarke C, Llach F. Animal model of aluminuminduced osteomalacia: Role of chronic renal failure. Kidney Int. 1983; 23:327-35. [PubMed: 6842959]

Rocha MS, Lucci CM, Longo JP, Galera PD, Simioni AR, Lacava ZG, et al. Aluminum-chloridephthalocyanine encapsulated in liposomes: activity against naturally occurring dog breast cancer cells. J Biomed Nanotechnol. 2012; 8:251-7. [PubMed: 22515076]

Rödelsperger K, Brückel B, Manke J, Woitowitz H-J, Pott F. Potential health risks from the use of fibrous mineral absorption granulates. Br J Ind Med. 1987; 44:337-43. [PubMed: 2954581]

Romanowski B, Schwarz TF, Ferguson LM, Peters K, Dionne M, Schulze K, et al. Immunogenicity and safety of the HPV-16/18 AS04-adjuvanted vaccine administered as a 2-dose schedule compared with the licensed 3-dose schedule: results from a randomized study. Hum Vaccines. 2011; 7:1374-86.

Rose M, Baxter M, Brereton N, Baskaran C. Dietary exposure to metals and other elements in the 2006 UK Total Diet Study and some trends over the last 30 years. Food Addit Contam A. 2010; 27:1380-404.

Rosenlof K, Fyhrquist F, Tenhunen R. Erythropoietin, aluminum and anemia in patients on hemodialysis. Lancet. 1990; 1:247-9. [PubMed: 1967718]

Rossbach B, Buchta M, Csanady GA, Filser JG, Hilla W, Windorfer K. Biological monitoring of welders exposed to aluminum. Toxicol Lett. 2006; 162:239-45. [PubMed: 16280209]

Rui D, Yongjian Y. Aluminum chloride induced oxidative damage on cells derived from hippocampus and cortex of ICR mice. Brain Res. 2010; 1324:96-102. [PubMed: 20156420]

Rusina R, Matej R, Kasparova L, Kukal J, Urban P. Higher aluminum concentration in Alzheimer's disease after Box-Cox data transformation. Neurotox Res. 2011; 20:329-33. [PubMed: 21567285]

Ryu RK, Bovill EG, Skinner HB, Murray WR. Soft tissue sarcoma associated with aluminum oxide ceramic total hip arthroplasty. Clin Orthop Relat Res. 1987; 216:207-12. [PubMed: 3815950]

Sadiq MI, Chowdhury B, Chandrasekaran N, Mukherjee A. Antimicrobial sensitivity of Escherichia coli to alumina nanoparticles. Nanomed Nanotechnol Biol Med. 2009; 5:282-6.

Safe Work Australia. Hazardous Substances Information System (HSIS). 2012. Available at: http:// hsis.safeworkaustralia.gov.au/ExposureStandards [Accessed 10 June 2013]

Sakula A. Pneumoconiosis due to Fuller's earth. Thorax. 1961; 16:176-9. [PubMed: 13745504]

Salib E, Hillier V. A case-control study of Alzheimer's disease and aluminum occupation. Br J Psychiatry. 1996; 168:244-9. [PubMed: 8837919] 
Saiyed SM, Yokel RA. Aluminum content of some foods and food products in the USA, with aluminum food additives. Food Addit Contam. 2005; 22:234-44. [PubMed: 16019791]

Salusky IB, Coburn JW, Nelson P, Goodman WG. Prospective evaluation of aluminum loading from formula in infants with uremia. J Pediatr. 1990; 116:726-9. [PubMed: 2329421]

Salusky IB, Coburn JW, Paunier L, Sherrard DJ, Fine RN. Role of aluminum hydroxide in raising serum aluminum levels in children undergoing continuous ambulatory peritoneal dialysis. $\mathrm{J}$ Pediatr. 1984; 105:717-20. [PubMed: 6502300]

Salusky IB, Foley J, Nelson P, Goodman WG. Aluminum accumulation during treatment with aluminum hydroxide and dialysis in childrenand young adults with chronic renal disease. N Engl J Med. 1991; 324:527-31. [PubMed: 1992306]

Sánchez-Iglesias S, Méndez-Álvarez E, Iglesias-Gonzáles J, Muñoz-Patiño A, Sánchez-Sellero I, Labandiera-Garciá JL, Soto-Otero R. Brain oxidative stress and selective behaviour of aluminum in specific areas of rat brain: potential effects in a 6-OHDA-induced model of Parkinson's disease. J Neurochem. 2009; 109:879-88. [PubMed: 19425176]

Sandhu G, Djebali D, Bansal A, Chan G, Smith SD. Serum concentrations of aluminum in hemodialysis patients. Am J Kidney Dis. 2011; 57:523-5. [PubMed: 21257246]

Sandora TJ, Pfoh E, Lee GM. Adverse events after administration of tetanus- diphtheria-acellular pertussis vaccine to healthcare workers. Infect Control Hosp Epidemiol. 2009; 30:389-91. [PubMed: 19239376]

SanMartín CD, Paula-Lima AC, Hidalgo C, Núñez MT. Sub-lethal levels of amyloid beta-peptide oligomers decrease non-transferrin-bound iron uptake and do not potentiate iron toxicity in primary hippocampal neurons. Biometals. 2012; 25:805-13. [PubMed: 22526560]

Santibáñez M, Bolumar F, García AM. Occupational risk factors in Alzheimer's disease: a review assessing the quality of published epidemiological studies. Occup Environ Med. 2007; 64:72332. [PubMed: 17525096]

Sappino AP, Buser R, Lesne L, Gimelli S, Bena F, Belin D, Mandriota SJ. Aluminium chloride promotes anchorage-independent growth in human mammary epithelial cells. J Appl Toxicol. 2012; 32:233-43. [PubMed: 22223356]

Sato K, Suzuki I, Kubota H, Furusho N, Inoue T, Yasukouchi Y, Akiyama H. Estimation of daily aluminum intake in Japan based on food consumption inspection results: impact of food additives. Food Sci Nutr. 2014; doi: 10.1002/fsn3.114

Savory J, Ghribi O. Can studies of aluminum toxicity in vivo and in vitro provide relevant information on the pathogenesis and etiology of Alzheimer's disease? J Alzheimers Dis. 2007; 11:429-30. [PubMed: 17656820]

Savory J, Herman MM, Ghribi O. Mechanisms of aluminum-induced neurodegeneration in animals: implications for Alzheimer's disease. J Alzheimers Dis. 2006; 10:135-44. [PubMed: 17119283]

Savory J, Rao JK, Huang Y, Letada PR, Herman MM. Age-related changes hippocampal changes in $\mathrm{Bcl}$ :Bax ratio, oxidative stress, redox-active iron and apoptosis associated with aluminuminduced neurodegeneration: Increased susceptibility with aging. Neurotoxicology. 1999; 20:80517. [PubMed: 10591516]

Schenk, RU.; Bjorksten, J.; Yeager, L. Composition and consequences of aluminum in water, beverages and other ingestibles. In: Lewis, TE., editor. Environmental Chemistry and Toxicology of Aluminum. Chelsea, MI: Lewis Publishers; 1989. p. 247-69.

Schneider K, Schwarz M, Burkholder I, Kopp-Schneider A, Edler L, Kinsner-Ovaskainen A, et al. "ToxRTool", a new tool to assess the reliability of toxicological data. Toxicol Lett. 2009; 189:138-44. [PubMed: 19477248]

Schneider J, Walter D, Brückel B, Rödelsperger K. Primary particles and their agglomerate formation as modifying risk factors of nonfibrous nanosized dust. J Toxicol Environ Health A. 2013; 76:131-41. [PubMed: 23294301]

Schönholzer KW, Sutton RA, Walker VR, Sossi V, Schulzer M, Orvig C, et al. Intestinal absorption of trace amounts of aluminum in rats studied with 26aluminum and accelerator mass spectrometry. Clin Sci. 1997; 92:379-83. [PubMed: 9176037] 
Schrag M, Crofton A, Zabel M, Jiffry A, Kirsch D, Dickson A, et al. Effect of cerebral amyloid angiopathy on brain iron, copper and zinc in Alzheimer's disease. J Alzheimer Dis. 2011; 24:137-49.

Seo J, Lee TJ, Ko S, Yeo H, Kim S, Noh T, et al. Heirarchal and multifunctional three-dimensional network of carbon nanotubes for microfluidic applications. Adv Mater. 2012; 24:1975-9. [PubMed: 22422430]

Sharma D, Sethi P, Hussain E, Singh R. Curcumin counteracts the aluminium-induced ageing-related alterations in oxidative stress, $\mathrm{Na}+\mathrm{K}+\mathrm{ATPase}$ and protein kinase $\mathrm{C}$ in adult and old rat brain regions. Biogerontology. 2009; 10:489-502. [PubMed: 19020987]

Shati AA, Elsaid FG, Hafez EE. Biochemical and molecular aspects of aluminium chloride-induced neurotoxicity in mice and the protective role of Crocus sativus L. extraction and honey syrup. Neurosci. 2011; 175:66-74.

Shirodkar S, Hutchinson RL, Perry DL, White JL, Hem SL. Aluminum compounds used as adjuvants in vaccines. Phar Res. 1990; 7:1282-8.

Shoenfeld Y, Agmon-Levin N. 'ASIA' - autoimmune/inflammatory syndrome induced by adjuvants. J Autoimmun. 2011; 36:4-8. [PubMed: 20708902]

Shrivastava S. Combined effect of HEDTA and selenium against aluminum induced oxidative stress in rat brain. J Trace Elem Med Biol. 2012; 26:210-14. [PubMed: 22575537]

Siegrist CA. Vaccine adjuvants and macrophagic myofasciitis. Arch Pediatr. 2005; 12:96-101. [PubMed: 15653065]

Sjogren B, Gustavsson P, Hogstedt C. Neuropsychiatric symptoms among welders exposed to neurotoxic metals. Br J Ind Med. 1990; 47:704-7. [PubMed: 2223663]

Slanina P, Falkeborn Y, Frech W, Cedergren A. Aluminum concentrations in the brain and bone of rats fed citric acid, aluminum citrate and aluminum hydroxide. Food Chem Toxicol. 1984; 22:391-7. [PubMed: 6539288]

Small GW, Ercoli LM, Silverman DHS, Huang SC, Komo S, Bookheimer SY, et al. Cerebral metabolic and cognitive decline in persons at genetic risk for Alzheimer's disease. Proc Natl Acad Sci USA. 2000; 97:6037-42. [PubMed: 10811879]

Smith AJ, Faugére M-C, Abreo K, Fanti P, Julian B, Malluche HH. Aluminum-related bone disease in mild and advanced renal failure: Evidence for high prevalence and morbidity studies on etiology and diagnosis. Am J Nephrol. 1986; 6:275-83. [PubMed: 3777036]

Smith BS, Kothari H, Hayes BD. Effect of additive selection on calculated parenteral content of parenteral nutrient solutions. Am J Health Syst Pharm. 2007; 64:730-9. [PubMed: 17384359]

Sokolovska A, Hem SL, HogenEsch H. Activation of dendritic cells and induction of CD4(+) T cell differentiation by aluminum-containing adjuvants. Vaccine. 2007; 25:4575-85. [PubMed: 17485153]

Solfrizzi V, Panza F, Frisardi V, Seripa D, Logroscino G, Imbimbo BP, Pilotto A. Diet and Alzheimer's disease risk factors or prevention: the current evidence. Expert Rev Neurother. 2011; 11:677-708. [PubMed: 21539488]

Sood PK, Nahar U, Nehru B. Curcumin attenuates aluminum-induced oxidative stress and mitochondrial dysfunction in rat brain. Neurotox Res. 2011; 20:351-61. [PubMed: 21656326]

Sood PK, Nahar U, Nehru B. Stress proteins and glial cell functions during chronic aluminum exposures: Protective role of curcumin. Neurochem Res. 2012; 37:639-46. [PubMed: 22130689]

Sorenson JR, Campbell IR, Tepper LB, Lingg RD. Aluminum in the environment and human health. Environ Health Perspect. 1974; 8:3-95. [PubMed: 4470920]

Stadler T, Buteler M, Weaver DK. Novel use of nanostructured alumina as an insecticide. Pest Manag Sci. 2010; 66:577-9. [PubMed: 20127753]

Stahl T, Taschan H, Brunn H. Aluminium content of selected foods and food products. Environ Sci Eur. 2011; 23:37-48.

Steinhagen WH, Cavender FL, Cockrell BY. Six month inhalation exposures of rats and guinea pigs to aluminum chlorhydrate. J Environ Pathol Toxicol. 1978; 1:267-77. [PubMed: 722194]

Stevanović ID, Jovanovic MD, Colic M, Jelenkovic A, Bokonjic D, Ninkovic M, Stojanovic I. N-nitroL-arginine methyl ester influence on aluminium toxicity in the brain. Folia Neuropathol. 2011; 49:219-29. [PubMed: 22101955] 
Streker M, Reuther T, Verst S, Kerscher M. Hyperhidrosis axillaries - Effektivitat und Vertraglichkeit eines aluminiumchloridhaltigen Antiperspirants; Prospective Evaluation on 20 Patienten mit idiopathischer Hyperhidrosis axillaries. Hautartz. 2010; 61:139-44.

Strozyk D, Launer LJ, Adlard PA, Cherny RA, Tsatsanis A, Volitakis I, et al. Zinc and copper modulate Alzheimer A $\beta$ levels in human cerebrospinal fluid. Neurobiol Aging. 2009; 30:106977. [PubMed: 18068270]

Sumathi T, Shobana C, Kumari BR, Nandhini DN. Protective effect of Cynodon dactylon in ameliorating the aluminium-induced neurotoxicity in rat brain regions. Biol Trace Elem Res. 2011; 144:843-53. [PubMed: 21448563]

Sun H, Hu C, Jia L, Zhu Y, Zhao H, Shao B, et al. Effects of aluminum exposure on serum sex hormones and androgen receptor expression in male rats. Biol Trace Elem Res. 2011b; 144:1050-8. [PubMed: 21647756]

Sun J, Wang S, Zhao D, Hun FH, Weng L, Liu H. Cytotoxicity, permeability, and inflammation of metal oxide nanoparticles in human cardiac microvascular endothelial cells: cytotoxicity, permeability, and inflammation of metal oxide nanoparticles. Cell Biol Toxicol. 2011a; 27:33342. [PubMed: 21681618]

Sun Z-Z, Chen Z-B, Jiang H, Li L-L, Li E-G, Xu Y. Alteration of A $\beta$ metabolism-related molecules in predementia by $\mathrm{AlCl}_{3}$ and D-galactose. Age (Dordr). 2009; 31:277-84. [PubMed: 19468866]

Swaile DF, Elstun LT, Benzing KW. Clinical studies of sweat rate reduction by an over-the-counter soft-solid antiperspirant and comparison with a prescription antiperspirant product in male panelists. Br J Dermatol. 2012; 166:22-6. [PubMed: 22385032]

Taiwo OA. Diffuse parenchymal diseases associated with aluninum use and primary aluminum production. J Occup Environ Med. 2014; 56(5S):S18-22.

Tariba B. Metals in wine-impact on wine quality and health outcomes. Biol Trace Elem Res. 2011; 144:143-56. [PubMed: 21479541]

Theeten H, Van DP, Hoppenbrouwers K, Vandermeulen C, Leback E, Sokal EM, et al. Effects of lowering the aluminium content of a dTpa vaccine on its immunogenicity and reactogenicity when given as a booster to adolescents. Vaccine. 2005; 23:1515-21. [PubMed: 15670888]

Theng BK, Yuan G. Nanogeoscience: nanoparticles in the soil environment. Elements. 2008; 4:395-9.

Theng BKG, Russell M, Churchman GJ, Parfitt RL. Surface properties of allophone, halloysite and imogolite. Clays Clay Miner. 1982; 30:143-9.

Thinakaran G, Koo EH. Amyloid precursor protein trafficking, processing and function. J Biol Chem. 2008; 283:29615-9. [PubMed: 18650430]

Thirunavukkarasu SV, Upadhyay LU, Venkataraman S. Effect of aluminum induced toxicity on behavioral and hematological parameters under the influence of Manasamitra vatakam (an Ayurvedic formulation) in rats. PhOL. 2011; 1:594-603.

Thirunavukkarasu SV, Venkataraman S, Lokesh U. Effect of aluminum chloride on testicular function under the influence of Manasamita vatakam an indigenous formulation. PhOL. 2010; 1:236-42.

Thirunavukkarasu SV, Venkataraman S, Raja S, Upadhyay L. Neuroprotective effect of Manasamitra vatakam against aluminium induced cognitive impairment and oxidative damage in the cortex and hippocampus of rat brain. Drug Chem Toxicol. 2012; 35:104-15. [PubMed: 21787249]

Toda S, Yase Y. Effect of aluminum on iron-induced lipid peroxidation and protein oxidative modification of mouse brain homogenate. Biol Trace Elem Res. 1998; 61:207-17. [PubMed: 9517491]

Tomljenovic L. Aluminum and Alzheimer's disease: after a century of controversy is there a possible link? J Alzheimers Dis. 2011; 23:567-98. [PubMed: 21157018]

Tomljenovic L, Shaw CA. Aluminum vaccine adjuvants: are they safe? Curr Med Chem. 2011a; 18:2630-7. [PubMed: 21568886]

Tomljenovic L, Shaw CA. Do aluminum vaccine adjuvants contribute to the rising prevalence of autism? J Inorg Biochem. 2011b; 105:1489-99. [PubMed: 22099159]

Tomljenovic L, Shaw CA. Mechanisms of aluminum adjuvant toxicity and autoimmunity in pediatric populations. Lupus. 2012; 21:223-30. [PubMed: 22235057] 
Touam M, Martinez F, Lacour B, Bourdon R, Zingraff J, Dicuilio S, Drueke T. Aluminum-induced, reversible microcytic anemia in chronic renal failure: Clinical and experimental studies. Clin Nephrol. 1983; 19:295-8. [PubMed: 6872366]

Tripathi S, Mahdi AA, Hasan M, Mitra K, Mahdi F. Protective potential of Bacopa monniera (Brahmi) on aluminum induced cerebellar toxicity and associated neuromuscular status in aged rats. Cell Mol Biol (Noisy-le-grand). 2011; 57:3-15. [PubMed: 21366957]

Tsaousi A, Jones E, Case CP. The in vitro genotoxicity of orthopaedic ceramic $\left(\mathrm{Al}_{2} \mathrm{O}_{3}\right)$ and metal (CoCr alloy) particles. Mutat Res. 2010; 29:1-9. [PubMed: 20139029]

Tsunoda M, Sharma RP. Modulation of tumor necrosis factor alpha expression in mouse brain after exposure to aluminum in drinking water. Arch Toxicol. 1999; 73:419-26. [PubMed: 10650912]

Turconi G, Minoia C, Ronchi A, Roggi C. Dietary exposure estimates of twenty-one trace elements from a Total Diet Study carried out in Pavia, Northern Italy. Br J Nutr. 2009; 101:1200-8. [PubMed: 19007448]

Turkez H, Geyikoĝlu F. The efficacy of bismuth subnitrate against genotoxicity and oxidative stress induced by aluminum sulphate. Toxicol Ind Health. 2011; 27:133-42. [PubMed: 20823050]

Turkez H, Geyikoĝlu F, Tatar A. Borax counteracts genotoxicity of aluminum in rat liver. Toxicol Ind Health. 2013; 29:775-9. [PubMed: 22491726]

Turkez H, Yousef MI, Geyikoĝlu F. Propolis prevents aluminium-induced genetic and hepatic damages in rat liver. Food Chem Toxicol. 2010; 48:2741-6. [PubMed: 20637254]

United Kingdom Medicines and Healthcare Regulatory Agency. Calcium gluconate injection in smallvolume glass containers: new contraindications due to aluminium exposure risk. Drug Safety Update. 2010a; 4(1):A2. Available at: http://www.mhra.gov.uk/home/groups/pl-p/documents/ publication/con090933.pdf [Accessed 11 April 2014].

United Kingdom Medicines and Healthcare Regulatory Agency. Calcium gluconate $10 \%$ in $10 \mathrm{ml}$ glass containers: risk of aluminium exposure. MHRA Public Assessment Report. 2010b Sep 6. Available at: http://www.mhra.gov.uk/home/groups/pl-p/documents/websiteresources/ con093936.pdf [Accessed 11 April 2014]

US DHHS (US Department of Health and Human Services). Antiperspirant drug products for over-thecounter human use; tentative final monograph (proposed rule). 21 CFR Part 350. Federal Register. 1982; 47:36492-505.

US DHHS (US Department of Health and Human Services). Antiperspirant drug products for over-thecounter human use; final monograph. 21 CFR Parts 310, 350 and 369. Federal Register. 2003; 68:34273-93. [PubMed: 12795305]

US FDA (US Food and Drug Administration). Aluminum in large and small volume parenterals used in total parenteral nutrition: proposed rule. Federal Register. 1998; 63:176-85. [PubMed: 10176836]

US FDA (US Food and Drug Administration). Amendment of regulations on parenteral nutrition; delay of effective date. Federal Register. 2003; 68:32979-81.

US FDA (US Food and Drug Administration). Title 21 Food and Drugs Chapter I - Food and Drug Administration Title 21 Vol. 4. Subchapter C-Drugs: General. Part 201 Labeling Subpart G. Sec. 201.323. Aluminum in large and small volume parenterals used in parenteral nutrition. (Federal Register 65: 4110 Jan 262000 as amended at Federal Register 67: 70691 and Federal Register 68: 32981 June 3 2003). 2013. Available at http://www.accessdata.fda.gov/scripts/cdrh/cfdocs/ cfCFR/CFRsearch [Accessed on 5 September 2013]

van der Put NM, Steegers-Theunissen RP, Frosst P, Trijbels FJ, Eskes TK, van den Heuvel LP, et al. Mutated methylenetetrahydrofolate reductase as a risk factor for spina bifida. Lancet. 1995; 346:1070-1. [PubMed: 7564788]

van der Voet GB, de Wolff FA. Intestinal absorption of aluminum from antacids: A comparison between hydrotalcite and algeldrate. J Toxicol Clin Toxicol. 1986-87; 24:545-53. [PubMed: 3573126]

Verbeken G, Schoeters D, Verween G, De VD, Pascual B, De CP, Geukens K, et al. Potential release of aluminum and other metals by food- grade aluminum foil used for skin allograft cryo preservation. Cell Tissue Bank. 2011; 12:241-6. [PubMed: 20146011] 
Verdier F, Burnett R, Michelet-Habchi C, Moretto P, Fievet-Groyne F, Sauzeat E. Aluminium assay and evaluation of the local reaction at several time points after intramuscular injection of aluminium containing vaccines in the Cynomolgus monkey. Vaccine. 2005; 23:1359-67. [PubMed: 15661384]

Verghese J, Castellano M, Holtzman DM. Apolipoprotein E in Alzheimer's disease and other neurological disorders. Lancet Neurol. 2011; 10:241-52. [PubMed: 21349439]

Verma NK, Moore E, Blau W, Volkov Y, Babu PR. Cytotoxicity evaluation of nanoclays in human epithelial cell line A549 using high content screening and real-time impedance analysis. J Nanoparticle Res. 2012; 14:1137.

Verstraeten SV, Golub MS, Keen CL, Oteiza PI. Myelin is a preferential target of aluminum-mediated oxidative damage. Arch Biochem Biophys. 1997b; 344:289-94. [PubMed: 9264541]

Verstraeten SV, Nogueira LV, Schreier S, Oteiza PL. Effect of trivalent metal ions on phase separation and membrane lipid packing: role in lipid peroxidation. Arch Biochem Biophys. 1997a; 338:1217. [PubMed: 9015396]

Verstraeten T, Descamps D, David MP, Zahaf T, Hardt K, Izurieta P, et al. Analysis of adverse events of potential autoimmune aetiology in a large integrated safety database of AS04 adjuvanted vaccines. Vaccine. 2008; 26:6630-8. [PubMed: 18845199]

Viezeliene D, Jansen E, Rodovicius H, Kasauskas A, Ivanov L. Protective effect of selenium on aluminium-induced oxidative stress in mouse liver in vivo. Environ Toxicol Pharmacol. 2011; 31:302-6. [PubMed: 21787698]

Viezeliene D, Rodovicius H, Ivanov L. Effect of selenium on aluminium-induced changes in the translation system in mouse liver in vivo. Trace Elem Electrolytes. 2012; 29:78-82.

Vittori D, Pregi N, Pérez G, Garbossa G, Nesse A. The distinct erythropoietic functions that promote cell survival and proliferation are affected by aluminum exposure through mechanisms involving erythropoietic receptor. Biochim Biophys Acta. 2005; 1743:29-36. [PubMed: 15777837]

Vota DM, Crisp RL, Nesse AB, Vittori DC. Oxidative stress due to aluminium exposure induces eryptosis which is prevented by erythropoietin. J Cell Biochem. 2012; 113:1581-9. [PubMed: 22174104]

Wada K. Minerals formed and mineral formation from volcanic ash by weathering. Chem Geol. 1987; 60:17-28.

Wagner AJ, Bleckmann CA, Murdock RC, Schrand AM, Schlager JJ, Hussain RC. Cellular interaction of different forms of aluminum nanoparticles in rat alveolar macrophages. J Phys Chem B. 2007; 111:7353-9. [PubMed: 17547441]

Wagner L, Verma A, Meade BD, Reiter K, Narum DL, Brady RA, et al. Structural and immunological analysis of anthrax recombinant protective antigen adsorbed to aluminum hydroxide adjuvant. Clin Vaccine Immunol. 2012; 19:1465-73. [PubMed: 22815152]

Wald N. Folic acid and the prevention of neural tube defects. Ann NY Acad Sci. 1993; 678:112-29. [PubMed: 8494254]

Wallace WE Jr, Vallyathan V, Keane MJ, Robinson V. In vitro biological toxicity of native and surface modified silica and kaolin. J Toxicol Environ Health. 1985; 16:415-24. [PubMed: 3003373]

Walton JR. A bright field/fluorescent stain for aluminum: its specificity, validation and staining characteristics. Biotech Histochem. 2004; 79:169-76. [PubMed: 15764283]

Walton JR. Evidence for participation of aluminum in neurofibrillary tangle formation and growth in Alzheimer's disease. J Alzheimers Dis. 2010; 22:65-72. [PubMed: 20847423]

Walton JR. Cognitive deterioration and associated pathology induced by chronic low level aluminum ingestion in a translational rat model provides an explanation of Alzheimer's disease, tests for susceptibility and avenues for treatment. Int J Alzheimers Dis. 2012a; 2012:914947. [PubMed: 22928148]

Walton JR. Aluminum disruption of calcium homeostasis and signal transduction resembles change that occurs in aging and Alzheimer's disease. J Alzheimers Dis. 2012b; 29:255-73. [PubMed: 22330830]

Wang B, Xing W, Zhao Y, Deng X. Effects of chronic aluminum exposure on memory through multiple signal transduction pathways. Environ Toxicol Pharmacol. 2010a; 29:308-13. [PubMed: 21787618] 
Wang N, She Y, Zhu Y, Zhao H, Shao B, Sun H, et al. Effects of subchronic aluminum exposure on the reproductive function in female rats. Biol Trace Elem Res. 2012a; 145:382-7. [PubMed: 21932046]

Watson LC, Gies D, Thompson E, Thomas B. Randomized control trial: evaluating aluminum-based antiperspirant use, axilla skin toxicity, and reported quality of life in women receiving external beam radiotherapy for treatment of Stage 0, I, and II breast cancer. Int J Radiat Oncol. 2012; 83:e29-34.

Waxweiler RJ, Zumwalde RD, Ness GO, Brown DP. A retrospective cohort mortality study of males mining and milling attapulgite clay. Am J Ind Med. 1988; 13:305-15. [PubMed: 3354582]

Weberg R, Berstad A. Gastrointestinal absorption of aluminum from single doses of aluminum containing antacids in man. Eur J Clin Invest. 1986; 16:428-32. [PubMed: 3100311]

Wei SH, Chao YN, Huang SE, Lee TF, Chang LY. Adverse effects of tetanus toxoid, reduced diphtheria toxoid, and acellular pertussis vaccine in 6- to 7-year-old children. Pediatr Neonatol. 2011; 52:38-41. [PubMed: 21385656]

Weinbruch S, Benker N, Koch W, Ebert M, Drablos PA, Skaugset NP, et al. Hygroscopic properties of the workroom aerosol in aluminium smelter potrooms: a case for transport of HF and SO2 into the lower airways. J Environ Monit. 2010; 12:448-54. [PubMed: 20145885]

Wells, GA.; Shea, B.; O’Connell, D.; Peterson, J.; Welch, V.; Losos, M.; Tugwell, P. The NewcastleOttawa Scale (NOS) for assessing the quality of nonrandomized studies in meta-analyses. 2003. Available at: www.ohri.ca/programs/clinical_epidemiology/oxford.htm [Accessed 19 March 2013]

Westberg HB, Seldén AI, Bellander T. Exposure to chemical agents in Swedish aluminum foundries and aluminum remelting plants - a comprehensive survey. Appl Occup Environ Hyg. 2001; 16:66-77. [PubMed: 11202030]

WHO (World Health Organization). Guidelines for Drinking Water Quality. Vol 1, Recommendations. Lyon: World Health Organization; 1984. p. 80

WHO (World Health Organization). Recommendations. 3rd. Vol. 1. Geneva: World Health Organization; 2004. Guidelines for Drinking Water Quality.

WHO (World Health Organization). Aluminium in Drinking Water. Background Document for Development of WHO Guidelines for Drinking-Water Quality. WH,O/HSE/WSH/10.01/13. Geneva: World Health Organization; 2010. p. 1-15.

Wharton SB, Brayne C, Savva GM, Matthews FE, Forster G, Simpson J, et al. Epidemiological neuropathy: the MRC cognition function and aging study experience. J Alzheimers Dis. 2011; 25:359-72. [PubMed: 21422529]

Whitehead AS, Gallagher P, Mills JL, Kirke PN, Burke H, Molloy AM, et al. A genetic defect in 5,10methylenetetrahydrofolate reductase in neural tube defects. Q J Med. 1995; 88:763-6.

Wier HA, Kuhn RJ. Aluminum toxicity in neonatal parenteral nutrition: what can we do? Ann Pharmacother. 2012; 46:137-40. [PubMed: 22215685]

Wijnans L, de Bie S, Dieleman J, Bonhoeffer J, Sturkenboom M. Safety of pandemic H1N1 vaccines in children and adolescents. Vaccine. 2011; 29:7559-71. [PubMed: 21821086]

Wiles M, Huebner H, Afriyie-Gyawu E, Taylor R, Bratton G, Phillips T. Toxicological evaluation and metal bioavailability in pregnant rats following exposure to clay minerals in the diet. J Toxicol Environ Health A. 2004; 67:863-74. [PubMed: 15205041]

Wilhelm M, Ghosh JK, Su J, Cockburn M, Jerret M, Ritz B. Traffic-related air toxics and term low birth weight in Los Angeles County, California. Environ Health Perspect. 2012; 120:132-8. [PubMed: 21835727]

Willhite CC, Ball GL, McLellan CJ. Total allowable concentrations of monomeric inorganic aluminum and hydrated aluminum silicates in drinking water. Crit Rev Toxicol. 2012; 42:358-442. [PubMed: 22512666]

Wilson JW. Nutritional deficiency produced in the mouse by feeding bentonite. J Natl Cancer Inst. 1953; 14:57-63. [PubMed: 13097137]

Wilson JW. Hepatomas produced in mice by feeding bentonite in the diet. Ann N Y Acad Sci. 1954; 57:678-86. [PubMed: 13181297] 
Wisniewski, HM. The role of aluminium in Alzheimer's disease. In: Priest, ND.; O'Donnell, TV., editors. Managing Health in the Aluminium Industry. London: Middlesex University Press; 1997. p. 263-73.Available at: http://www.world-aluminium.org/cache/f0000116.pdf [Accessed 10 June 2013]

Wisniewski HM, Wen GY. Review aluminum and Alzheimer's disease. Ciba Found Symp. 1992; 169:142-54. [PubMed: 1490420]

Wong WW, Chung SW, Kwong KP, Yin HY, Xiao Y. Dietary exposure to aluminium of the Hong Kong population. Food Addit Contam A. 2010; 27:457-63.

Wood SJ, Maleff B, Hart T, Wetzel R. Physical, morphological and functional differences between $\mathrm{pH}$ 5.8 and 7.4 aggregates of the Alzheimer's amyloid peptide Abeta. J Mol Biol. 1996; 256:870-7. [PubMed: 8601838]

Wu Z, Du Y, Xue H, Wu Y, Zhou B. Aluminum induces neurodegeneration and its toxicity arises from increased iron accumulation and reactive oxygen species (ROS) production. Neurobiol Aging. 2012a; 33:199.e1-12. [PubMed: 20674094]

Wu X, Li J, Hu JN, Deng ZY. The effects of glutamate and citrate on absorption and distribution of aluminum in rats. Biol Trace ElemRes. 2012b; 148:83-90.

Wu MJ, Murphy PA, O’Doherty PJ, Mieruszynski S, Jones M, Kersaitis C, et al. Delineation of the molecular mechanism for disulfide stress-induced aluminium toxicity. Biometals. 2012c; 25:55361. [PubMed: 22403011]

Wu L, Rosa-Neto P, Hsiung GY, Sadovnick AD, Masellis M, Black SE, et al. Early-onset familiar Alzheimer's disease (EOFAD). Can J Neurol Sci. 2012d; 39:436-45. [PubMed: 22728850]

Xiao F, Li XG, Zhang XY, Hou JD, Lin LF, Gao Q, Luo HM. Combined administration of D-galactose and aluminium induces Alzheimer-like lesions in brain. Neurosci Bull. 2011; 27:143-55. [PubMed: 21614097]

Xie CX, Yokel RA. Aluminum facilitation of iron-mediated lipid peroxidation is dependent on substrate, $\mathrm{pH}$ and aluminum and iron concentrations. Arch Biochem Biophys. 1996; 327:222-6. [PubMed: 8619606]

Yanagishita T, Tamada Y, Ohshima Y, Ito K, Akita Y, Watanabe D. Histological localization of aluminum in topical aluminum chloride treatment for palmar hyperhidrosis. J Dermatol Sci. 2012; 67:69-71. [PubMed: 22429702]

Yang X, Bi S, Yang L, Zhu Y, Wang X. Multi-NMR and fluorescencespectra study the effects of aluminium (III) on coenzyme NADH in aqueous solutions. Spectrochim Acta A Mol Biomol Spectrosc. 2003; 59:2561-9. [PubMed: 12963452]

Yang X, Cai L, Peng Y, Li H, Chen RF, Shen RF. Effects of Al(III) and nano-Al(13) species on malate dehydrogenase activity. Sensors (Basel). 2011; 11:5740-53. [PubMed: 22163924]

Yang X, Zhang Q, Li L, Shen R. Structural features of aluminium (III) complexes with bioligands in glutamate dehydrogenase reaction system - a review. J Inorg Biochem. 2007; 101:1242-50. [PubMed: 17643493]

Yates CM, Butterworth J, Tennant MC, Gordon A. Enzyme activities in relation to $\mathrm{pH}$ and lactate in postmortem brain in Alzheimer-type and other dementias. J Neurochem. 1990; 55:1624-30. [PubMed: 2213015]

Yin da P, Zhu BP, Wang HQ, Cao L, Wu WD, Jiang KY, et al. Effect of aluminum hydroxide adjuvant on the immunogenicity of the 2009 pandemic influenza A/H1N1 vaccine: multi-level modeling of data with repeated measures. Biomed Environ Sci. 2011; 24:624-9. [PubMed: 22365398]

Yiu G. Rapid communications: Antiperspirant induced DNA damage in canine cells by Comet assay. Toxicol Mech Methods. 2004; 15:25-8. [PubMed: 20021076]

Yokel RA. Aluminum produces age related behavioral toxicity in the rabbit. Neurotoxicol Teratol. 1989; 11:237-42. [PubMed: 2755420]

Yokel RA. The toxicology of aluminum in the brain: a review. Neurotoxicology. 2000; 21:813-28. [PubMed: 11130287]

Yokel RA. Brain uptake, retention and efflux of aluminum and manganese. Environ Health Perspect. 2002; 110:699-704. [PubMed: 12426115] 
Yokel, RA. El-Samragy, Y., editor. Aluminum in food - the nature and contribution of food additives. Food Additives. 2012. In Tech 203-228. Available at: http://www.intechopen.com/articles/show/ title/aluminum-in-food-the-nature-and-contributionof-food-additives [Accessed 26 August 2013]

Yokel, RA. Aluminum. In: Cabello, A., editor. Encyclopedia of Human Nutrition. 3rd. Vol. 1. Waltham, MA: Academic Press; 2013. p. 57-63.

Yokel RA, Florence RL. Aluminium bioavailability from the approved food additive leavening agent acidic sodium aluminum phosphate, incorporated into a baked good, is lower than from water. Toxicology. 2006; 227:86-93. [PubMed: 16949191]

Yokel RA, Florence RL. Aluminum bioavailability from tea infusion. Food Chem Toxicol. 2008; 46:3659-63. [PubMed: 18848597]

Yokel RA, Hicks CL, Florence RL. Aluminum bioavailability from basic sodium aluminum phosphate, an approved food additive emulsifying agent incorporated into cheese. Food Chem Toxicol. 2008; 46:2261-6. [PubMed: 18436363]

Yokel RA, MacPhail RC. Engineered nanomaterials: exposures, hazards and risk prevention. J Occup Med Toxicol. 2011; 6:7. Available at: http://www.occup-med.com/content/6/1/7 [Accessed 10 June 2013]. [PubMed: 21418643]

Yokel RA, McNamara PJ. Aluminum bioavailability and disposition in adult and immature rabbits. Toxicol Appl Pharmacol. 1985; 77:344-52. [PubMed: 3975904]

Yokel RA, McNamara PJ. Aluminum toxicokinetics: an updated minireview. Pharmacol Toxicol. 2001; 88:159-67. [PubMed: 11322172]

Yokel RA, Rhineheimer SS, Brauer RD, Sharma P, Elmore D, McNamara PJ. Aluminum bioavailability from drinking water is very low and is not appreciably influenced by stomach contents or water hardness. Toxicology. 2001; 161:93-101. [PubMed: 11295258]

Yoon PW, Jang WY, Yoo JJ, Yoon KS, Kim HJ. Malignant fibrous histiocytoma at the site of an alumina-on-alumina-bearing total hip arthroplasty mimicking infected trochanteric bursitis. $\mathbf{J}$ Arthroplasty. 2011; 27:324e9-12. [PubMed: 21435828]

Yoshida S, Gershwin ME, Keen CL, Donald JM, Golub MS. The influence of aluminum on resistance to Listeria monocytogenes in Swiss-Webster mice. Int Arch Allergy Appl Immunol. 1989; 89:404-9. [PubMed: 2793227]

Yousef MI. Aluminum-induced changes in hemato-biochemical parameters, lipid peroxidation and enzymes of male rabbits: protective role of ascorbic acid. Toxicology. 2004; 199:47-57. [PubMed: 15125998]

Yu Z, Han S, Zhu J, Sun X, Ji C, Guo X. Prepregnancy body mass index in relation to infant birth weight and offspring overweight/obesity: a systematic review and meta-analysis. PloS One. 2013; 8:e61627. [PubMed: 23613888]

Yu HY, Zhang KL. Links between environmental geochemistry and rate of birth defects: Shanxi Province, China. Sci Total Environ. 2011; 409:447-51. [PubMed: 21106228]

Yu SL, Shi WX, Lu Y, Yang JX. Characterization and anti-fouling performance of nano- $\mathrm{Al}_{2} \mathrm{O}_{3} / \mathrm{PVDF}$ membrane for Songhua river raw water filtration. Water Sci Technol. 2011; 64:1892-7. [PubMed: 22020484]

Yuan C-Y, Lee Y-J, Wang Hsu G-S. Aluminum overload increases oxidative stress in four functional brain areas of neonatal rats. J Biomed Sci. 2012; 19:51. [PubMed: 22613782]

Yue CS, Christie M, Lavergne V, Sikaneta T, Taskapan H, Mardini K, et al. Aluminum toxicokinetics in peritoneal dialysis patients. Clin Toxicol (Phila). 2011; 49:659-63. [PubMed: 21819285]

Yumoto S, Kakimi S, Ohsaki A, Ishikawa A. Demonstration of aluminum in amyloid fibers in the cores of senile plaques in the brains of patients with Alzheimer's disease. J Inorg Biochem. 2009; 103:1579-84. [PubMed: 19744735]

Yumoto S, Nagai H, Kobayashi K, Tamate A, Kakimi S, Matsuzaki H. 26Al incorporation into the brain of suckling rats through maternal milk. J Inorg Biochem. 2003; 97:155-60. [PubMed: 14507472]

Yumoto S, Nagai H, Matsuzaki H, Matsumara H, Tada W, Nagatsuma E, Kobayashi K. Aluminum incorporation into the brain of rat fetuses and sucklings. Brain Res Bull. 2001; 15:229-34. [PubMed: 11470320] 
Zagorski MG, Barrow CJ. NMR studies of amyloid beta peptides: proton assignments, secondary structure and mechanism of an alpha-helix-beta-sheet conversion for a homologous 28 residue Nterminal fragment. Biochemistry. 1992; 31:5621-31. [PubMed: 1610809]

Zatta P, Kiss T, Suwalsky M, Berthon G. Aluminium (III) as a promoter of cellular oxidation. Coord Chem Rev. 2002; 228:271-84.

Zeager M, Woolf AD, Goldman RH. Wide variation in reference values for aluminum levels in children. Pediatrics. 2012; 129:e142-7. [PubMed: 22144700]

Zeng KW, Fu H, Liu GX, Wang XM. Aluminum maltolate induces primary rat astrocyte apoptosis via overactivation of the class III PI3K/Beclin 1-dependent autophagy signal. Toxicol In Vitro. 2011; 26:215-20. [PubMed: 22138567]

Zhang L, Li X, Gu Q, Zhu Y, Zhao H, Li Y, Zhang Z. Effects of subchronic aluminum exposure on serum concentrations of iron and iron- associated proteins in rats. Biol Trace Elem Res. 2011a; 141:246-53. [PubMed: 20563666]

Zhang QL, Jia L, Jiao X, Guo WL, Ji JW, Yang HL, Niu Q. APP/PS1 transgenic mice treated with aluminum: an update of Alzheimer's disease model. Int J Immunopathol Pharmacol. 2012; 25:49-58. [PubMed: 22507317]

Zhang QL, Li MQ, Ji JW, Gao FP, Bai R, Chen CY, et al. In vivo toxicity of nano-alumina on mice neurobehavioral profiles and the potential mechanisms. Int J Immunopathol Pharmacol. 2011b; 24:S23-9.

Zhang QL, Niu Q, Niu PY, Ji XL, Zhang C, Wang L. Novel interventions targeting on apoptosis and necrosis induced by aluminum chloride in neuroblastoma cells. J Biol Regul Homeost Agents. 2010a; 24:137-48. [PubMed: 20487627]

Zhang QL, Niu Q, Niu PY, Shi YT, Liu CY, Di GM, et al. Bax gene silencing: a potential intervention in aluminum-induced neural cell death. J Biol Regul Homeost Agents. 2010b; 24:7-17. [PubMed: 20385067]

Zhang XQ, Yin LH, Tang M, Pu YP. ZnO, TiO2, $\mathrm{SiO}_{2}$, and $\mathrm{Al}_{2} \mathrm{O}_{3}$ nanoparticles- induced toxic effects on human fetal lung fibroblasts. Biomed Environ Sci. 2011c; 24:661-9. [PubMed: 22365403]

Zhao J, Castranova V. Toxicology of nanomaterials used in nanomedicine. J Toxicol Environ Health B. 2011; 14:593-632.

Zhu Y, Han Y, Zhao H, Li J, Hu C, Li Y, Zhang Z. Suppressive effect of accumulated aluminum trichloride on the hepatic microsomal cytochrome P450 enzyme system in rats. Food Chem Toxicol. 2013; 51:210-14. [PubMed: 23059508]

Zhu Y, Hu C, Li X, Shao B, Sun H, Zhao H, Li Y. Suppressive effects of aluminum trichloride on the T lymphocyte immune function of rats. Food Chem Toxicol. 2012a; 50:532-5. [PubMed: 22198605]

Zhu Y, Li X, Chen C, Wang F, Li J, Hu C, et al. Effects of aluminum trichloride on the trace elements and cytokines in the spleen of rats. Food Chem Toxicol. 2012b; 50:2911-5. [PubMed: 22659008]

Zhu FC, Wang H, Fang HH, Yang JG, Lin XJ, Liang XF, et al. A novel influenza A (H1N1) vaccine in various age groups. N Engl J Med. 2009; 361:2414-23. [PubMed: 19846844]

Zhu Y, Xu J, Sun H, Hu C, Zhao H, Shao B, et al. Effects of aluminum exposure on the allergic responses and humoral immune function in rats. Biometals. 2011a; 24:973-7. [PubMed: 21431358]

Zhu Y, Zhao H, Li X, Zhang L, Hu C, Shao B, et al. Effects of subchronic aluminum exposure on the immune function of erythrocytes in rats. Biol Trace Elem Res. 2011b; 143:1576-80. [PubMed: 21279465]

Zuo R, Ornek D, Wood TK. Aluminum- and mild steel-binding peptides from phage display. Appl Microbiol Biotechnol. 2005; 68:505-9. [PubMed: 15703906] 


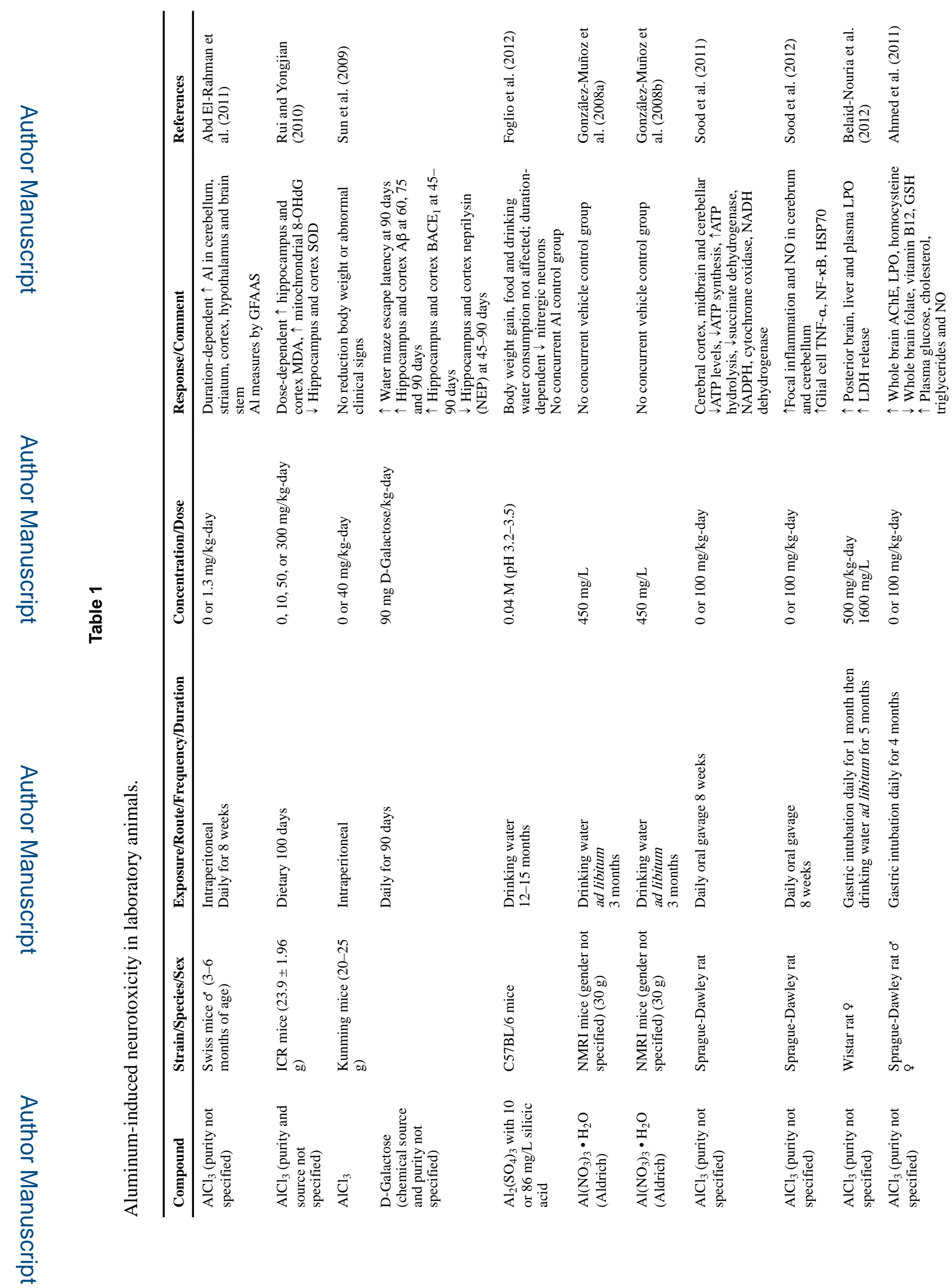

Crit Rev Toxicol. Author manuscript; available in PMC 2016 August 25. 
Willhite et al.

Page 124

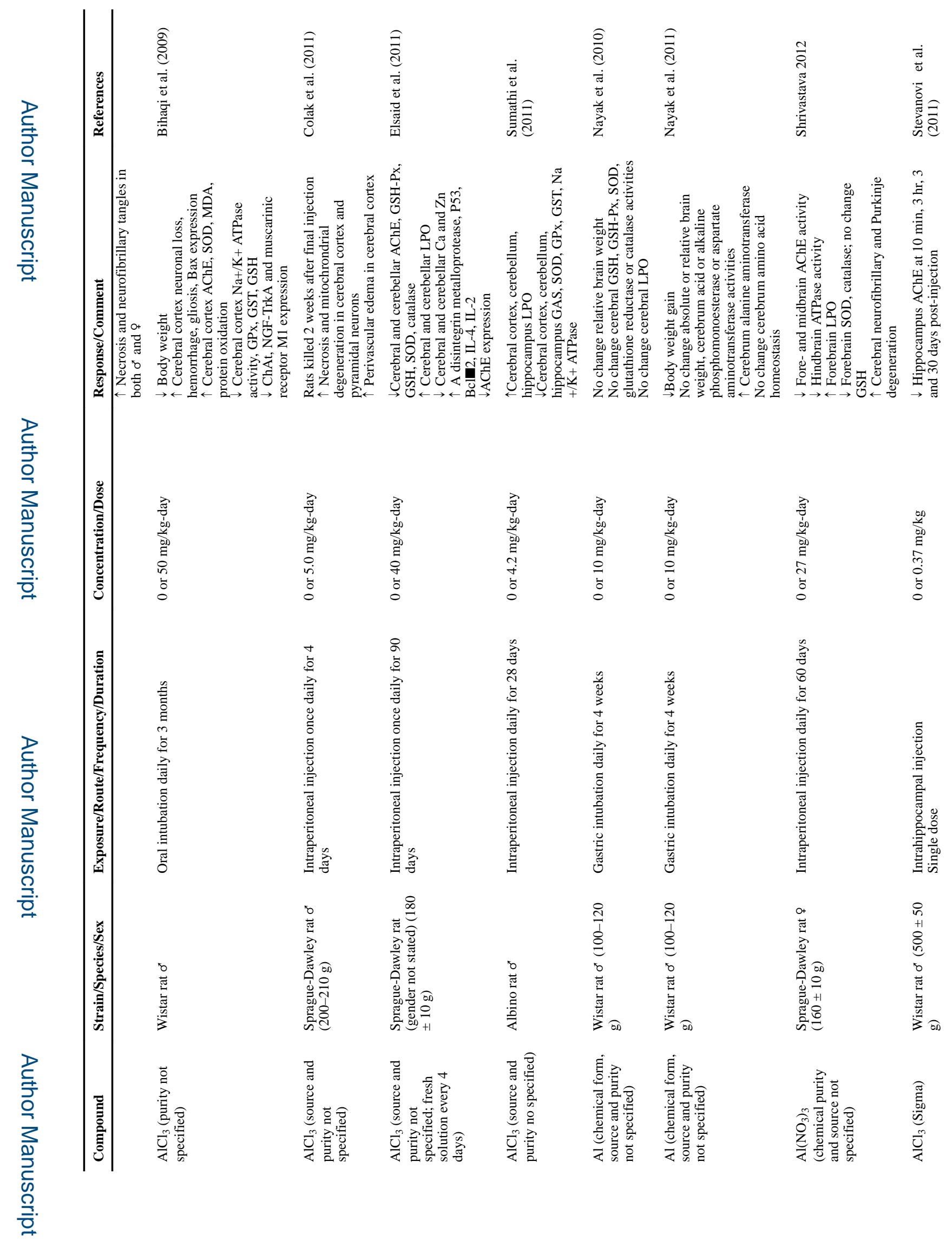

Crit Rev Toxicol. Author manuscript; available in PMC 2016 August 25. 
Willhite et al.

Page 125

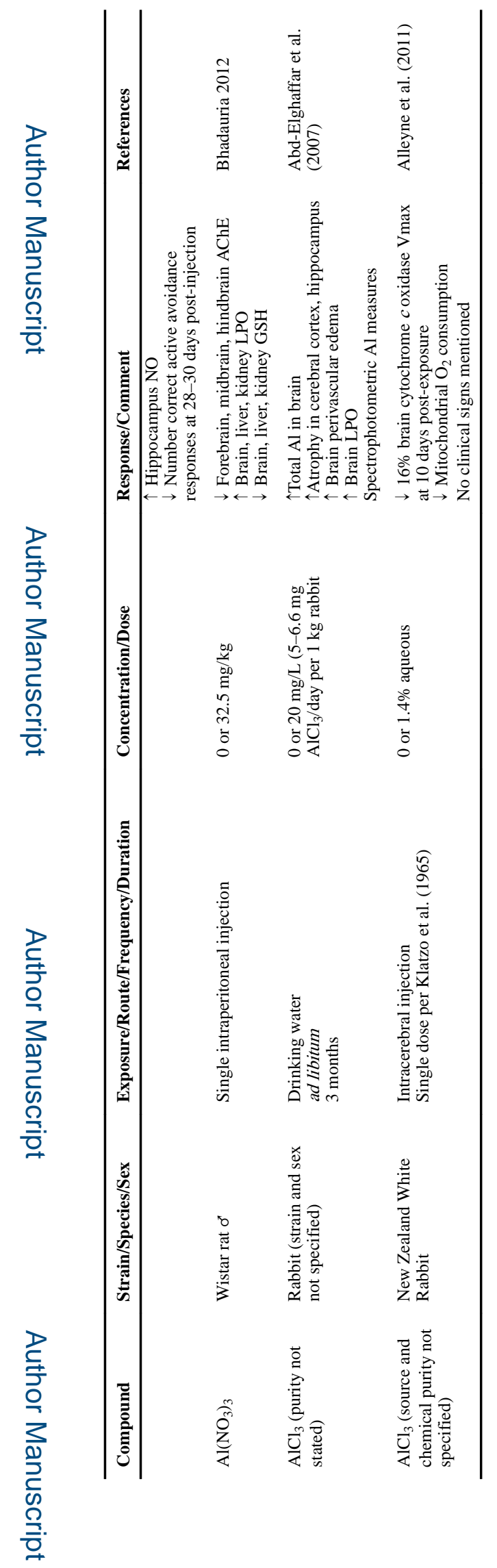

Crit Rev Toxicol. Author manuscript; available in PMC 2016 August 25. 


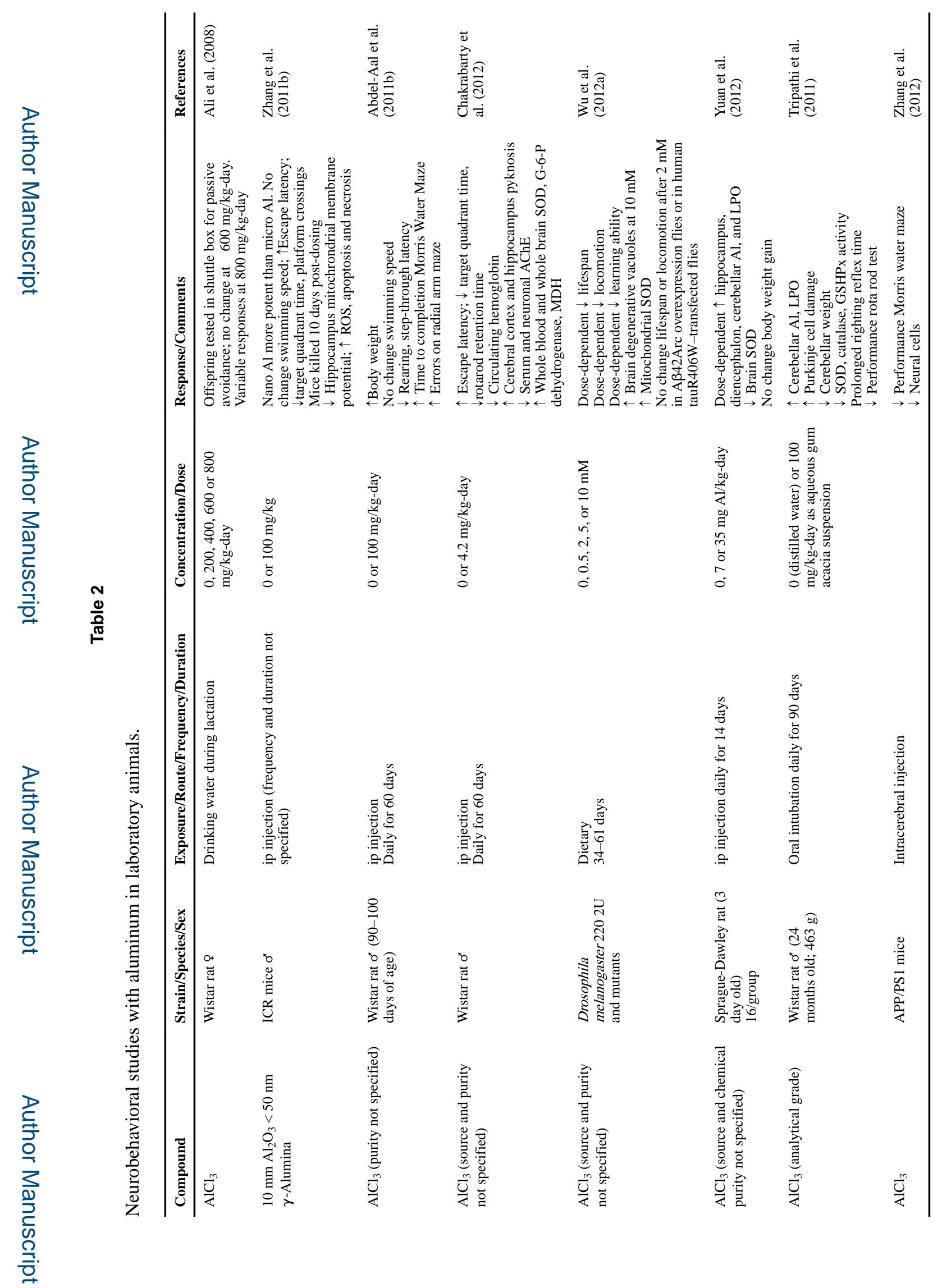

Crit Rev Toxicol. Author manuscript; available in PMC 2016 August 25. 


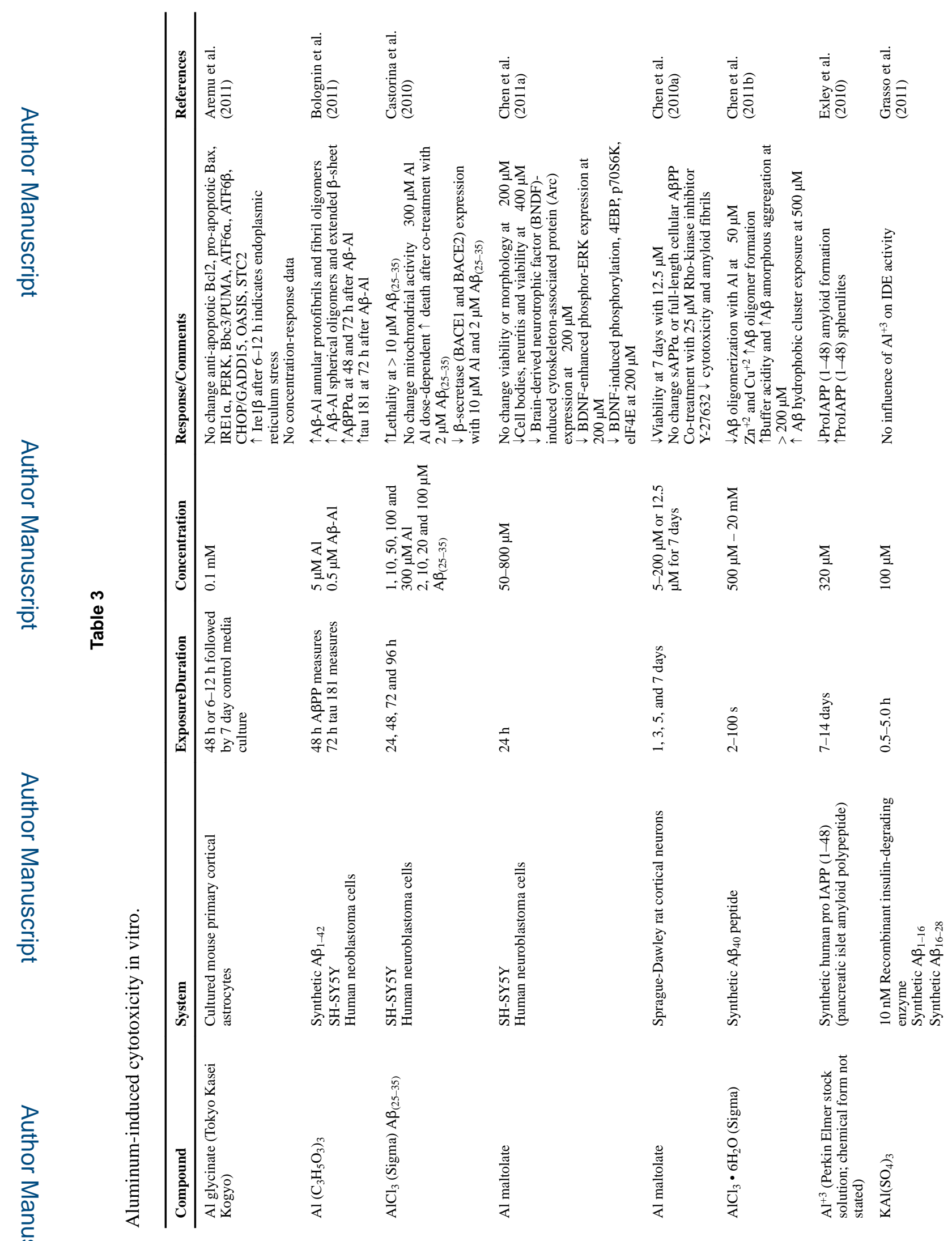

Crit Rev Toxicol. Author manuscript; available in PMC 2016 August 25. 
Willhite et al.

Page 128

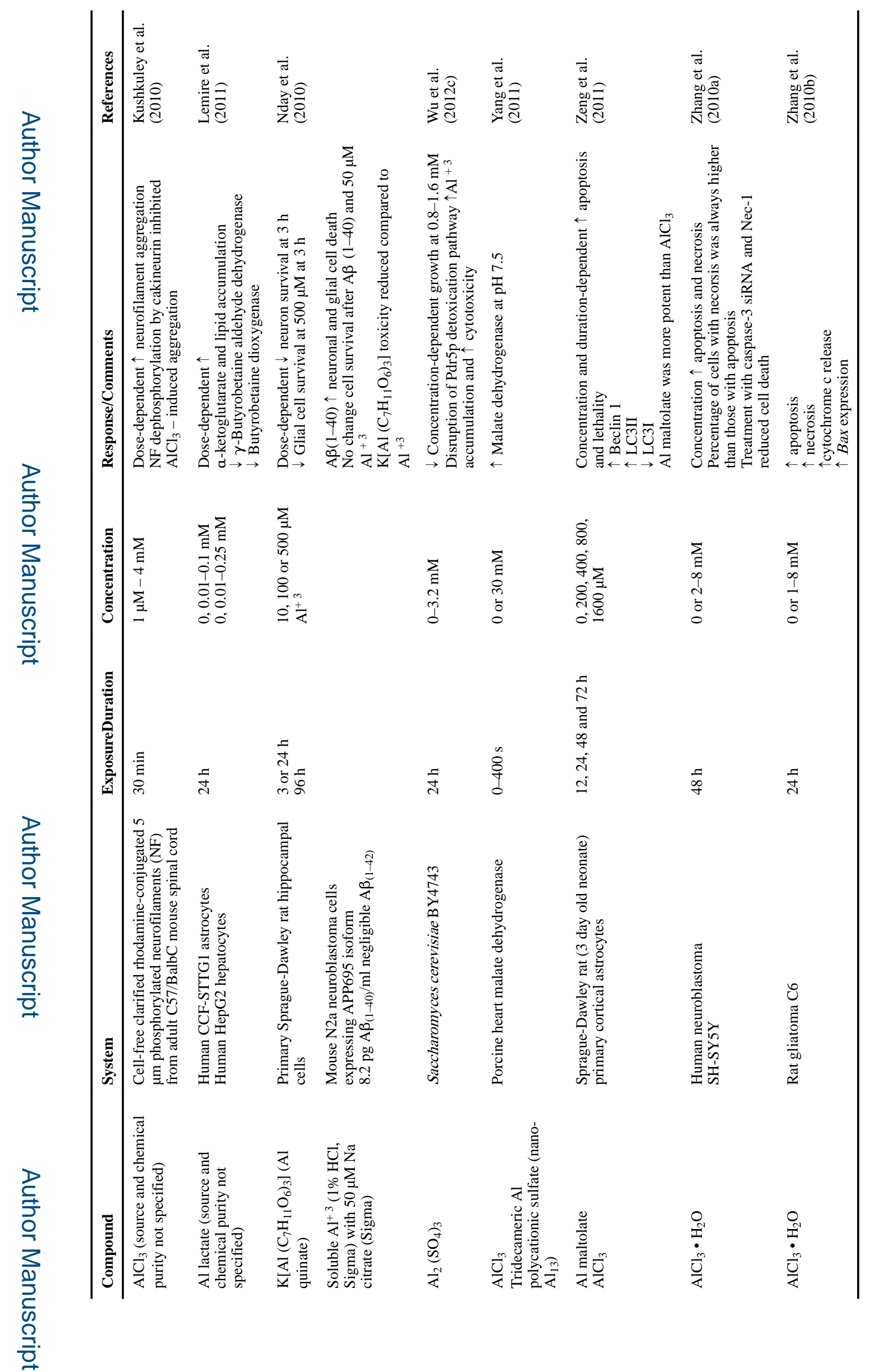

Crit Rev Toxicol. Author manuscript; available in PMC 2016 August 25. 


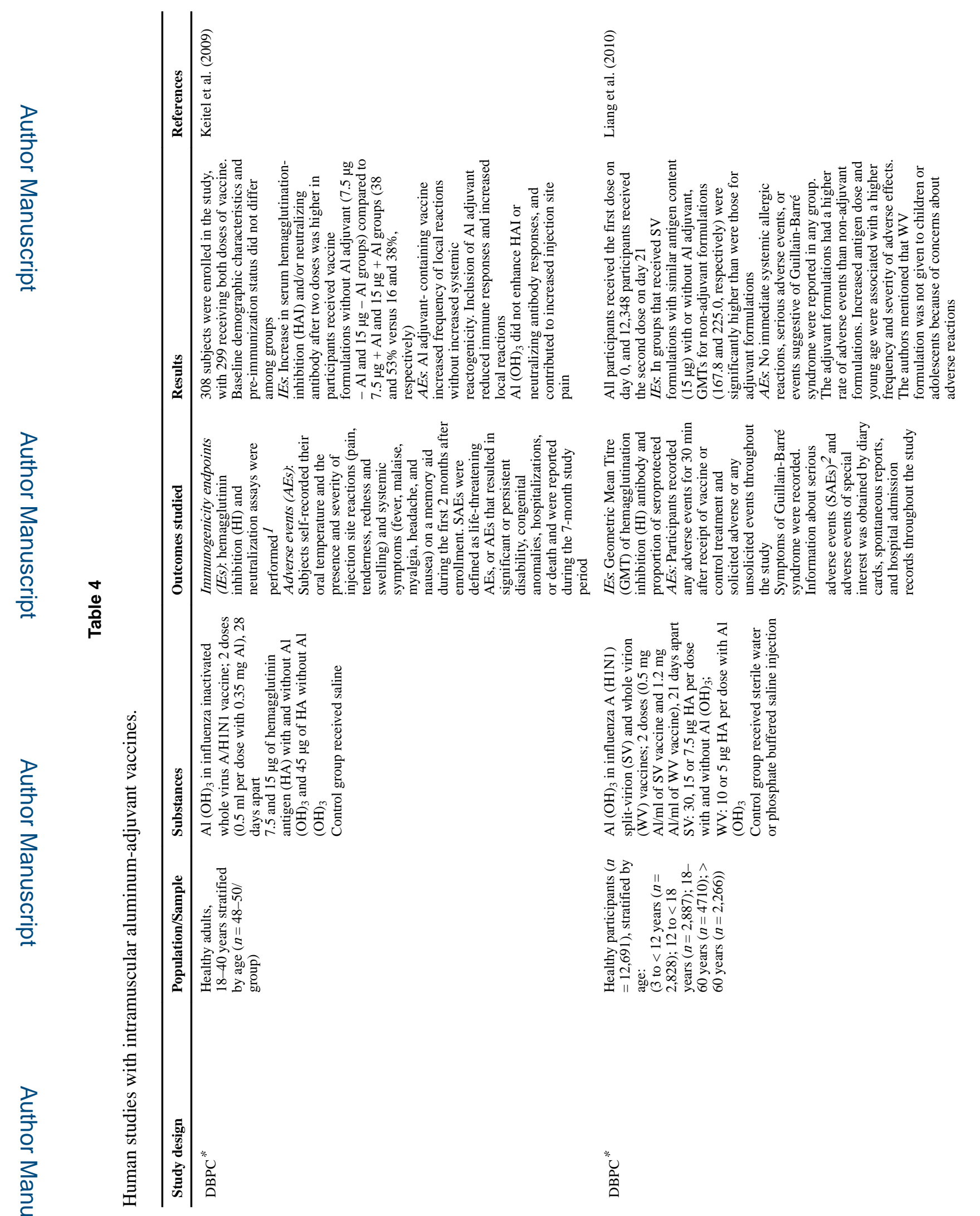

Crit Rev Toxicol. Author manuscript; available in PMC 2016 August 25. 
Willhite et al.

Page 130

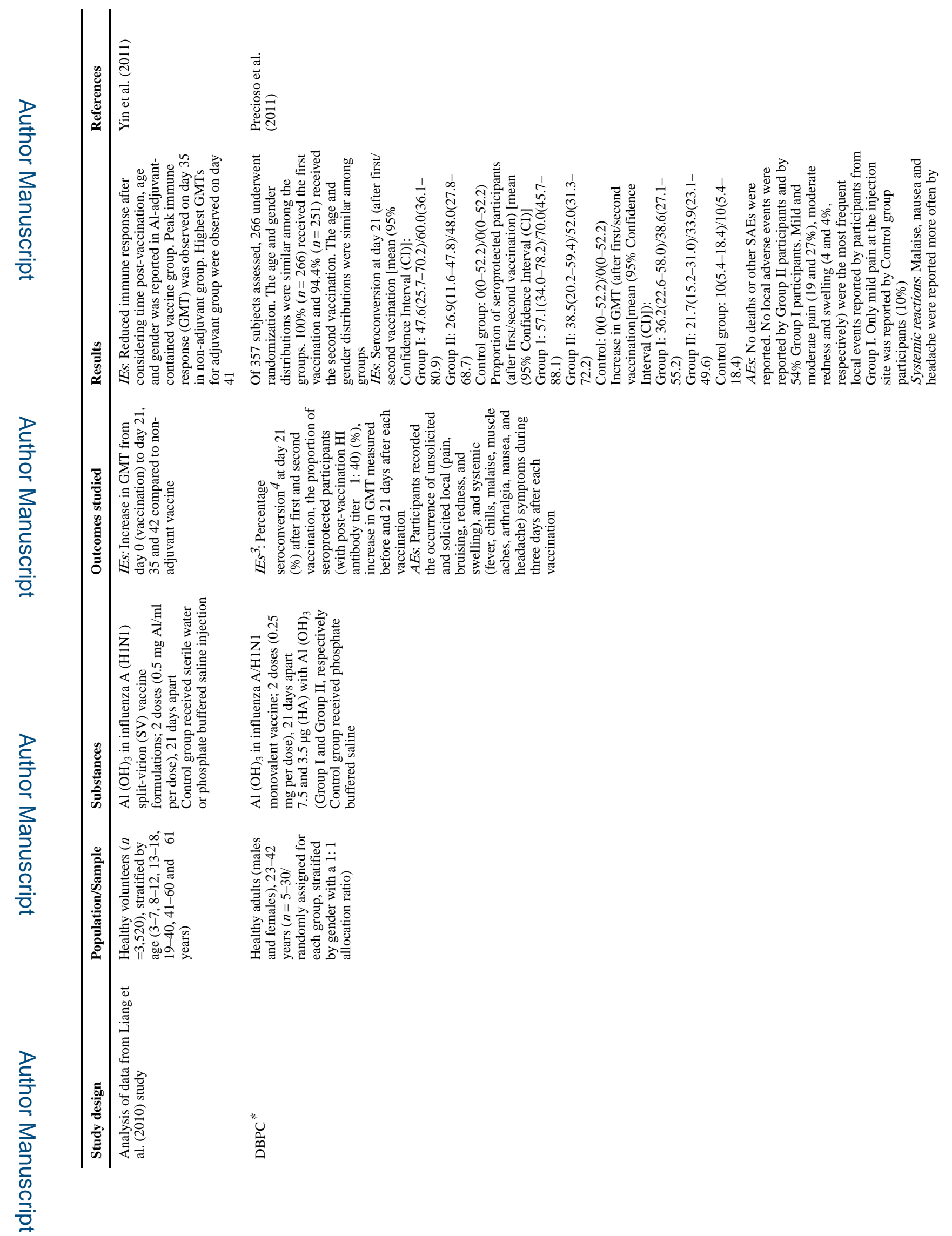

Crit Rev Toxicol. Author manuscript; available in PMC 2016 August 25. 
Willhite et al.

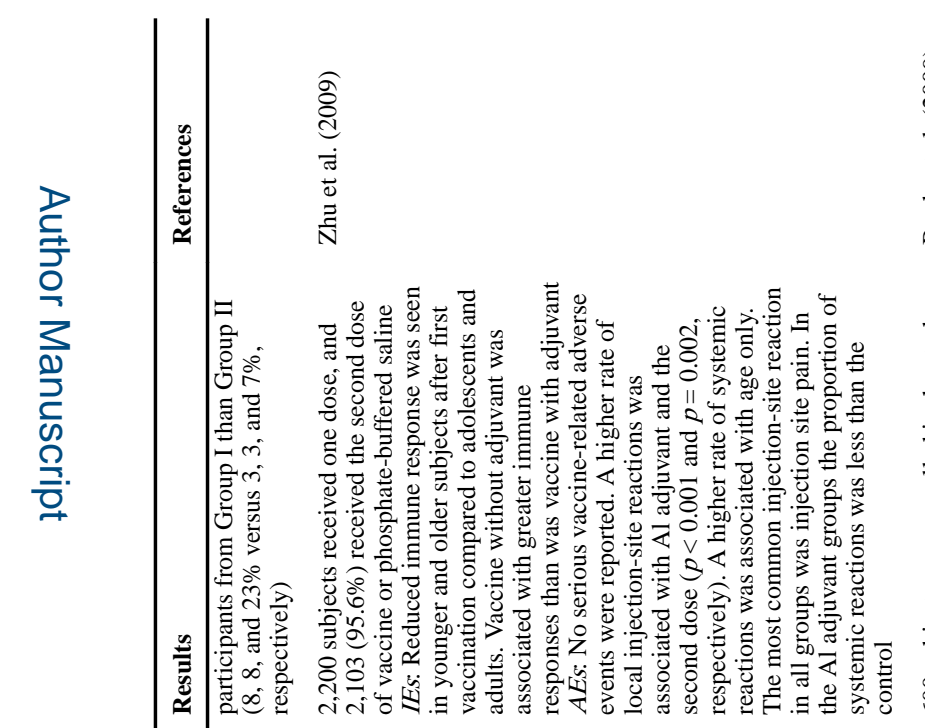

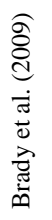
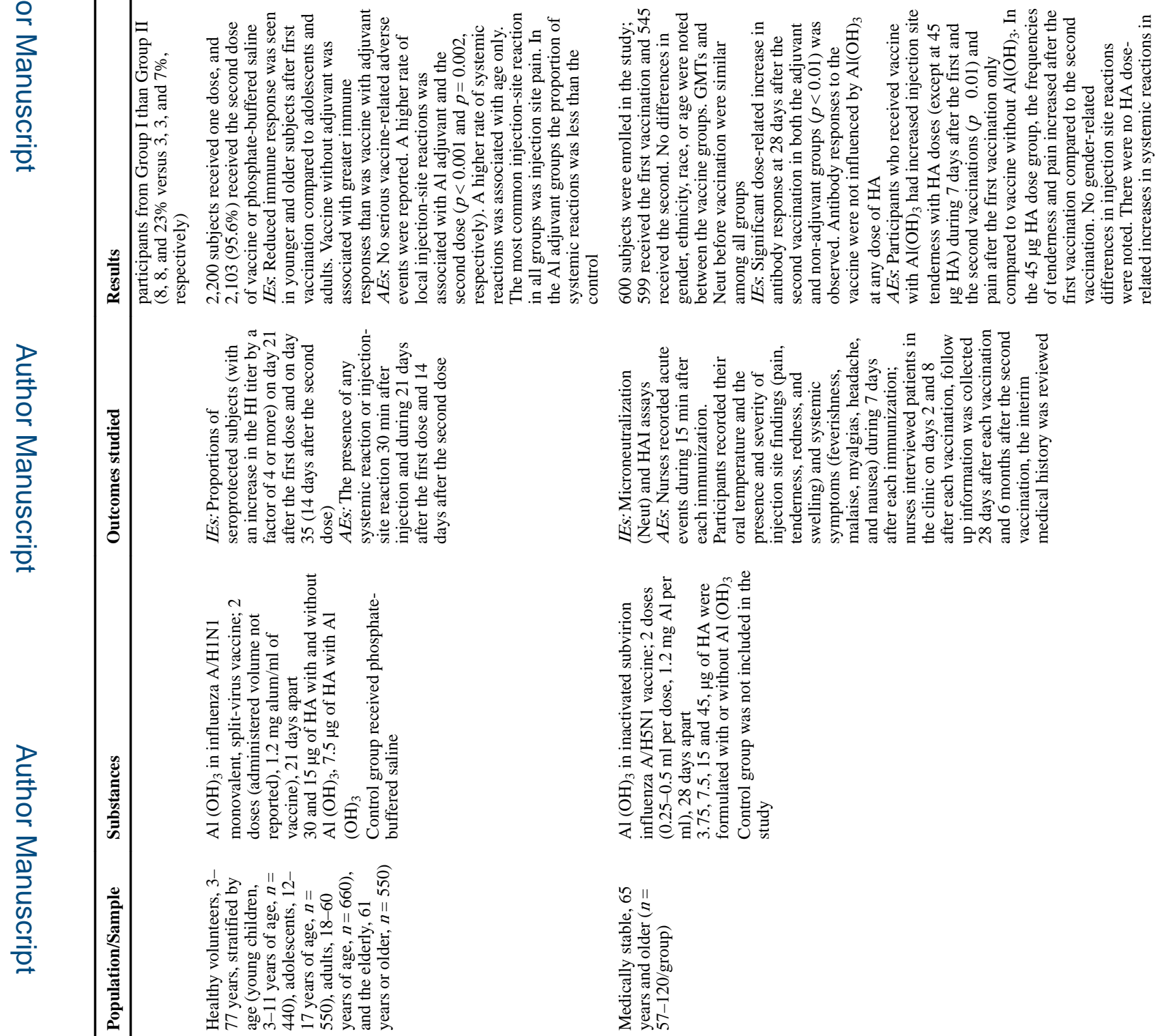

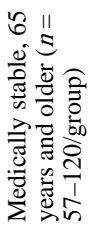

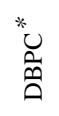

$\stackrel{*}{*}$ 
Willhite et al.

Page 132

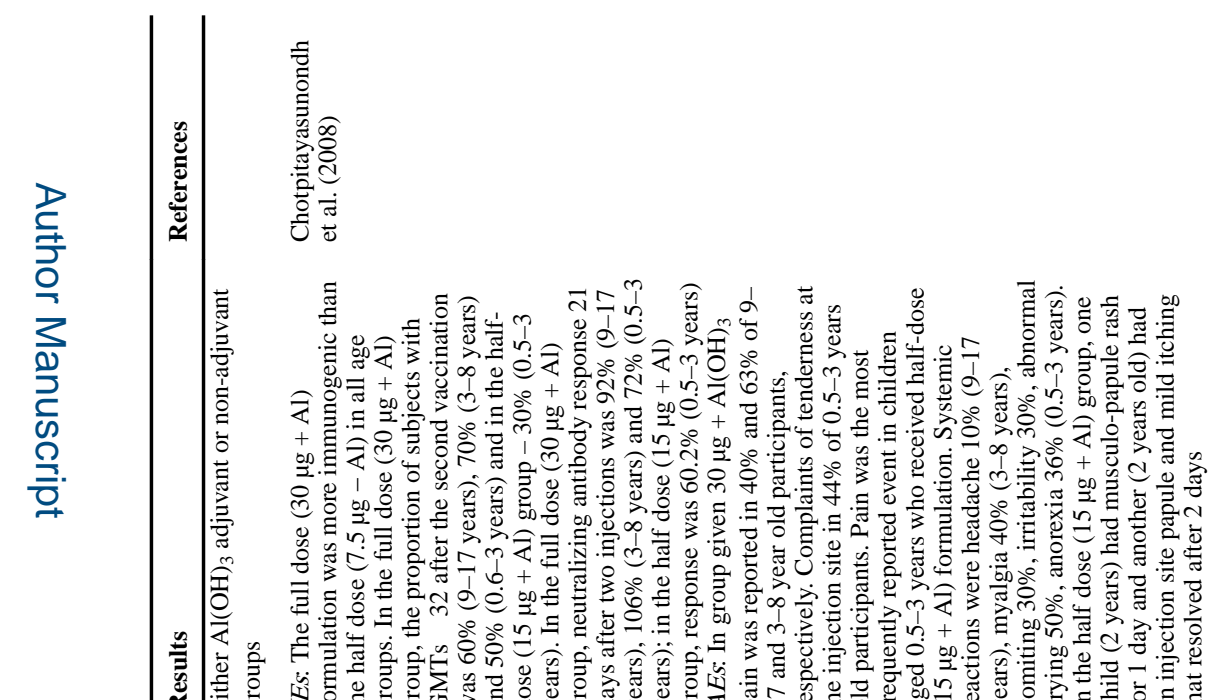

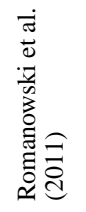
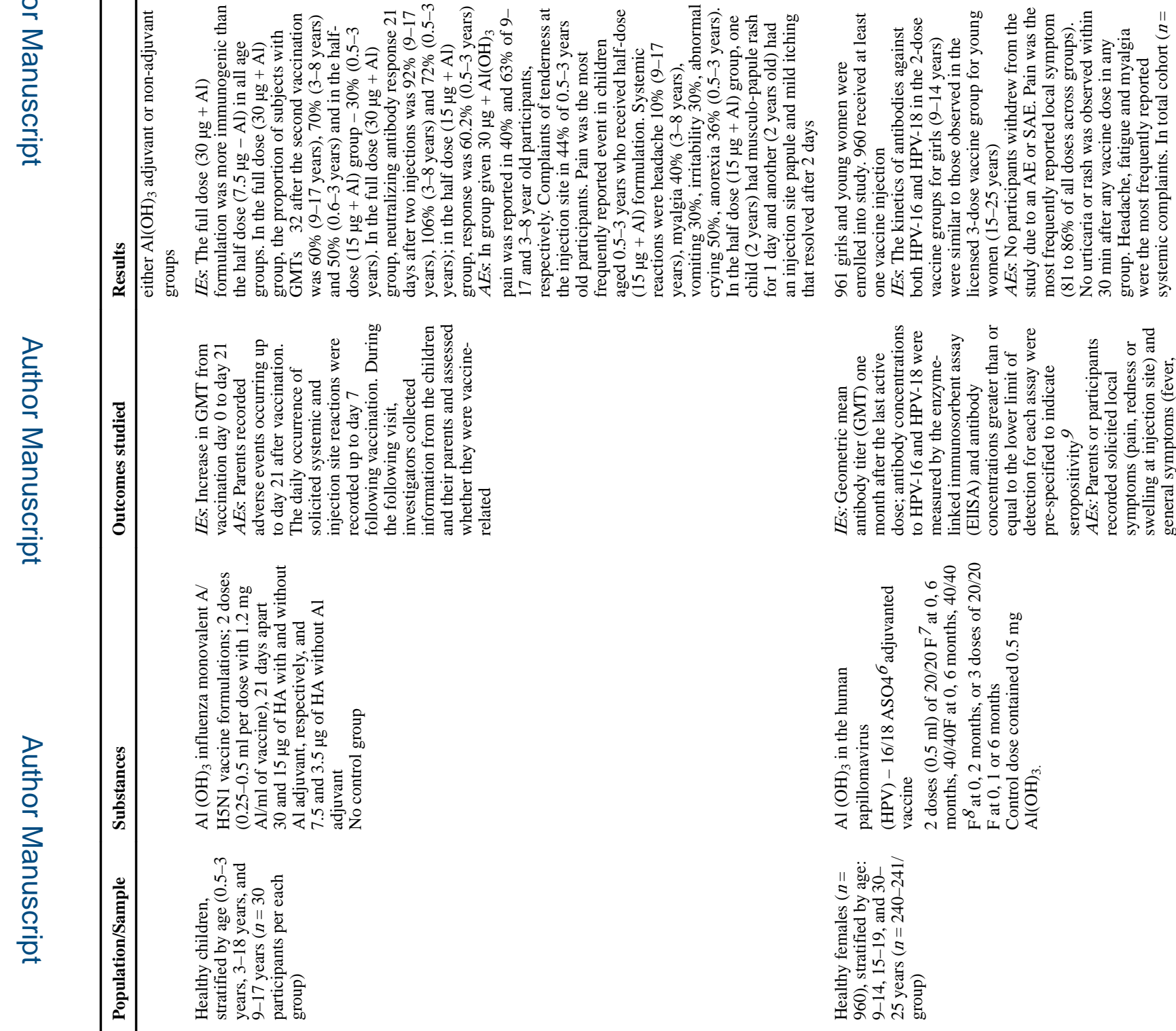

후
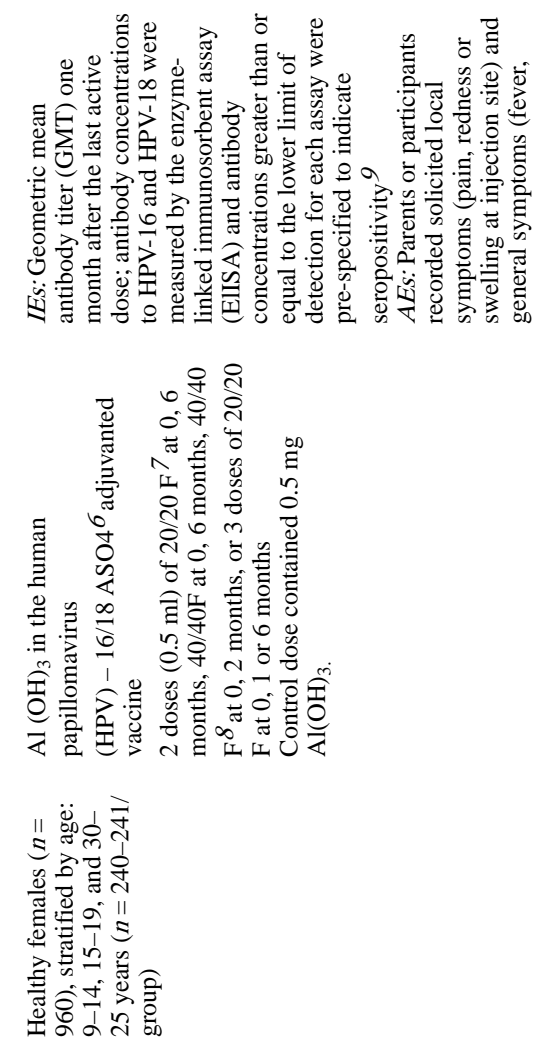

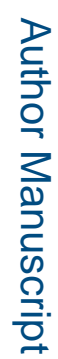

$\stackrel{*}{*}$

Crit Rev Toxicol. Author manuscript; available in PMC 2016 August 25. 
Willhite et al.

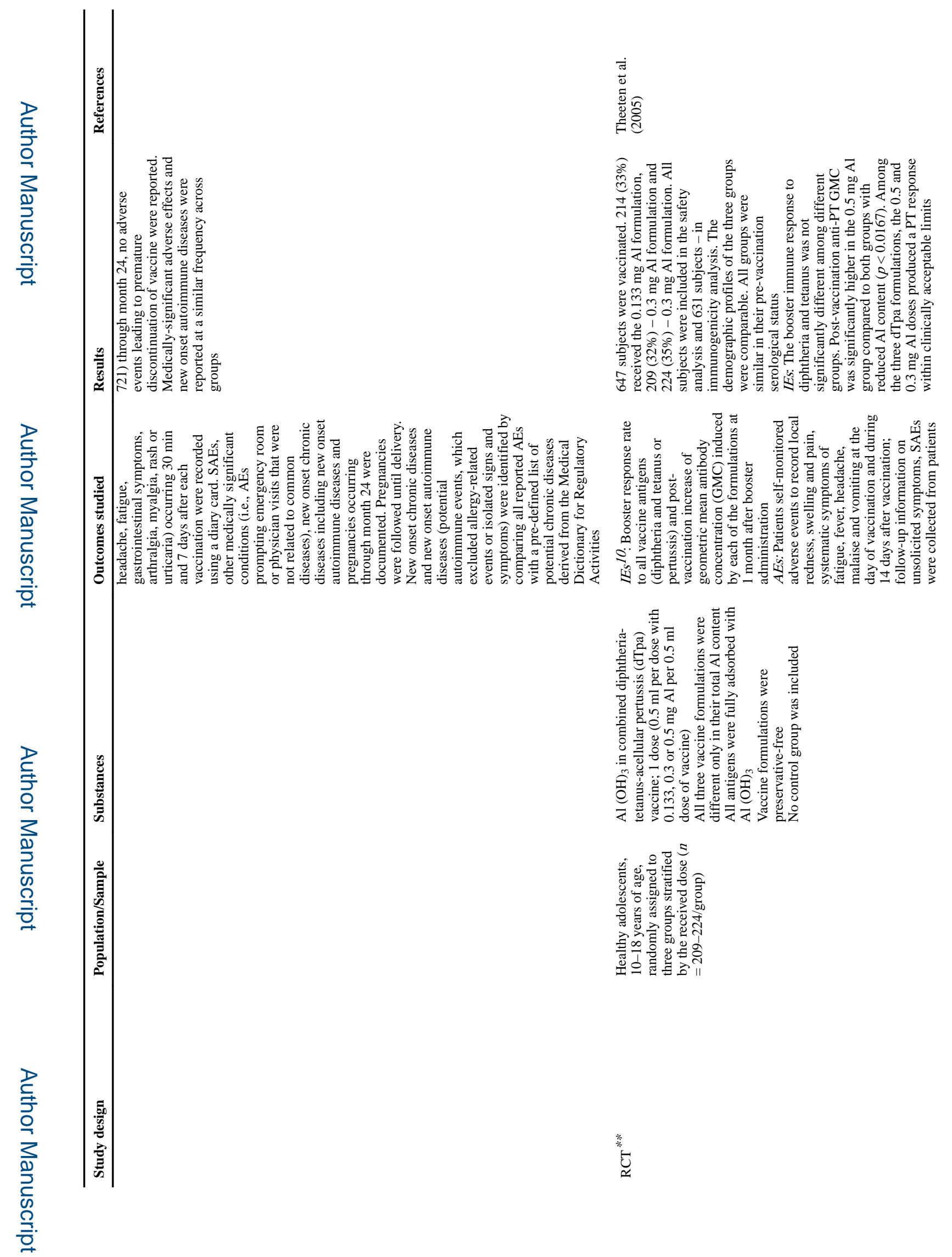

Crit Rev Toxicol. Author manuscript; available in PMC 2016 August 25. 


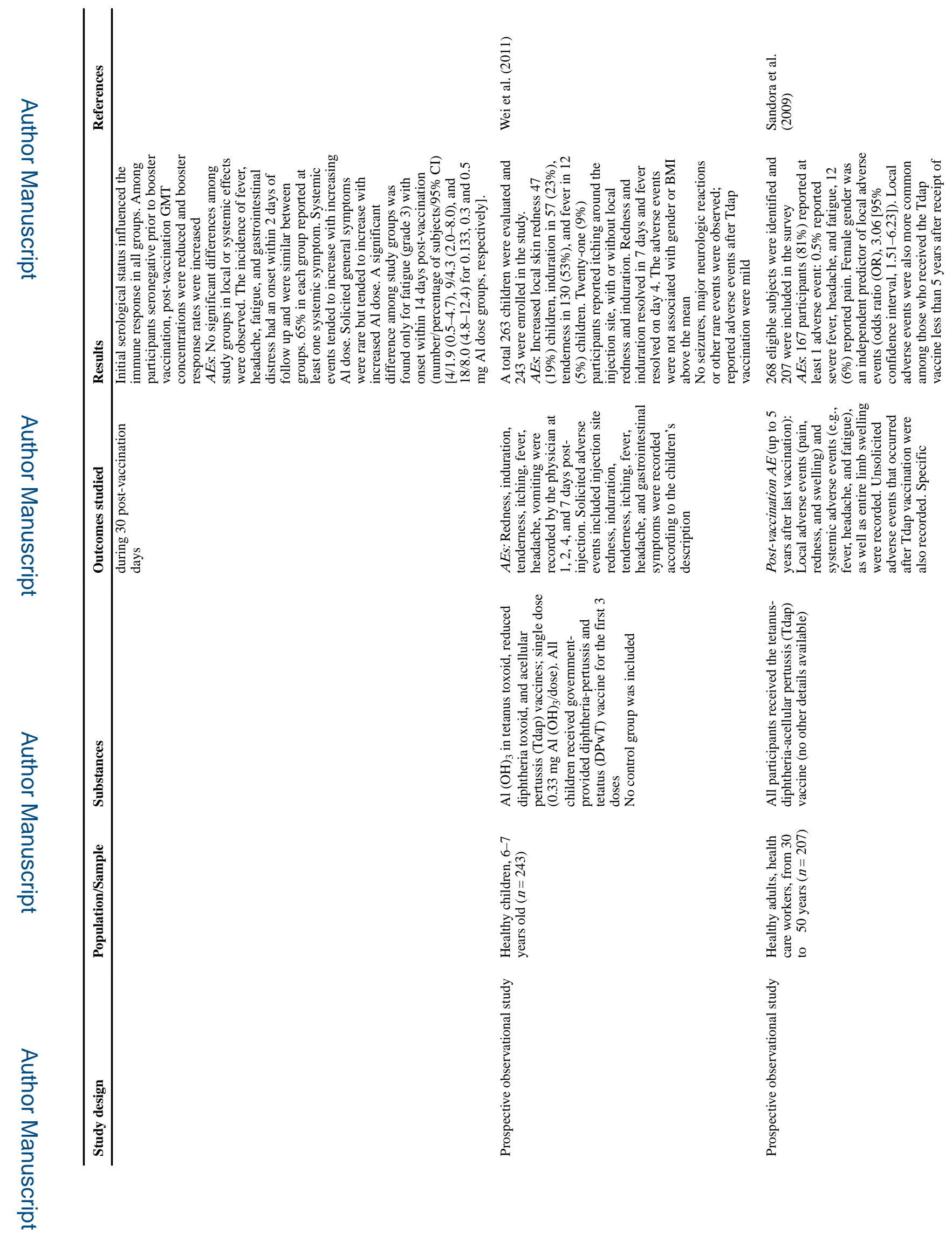

Crit Rev Toxicol. Author manuscript; available in PMC 2016 August 25. 


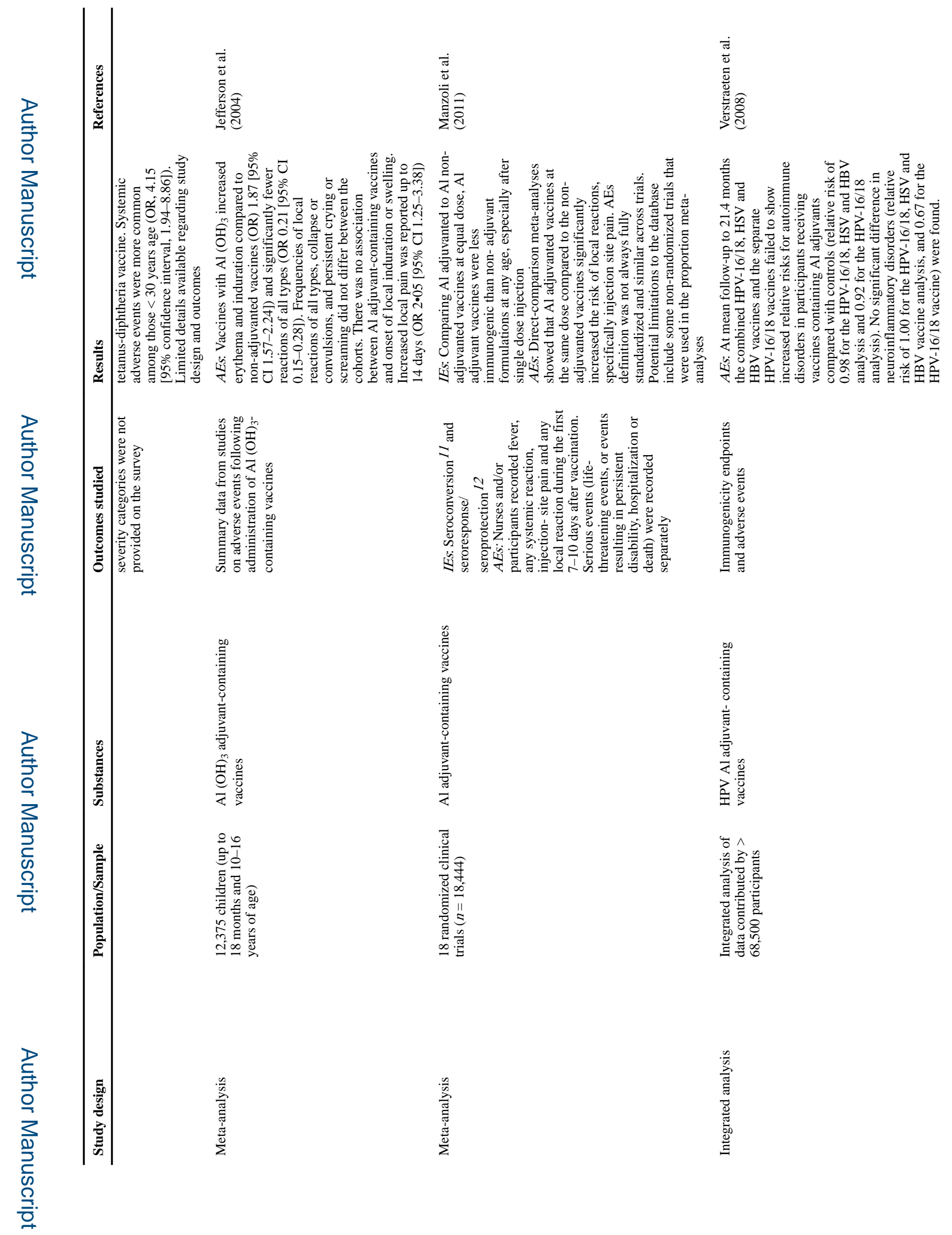

Crit Rev Toxicol. Author manuscript; available in PMC 2016 August 25. 
Willhite et al.

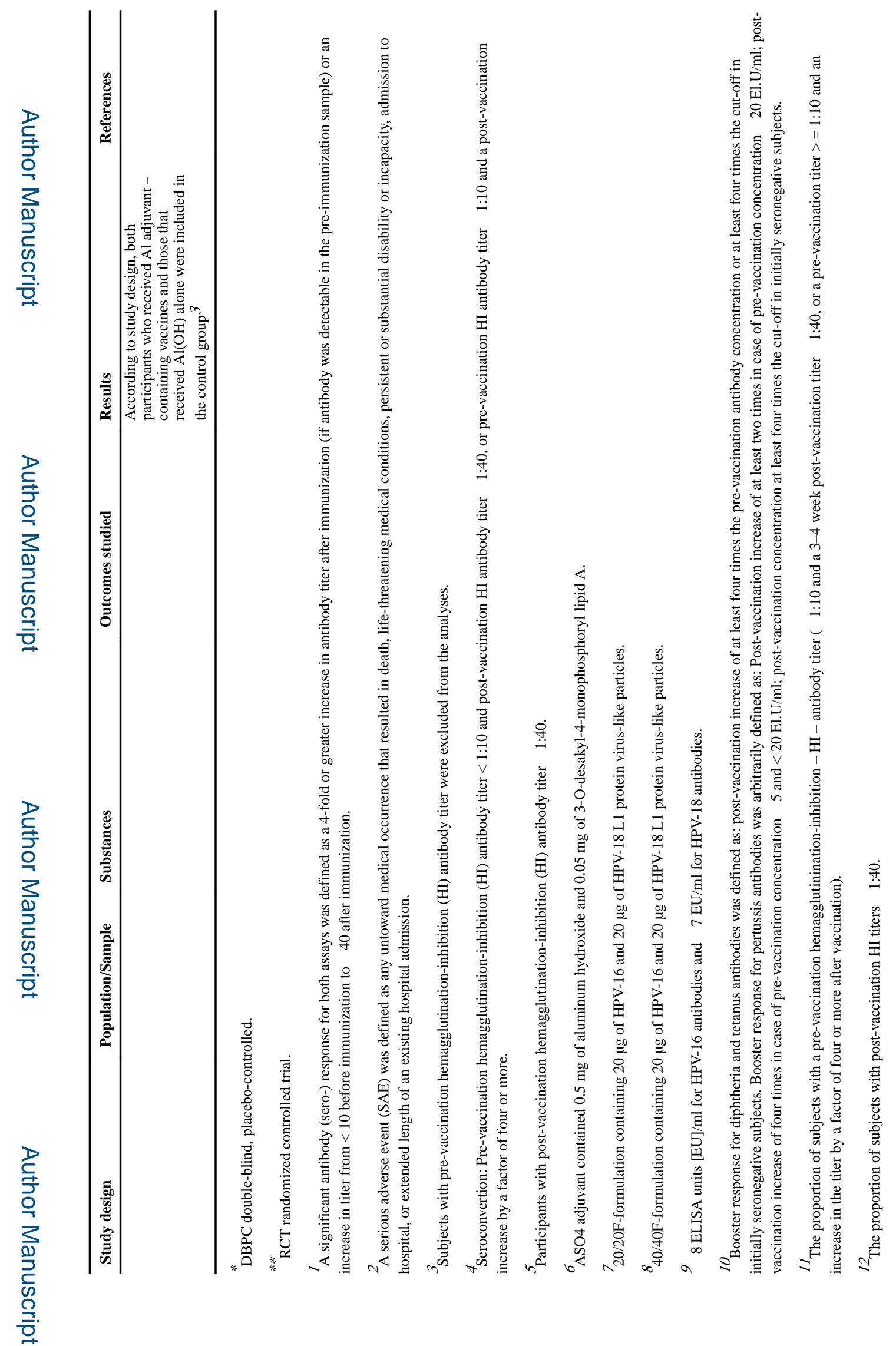

Crit Rev Toxicol. Author manuscript; available in PMC 2016 August 25. 


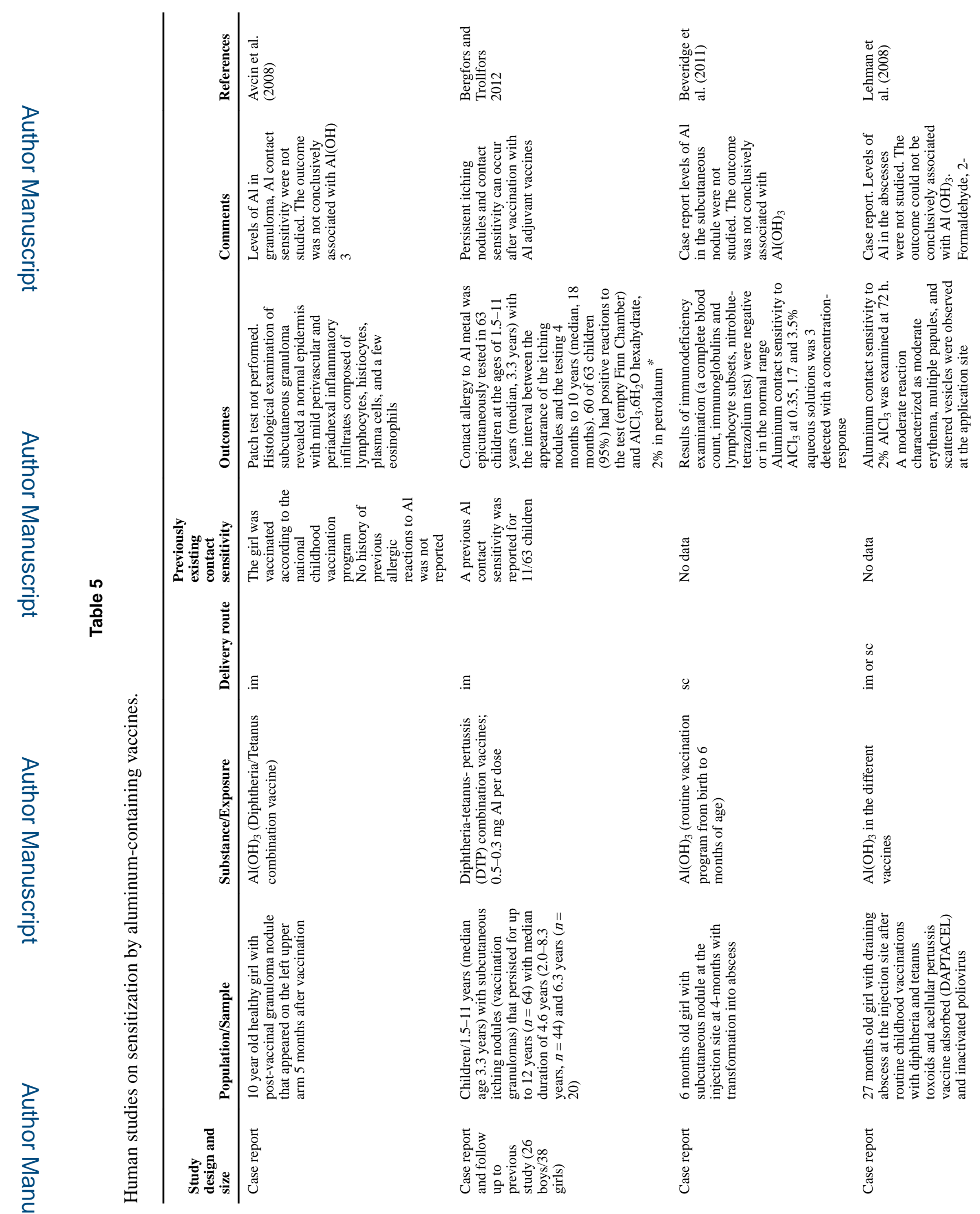

Crit Rev Toxicol. Author manuscript; available in PMC 2016 August 25. 
Willhite et al.

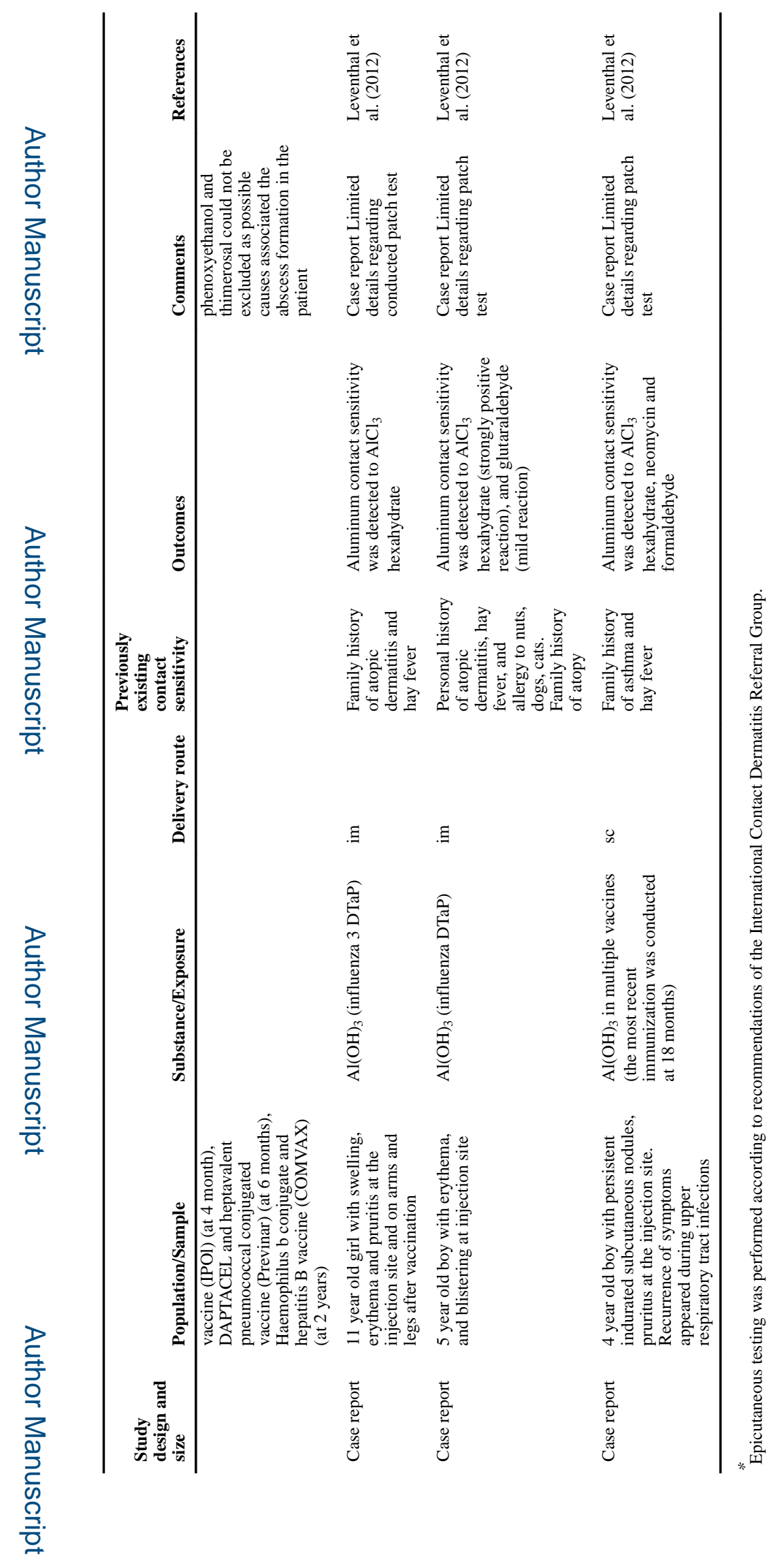

Crit Rev Toxicol. Author manuscript; available in PMC 2016 August 25. 


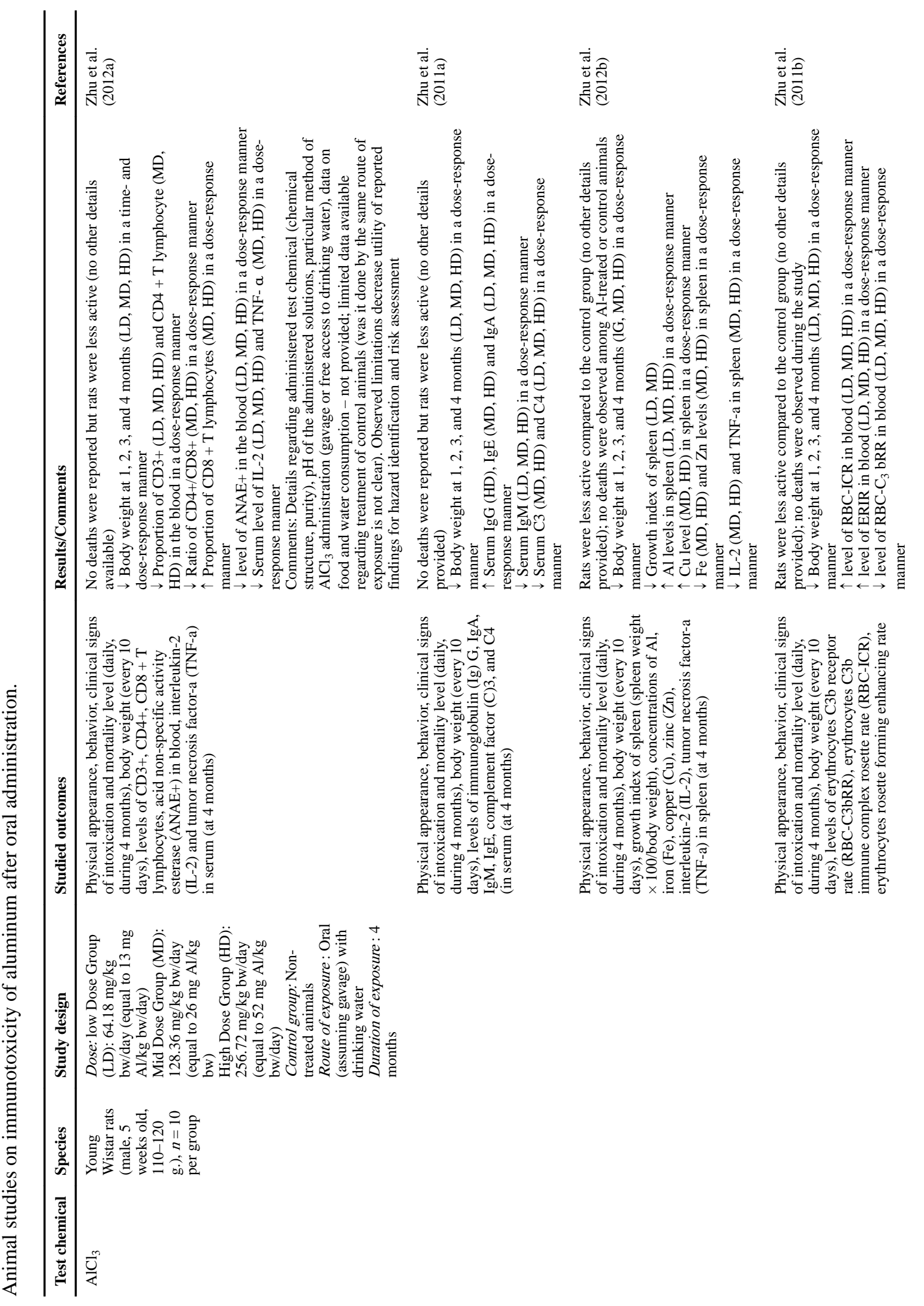

Crit Rev Toxicol. Author manuscript; available in PMC 2016 August 25. 
Willhite et al.

Page 140

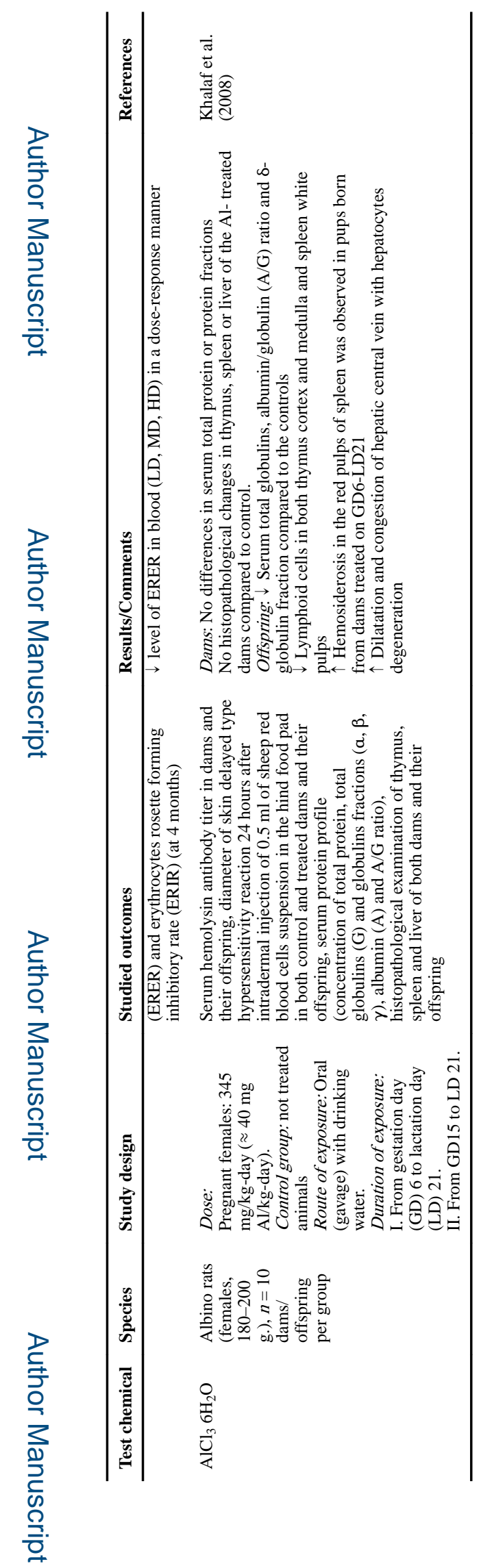

Crit Rev Toxicol. Author manuscript; available in PMC 2016 August 25. 


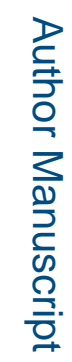

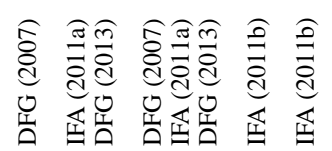

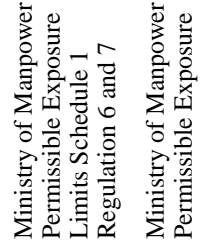

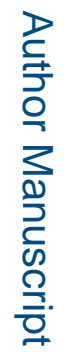

娄

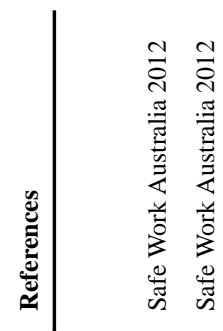

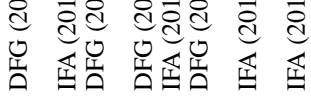

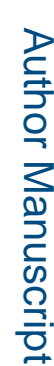

岂

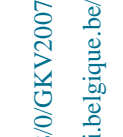

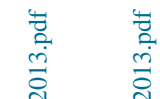

爸这

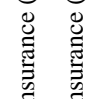

跣的

离

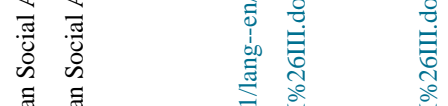

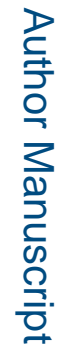

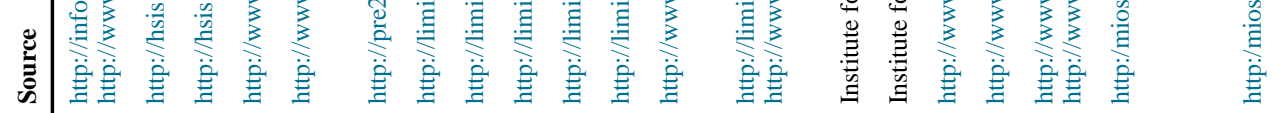

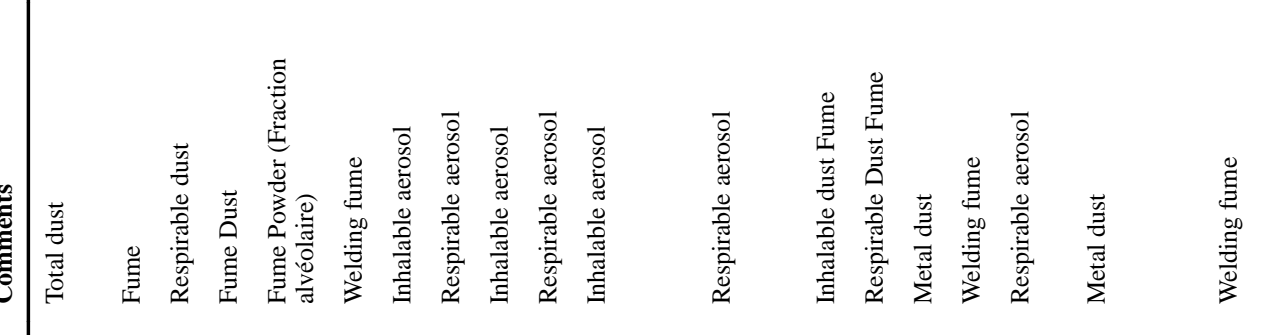

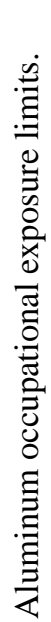

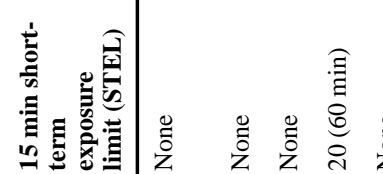

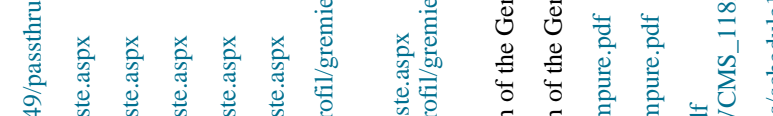

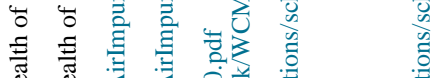

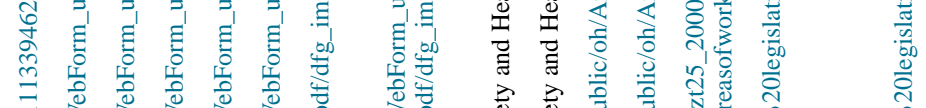

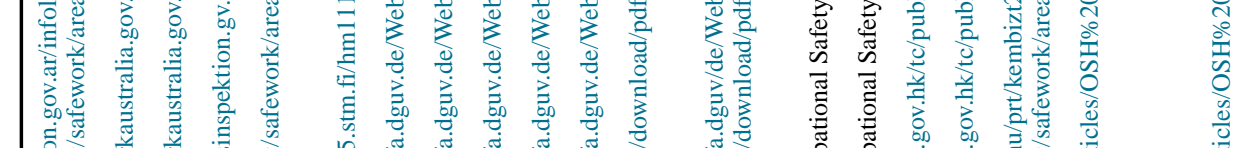

क्ष

D. 


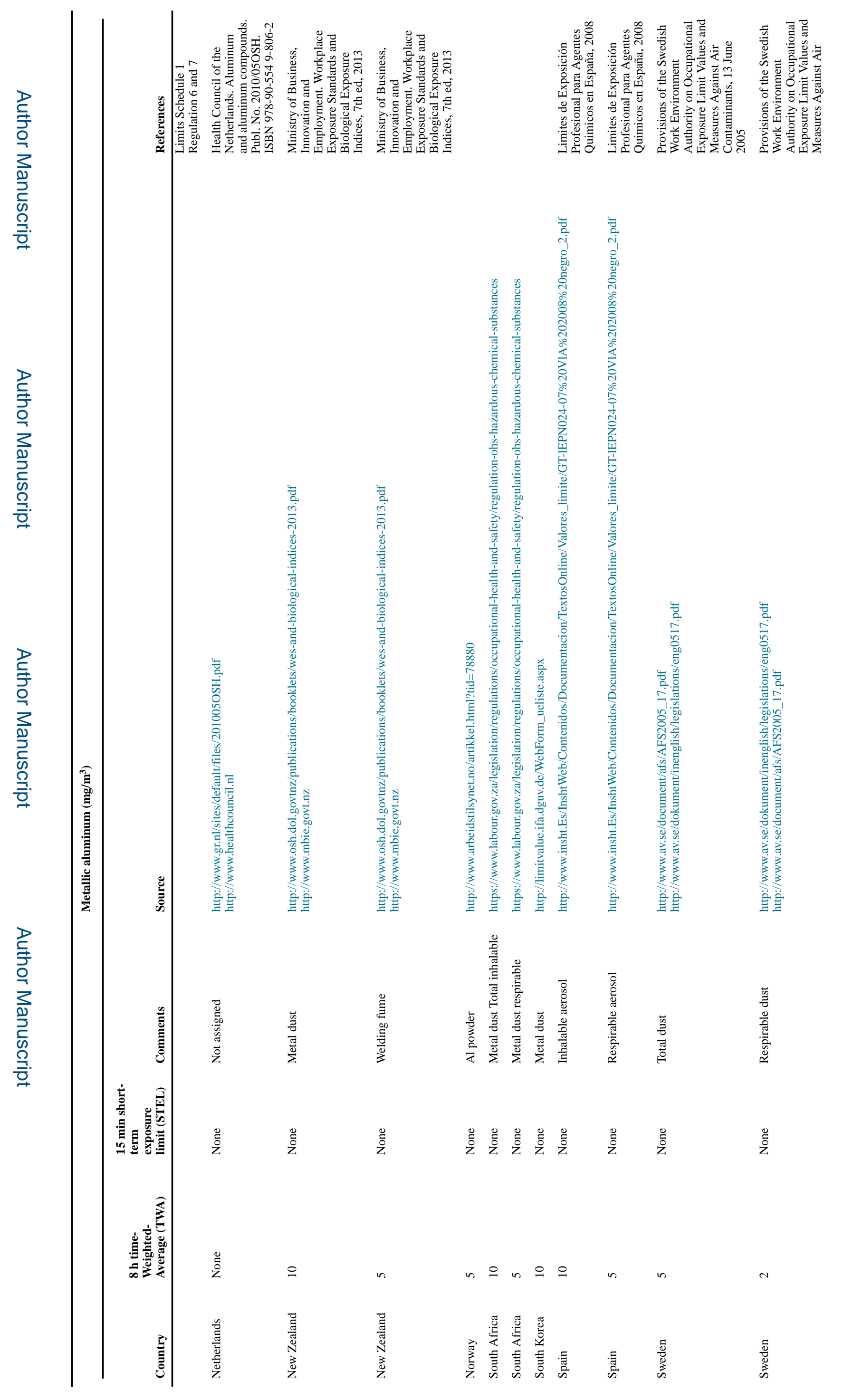




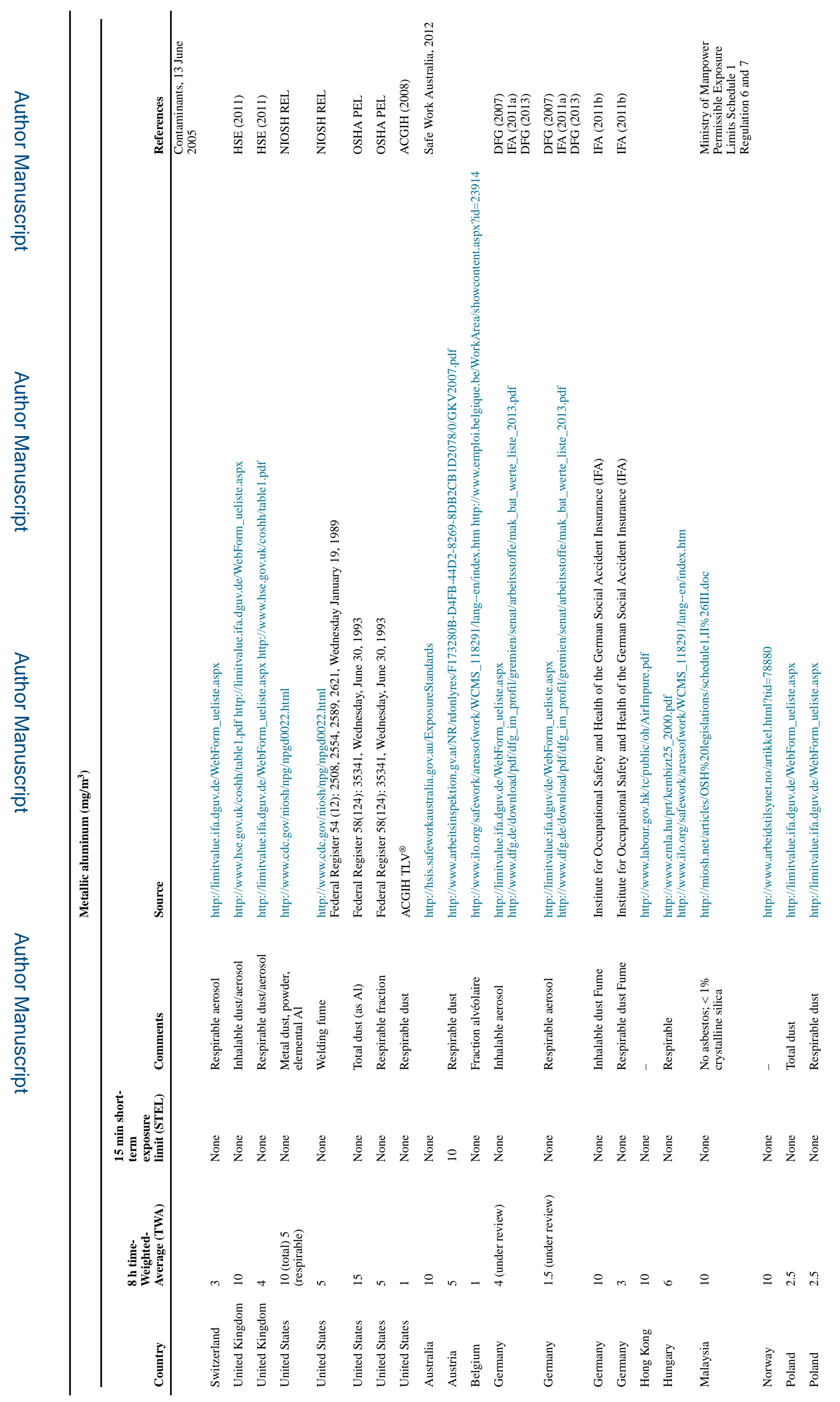



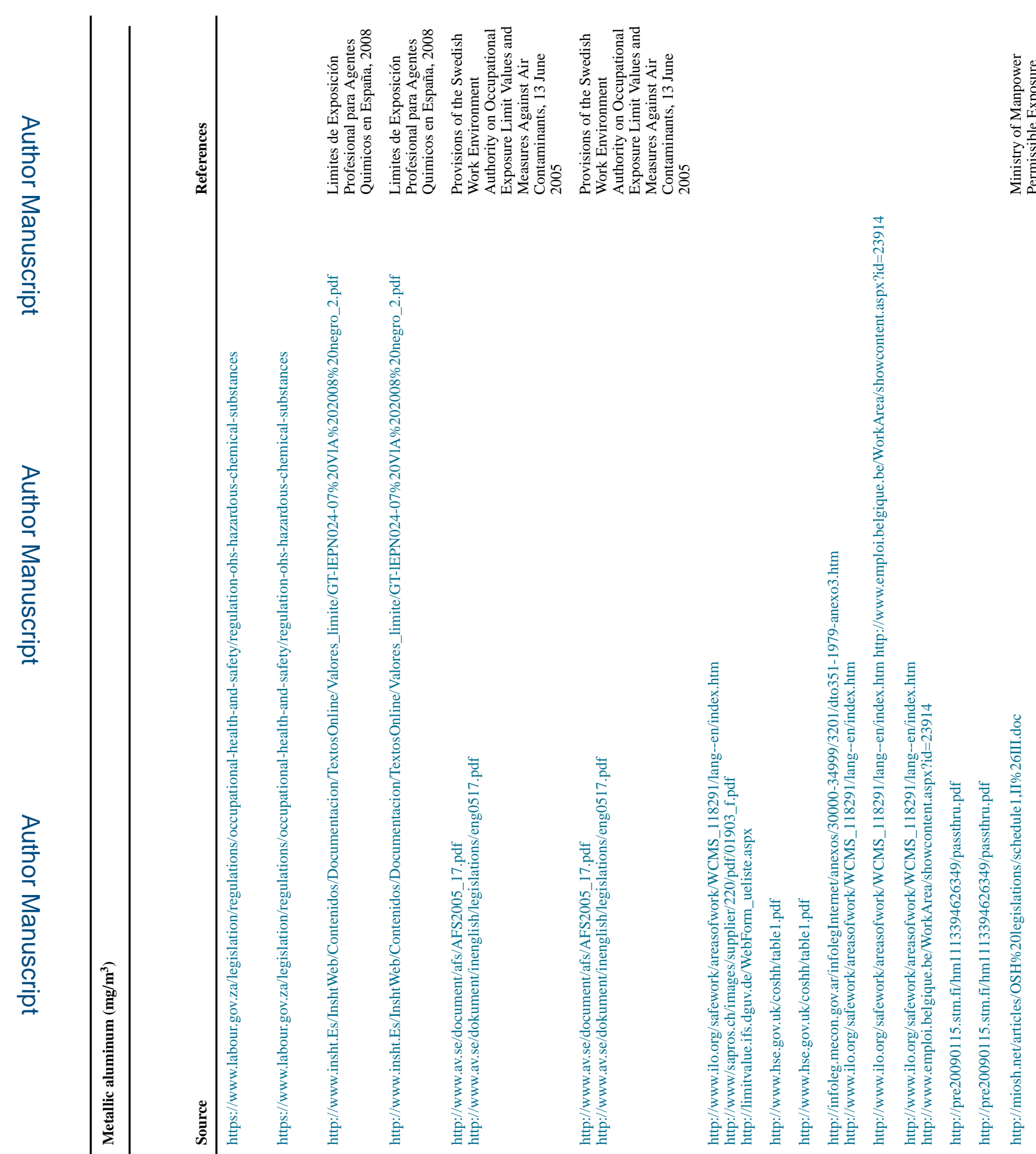

?

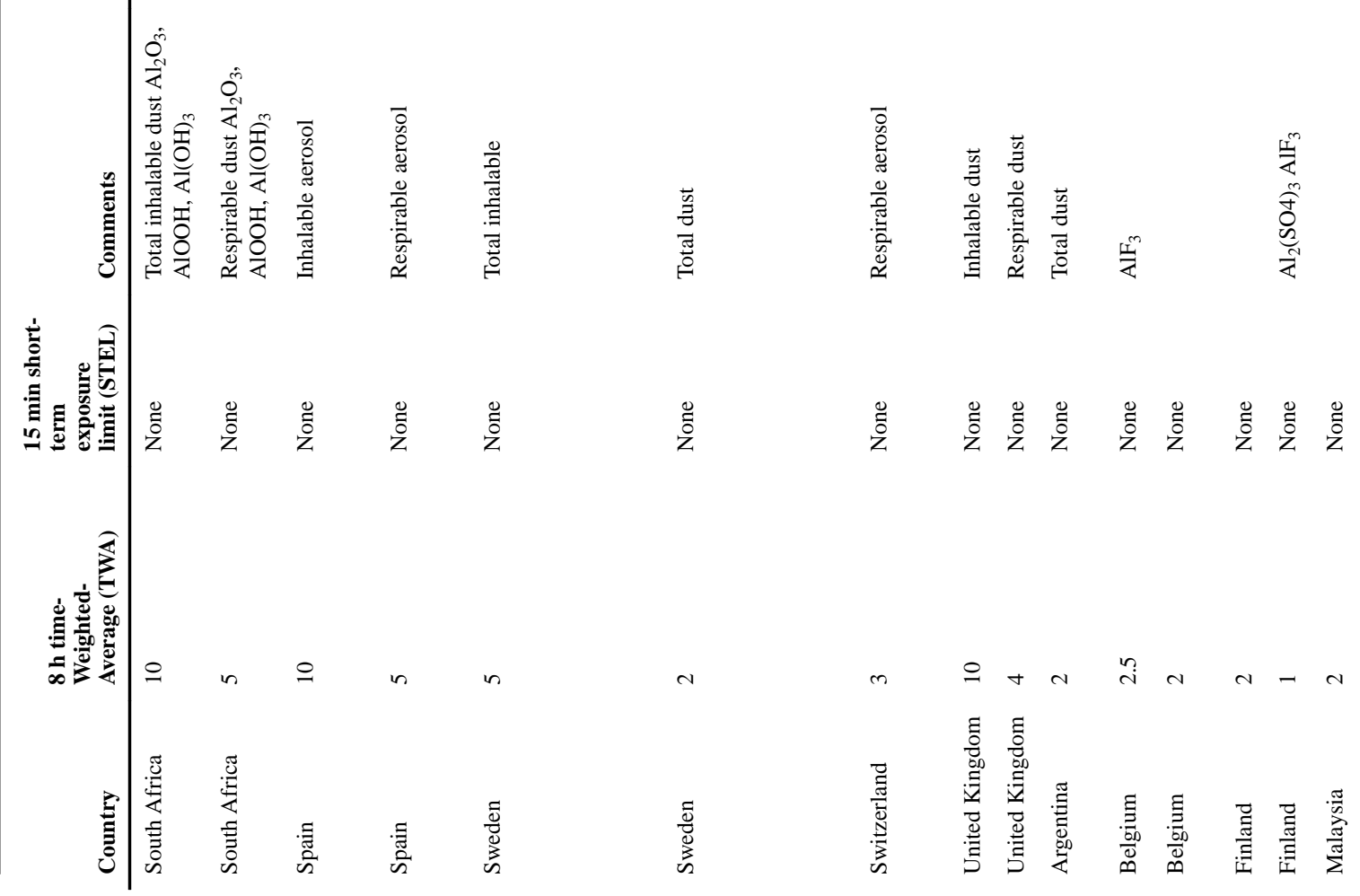




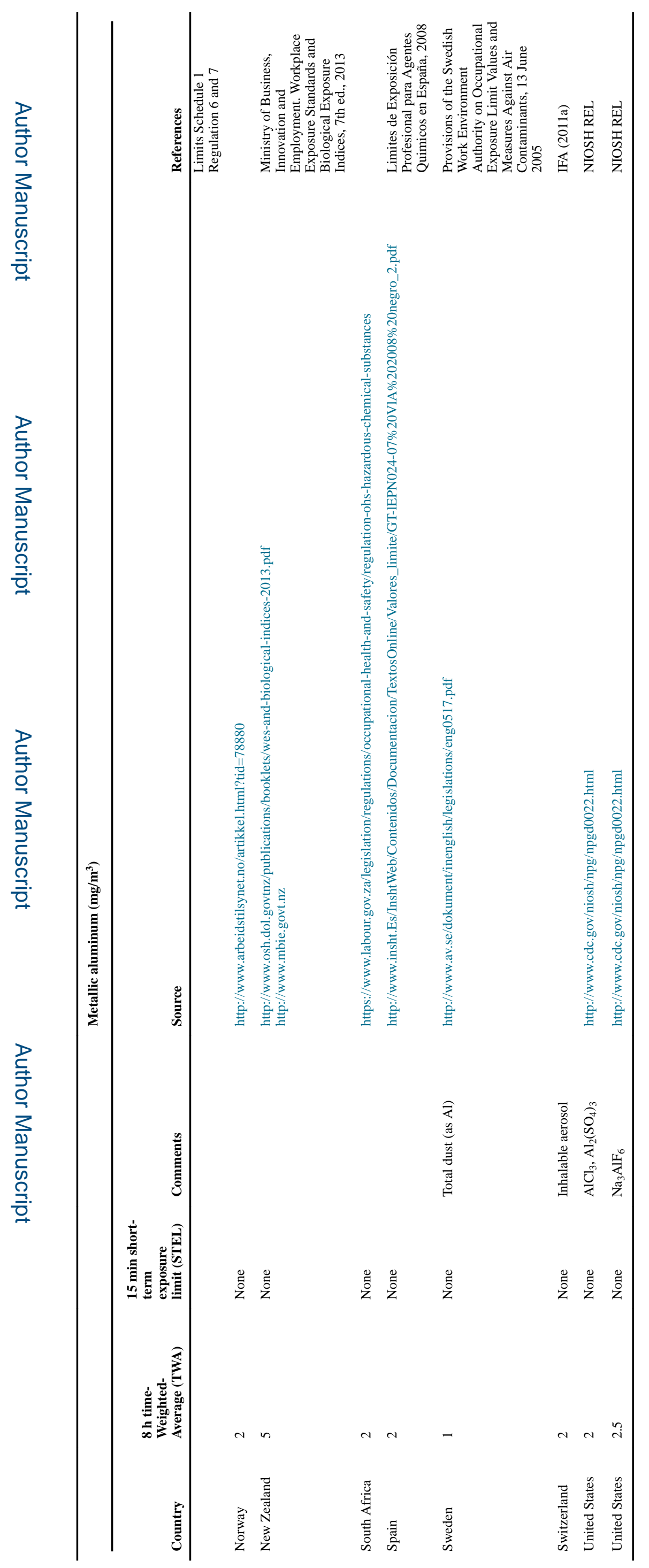

